US Army Corps

of Engineers

Waterways Experiment

Station

Computer-Aided Structural Engineering (CASE) Project

The Shear Ring Method and the Program RingWall

by Mete Oner, Stillwater, OK

Reed L. Mosher, WES

Approved For Public Release; Distribution Is Unlimited

Prepared for Headquarters, U.S. Army Corps of Engineers 
The contents of this report are not to be used for advertising, publication, or promotional purposes. Citation of trade names does not constitute an official endorsement or approval of the use of such commercial products.

The findings of this report are not to be construed as an official Department of the Army position, unless so designated by other authorized documents. 


\title{
The Shear Ring Method and the Program RingWall
}

\author{
by Mete Oner \\ 1809 South Mansfield Street \\ Stillwater, OK 74078 \\ Reed L. Mosher \\ U.S. Army Corps of Engineers \\ Waterways Experiment Station \\ 3909 Halls Ferry Road \\ Vicksburg, MS 39180-6199
}

Final report

Approved for public release; distribution is unlimited

\author{
Prepared for U.S. Army Corps of Engineers \\ Washington, DC 20314-1000 \\ Under Work Unit 31589
}




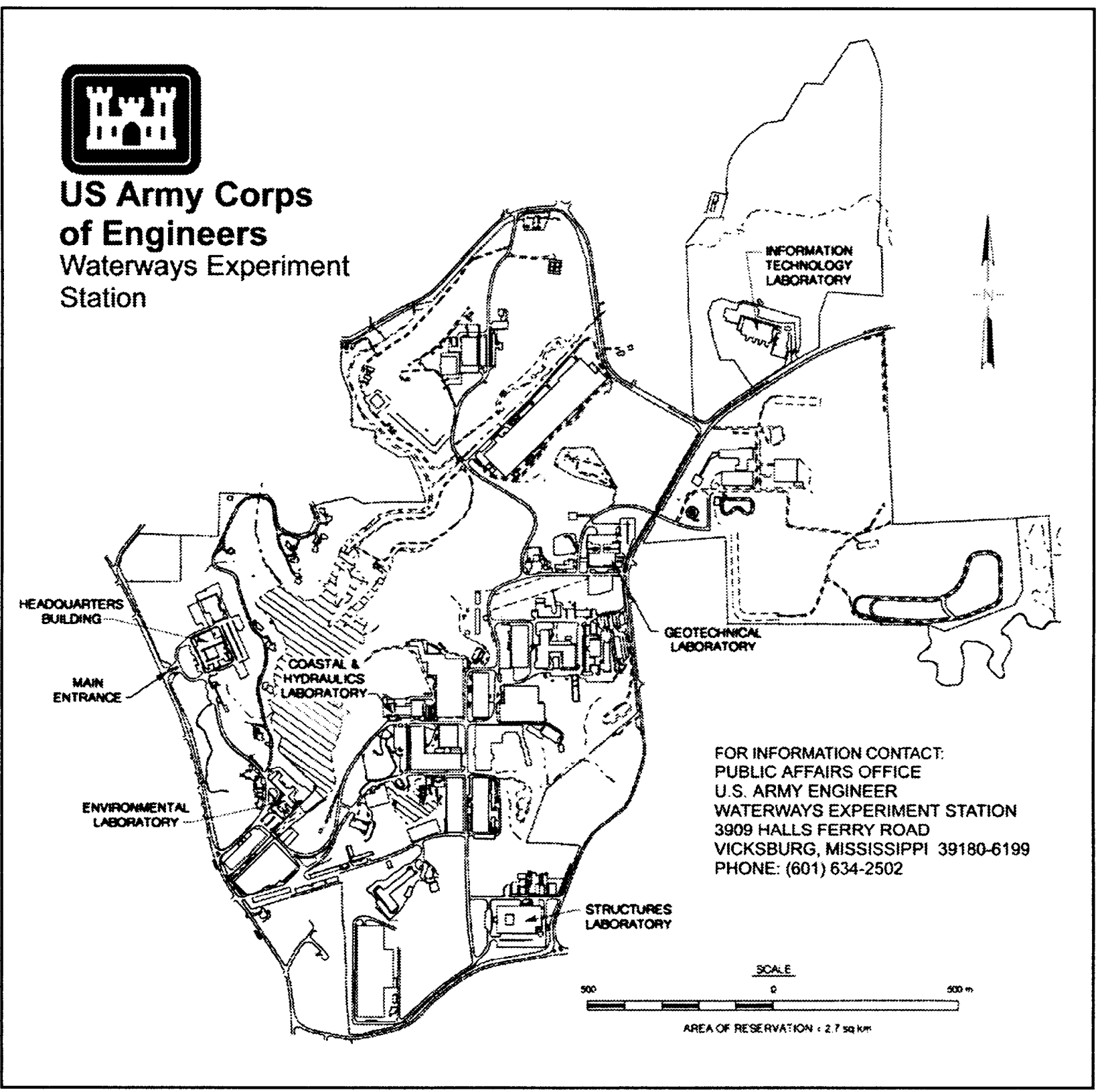

Waterways Experiment Station Cataloging-in-Publication Data

Oner, Mete.

The shear ring method and the program ringwall / by Mete Oner ; prepared for U.S. Army Corps of Engineers.

127 p. : ill. ; $28 \mathrm{~cm}$. - (Technical report ; ITL-98-5)

Includes bibliographical references.

1. Soil-structure interaction - Computer programs. 2. Finite element method-Computer programs. 3. Structural engineering - Computer programs. 4. Floods - Computer programs. I. United States. Army. Corps of Engineers. II. U.S. Army Engineer Waterways Experiment Station. III. Information Technology Laboratory (U.S. Army Engineer Waterways Experiment Station) IV. Title. V. Computer-aided Structural Engineering Project. VI. Series: Technical report (U.S. Army Engineer Waterways Experiment Station) ; ITL-98-5.

TA7 W34 no.ITL-98-5 


\section{Contents}

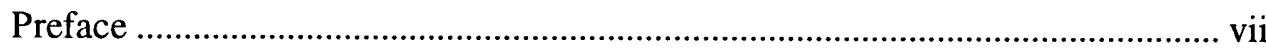

1 -Overview of the Shear Ring Method ……….................................................

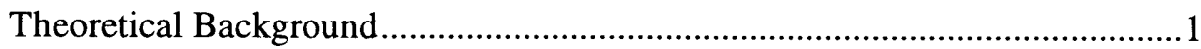

The origins

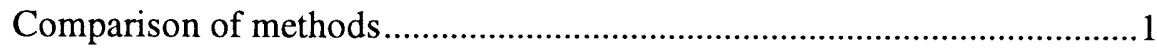

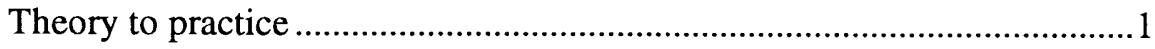

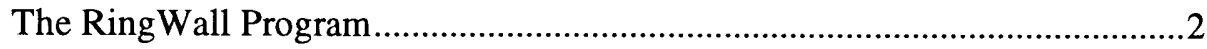

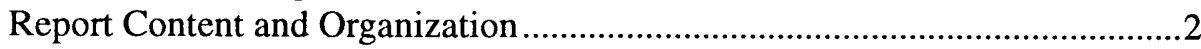

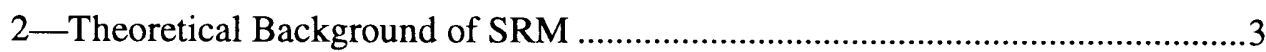

E99 Wall Test and the Verification of FEMSSI..................................................

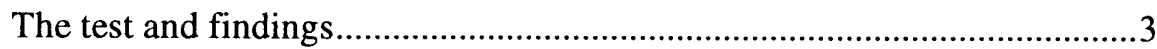

Comparisons of experimental and FEMSSI results ..................................6

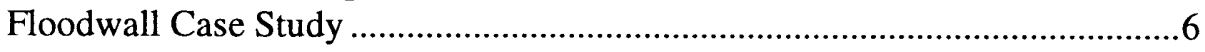

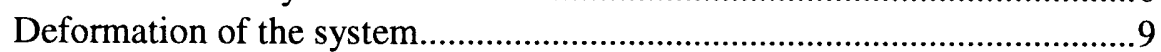

The development of the shear ring method...............................................10

The Results of Verification Studies .............................................................15

Verification of Floodwall Procedure by Full-Scale Tests .............................16

Extension to Anchored Walls and Verification ............................................21

Bjerrum, Clausen, and Duncan piles........................................................22

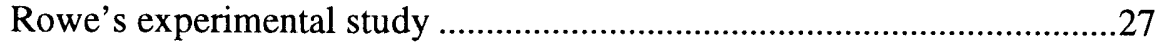

Systematic Verification Study_Anchored Wall Cases ................................28

Construction of typical wall cases.........................................................29

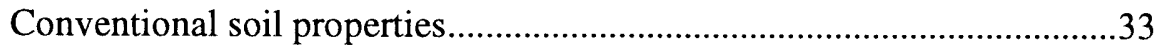

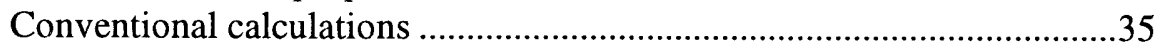

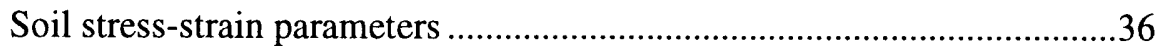

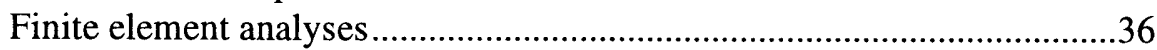

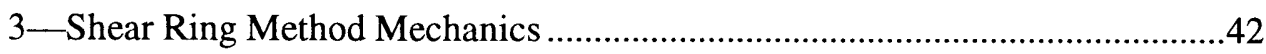

Basics of the Method ............................................................................42

Soil Modulus Variation...........................................................................43

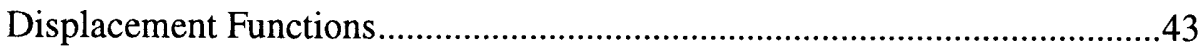

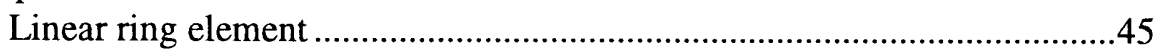

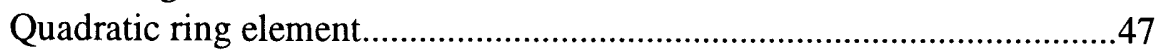

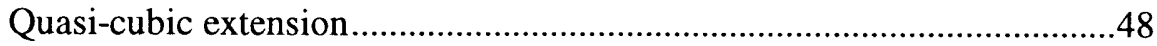

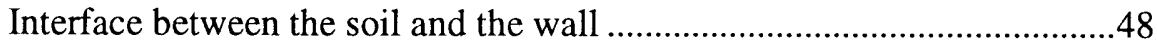




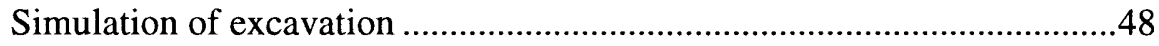

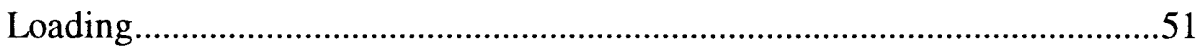

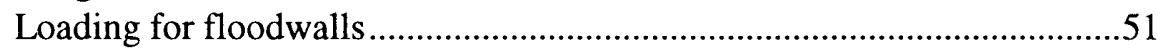

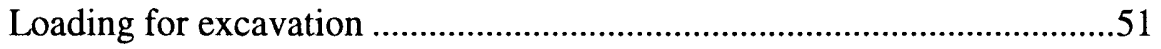

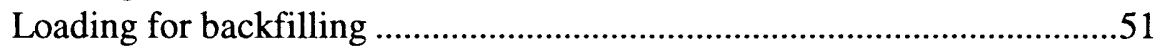

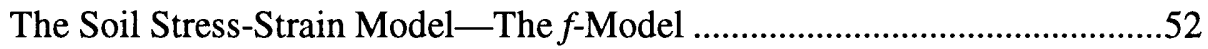

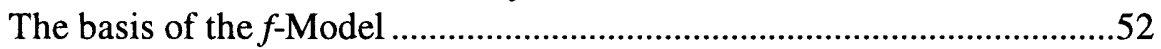

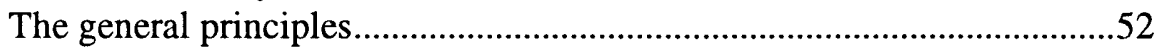

The essential soil characteristics ............................................................52

The working equations of the $f$-Model ...................................................53

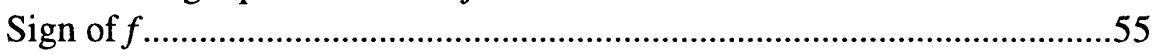

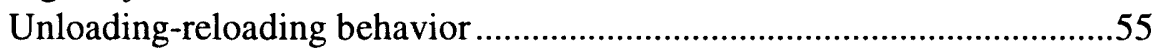

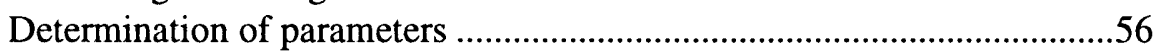

Typical parameter values ...............................................................57

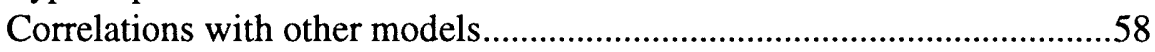

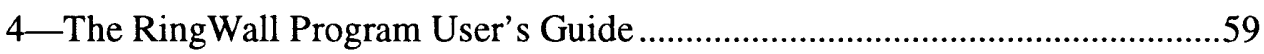

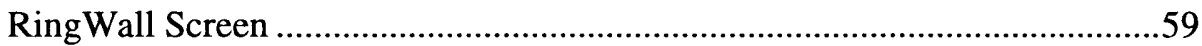

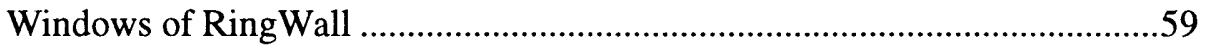

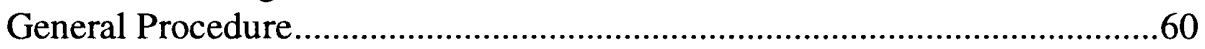

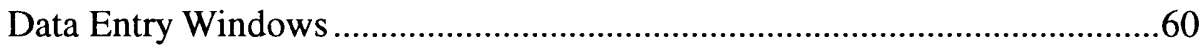

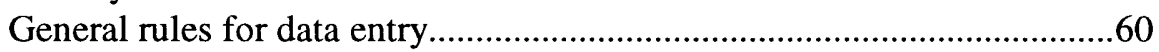

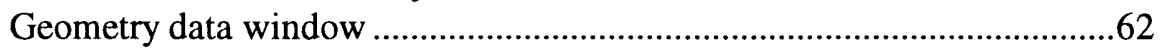

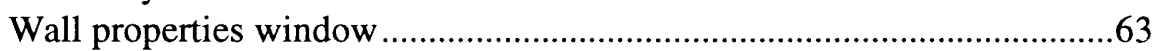

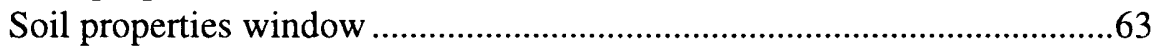

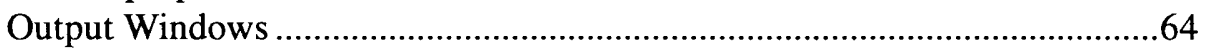

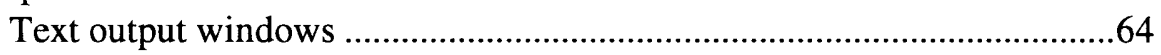

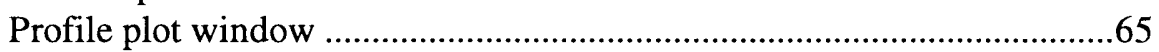

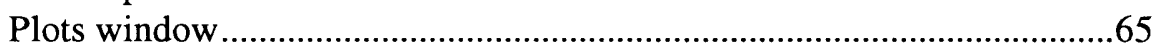

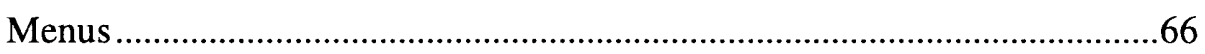

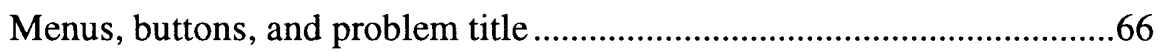

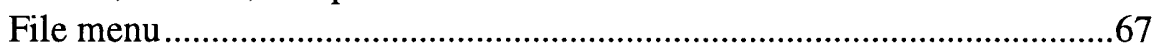

Edit menu: Cut, Copy, Paste commands .............................................69

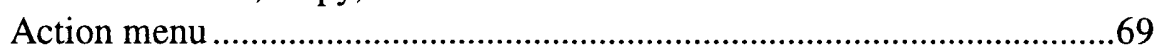

Window menu: Tile, Cascade, Arrange Icons commands ..........................71

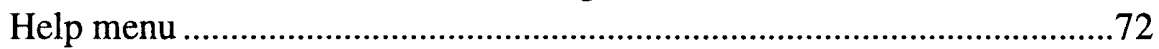

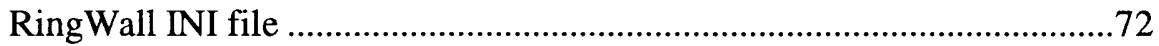

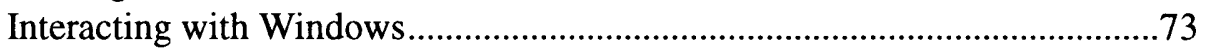

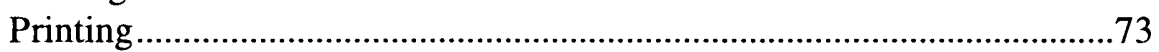

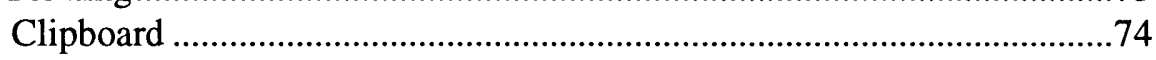

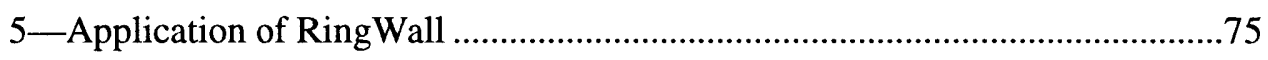

Typical Sequence of Steps for Analysis and Design....................................75

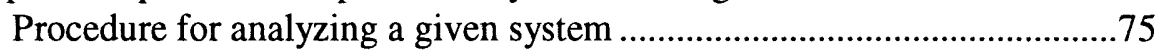

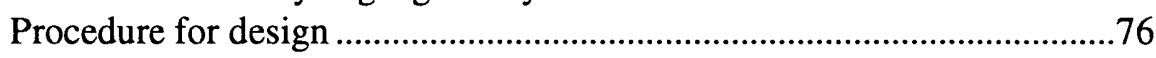

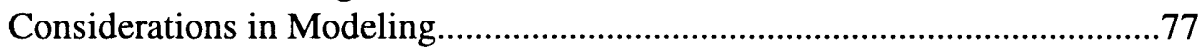

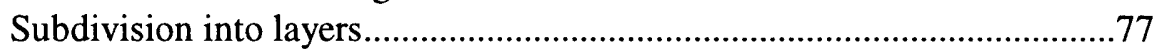

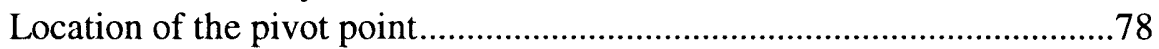

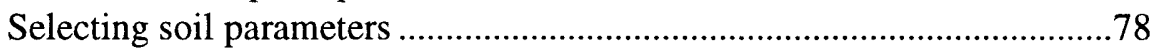




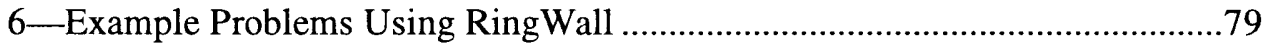

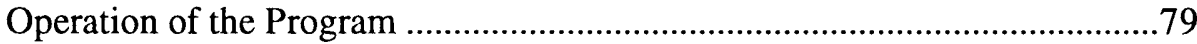

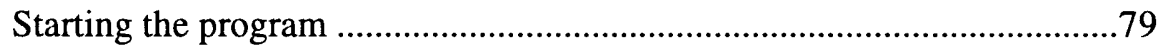

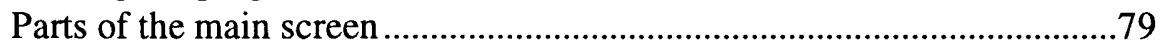

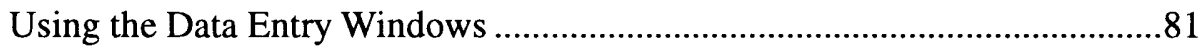

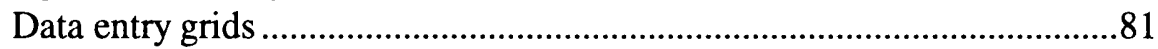

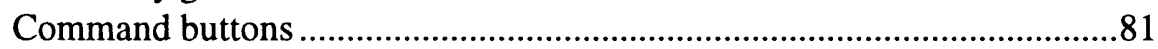

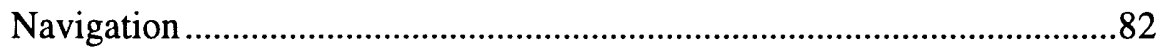

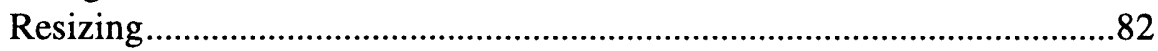

Example 1: Entering a New Problem .........................................................82

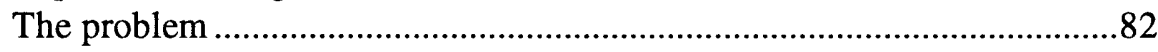

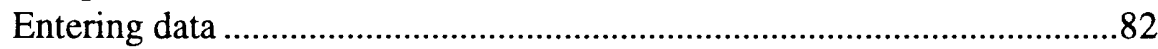

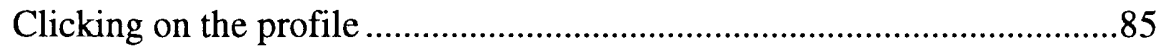

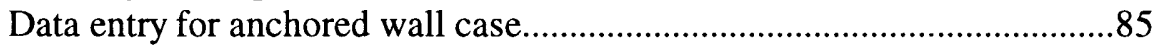

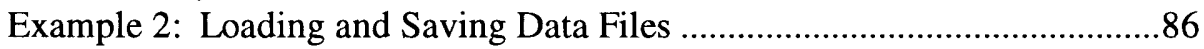

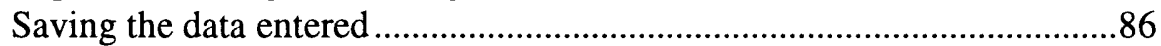

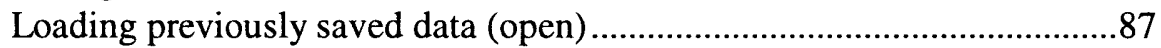

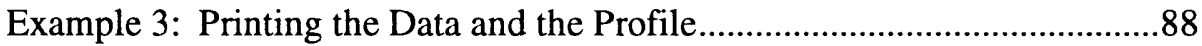

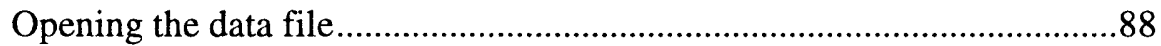

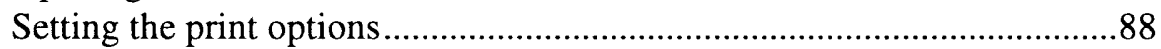

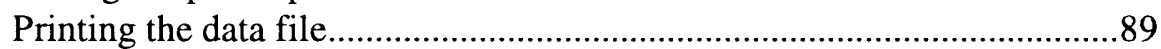

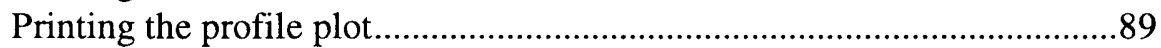

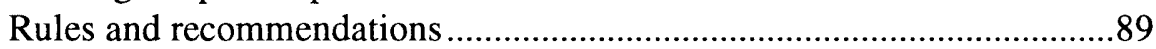

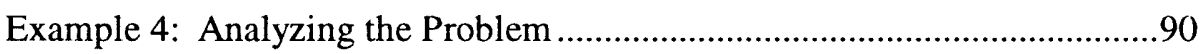

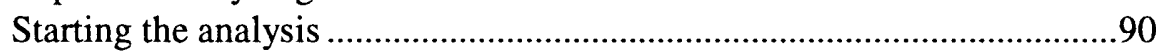

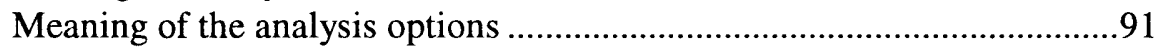

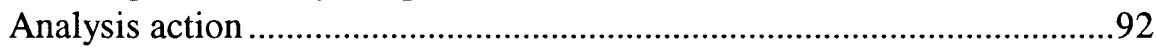

Example 5: Printing the Results and Graphs..............................................93

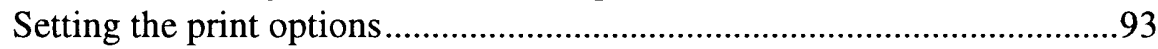

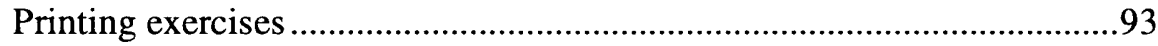

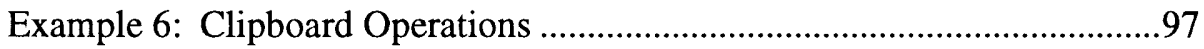

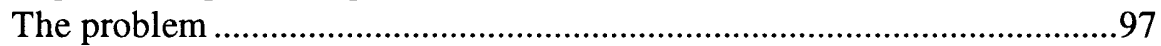

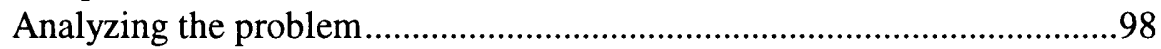

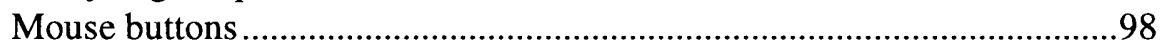

Copying to clipboard and pasting ..............................................................99

Example 7: Design Example...................................................................100

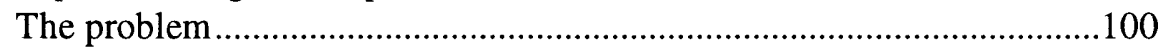

Designing the wall ............................................................................... 100

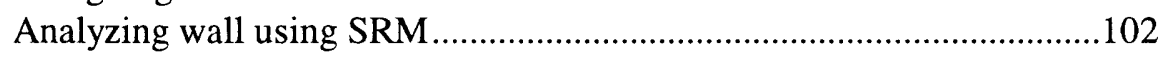

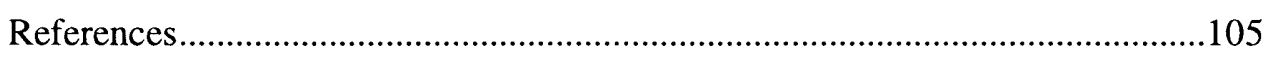

Appendix A: Derivation of Hoop Modulus.................................................. A1

Appendix B: Stiffness Matrix of the Quadratic Shear Ring Element................ B1

Appendix C: Beam Element Stiffness Matrix ................................................ C1

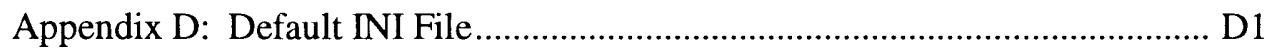

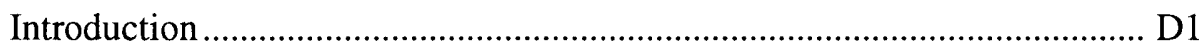




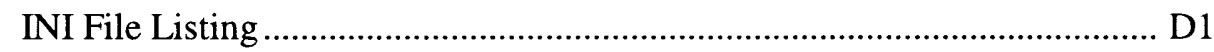

Appendix E: I/O File Formats …................................................................ E1

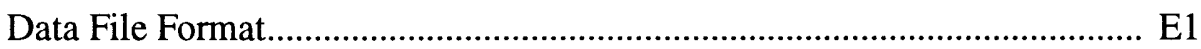

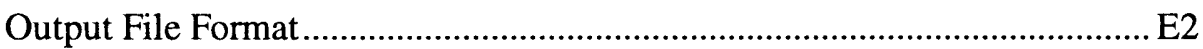

SF 298 


\section{Preface}

This manual describes the theory and development of the Shear Ring Method for analysis/design of floodwalls and anchored sheet-pile retaining walls. The user's manual for the program RingWall, which is based on the Shear Ring Method, is also presented. The computer program and theoretical/user's guide were written with funds provided to the U. S. Army Engineer Waterways Experiment Station (WES), Vicksburg, MS, by Headquarters, U.S. Army Corps of Engineers, Civil Works Directorate, under the Structural Engineering Research Program work unit 31589 of the Computer-Aided Structural Engineering (CASE) Project.

The computer program was written by Dr. Mete Oner, Stillwater, OK. The report was written by Dr. Oner and Dr. Reed L. Mosher, Chief, Structural Mechanics Division (SMD), Structures Laboratory (SL), WES.

The work was managed, coordinated, and monitored by Dr. Mosher, SL, and Mr. Michael E. Pace, Computer-Aided Engineering Division (CAED), Information Technology Laboratory (ITL), WES. Dr. Bryant Mather was Director, SL; Mr. H. Wayne Jones was Chief, CAED; and Dr. N. Radhakrishnan was Director, ITL.

At the time of publication of this report, Director of WES was Dr. Robert W. Whalin. Commander was COL Robin R. Cababa, EN.

The contents of this report are not to be used for advertising, publication, or promotional purposes. Citation of trade names does not constitute an official endorsement or approval of the use of such commercial products. 


\section{Overview of the Shear Ring Method}

\section{Theoretical Background}

\section{The origins}

The Shear Ring Method (SRM) was developed originally for floodwalls. It had long been realized that the conventional soil-structure interaction method (SSI) based on the classical "beam-on-elastic-foundation" theory had serious limitations when applied to floodwalls. This conclusion had been reached by comparing full-scale test results, comprehensive stress and deformation analyses by plane strain finite element method (FEM) (e.g., Desai and Abel 1972), and conventional SSI analyses (Dawkins 1994a, 1994b). Once the usefulness of the Ring method had become clear, it was decided to extend it for use in anchored sheet-pile walls. Currently the method is available for both floodwalls and single-anchored sheet-pile walls.

\section{Comparison of methods}

Ordinary hand calculation methods, such as the free earth support method, are efficient design methods guiding the engineer in the selection of a pile section and depth of penetration. However, these methods supply no information to the engineer in terms of deformations to expect in and around the wall. The conventional SSI procedures (e.g., Dawkins 1994b) attempt to remedy this situation. It has now been established that methods based on this approach improve only slightly over the classical hand calculation procedures. Although SSI methods report displacements for the wall, these are only relative displacements, and fall short of providing any information on the overall deformations of the system including the ground around the wall. The following sections present some of these comparisons.

\section{Theory to practice}

The SRM makes use not only of all the classical and conventional concepts related to the design and analysis of flexible retaining structures; it also uses the 
concepts from the modern analysis approaches such as the nonlinear FEM. In addition to these theoretical principles, the implementation of the Ring Method, the RingWall program, is presented in this report.

\section{The RingWall Program}

The computer software that implements the SRM is called RingWall. This Windows-based program is described in Chapter 4. RingWall is a modern, userfriendly tool that allows the engineer to easily play "what-if games" to produce the best designs.

\section{Report Content and Organization}

Chapter 2 of this manual presents the theoretical background of the SRM. It traces the development of the method in broad lines emphasizing the main findings and conclusions of each stage. The main intention of this chapter is to provide the background information necessary for a good understanding of the superiorities and limitations of the method. Chapter 3 discusses the mechanics of the SRM. Chapter 4 presents the computer software, RingWall. Chapter 5 discusses the use of the RingWall program for analysis and design, and Chapter 6 presents examples using the program for analysis and design. The appendices contain details of the material presented for documentation and reference purposes. 


\section{Theoretical Background of SRM}

This chapter briefly discusses the development history of the SRM. It covers the period that started with the verification of the FEM used for analyzing typical wall systems, how and why a new method was developed, and the systematic verification and extension studies performed. The research work spanned several years from 1988 to 1992.

\section{E99 Wall Test and the Verification of FEMSSI}

The objective of this initial phase of the study was to develop and verify the advanced analysis tools required for the development studies that followed. The initial requirement was the verification of the finite element technology used in the computer program FEMSSI. This program includes the implementation details of the FEM, the soil constitutive model used, the soil-structure interface elements, the beam elements for modeling the sheet-pile wall, and the step-bystep construction sequence simulation. This verification and development study was a significant step because the procedures employed had to be the most reliable set of tools available.

The main engineering requirement for the success of such a major verification and development study was the control of the results by an actual, full-scale physical test in the field. Such a test had been performed earlier on a floodwall named the E99 Wall. The availability of the results of this full-scale test determined the first step of the development of the SRM.

\section{The test and findings}

The U.S. Army Corps of Engineers conducted a full-scale sheet-pile test on a section constructed near an existing levee. Details of the tests and instrumentation are reported by Jackson (1988). Conditions at the test site are shown in

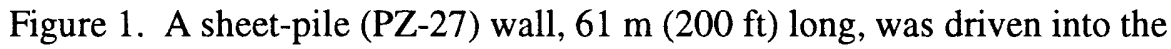
landside berm of the Item E99, East Atchafalaya Basin protection levee just south of Morgan City, LA. The piling had an exposed height of approximately $3 \mathrm{~m}$ 


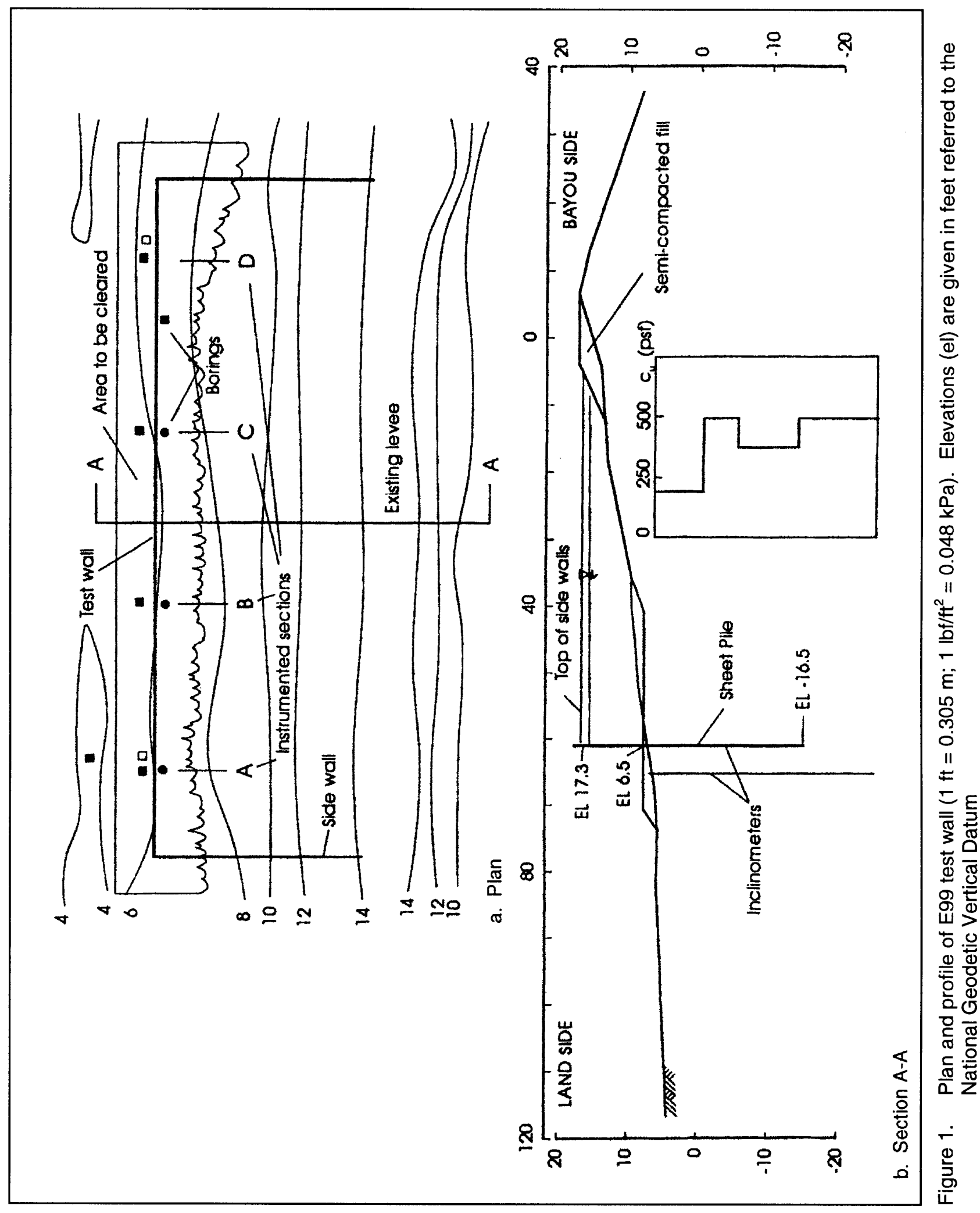


(10 ft ) and was driven to an embedment of approximately $7 \mathrm{~m}(23 \mathrm{ft})$. (The ground surface parallel to the long dimension of the wall was not perfectly horizontal.) Water was ponded between the levee and the sheet pile in stages over a period of 2 months, simulating a flood condition. Measured effects at four locations along the wall included strains in the sheet pile, pile head deflections, soil displacements indicated by inclinometers and site survey, and pore pressures indicated by piezometers. Although the test configuration does not duplicate an actual floodwall system, it does provide a means of comparing experimental and analytical results for the interaction of the sheet pile, soil, and water.

Subsoil exploration at the site indicated a strength depth profile somewhat similar to those for natural soils at other sites where floodwalls have been built. The soil strength generally increased with depth. The idealized soil profile for analysis extracted from data reported by Jackson (1988) is given in Table 1.

\begin{tabular}{|c|c|c|c|c|c|}
\hline \multirow{2}{*}{$\begin{array}{l}\text { Elevation } \\
\text { Range } \\
\mathrm{ft}^{1}\end{array}$} & \multirow{2}{*}{$\begin{array}{l}\text { Layer } \\
\text { Thickness } \\
\mathrm{ft}^{1}\end{array}$} & \multicolumn{2}{|c|}{$c$} & \multicolumn{2}{|c|}{ Unit Weight } \\
\hline & & $\mathrm{lb} f / f \mathrm{tt}^{2}$ & $\mathrm{kPa}$ & pef & $\mathrm{kN} / \mathrm{m}^{3}$ \\
\hline 6.5 to -1 & 7.5 & 200 & 19 & 104 & 16.3 \\
\hline-1.0 to -5 & 4.0 & 500 & 48 & 107 & 16.8 \\
\hline-5.0 to -14 & 9.0 & 350 & 33 & 106 & 16.7 \\
\hline-14.0 to -19 & 6.0 & 500 & 48 & 104 & 16.3 \\
\hline-19.0 to -29 & 10.0 & 500 & 48 & 101 & 15.9 \\
\hline-29.0 to -44 & 15.0 & 550 & 53 & 100 & 15.7 \\
\hline
\end{tabular}

Stress-strain data were not available for the soils at the E99 site. Consequently the $E_{50} / c_{u}$ ratio, where $E_{50}$ is the secant Young's modulus value at 50 percent mobilized strength level and $c_{u}$ is the undrained shear strength, needed in the soil model could not be directly evaluated. Because of the similarity of the E99 soils to those at other sites, the ratio is expected to be in the range of 150 to 350 as discussed in Oner, Dawkins, and Hallal. ${ }^{1}$ Subsequently, sensitivity analyses were performed to investigate the influence of this parameter.

The original plan (Jackson 1988) was to raise and then lower the water level in steps to simulate a flood hydrograph for the test location. Displacement timehistories of wall deflections at the four instrumented sections are given by Jackson (1988). Displacements at the four sections closely followed the rising water level up to a nominal head of $1.8 \mathrm{~m}(6 \mathrm{ft})$ and remained essentially constant

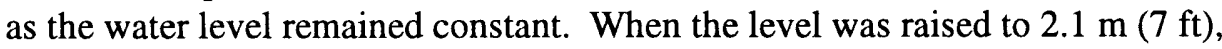
displacements at sections $C$ and $D$ (Figure 1) stabilized after a few days. However, at sections $\mathrm{A}$ and $\mathrm{B}$, displacements were still increasing after 15 days. As the water head increased, deflections at all sections were still increasing after

1 M. Oner, W. P. Dawkins, and I. Hallal. (1987). "Nonlinear finite element analysis of floodwall structures," conducted for U.S. Army Engineer Waterways Experiment Station, Vicksburg, MS. 
9 days. The rate was the highest at Section A and progressively lower at B, C, and D. On the ninth day, at a $2.4-\mathrm{m}(8-\mathrm{ft})$ head, seals in the wall ruptured, allowing the ponded water to drain rapidly.

Rupture of the seals was initiated by very large displacements near Section A. Due to the sloping surface parallel to the wall, the effective water head at A was approximately $0.15 \mathrm{~m}(6 \mathrm{in}$.) greater than the nominal, and the effective embedment depth was reduced by $0.15 \mathrm{~m}$ ( 6 in.). In addition, during site preparation, fill was placed on the natural ground surface, and the strength of this temporary fill was probably lower than that of the natural soil. While these variations are not significant for low heads, they combine to aggravate conditions at impending failure.

\section{Comparisons of experimental and FEMSSI results}

The measured pile head displacement is compared with those calculated by FEM in Figure 2. It is observed that good agreement is obtained between measured and calculated displacements when $E_{50} / c_{u}$ ratios between 200 and 300 are used. The measured deflections in Section A of the test wall are larger than those of the other sections because of the somewhat smaller embedment and a higher water level at that section due to the unevenness of the ground surface. The bending moments in the pile are compared in Figure 3. Again the agreement of the measured values and those calculated by FEM is close. The difference between the two is actually smaller than the scatter in the measured values. Once again, Section A is seen to be stressed at a somewhat higher level.

The agreement of FEM results with measurements was found to be excellent. Perhaps equally important was that the great detail of the FEM analysis provided an understanding that was otherwise impossible to obtain: the E99 wall did not seem to have behaved as conventional methods of design and analysis assume. The active and passive areas were ambiguous, and the overall deformation of the soil was significant compared to the relative movement of the wall. Also the relative movement between the soil and the wall is given a significant role in the classical as well as current soil-structure interaction methods. Essentially no relative movement was found in these studies. These features are discussed in detail in Oner et al. ${ }^{1}$ The E99 wall study concluded that a number of typical floodwall systems had to be selected and studied in the same fashion.

\section{Floodwall Case Study}

Following the conclusion of the E99 wall study, a number of typical floodwall systems were selected and the same detailed study was performed on each

\footnotetext{
1 M. Oner, W. P. Dawkins, I. Hallal, and C. C. Lai. (1988). "Development of a new method for soil structure interaction analysis of floodwalls," conducted for U.S. Army Engineer Waterways Experiment Station, Vicksburg, MS.
} 


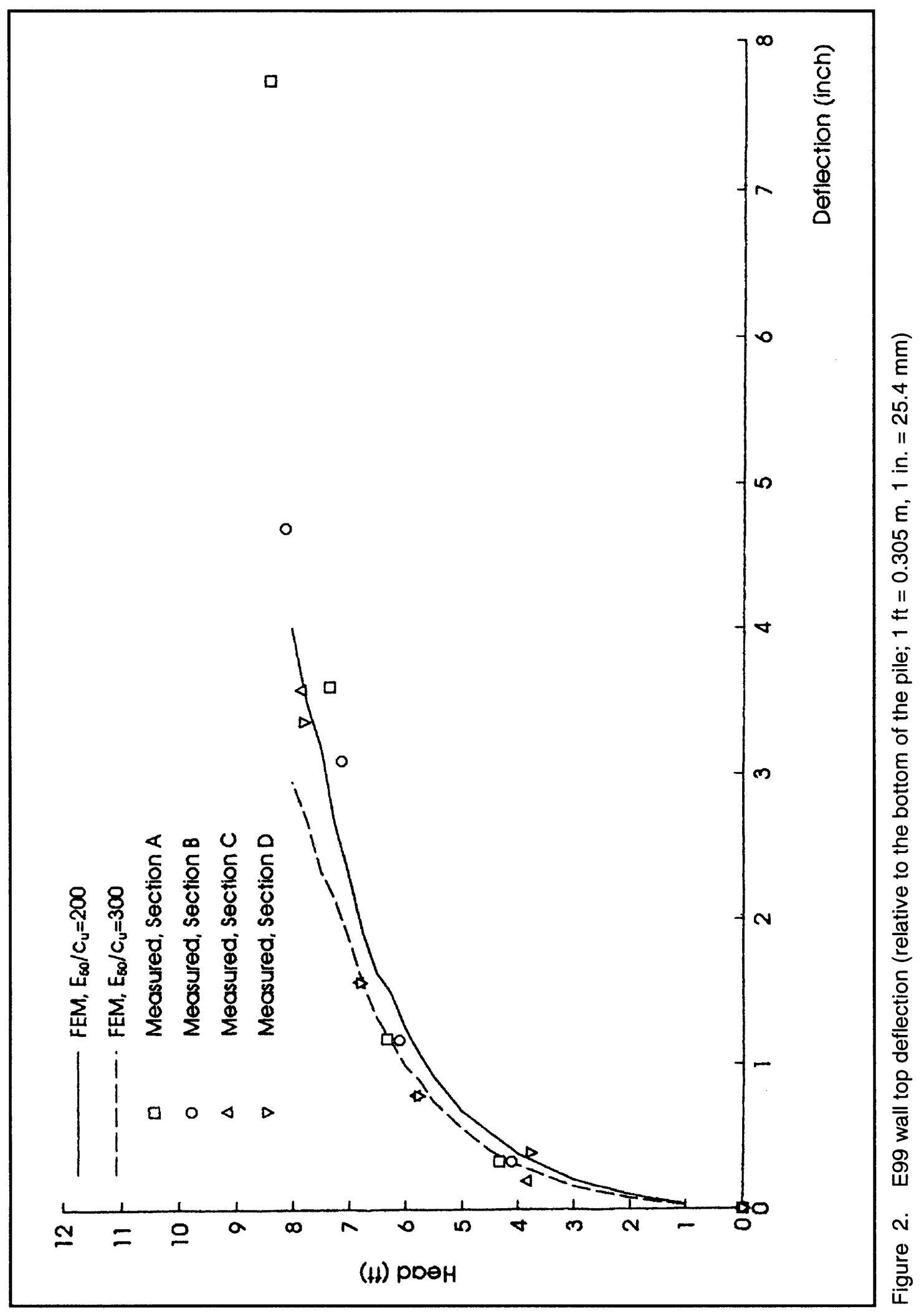




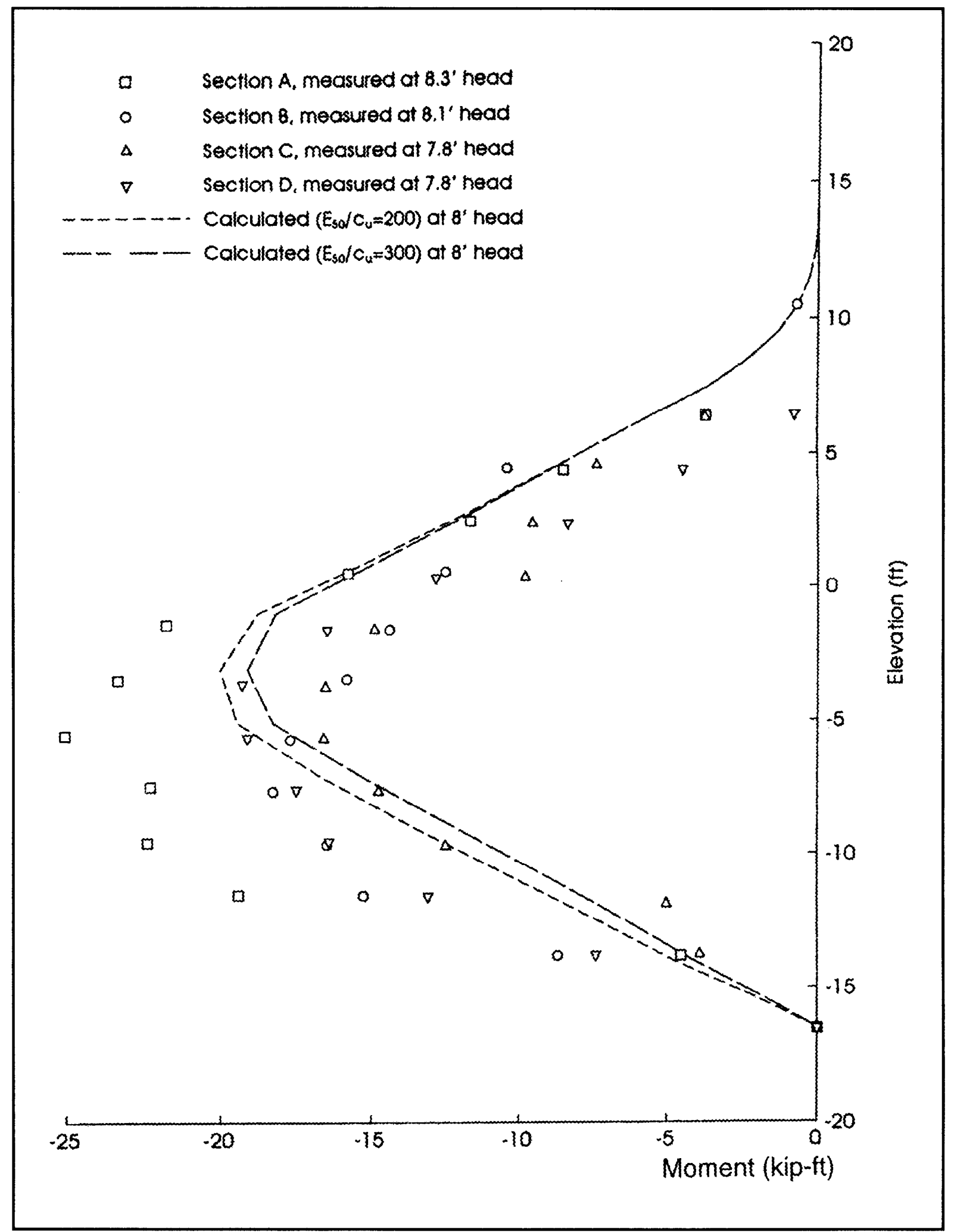

Figure 3. E99 wall: comparison of measured and calculated bending moments $(1 \mathrm{ft}=$ $0.305 \mathrm{~m}, 1 \mathrm{kip}-\mathrm{ft}=1,355.8 \mathrm{~N}-\mathrm{m}$ ) 
test wall, this time only numerically. The geometric characteristics for typical floodwalls were selected based on the observation that the typical levee was $3 \mathrm{~m}$ $(10 \mathrm{ft})$ high, and generally had side slopes of $1: 4$, the sheet-pile wall was installed approximately in the middle, and the penetration varied between 3 to $9 \mathrm{~m} \mathrm{(10} \mathrm{to}$ $30 \mathrm{ft}$ ). The typical section is shown in Figure 4.

To acquire representative values of the strength properties of the soils involved at floodwall sites, available field data and laboratory test data provided by the Corps of Engineers for several sites along the lower Mississippi River and previously published data were examined. The soils along the lower Mississippi are generally medium to very soft, fully saturated clays generally classified as $\mathrm{CH}$ according to the Unified Soil Classification System. Average properties of the clays are as follows: water content, 64 percent; void ratio, 1.8; plastic limit, 30; liquid limit, 84; and liquidity index, 0.7. Undrained shear strengths, $c_{u}$, for several sites are shown in Figure 5.

All profiles indicate that the strength of the levee material is higher than that

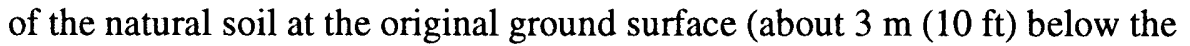
levee crest). The strength of the natural soil immediately below the levee is only slightly lower than that of the levee and decreases to a minimum at about $6 \mathrm{~m}$ $(20 \mathrm{ft})$ below the crest. The higher strength near the original surface suggests some consolidation due to levee overburden and/or prior desiccation. Below $6 \mathrm{~m}$ $(20 \mathrm{ft})$ the strength increases with depth in a manner typical of normally consolidated clays. The lines drawn on the test data in Figure 5 indicate the selected strength profiles to be used in analyses. The high- and medium-strength profiles were used in the analyses. The low-strength profile was not used because this strength level is not sufficient to carry the levee itself.

For the purposes of the systematic finite element case study, six floodwalls were made up by considering three penetration depths $(3,6$, and $9 \mathrm{~m}(10,20$, and $30 \mathrm{ft})$ ) and two idealized shear strength profiles. The cases were named $\mathrm{H} 10$, $\mathrm{H} 20, \mathrm{H} 30, \mathrm{M} 10, \mathrm{M} 20, \mathrm{M} 30$, for the high $(\mathrm{H})$ and medium (M) strength profiles and with numbers indicating the penetration depths. A typical finite element grid used in these analyses is shown in Figure 6.

\section{Deformation of the system}

Figure 7 illustrates the deformation of the system for the $6-\mathrm{m}(20-\mathrm{ft})$ pile in the high-strength profile at a $4.9-\mathrm{m}(16-\mathrm{ft})$ head. The most striking aspect of the deformations is that the entire levee system was undergoing essentially rigid body rotation about some point above the crest of the levee. The apparent rigid body rotation was observed for both soil strength profiles and appeared to be relatively insensitive to the extent of pile penetration. 


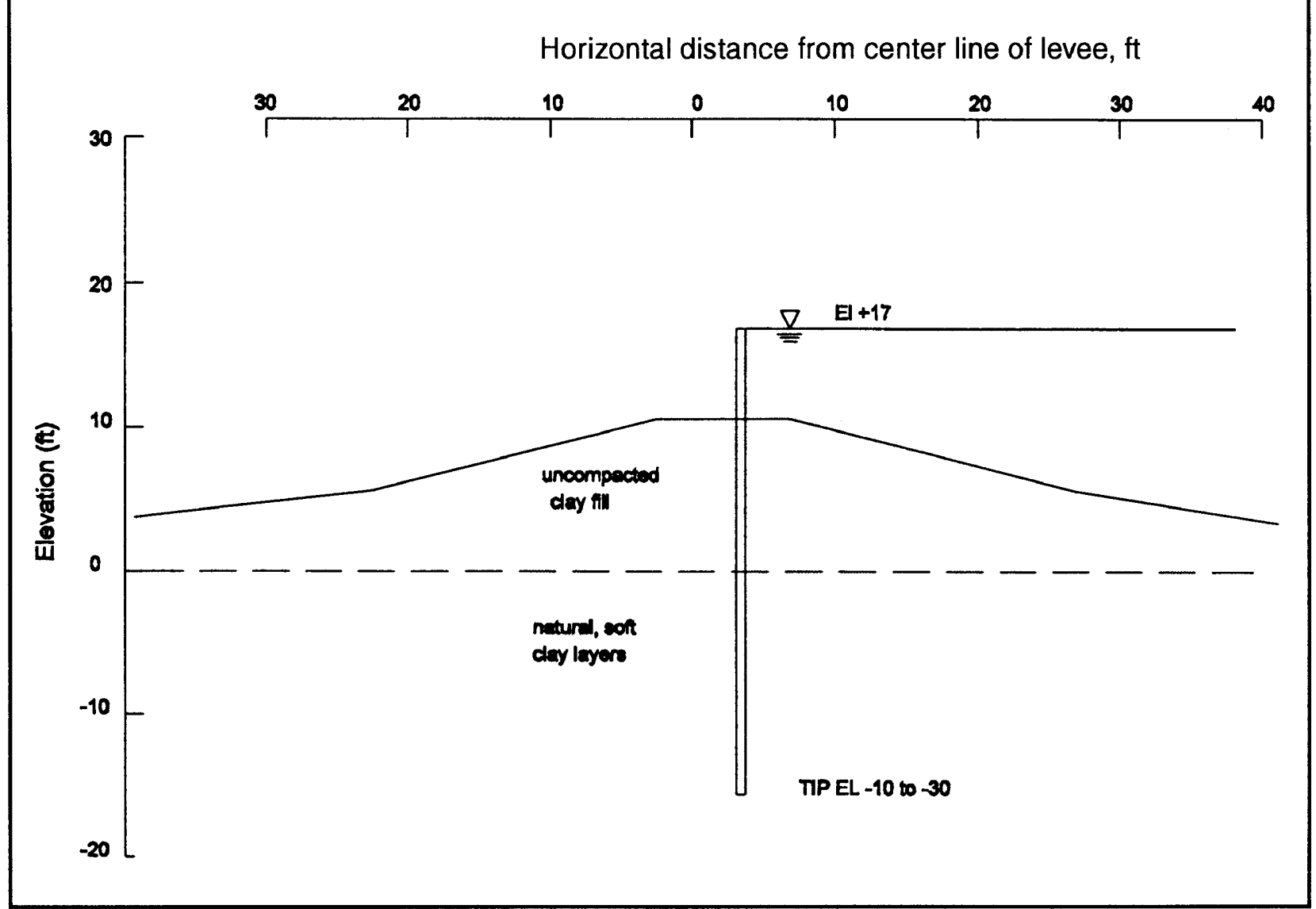

Figure 4. Cross section of a typical floodwall $(1 \mathrm{ft}=0.3048 \mathrm{~m})$

\section{The development of the shear ring method}

An attempt was made to relate the local wall displacement to the soil-wall contact pressure at the same location. The idea was to produce data in the generally assumed form, which had been used in the conventional SSI methods based on the beam on elastic foundation concept. This attempt failed. The reason for the failure was that the classical assumptions related to the development of lateral earth pressures were based on simple estimation, and not on any theoretical or experimental evidence. The earth pressures acting on the wall at various points were not directly and solely related to the wall deflection at the point considered; they were a result of very complex SSI phenomena. It had become clear that SSI could not be analyzed by representing the soil as a series of springs. The stress-strain relationship of the soil and its deformation had to be taken into account for a reliable analysis.

These observations have led to the development of a new SSI analysis method where the soil is represented explicitly, not just as springs. The new method is based on the assumption that the entire system, not just the wall, but 


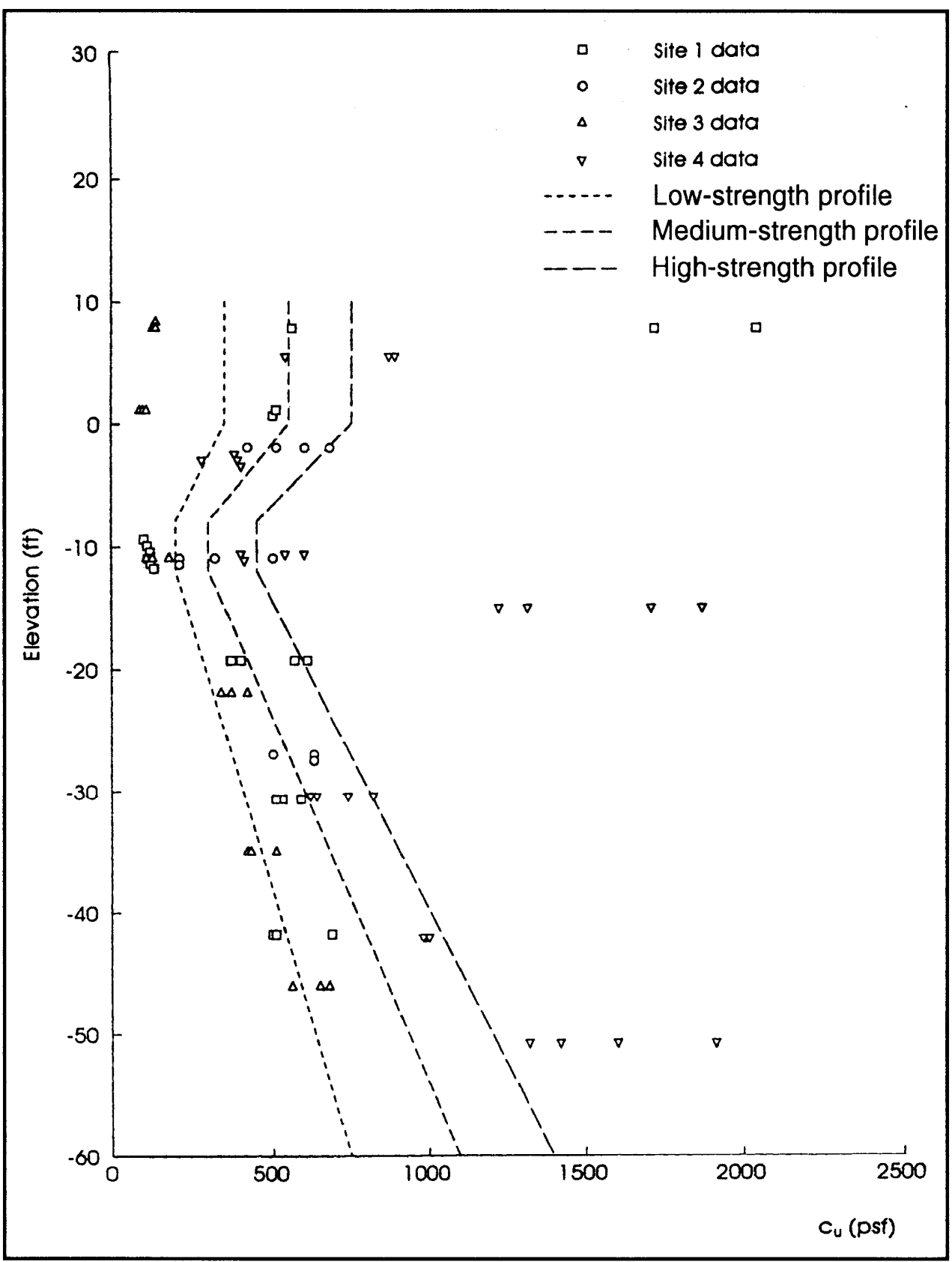

Figure 5. Idealized shear strength profiles with data from typical floodwall sites $\left(1 \mathrm{lbf} / \mathrm{ft}^{2}=0.048 \mathrm{kPa}, 1 \mathrm{ft}=0.305 \mathrm{~m}\right.$ )

the soil close to it, would rotate around a point. This point is called the pivot, and the soil essentially rotates around this point. The soil near and below the wall is subdivided, for analysis purposes, into a number of concentric circular rings with centers at the pivot point (Figure 8). The rings are considered to deform mainly in shear, hence the name Shear Ring Method. 


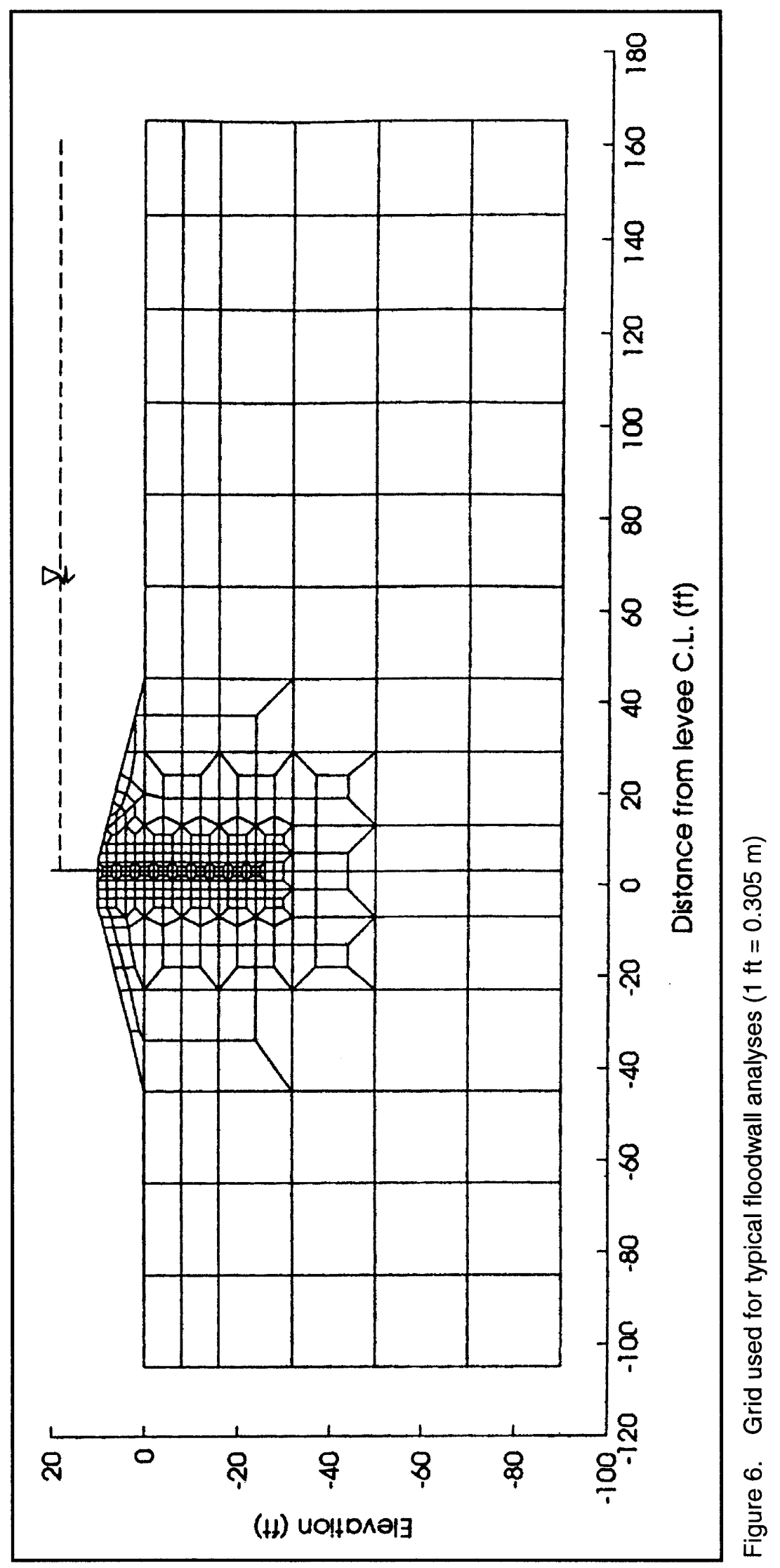




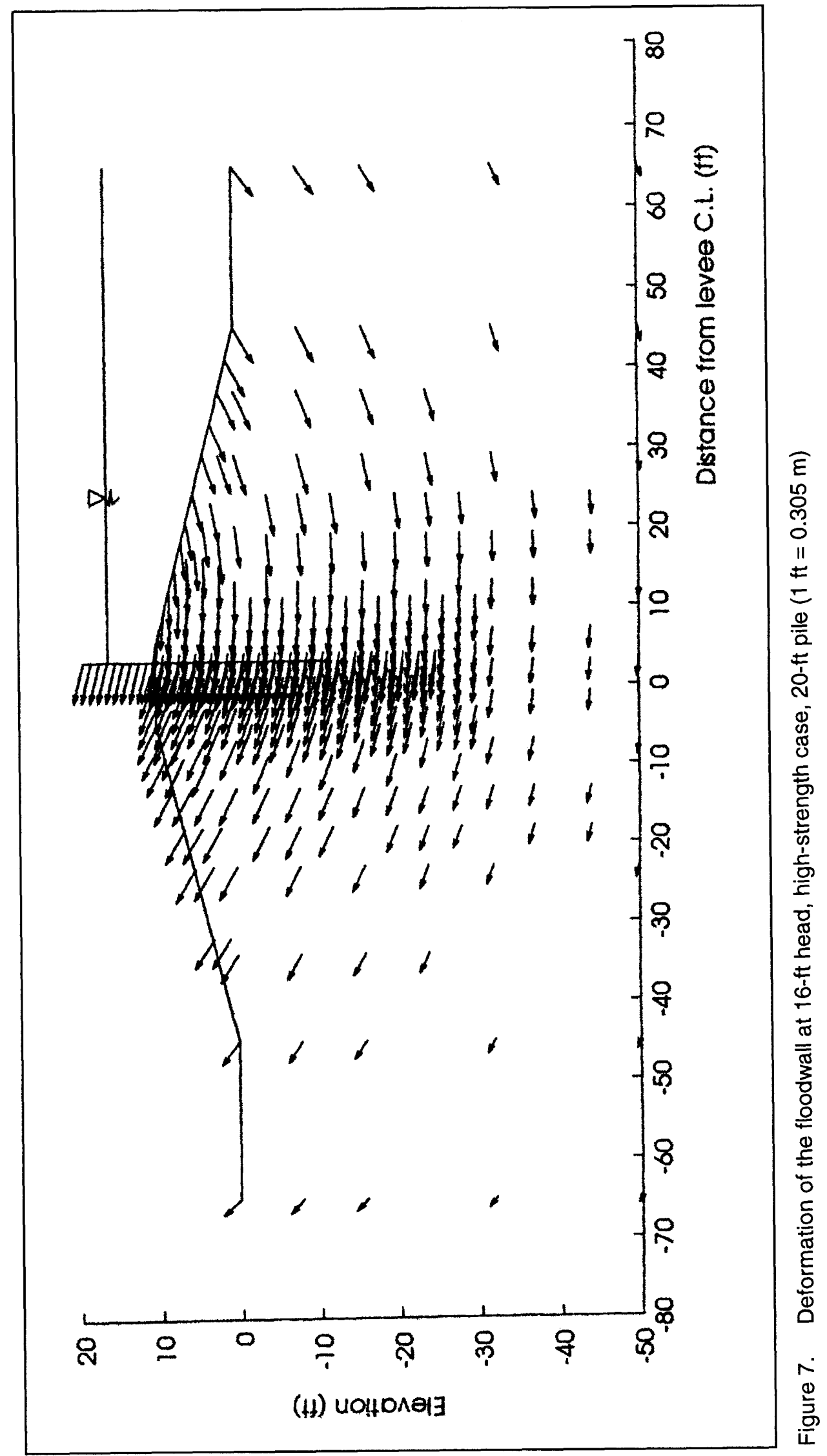




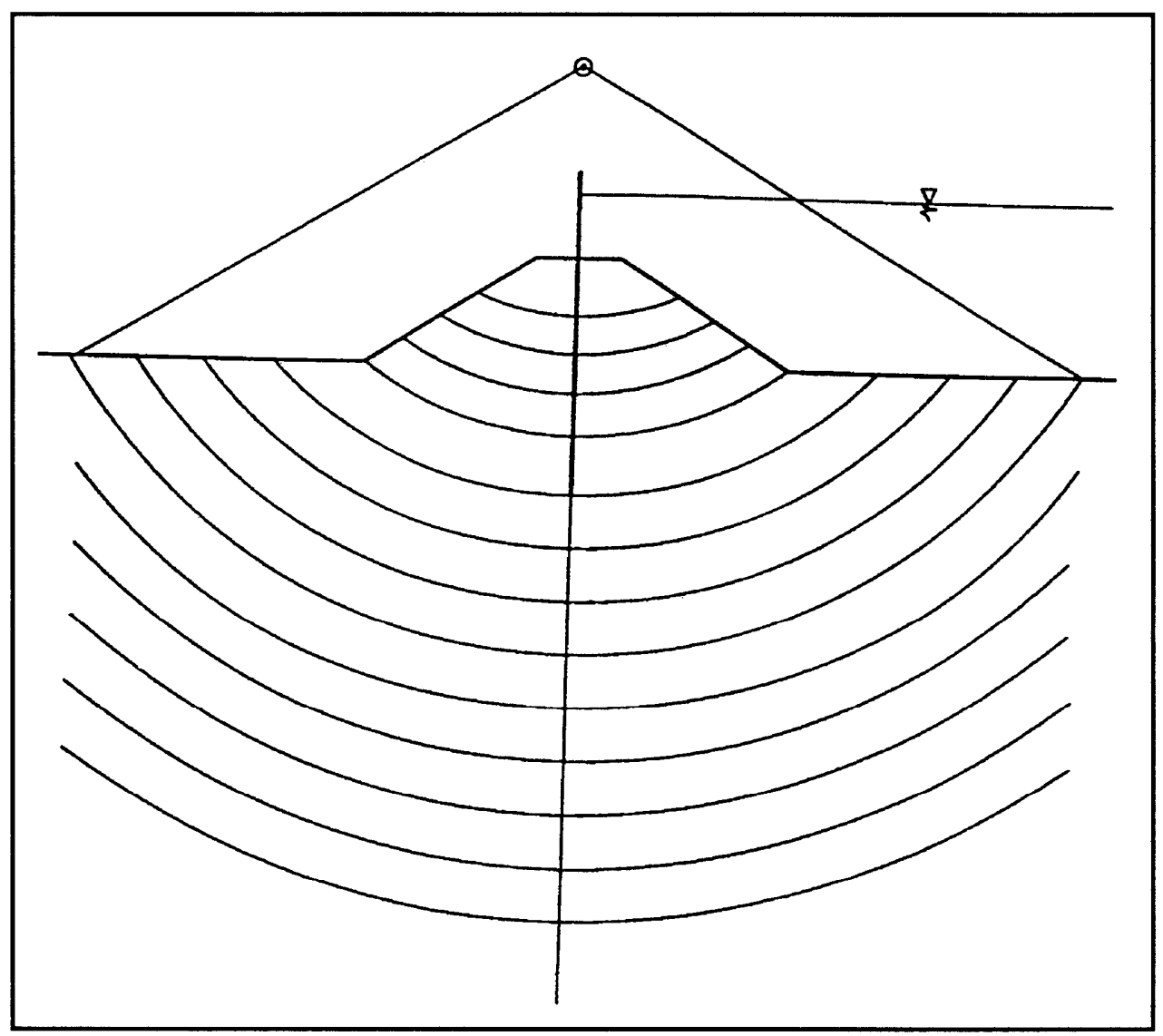

Figure 8. Shear ring model of a floodwall

The SRM formulation is somewhat more complex than the conventional SSI, because of the inclusion of the soil in the model. No assumptions are made on the lateral earth pressures; they are part of the solution. The method produces results that are comparable to a comprehensive finite element analysis, but with these advantages:

a. Data to be supplied to SRM are a small fraction of what a finite element program requires.

b. The SRM can be run on a desktop computer and produces answers in a few seconds or minutes.

c. The results can be easily interpreted.

The details of the SRM are discussed in Chapter 3. The remainder of this section presents the verification studies performed for the SRM. 


\section{The Results of Verification Studies}

Figures 9 through 15 compare the FEM results with the conventional SSI and the new SRM analyses. Figure 9 compares levee crest displacements as a function of the water head on the wall, for the medium penetration 6-m $(20-\mathrm{ft})$ cases for both soil strength profiles. The agreement is found to be excellent at all head levels for both soil profiles. Conventional SSI results are not comparable with these since SSI is not capable of producing absolute displacements; it only gives the displacements relative to some point on the wall (such as the tip of the pile) that is assumed to be stationary. Figure 10 compares moments calculated by FEM versus SRM for the three walls in the high-strength profile. Excellent agreement is found between the two methods. Similar agreement is found in the comparison for the medium-strength cases (Figure 11). In order to see how the conventional SSI performs for the same problems, calculated moments are compared in Figure 12 for the high-strength cases. It is clear that the conventional SSI performs poorly in these cases, except perhaps the very rigid wall case of $3-\mathrm{m}$ (10-ft) pile.

All the comparisons discussed in the previous paragraph are for the final flood elevation used in the numerical tests. In order to see if the method is capable of capturing safer load levels also, moments are plotted in Figures 13 and 14 for lower flood levels for the 3- and 9-m (10- and 30-ft) walls. In all cases it is clearly observed that SRM successfully duplicated the FEM results. Finally, net earth pressures on the walls are compared in Figure 15 for 3- and 9-m (10- and $30-\mathrm{ft}$ ) piles in the high-strength soil. Again very good agreement is found between the FEM and SRM results.

The results of these comprehensive FEM analyses have revealed that a typical floodwall will not behave as it is usually assumed in a conventional design analysis method. This observation has led to the development of a new method of analysis, the SRM. Based on the results of the studies presented in this report it can be concluded that

a. The new method reproduces the FEM results reasonably accurately at a small fraction of the cost.

b. It is only slightly more complicated than a conventional SSI procedure, thus capable of serving as a design method.

c. The two-dimensional soil profile is represented in the model allowing the influence of levee slopes to be taken into account without any additional effort.

$d$. The conventional soil properties, such as the shear strength parameters, are used as input to the SRM as opposed to one-dimensional soil response curves required in a conventional SSI analysis. 


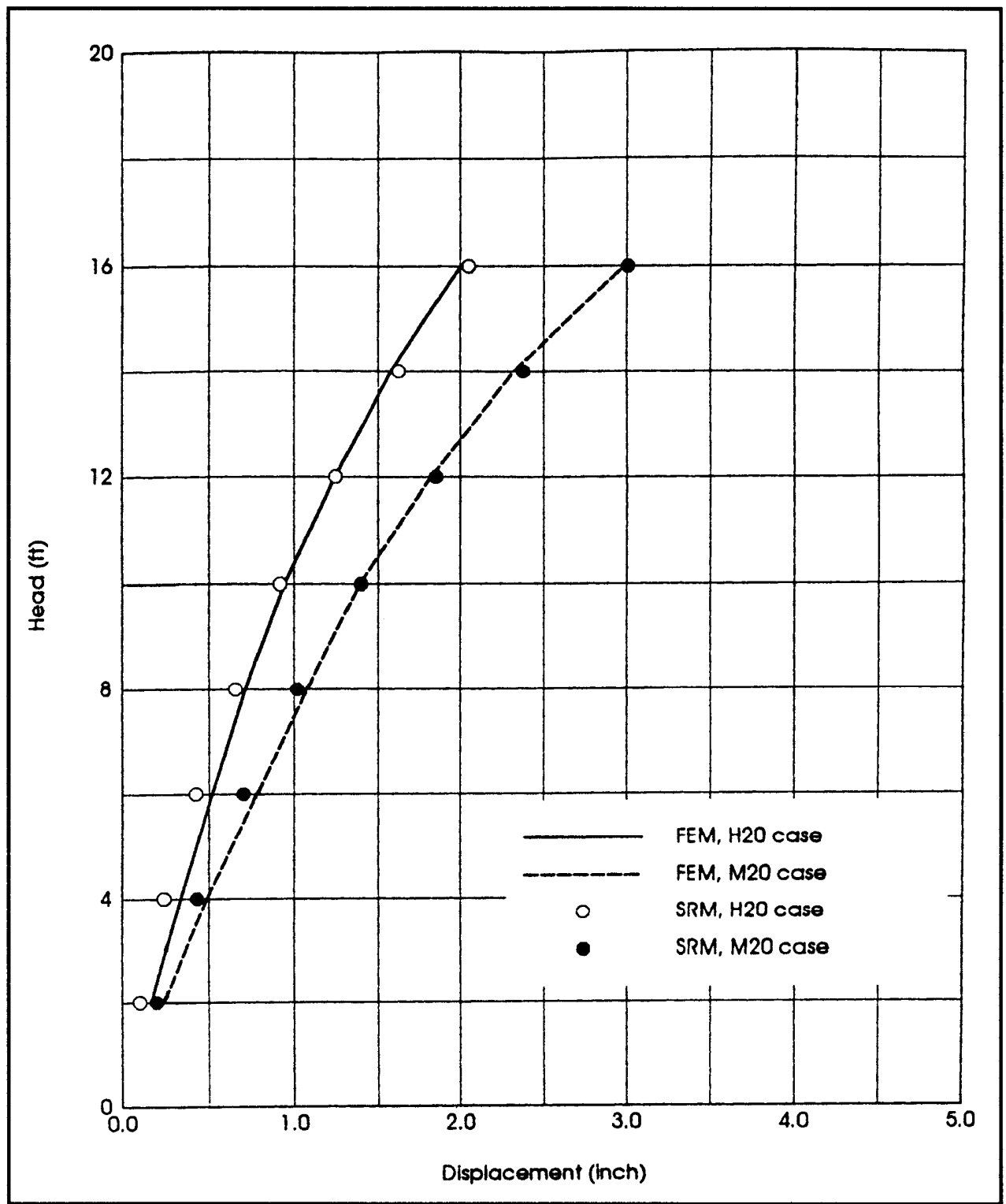

Figure 9. Comparison of FEM and SRM solutions, crest displacements $(1 \mathrm{ft}=$ $0.305 \mathrm{~m}, 1$ in. $=25.4 \mathrm{~mm}$ )

\section{Verification of Floodwall Procedure by Full-Scale Tests}

After the development of the SRM and its various extensions, it was discovered that a series of full-scale floodwall tests were performed in the 1940's by the U.S. Army Engineer District, Louisville. This provided a unique opportunity for verifying the SRM. The tests were done in four-sided "boxes" constructed by 


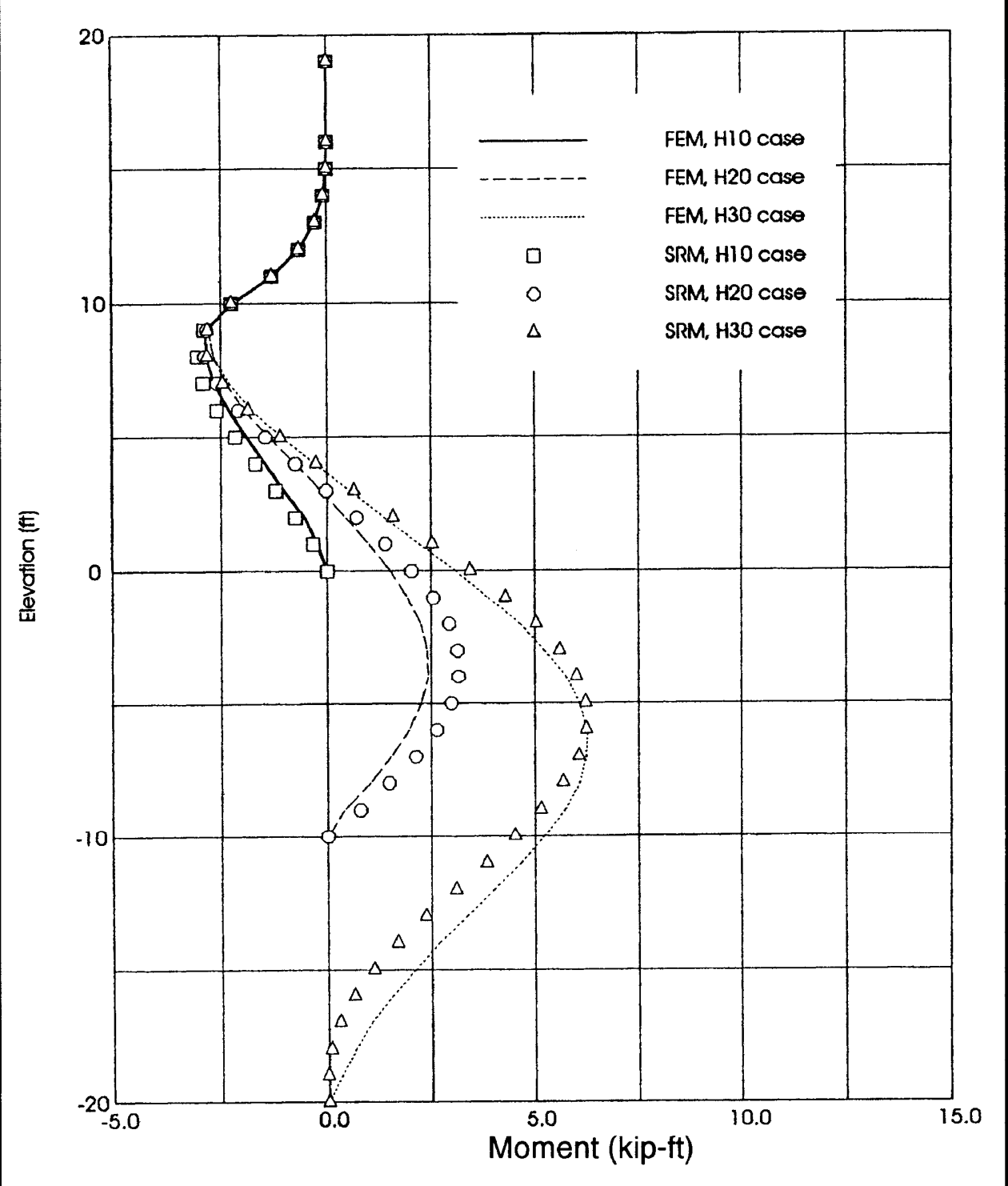

Figure 10. Comparison of FEM and SRM results, high-strength profile, all three piles, at $16-\mathrm{ft}$ head $(1 \mathrm{ft}=0.305 \mathrm{~m}, 1 \mathrm{kip}-\mathrm{ft}=1,355.8 \mathrm{~N}-\mathrm{m})$

steel sheet-pile walls and the flood was intended to be simulated by filling the boxes with water. Figure 16 is a reproduction of the drawings for one of the walls from the original report.

Clearly the boundary conditions of the tests did not simulate a flood condition, where water covers large areas on one side of the wall. Therefore the test as well as flood conditions were studied by modern analysis procedures to understand the soil-structure interaction mechanisms involved in these systems. The comprehensive FEM equipped with suitable models of the soil-structure 


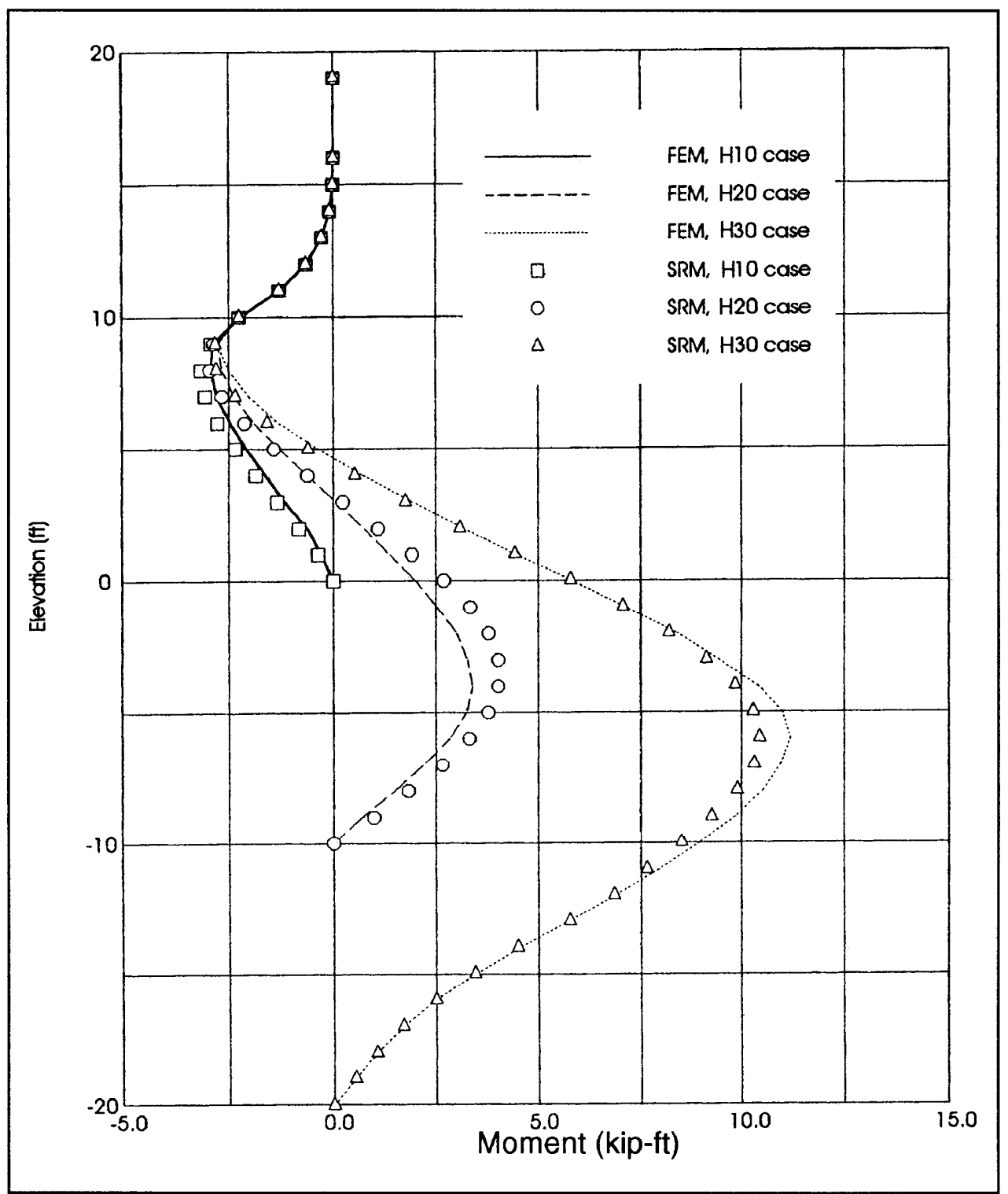

Figure 11. Comparison of FEM and SRM results, medium-strength profile, 16-ft head $(1 \mathrm{ft}=0.305 \mathrm{~m}, 1 \mathrm{kip}-\mathrm{ft}=1,355.8 \mathrm{~N}-\mathrm{m})$

interface, nonlinear soil behavior, and loading sequence was also employed in the study as well as the SRM. It may be noted that while the FEM can consider both the test and the flood conditions, the SRM can simulate only the flood condition.

Table 2 gives the general characteristics of these floodwall tests.

The soil properties used in the analyses of the test walls are given in Table 3. The $m$ parameter shown in this table is the main parameter of the stress-strain model. For the angle of internal friction $\phi=0$ case, it is defined as the ratio $m=$ $E_{5} / c_{u}$. 


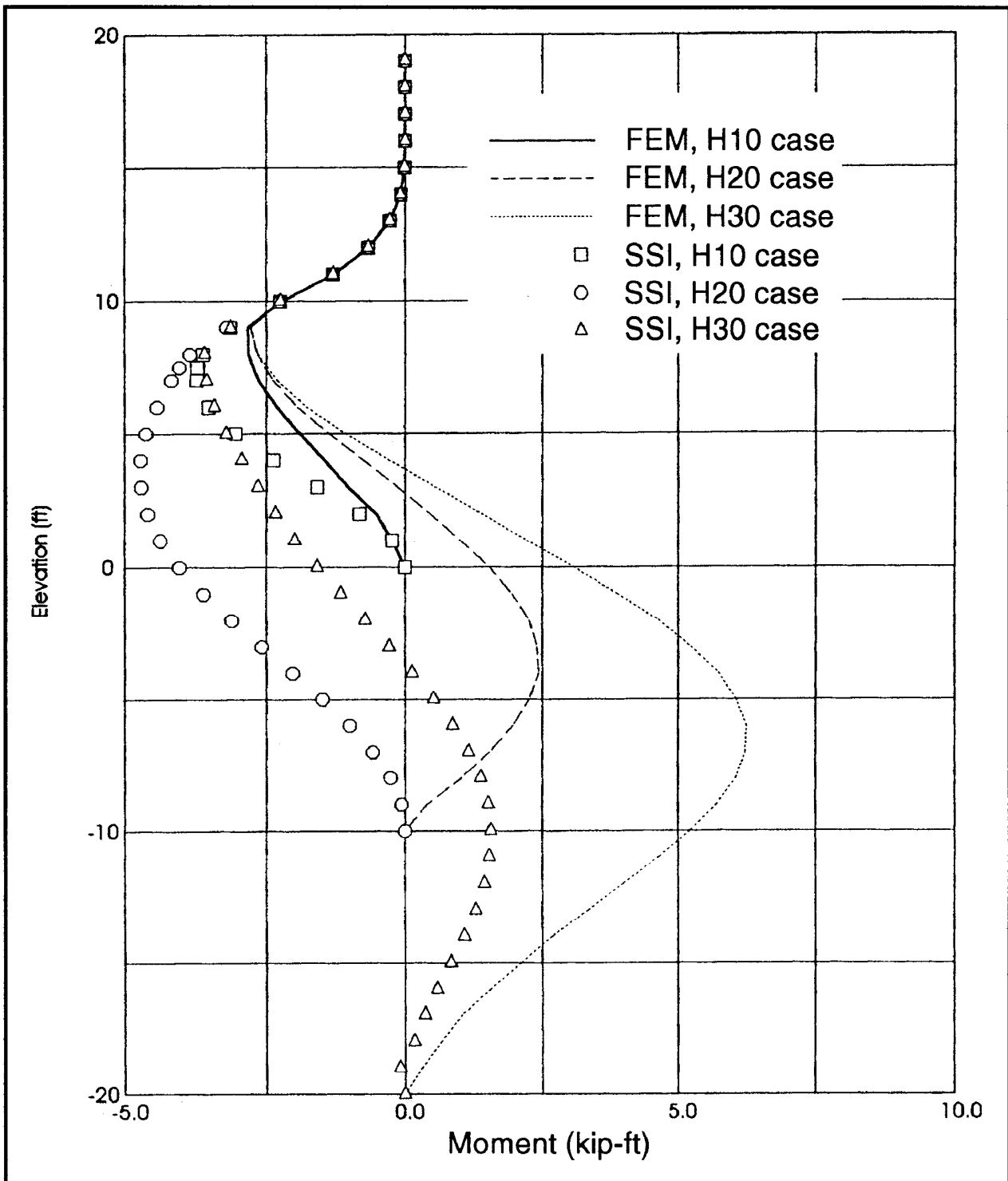

Figure 12. Comparison of FEM and conventional SSI results, high-strength profile, $16-\mathrm{ft}$ head $(1 \mathrm{ft}=0.305 \mathrm{~m}, 1 \mathrm{kip}-\mathrm{ft}=1,355.8 \mathrm{~N}-\mathrm{m})$

The finite element grids used are shown, in a simplified form, in Figure 17. Notice the difference in the grids used for modeling the test and flood conditions. The walls were also analyzed by SRM for flood conditions.

Comparisons of the results for one of the walls (Wall $A$ ) are given in Figures 18 and 19. The comparisons for the other two walls are essentially the same. In Figure 18 the FEM results for the test conditions are shown to be very close to those predicted by the comprehensive FEM analysis, which verifies the FEM techniques and the soil parameters used. The FEM analysis and the SRM predictions are also very close; this indicates that SRM is doing an exceptionally 


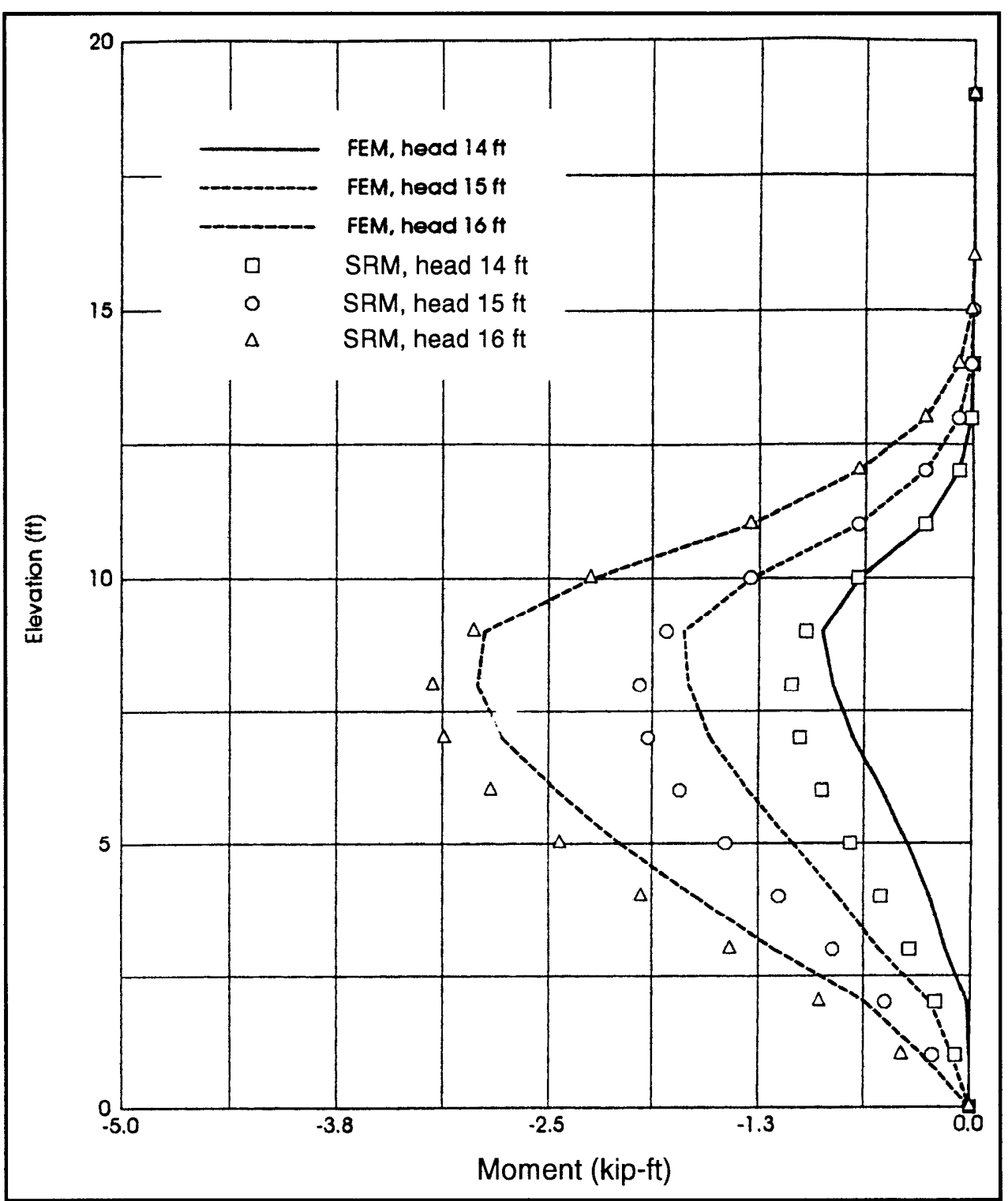

Figure 13. Variation of moment as water head increases, medium-strength profile, 10 -ft pile $(1 \mathrm{ft}=0.305 \mathrm{~m}, 1 \mathrm{kip}-\mathrm{ft}=1,355.8 \mathrm{~N}-\mathrm{m})$

good job predicting the flood conditions. These results are all for the highest water level used. Comparisons of the development of the deflections as water levels increase are shown in Figure 19. In this figure it is clearly observed that the SRM predictions are very favorable throughout the water level range, indicating that the nonlinearity of the soil behavior is represented in the SRM reliably. 


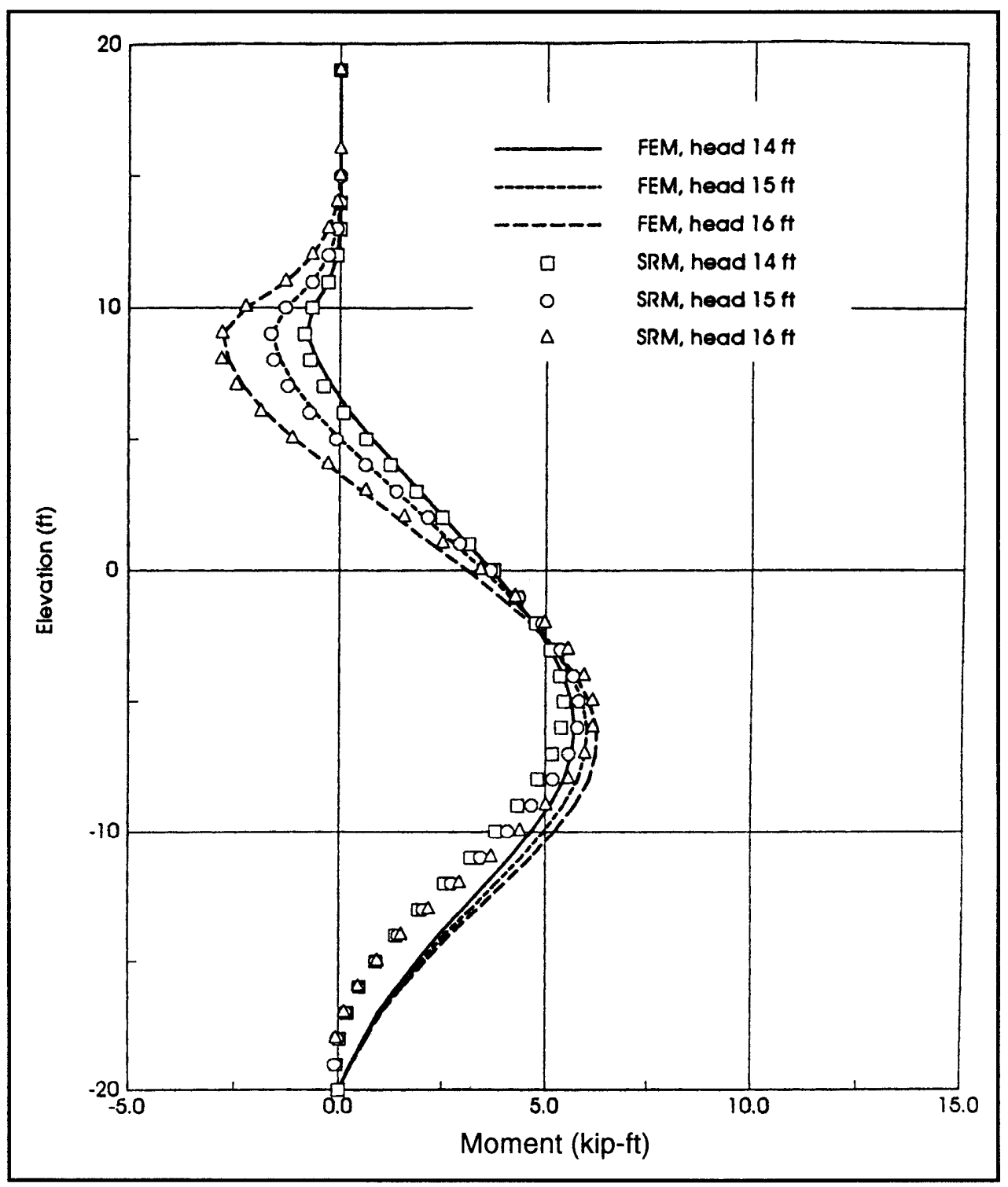

Figure 14. Variation of moment as water head increases, high-strength profile, $30-\mathrm{ft}$ pile $(1 \mathrm{ft}=0.305 \mathrm{~m}, 1 \mathrm{kip}-\mathrm{ft}=1,355.8 \mathrm{~N}-\mathrm{m})$

\section{Extension to Anchored Walls and Verification}

The success of the SRM in floodwall problems has made it desirable to extend the usefulness of the idea to other types of wall systems, particularly the anchored sheet-pile walls. There are two well known earlier studies on anchored sheet-pile walls. Bjerrum, Clausen, and Duncan (1972) is a comprehensive FEM study on two typical anchored sheet-pile walls. The other one is Rowe's (1955) systematic study, which has led to the well known moment reduction curves. The results of these studies were chosen as the basis for comparisons. 


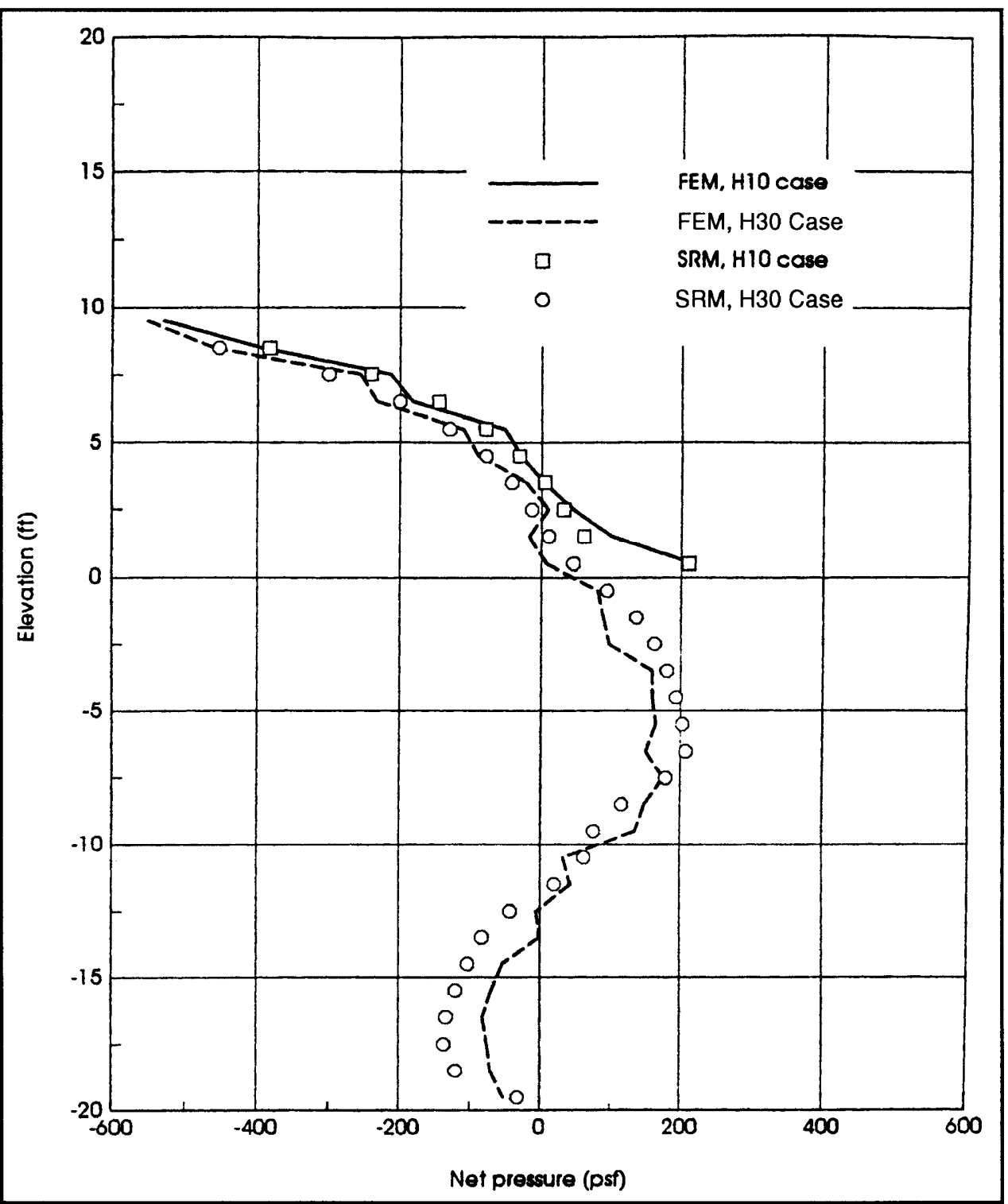

Figure 15. Net earth pressure on the pile at water head of $16 \mathrm{ft}$, high-strength case, 10 - and 30-ft piles ( $\left.1 \mathrm{ft}=0.305 \mathrm{~m} ; 1 \mathrm{lbf} / \mathrm{ft}^{2}=0.048 \mathrm{kPa}\right)$

\section{Bjerrum, Clausen, and Duncan piles}

Figure 20 shows the profile of the anchored sheet-pile walls used in the Bjerrum, Clausen, and Duncan (1972) study. The wall has a 17-m free height and is embedded $8 \mathrm{~m}$. The soil is a loose sand, with a $\phi$ of $30 \mathrm{deg}$. The same walls were studied further by Smith and Boorman (1974) using similar FEM procedures. Their results confirmed the earlier results. Two wall stiffnesses were considered, which were referred to as Pile A and Pile B. These two stiffnesses, in terms of Rowe's $\log \rho$ values, are -2.88 and -2.52 , where $\rho$ is the flexibility 


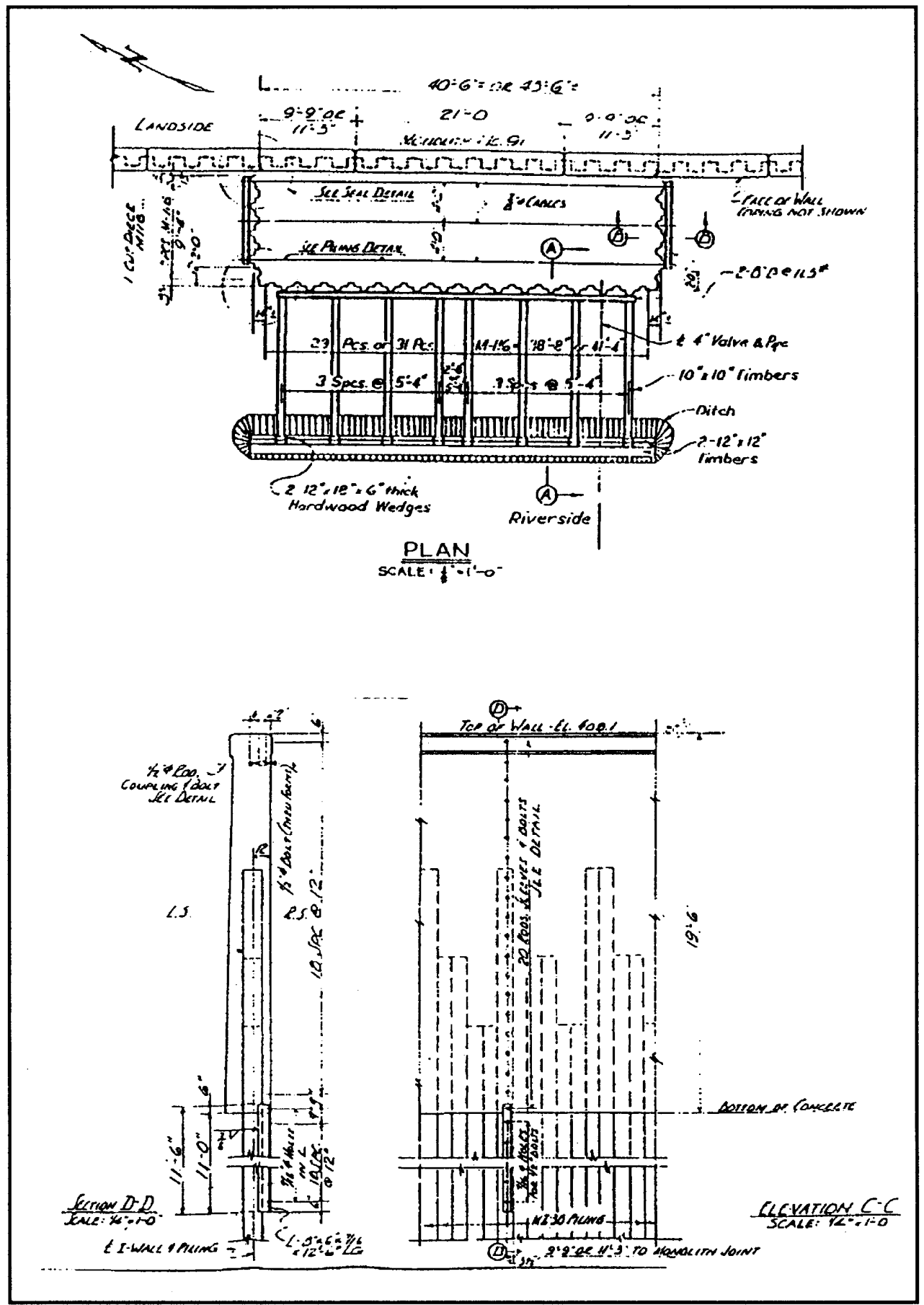

Figure 16. Plan and profile of a floodwall test

number, inside the typical range. These two walls were analyzed by the free earth support (FES) method, the SRM, and also the conventional SSI method (CWALSSI program (Dawkins 1994a)). 


\begin{tabular}{|c|c|c|c|c|}
\hline \multicolumn{5}{|c|}{$\begin{array}{l}\text { Table } 2 \\
\text { General Characteristics of the Floodwall Tests }{ }^{1}\end{array}$} \\
\hline $\begin{array}{l}\text { Test } \\
\text { Wall }\end{array}$ & Location & Soil Type & $\begin{array}{l}\text { Maximum Water } \\
\text { Head, ft }\end{array}$ & $\begin{array}{l}\text { Dimensions, } \mathrm{ft} \\
(\mathrm{W} L \mathrm{H})\end{array}$ \\
\hline A & Paducah, KY & Silty clay & 9.5 & $40^{\prime} \times 20^{\prime} \times 20^{\prime}$ \\
\hline B & Paducah, KY & Silty clay & 19.3 & $40^{\prime} \times 20^{\prime} \times 20^{\prime}$ \\
\hline C & Tell City, IN & Clayey silt & 15.4 & $11^{\prime} \times 42^{\prime} \times 19.5^{\prime}$ \\
\hline \multicolumn{5}{|c|}{$\begin{array}{l}\text { Note: } 1 \mathrm{ft}=0.305 \mathrm{~m} . \\
\text { After H. Hutchings, Jr. (1941). "Final report on flood wall stability investigations," Report to Chief } \\
\text { of Engineers, U.S. Army, U.S. Army Engineer District, Louisville. }\end{array}$} \\
\hline
\end{tabular}

\begin{tabular}{|c|c|c|c|c|c|c|}
\hline $\begin{array}{l}\text { Test } \\
\text { Wall } \\
\end{array}$ & Soil Type & $\begin{array}{l}\text { Average } \\
\text { Void Ratio, } \\
e \\
\end{array}$ & $\begin{array}{l}\text { Buoyant } \gamma \\
\text { Unit Weight } \\
{\mathrm{lb} / \mathrm{ft}^{3}}^{3}\end{array}$ & $\begin{array}{l}\text { Average } \\
c_{u}, \mathrm{Ibf} / \mathrm{ft}^{3} \\
\end{array}$ & $E_{50} / c_{u}$ & $\begin{array}{l}\text { Bending } \\
\text { Stiffness EI } \\
\text { lb॰in }^{2}\end{array}$ \\
\hline A & Silty clay & 0.60 & 66.3 & 500 & 200 & $4.2 \times 10^{7}$ \\
\hline B & Silty clay & 0.60 & 66.3 & 600 & 200 & $4.2 \times 10^{7}$ \\
\hline C & Clayey silt & 0.63 & 65.1 & 550 & 600 & $5.0 \times 10^{9 a}$ \\
\hline
\end{tabular}

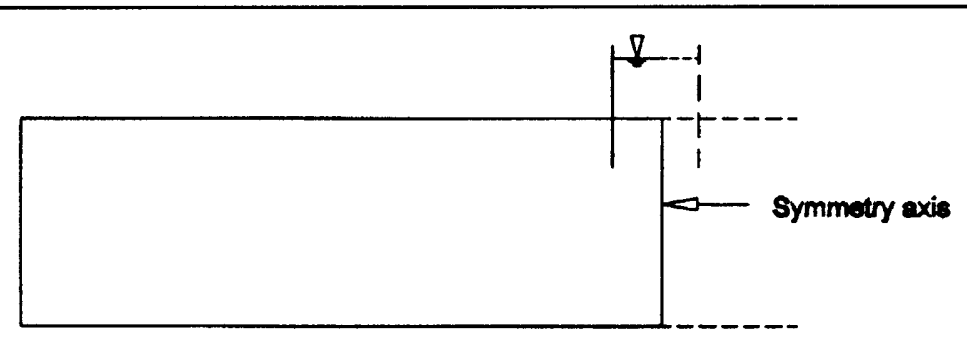

a. Test condition

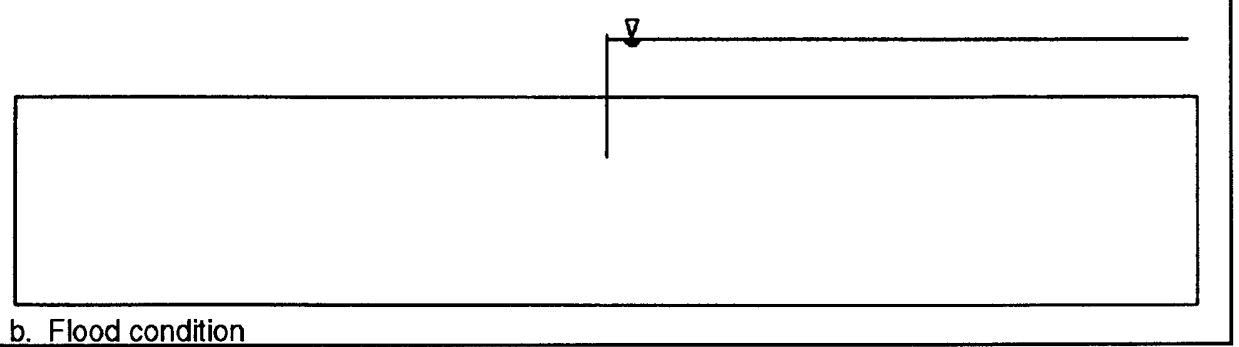

Figure 17. The sizes of the finite element grids for test and flood conditions 


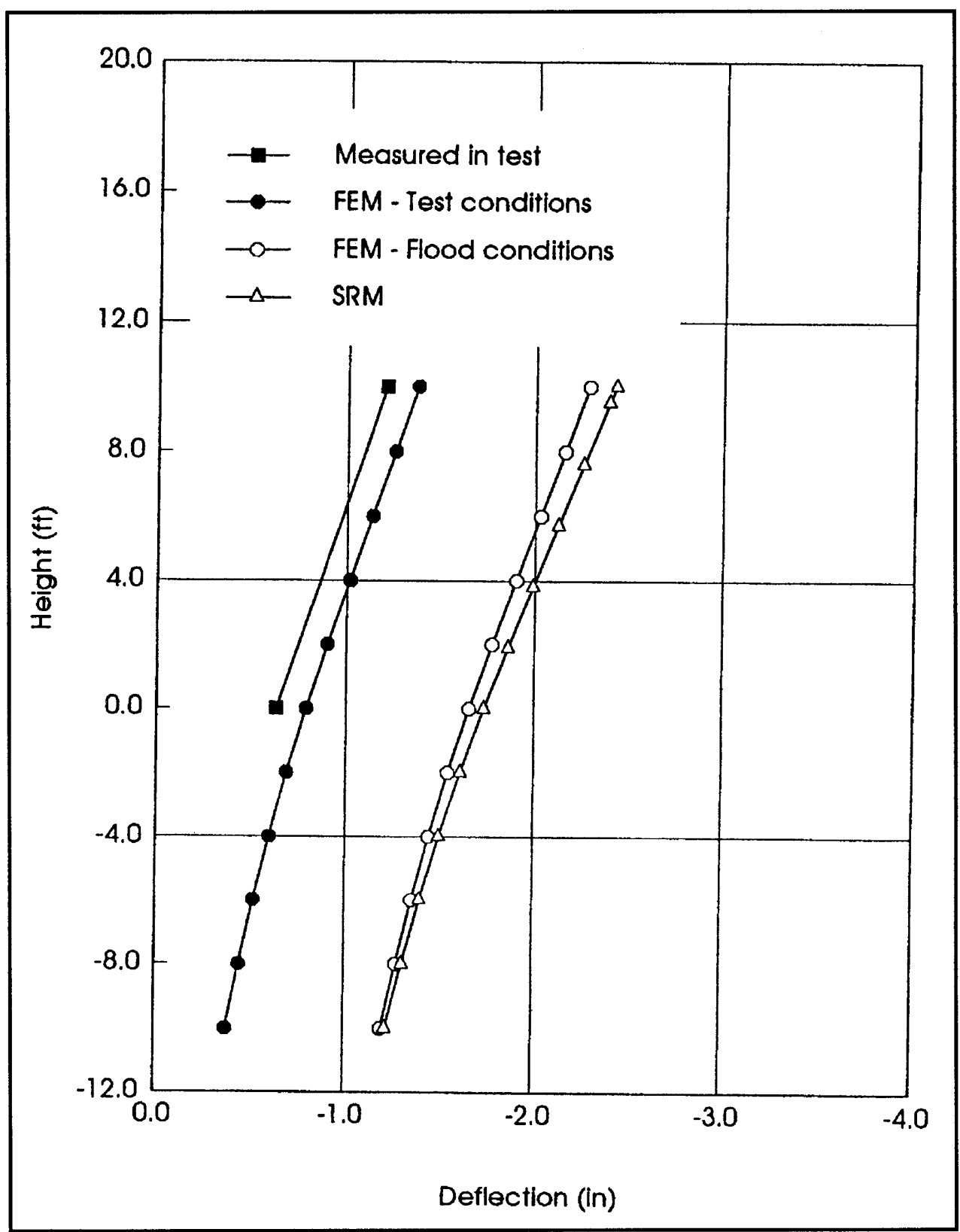

Figure 18. Comparison of deflection versus height, flood and measured conditions (Case A) $(1 \mathrm{ft}=0.305 \mathrm{~m} ; 1 \mathrm{in} .=25.4 \mathrm{~mm}$ )

Calculated bending moments are compared in Figure 21 for Pile A. It is observed that the conventional SSI analysis predicts moments that are very close to the FES results. The SRM (RingWall) results are seen to agree better with the FEM solution, and the two have a similar character of moment reversal below the dredge line. This moment reversal has been consistently observed earlier in Rowe's tests, and it has come to be described as the fixity below dredge line effect. As discussed by Bjerrum, Clausen, and Duncan (1972), the FES moments are unrealistically high. After Rowe's reduction factors are applied, the FES 


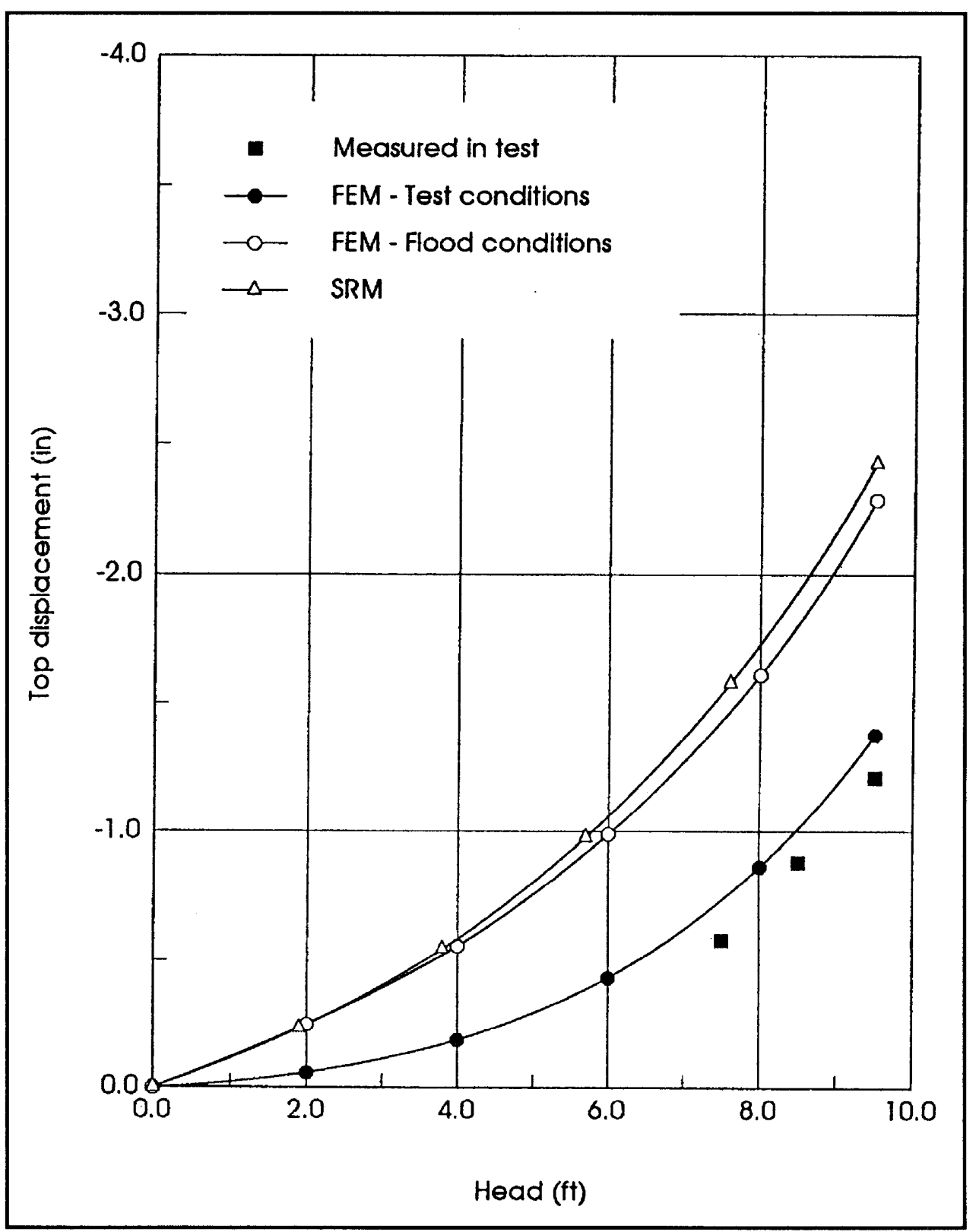

Figure 19. Comparison of head versus top displacement, flood and measured conditions (Case A) $(1 \mathrm{ft}=0.305 \mathrm{~m} ; 1 \mathrm{in} .=25.4 \mathrm{~mm})$

moments are closer to the values their study indicates. The SRM predictions are confirmed by these results. Figure 22 compares wall deflections calculated by the three methods. Again, the Bjerrum, Clausen, and Duncan study supports the SRM results closely, while the conventional SSI results do not fall in the same range as the other two.

Figures 23 and 24 present similar comparisons for Pile B, and the conclusions are also similar: the conventional SSI does not improve significantly over 


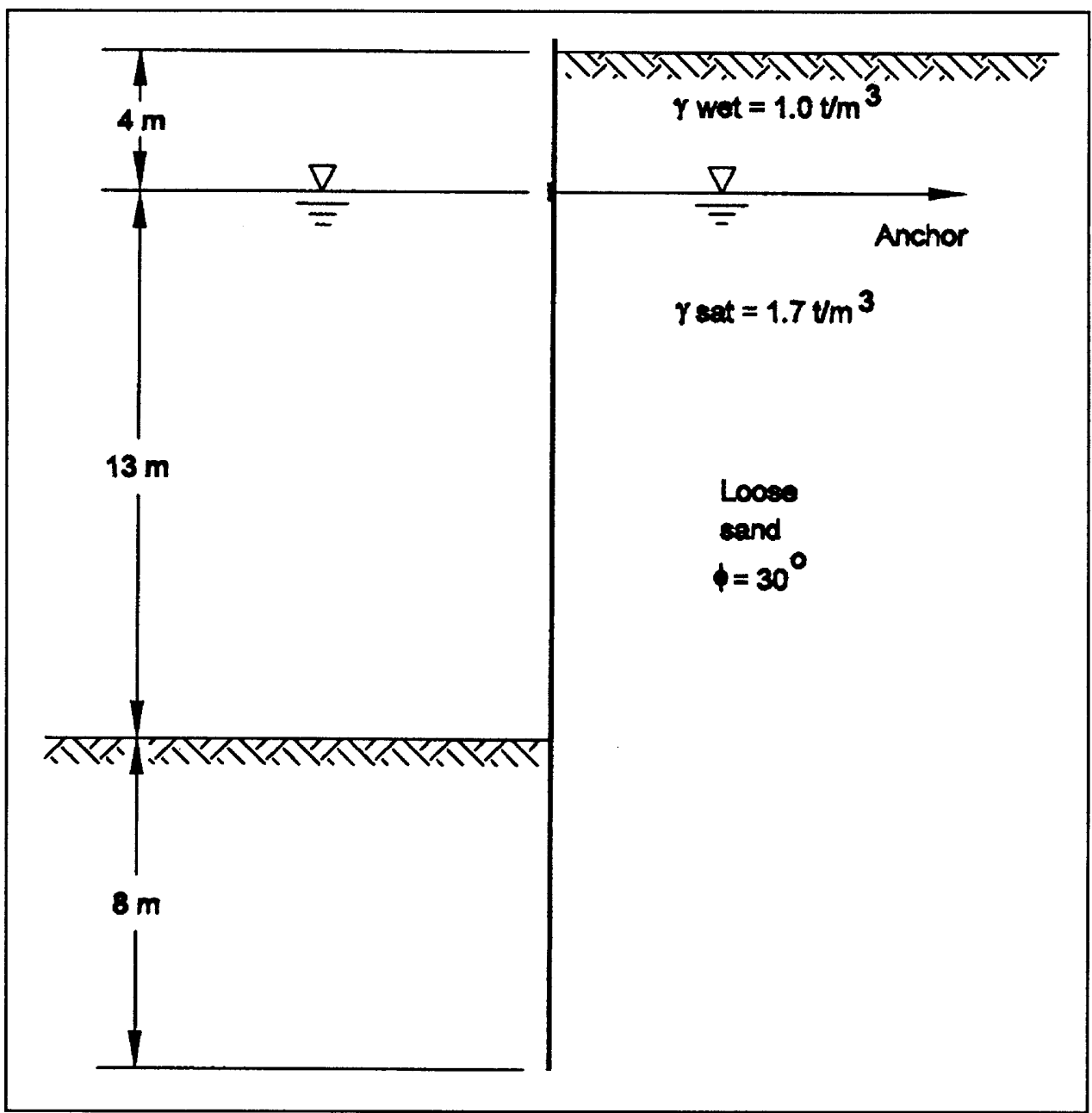

Figure 20. Anchored sheet-pile wall problem analyzed by Bjerrum, Clausen, and Duncan (1972) by FEM

the historic hand calculation method, FES method, and the SRM predicts deflections and bending moments that closely agree with comprehensive FEM analyses. These have provided further support for SRM.

\section{Rowe's experimental study}

The experimental study, which is the basis of the well known Rowe's moment reduction curves used in design, has also offered another opportunity for testing the SRM for a wider range of conditions.

Five walls were set up and numerically tested in both loose and dense sand. The wall stiffnesses were selected such that Rowe's $\log \rho$ values were $-2.0,-2.5$, $-3.0,-3.5$, and -4.0 , covering the entire practical range. The soil model 


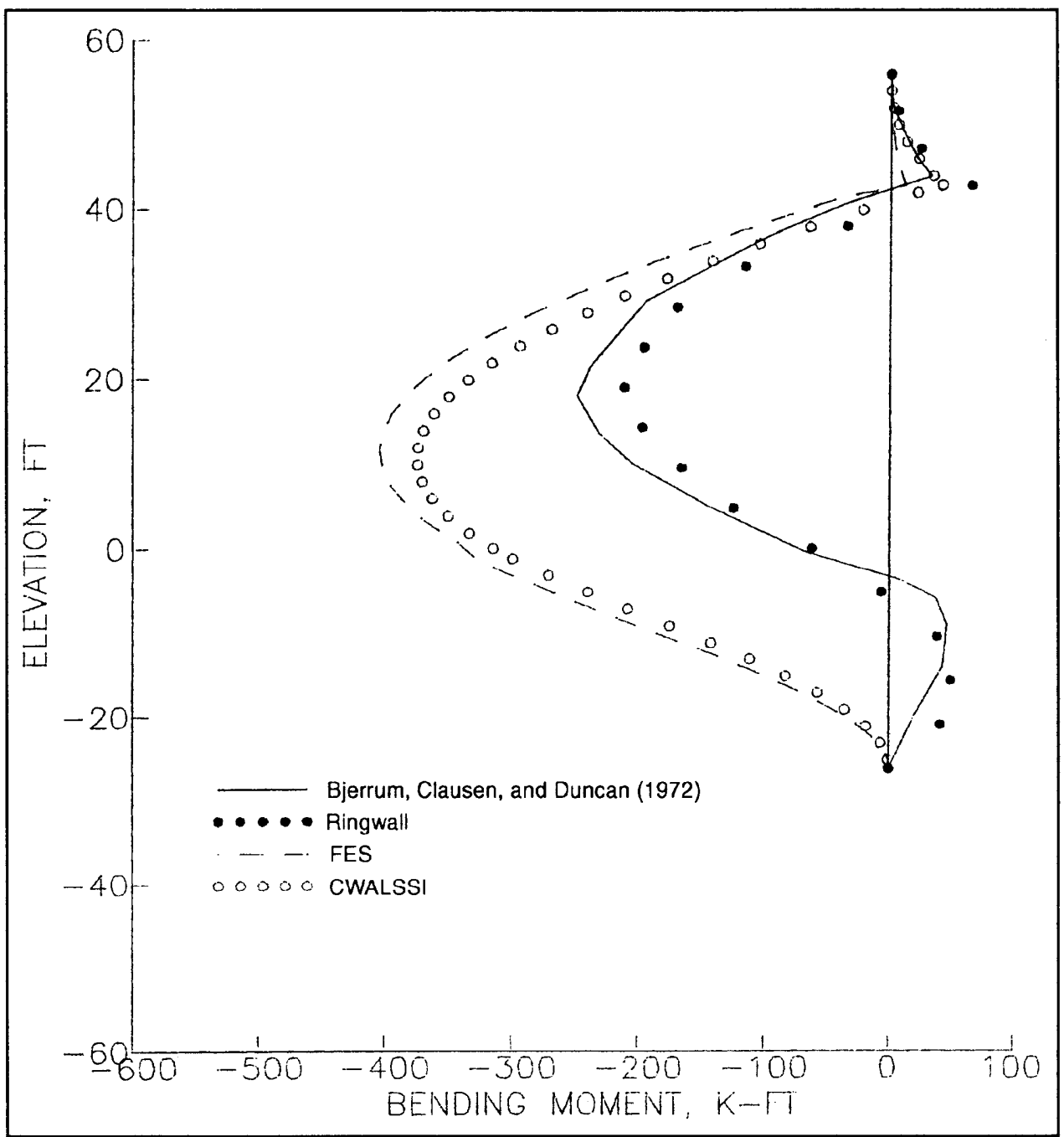

Figure 21. Comparison of moments, Bjerrum, Clausen, and Duncan (1972), $(1 \mathrm{ft}=0.305 \mathrm{~m} ; 1 \mathrm{kip}-\mathrm{ft}=1,355.8 \mathrm{~N}-\mathrm{m})$

parameters required for SRM analyses were determined using the laboratory test results given in the original paper (Rowe 1955). The results were put in the same format as Rowe presented his data, as shown in Figure 25. In this figure the lines are Rowe's average curves. It is observed that SRM successfully predicts the complete set of Rowe's moment reduction curves.

\section{Systematic Verification Study-Anchored Wall Cases}

In the previous phase of this research it was found that the SRM appeared to give reasonable results that compared favorably with a few anchored sheet-pile wall problems analyzed by Bjerrum, Clausen, and Duncan (1972). These cases, 


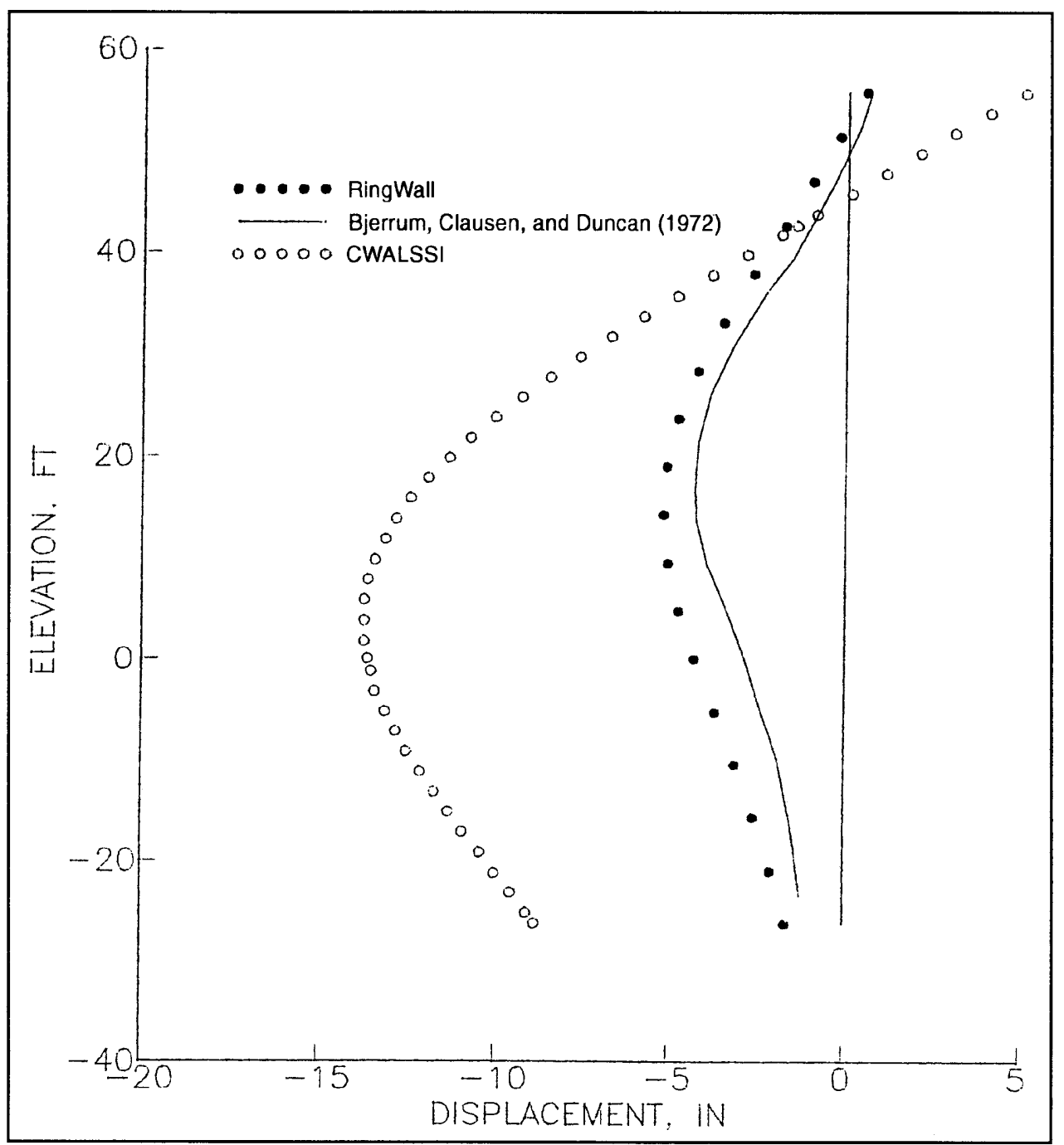

Figure 22. Comparison of displacements, Bjerrum, Clausen, and Duncan (1972), (1 ft = $0.305 \mathrm{~m} ; 1$ in. $=25.4 \mathrm{~mm})$

however, did not cover sufficient variations of soil conditions encountered in practice, and it was decided that a wider variety of cases should be analyzed by two-dimensional, nonlinear finite elements for verification of the SRM. This report covers the initial results of these studies.

\section{Construction of typical wall cases}

A number of somewhat idealized, anchored sheet-pile walls were set up by the procedures outlined in the following paragraphs.

To limit the number of cases to be analyzed, the free height of the sheet-pile wall was taken as $12 \mathrm{~m}$ (40 ft) for most cases. However, conventional (FES) calculations indicated that this is an unreasonably large height for profiles 


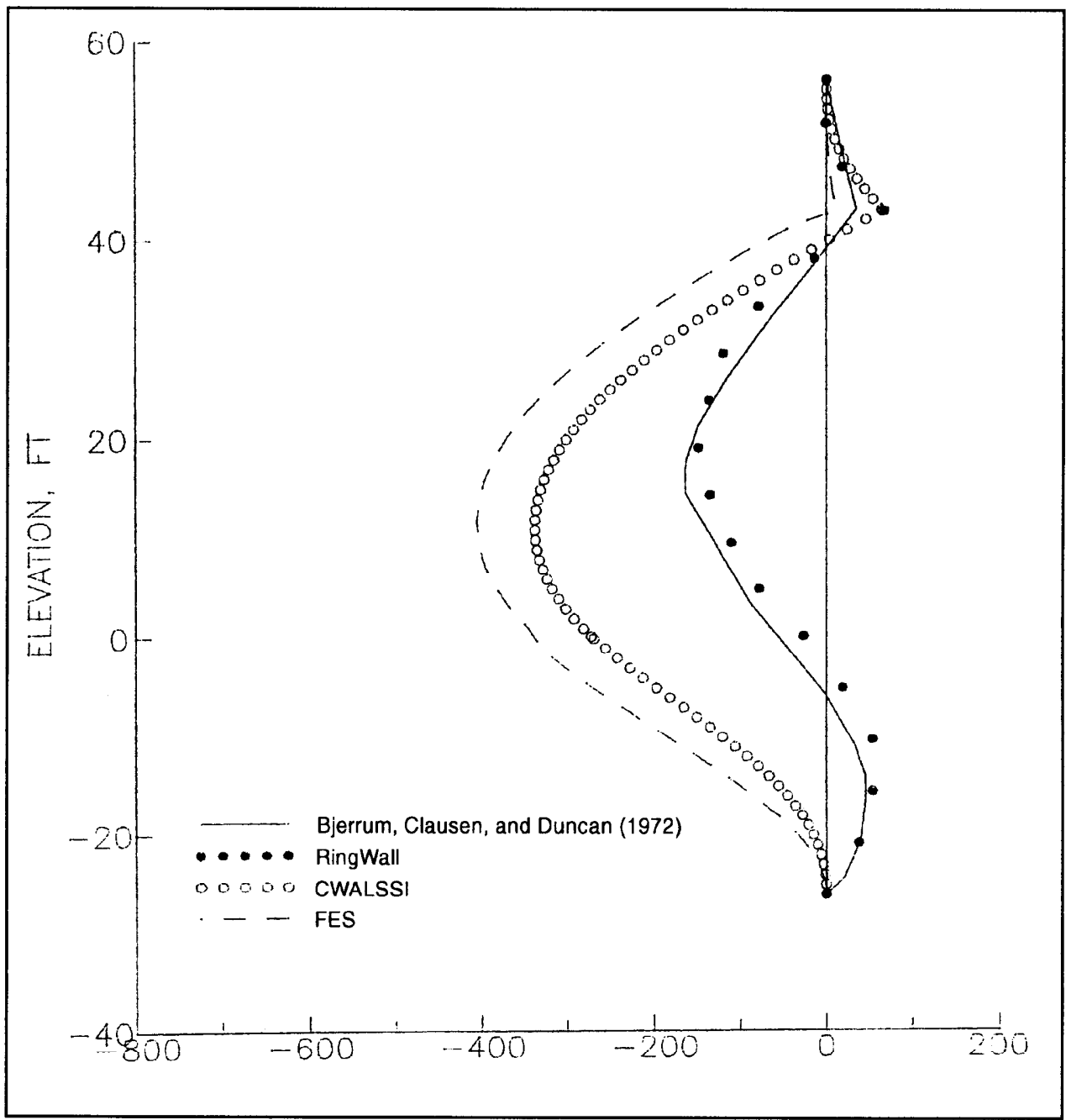

Figure 23. Comparison of moments, Bjerrum, Clausen, and Duncan (1972), (1 ft $=0.305 \mathrm{~m} ; 1 \mathrm{kip}-\mathrm{ft}=1,355.8 \mathrm{~N}-\mathrm{m}$ )

involving soft clays. In such cases the free wall height was reduced to $9 \mathrm{~m}$ $(30 \mathrm{ft})$. The anchor elevation was taken at one-fourth of the free height (measured from the top) in all cases. Groundwater table was assumed to be at the same level. The general appearance of a typical section is shown in Figure 26.

Two basic soil types (sand and clay) were considered at two densities each in making up the soil profiles. The clay types were also considered to be in undrained and drained conditions. The total number of soil types considered in this manner became six:

a. Loose sand (L).

b. Medium-dense sand (D). 


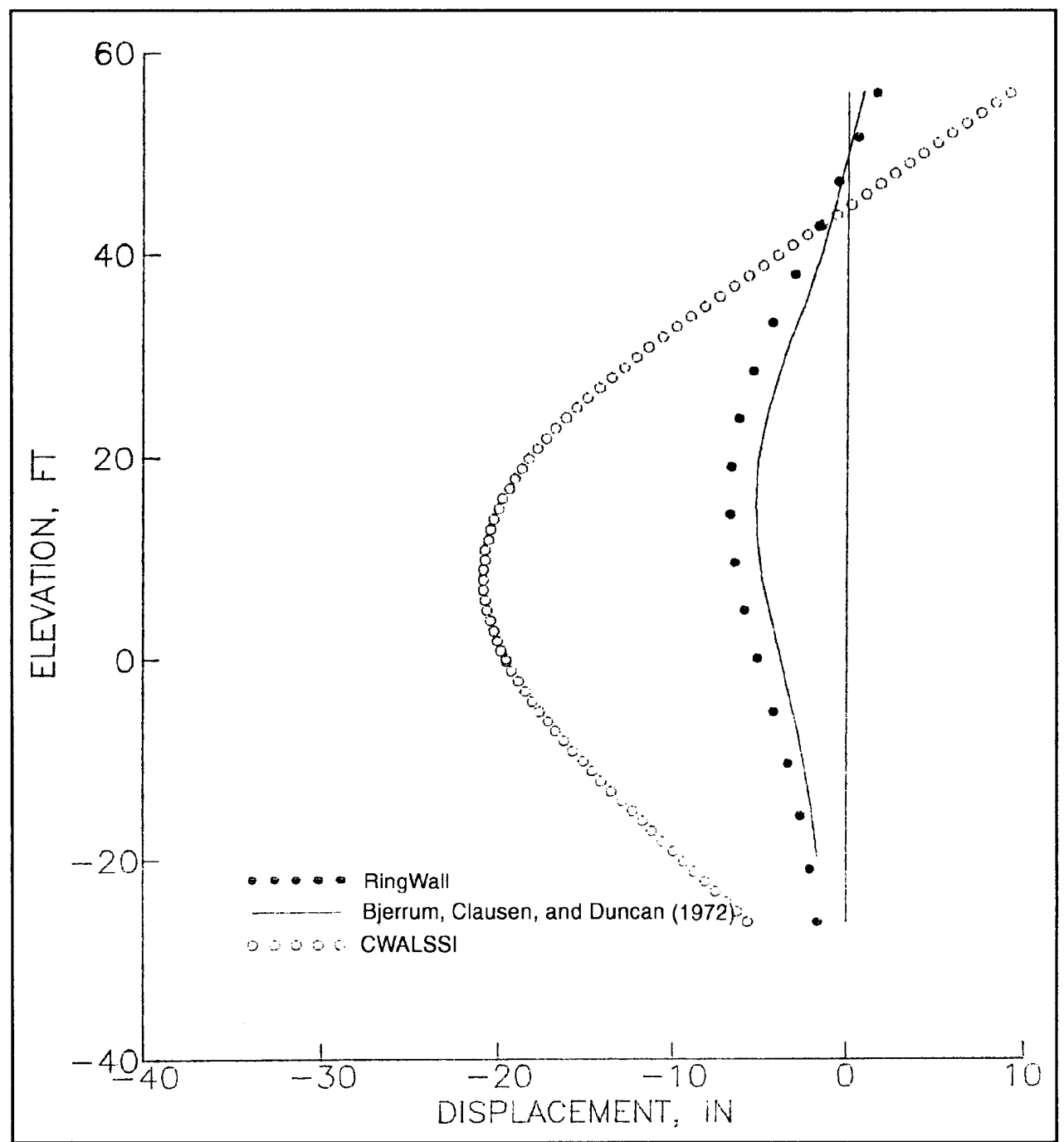

Figure 24. Comparison of displacements, Bjerrum, Clausen, and Duncan (1972), $(1 \mathrm{ft}=0.305 \mathrm{~m} ; 1 \mathrm{in} .=25.4 \mathrm{~mm})$

c. Soft clay, undrained (S).

d. Soft clay, drained (T).

e. Medium-stiff clay, undrained (M).

f. Medium-stiff clay, drained (N).

The soil type codes in parentheses in this list are used for case naming convention in the following paragraph. In various empirical correlations available, the loose sand is taken as one with a relative density of 0 to 40 percent, and the medium-dense sand is taken as one with a relative density in the range of 50 to 70 percent. The soft clay is considered to be normally consolidated with medium 


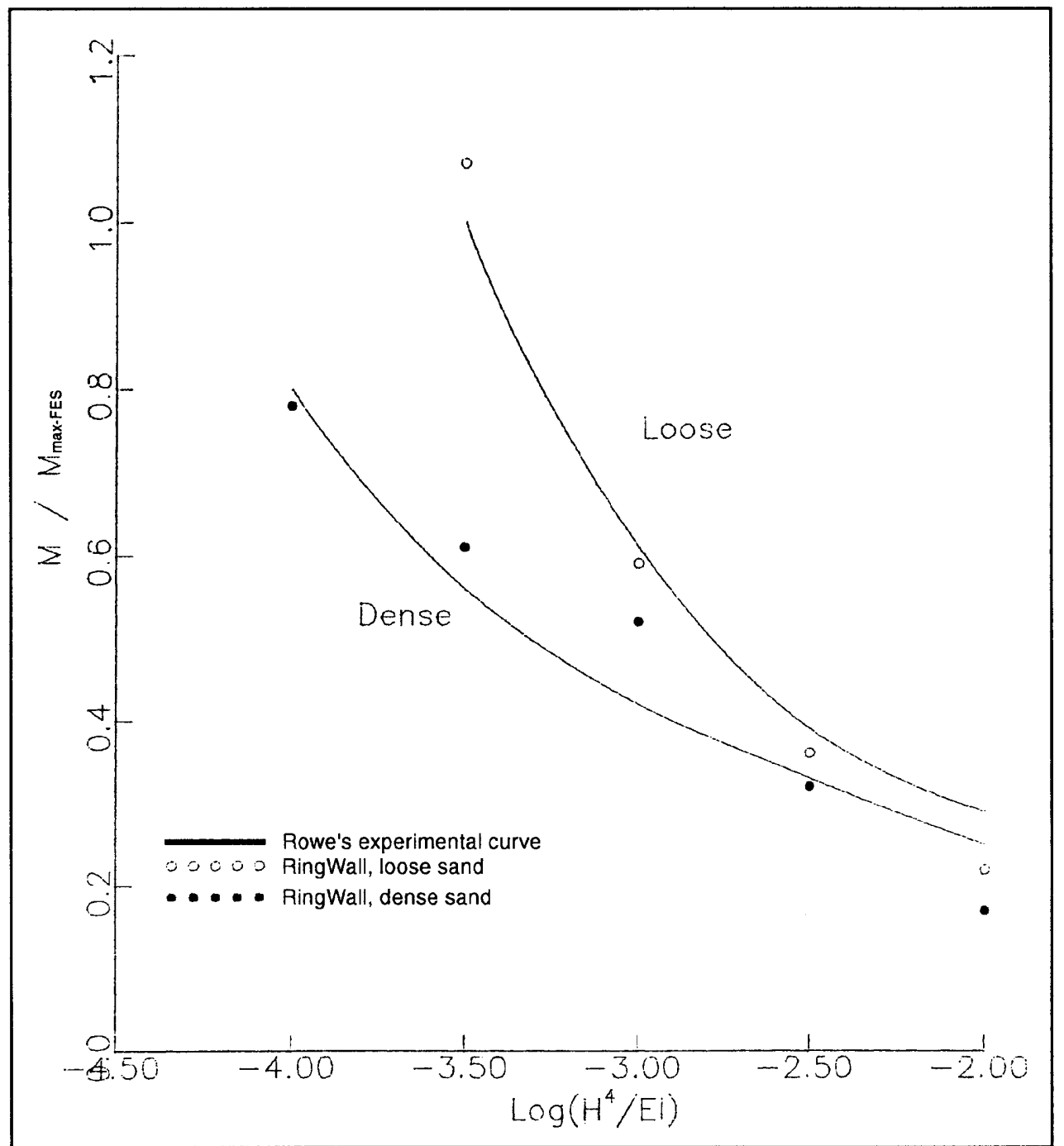

Figure 25. Comparison of shear ring maximum moments with Rowe's experimental data

to high plasticity index $(50+)$, while the medium-stiff clay is slightly overconsolidated, with a low to medium plasticity index (30 to 40 ).

These basic soil types are then assumed to occur, in any combination, above and below the dredge-line level (called backfill and foundation soils in the following discussion). The total number of combinations possible with six soil types is then 36. Due to the large number of cases possible, each case is given a two-letter identification (ID) code using the one-letter ID for a soil type. The first letter in a two-letter case-ID code indicates the soil above the dredge line and the second letter shows the soil type below the dredge line. For example, case SS means a uniform soft clay profile, and LD means loose sand backfill and mediumdense sand foundation soil. 


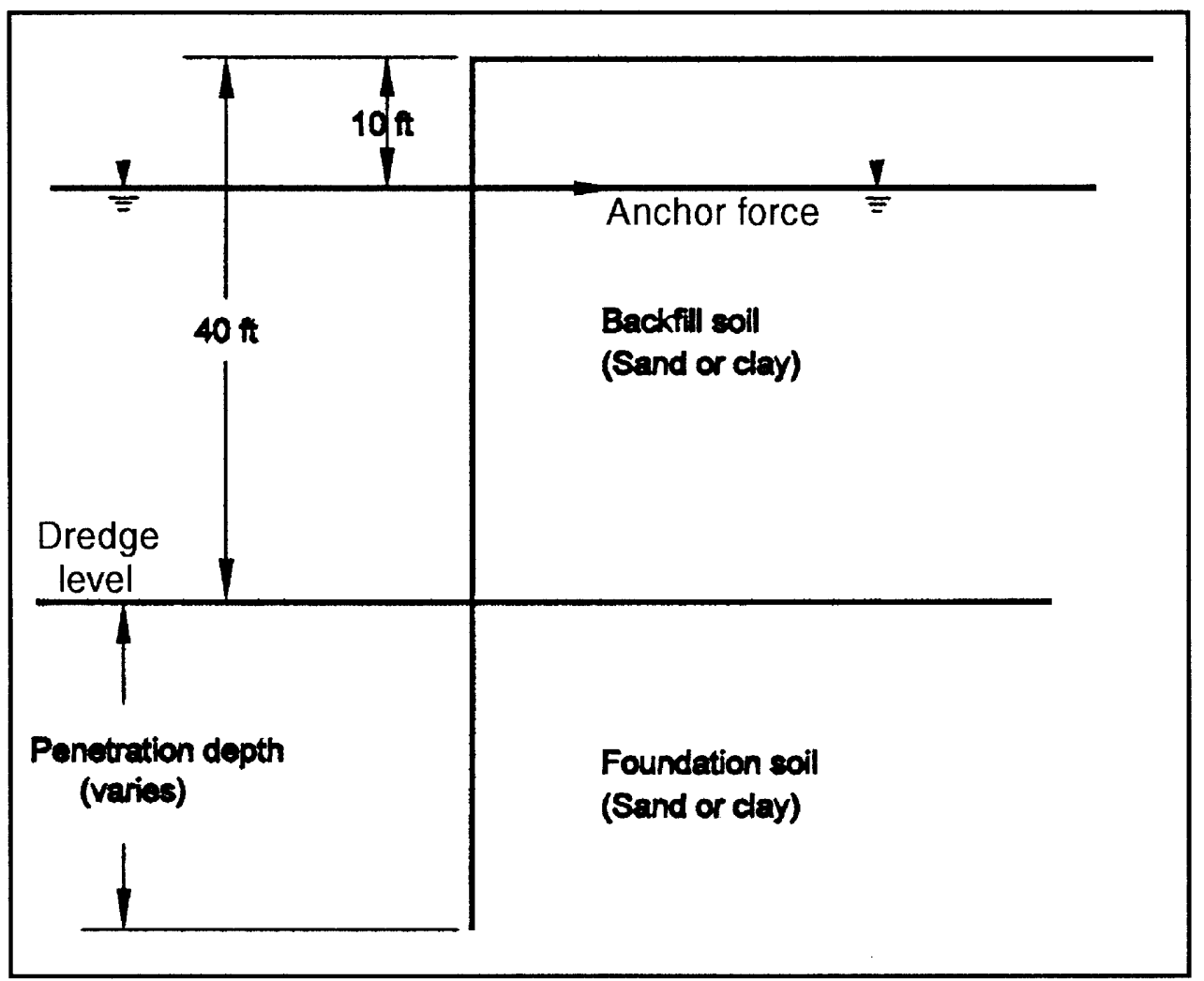

Figure 26. Typical anchored sheet-pile section considered in this study

The cases analyzed in the first round are the ones that were found critical or interesting. These are marked in Table 4 by double-line cell walls. These include the diagonal (i.e., uniform profiles), all-sand cases, and the cases that involve the highest stiffness contrast between the backfill and foundation soils.

\section{Conventional soil properties}

The conventional (shear strength and unit weight) properties assigned to each soil type are listed in Table 5. These are needed in both conventional (FES) calculations and FEM analyses. The unit weights are based on the void ratio $e$ and specific gravity $G_{s}$ values listed in the last column of the table. Typical void ratios for sands were selected considering data given by Youd (1972).

Values of $c_{u}$ for the two clay types are based on the conventional $c_{u} / p$ ratio ( $p$ denotes the effective vertical stress). The selection of the $c_{u} / p$ values is based on data compiled by Ladd et al. (1977). The effective vertical stresses used in constructing the $c_{u}$ profiles are based on the assumption that the current groundwater table is at the anchor level and the soil is normally consolidated (i.e., the $p$ in $c_{u} / p$ ratio is the current effective stress). For the medium-stiff case, two alternatives were considered: 


\begin{tabular}{|c|c|c|c|c|c|c|}
\hline $\begin{array}{l}\text { Backfill } \\
\text { Foundation }\end{array}$ & $\begin{array}{l}\text { Loose } \\
\text { Sand }\end{array}$ & $\begin{array}{l}\text { Medium } \\
\text { Dense } \\
\text { Sand }\end{array}$ & $\begin{array}{l}\text { Soft Clay } \\
\text { Undrained }\end{array}$ & $\begin{array}{l}\text { Medium } \\
\text { Stiff Clay, } \\
\text { Undrained }\end{array}$ & $\begin{array}{l}\text { Soft Clay } \\
\text { Drained }\end{array}$ & $\begin{array}{l}\text { Medium } \\
\text { Stiff Clay, } \\
\text { Drained }\end{array}$ \\
\hline \multicolumn{7}{|l|}{$\begin{array}{l}\text { Loose } \\
\text { Sand }\end{array}$} \\
\hline $\begin{array}{l}\text { Medium } \\
\text { Dense Sand }\end{array}$ & & $\begin{array}{l}\text { Stiffest } \\
\text { Profile }\end{array}$ & & & $\begin{array}{l}\text { Highest } \\
\text { Contrast }\end{array}$ & \\
\hline \multicolumn{7}{|l|}{$\begin{array}{l}\text { Soft Clay } \\
\text { Undrained }\end{array}$} \\
\hline \multicolumn{7}{|l|}{$\begin{array}{l}\text { Medium Stiff } \\
\text { Clay, } \\
\text { Undrained }\end{array}$} \\
\hline $\begin{array}{l}\text { Soft Clay } \\
\text { Drained }\end{array}$ & & $\begin{array}{l}\text { Highest } \\
\text { Contrast }\end{array}$ & & & $\begin{array}{l}\text { Softest } \\
\text { Profile }\end{array}$ & \\
\hline $\begin{array}{l}\text { Medium Stiff } \\
\text { Clay, } \\
\text { Drained }\end{array}$ & & & & & & \\
\hline
\end{tabular}

\begin{tabular}{|c|c|c|c|c|c|c|}
\hline \multicolumn{7}{|c|}{$\begin{array}{l}\text { Table } 5 \\
\text { Conventional Soil Properties Defining the Soil Types Considered }\end{array}$} \\
\hline Soil Type & $\begin{array}{l}\text { Cohesion } \\
c, \mathrm{lb} f / \mathrm{ft}^{2}\end{array}$ & $\begin{array}{l}\text { Drained } \\
\text { Angle of } \\
\text { Internal } \\
\text { Friction } \\
\phi, \text { deg }\end{array}$ & $\begin{array}{l}\text { Ratio of } \\
\text { Dry to } \\
\text { Wet Unit } \\
\text { Weight } \\
\gamma_{\text {dry/ wet, }} \\
\text { lb/ft }\end{array}$ & $\begin{array}{l}\text { Saturated } \\
\text { Unit } \\
\text { Weight } \\
\gamma_{\text {sat }} \mathrm{lb} / \mathrm{ft}^{3}\end{array}$ & $\gamma^{\prime}$ & $\gamma^{2}$ Based on \\
\hline $\begin{array}{l}\text { Loose } \\
\text { sand }\end{array}$ & 0 & 30 & 97 & 123 & 61 & $e=0.7, G_{s}=2.65$ \\
\hline $\begin{array}{l}\text { Medium- } \\
\text { dense } \\
\text { sand }\end{array}$ & 0 & 36 & 110 & 131 & 69 & $e=0.5, \mathrm{G}_{s}=2.65$ \\
\hline $\begin{array}{l}\text { Soft clay, } \\
\text { undrained } \mathrm{S}\end{array}$ & Varies $^{1}$ & 0 & 95 & 110 & - & $e=1.2, \mathrm{G}_{s}=2.70$ \\
\hline $\begin{array}{l}\text { Medium- } \\
\text { stiff clay, } \\
\text { undrained } \quad M\end{array}$ & Varies $^{2}$ & 0 & 110 & 120 & - & $e=0.8, G_{s}=2.70$ \\
\hline $\begin{array}{l}\text { Soft clay, } \\
\text { drained }\end{array}$ & 0 & 25 & 95 & - & 48 & $e=1.2, G_{s}=2.70$ \\
\hline $\begin{array}{l}\text { Medium- } \\
\text { stiff clay, } \\
\text { drained }\end{array}$ & 0 & 30 & 110 & - & 58 & $e=0.8, \mathrm{G}_{s}=2.70$ \\
\hline $\begin{array}{l}\text { Note: } 1 \mathrm{lbf} / \mathrm{ft}^{2}= \\
\text { Varies as } c_{u}= \\
2 \text { Varies as } c_{u}=\end{array}$ & $\begin{array}{l}88 \mathrm{~Pa}, 1 \mathrm{lb} \\
25 \sigma_{v}^{\prime} . \\
40 \sigma_{v}^{\prime} \text { from }\end{array}$ & $=16.02 \mathrm{~K}$ & 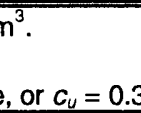 & the & & sion. \\
\hline
\end{tabular}

a. $\quad c_{u}=0.40 \sigma_{v}{ }^{\prime}$, representative of a low-plasticity clay, and $\sigma_{v}{ }^{\prime}$ calculated from the current profile, where $\sigma_{v}{ }^{\prime}$ is the effective vertical stress in $1 \mathrm{bf} / \mathrm{ft}^{2}$.

b. $\quad c_{u}=0.35 \sigma_{v}{ }^{\prime}$, representative of a medium plasticity (NC) clay, and $\sigma_{v}{ }^{\prime}$ calculated from some hypothetical maximum past pressure defined by a level higher than the current ground surface by $6 \mathrm{~m}(20 \mathrm{ft})$. 
The second condition represents a slightly overconsolidated clay due to erosion (average overconsolidation ratio about 1.5, decreasing with depth). An average $c_{u}$ profile was selected from the values calculated from these two methods. In all cases where the clay extends to the surface, the $c_{u}$ value was kept constant in the partly saturated layer above the groundwater table. This is thought to represent the desiccation effect usually observed in such soils. The $c_{u}$ profiles obtained in this manner are shown in Figure 27.

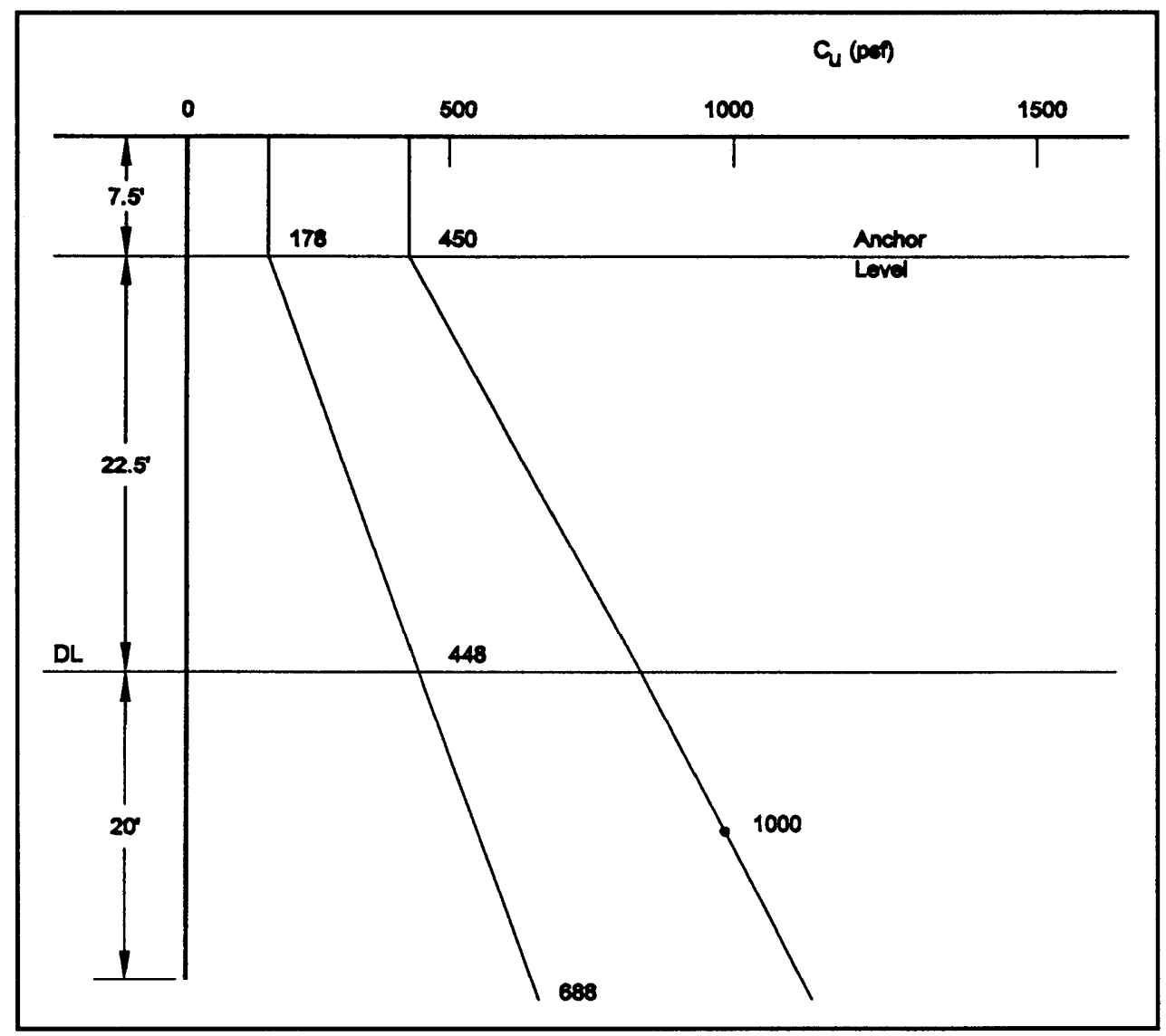

Figure 27. Undrained shear strength profiles used $\left(1 \mathrm{lbf} / \mathrm{ft}^{2}=0.048 \mathrm{kPa}\right)$

Values of $\phi^{\prime}$ for drained clay cases are based on the statistics given by Holtz and Kovacs (1981). The $\phi$ values used for sands are somewhat conservative (probably by about 2 to $4 \mathrm{deg}$ ) but intended to reflect typical practice.

\section{Conventional calculations}

Each typical section was first analyzed by the WALSHT program (Dawkins 1990). The penetration depths and the sections given by the FES method (Table 6) were taken as the basis for further study. Rowe's $\log \rho$ parameters for these systems are listed in Table 7. In some cases Rowe's moment reduction curves were not used since the geometric parameters of those cases were outside the range of applicability of the empirical data. Also, many sheet-pile sections 


\begin{tabular}{|c|c|c|c|c|}
\hline \multicolumn{5}{|c|}{$\begin{array}{l}\text { Table } 6 \\
\text { Results of FES Calculations }\end{array}$} \\
\hline Case & $\begin{array}{l}\text { Deflection of Top of } \\
\text { Wall } D, \mathrm{ft}\end{array}$ & $\begin{array}{l}\text { Anchor Force per } \\
\text { Unit Length of Wall } \\
A_{p}, \text { kips/ft } \\
\end{array}$ & $\begin{array}{l}\text { Maximum Moment in } \\
\text { Wall per Unit Length of } \\
\text { Wall } M_{\max }, \text { kip-ft/ft } \\
\end{array}$ & Section \\
\hline LL & 13.0 & 10.69 & 106.74 & PZ35 \\
\hline DD & 8.5 & 8.52 & 76.06 & PZ35 \\
\hline $\mathrm{DL}$ & 13.2 & 9.50 & 95.95 & PZ35 \\
\hline LD & 8.6 & 9.75 & 86.74 & $\mathrm{PZ40}$ \\
\hline SS & 23.5 & 10.77 & 99.99 & $\mathrm{PZ40}$ \\
\hline$\pi$ & 23.6 & 10.50 & 101.88 & PZ40 \\
\hline $\mathrm{MM}^{1}$ & 4.0 & 3.20 & 22.79 & $\mathrm{PZ22}$ \\
\hline NN & 17.2 & 9.01 & 77.59 & PLZ23 \\
\hline
\end{tabular}

\begin{tabular}{|c|c|c|c|c|}
\hline \multicolumn{5}{|c|}{$\begin{array}{l}\text { Table } 7 \\
\text { Rowe's Log } \rho \text { Parameter for the Systems Selected }\left(\rho=H^{4} / E\right)\end{array}$} \\
\hline Case & $\begin{array}{l}\text { Free Height of the } \\
\text { Wall } h, \mathrm{ft}\end{array}$ & $\begin{array}{l}\text { Depth of } \\
\text { Penetration } D, \mathrm{ft}\end{array}$ & $\begin{array}{l}\text { Total Height of } \\
\text { Wall } H, \mathrm{ft}\end{array}$ & $\log \rho^{1}$ \\
\hline $\mathrm{LL}$ & 40 & 13.0 & 53.0 & -3.12 \\
\hline $\mathrm{DD}$ & 40 & 8.5 & 48.5 & -3.28 \\
\hline $\mathrm{DL}$ & 40 & 13.5 & 53.5 & -3.11 \\
\hline LD & 40 & 8.6 & 48.6 & -3.41 \\
\hline SS & 30 & 23.6 & 53.6 & -3.24 \\
\hline$\pi$ & 30 & 23.6 & 53.6 & -3.24 \\
\hline NN & 30 & 17.2 & 47.2 & -3.08 \\
\hline
\end{tabular}

that were available until recently are no longer produced. As a result, the sections selected are, in general, very rigid.

\section{Soil stress-strain parameters}

The stress-strain parameters required in FEM (as well as SRM) analyses are selected based on data compiled from the literature. The parameters selected are listed in Table 8.

\section{Finite element analyses}

Rectangular grids (symmetrical about the sheet-pile wall) were used throughout. An example is seen in Figure 28 (after excavation of the soil in front of the wall). The advantage of this type of grid is that data files can be automatically 


\begin{tabular}{|c|c|c|c|c|c|c|}
\hline \multicolumn{7}{|c|}{$\begin{array}{l}\text { Table } 8 \\
\text { Soil Stress Strain Model Parameters Used }\end{array}$} \\
\hline Soil Type & & $\begin{array}{l}\text { At-Rest } \\
\text { Earth } \\
\text { Pressure } \\
\text { Coefficient } \\
K_{0} \\
\end{array}$ & $\begin{array}{l}\text { Modulus } \\
\text { NumberK } \\
\end{array}$ & $\begin{array}{l}\text { Modulus } \\
\text { Exponent } \\
n \\
\end{array}$ & $\begin{array}{l}\text { Modulus } \\
\text { Number } \\
\mathrm{m}^{1}\end{array}$ & 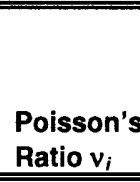 \\
\hline Loose sand & L & 0.50 & 375 & 0.5 & 120 & 0.30 \\
\hline Medium-dense sand & $\mathrm{D}$ & 0.41 & 750 & 0.5 & 200 & 0.40 \\
\hline Soft clay, undrained & $\mathrm{s}$ & 0.95 & - & 0.0 & 250 & 0.49 \\
\hline $\begin{array}{l}\text { Medium-stiff clay, } \\
\text { undrained }\end{array}$ & M & & - & 0.0 & 500 & 0.49 \\
\hline Soft clay, drained & $\mathrm{T}$ & 0.56 & & 0.9 & 15 & 0.35 \\
\hline $\begin{array}{l}\text { Medium-stiff clay, } \\
\text { drained }\end{array}$ & $\mathrm{N}$ & 0.50 & & 0.6 & 30 & 0.30 \\
\hline
\end{tabular}

generated; the disadvantage is that very thin and long elements occur toward the boundaries. A high aspect ratio is known to cause larger FEM discretization errors. However, this should not be very significant as such elements are away from the region of interest.

The dimensions of all the grids were set as $2 h$ deep and $4 h$ wide on both sides of the wall, where $h$ is the free height of the wall. The depth selection is arbitrary. The width selection was based on earlier studies of gravity retaining wall studies (e.g., Clough and Duncan1971) and a systematic analysis series done at the beginning of this study (on LL case) using $1 h, 2 h, 3 h, \ldots, 6 h$. These indicated that $4 h$ seemed to be a reasonable width as calculated stresses and deformations stabilized after that point. The boundary conditions imposed on all sides were roller (or smooth) type. In all cases the "front" of the wall was excavated starting from a level ground surface and ending at the dredge line, again horizontal. Typically 11 layers of elements were removed with 4 to 8 substeps each (increasing toward the end). A substep is an automatic division of loading (in this case those representing the forces due to excavation) into a specified number and imposing those fractional loads repeatedly; soil stress-strain parameters are updated after each substep, thereby stabilizing the nonlinear modeling calculations. In the preparatory test problems (with LL case) the calculated displacements and moments appeared to stabilize with 8 substeps, but some "overshooting" problem remained (overshooting means that Mohr-Coulomb failure criterion is slightly exceeded in some elements). It appears that much larger substeps should be used to eliminate overshooting completely. A typical FEM grid used in these verification studies is shown in Figure 28.

Both the FEM and the SRM require an anchor stiffness to be specified. The anchor stiffness values used in these analyses were determined by the following procedure.

The anchor stiffnesses were chosen based on two criteria: 


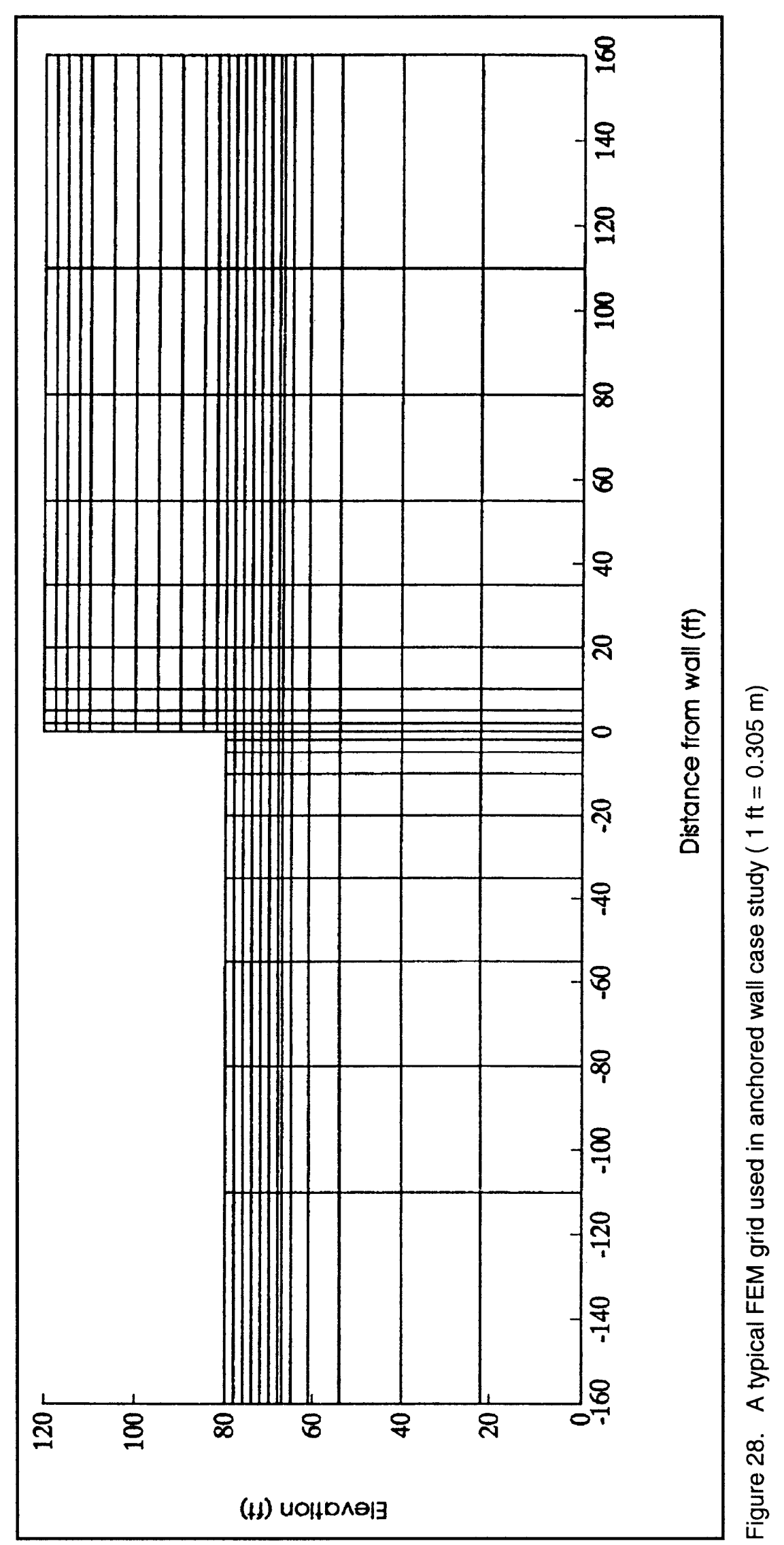


a. Realistic anchor rod length $L$ and cross-sectional end area $A$ were chosen and the anchor stiffness (per unit length of the wall) was calculated as:

$$
K_{\text {anch }}=\frac{A E}{L}
$$

where $E$ is the Young's modulus for steel. The anchor length was determined by standard procedures (requiring the anchor wall to remain inside the safe zone determined as in Figure 29). The cross-sectional area was determined from the anchor force per unit length of wall $A_{p}$ calculated by FES analysis. Thus,

$$
A=\frac{A_{p}}{\sigma_{\text {all }}}
$$

where $\sigma_{\text {all }}$ is the allowable stress.

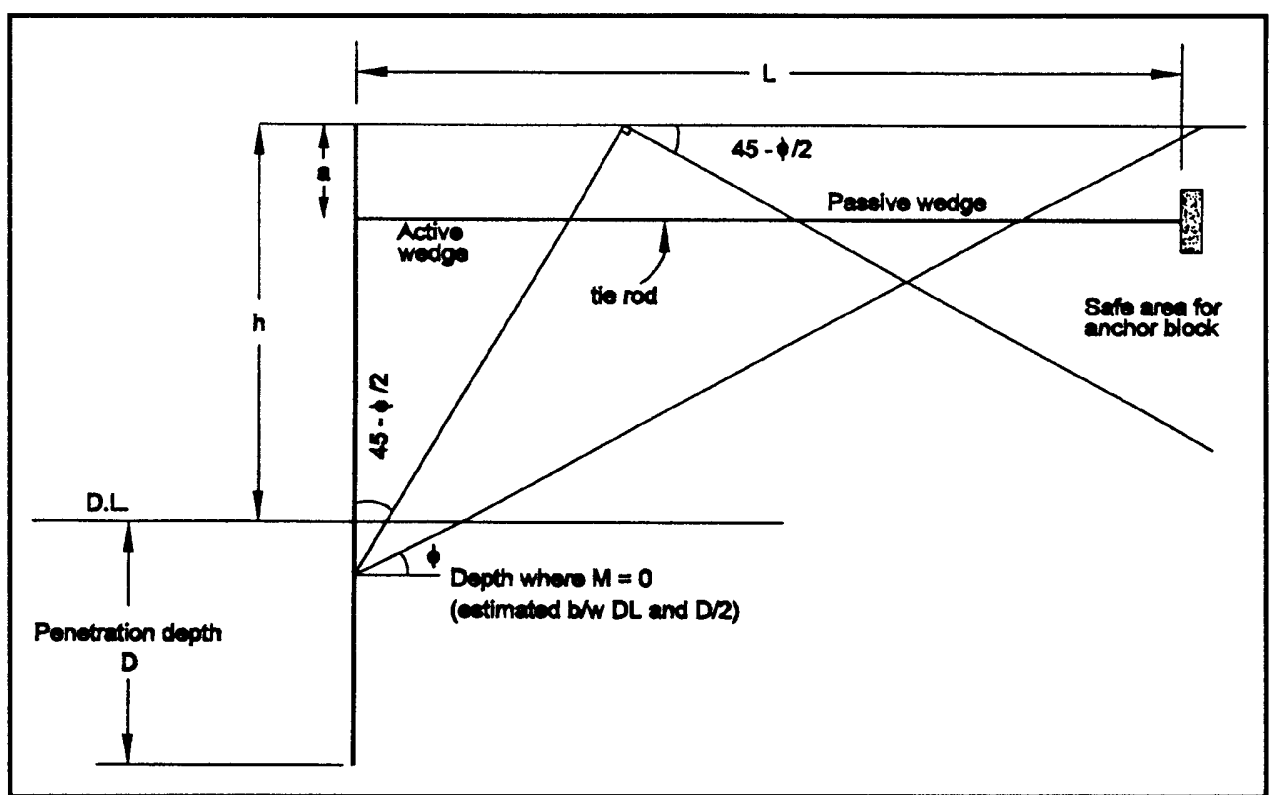

Figure 29. Determination of a safe location for the anchor block

b. An "expected anchor yield" of $\delta=0.001 \mathrm{H}$ (Rowe 1952,1955) was considered. This, combined with $A_{p}$ from FES analysis, gives the anchor stiffness as 


$$
K_{\text {anch }}=\frac{A_{p}}{\delta}
$$

The anchor stiffness found from the two procedures usually agreed closely. An average, rounded value was then set.

The interface properties were selected as follows. For sand and drained clay cases an interface friction angle equal to $2 / 3 \phi$ was specified. In undrained clay cases, friction was zero, but an adhesion equal to a fraction of $c_{u}$ was assigned; $c_{a}=\alpha c_{u}$, the fraction $\alpha$ determined as in vertically loaded pile foundations ( $\alpha=1$ for $c_{u}<24 \mathrm{kPa}\left(500 \mathrm{psf}\right.$ ), and decreasing with $c_{u}$ ). Various interface stiffnesses were tried on test problems and $16,018,460 \mathrm{~kg} / \mathrm{m}^{3}\left(10^{6} \mathrm{lb} / \mathrm{ft}^{3}\right)$ for normal stiffness and $1,601,846 \mathrm{~kg} / \mathrm{m}^{3}\left(10^{5} \mathrm{lb} / \mathrm{ft}^{3}\right)$ shear stiffness were chosen. Increasing or decreasing these values by a factor of 10 did not produce appreciable changes in stresses and deformations.

Displacements computed by two-dimensional FEM and SRM agree quite well for LL and DL, and reasonably well for DD and NN cases (Table 9). But a poorer correlation is found for LD, SS, and TT cases (LD and TT cases being the worst). These latter cases are also the ones where FEM discretization problems occurred; these cases should be rerun with a much larger number of substeps. However, these initial results indicate that the SRM provides reasonably good estimates: when the pile displacement is small (less than about 127 to $254 \mathrm{~mm}$ ( 5 to 10 in.)), they are predicted accurately; and when the displacements are excessive ( $>254 \mathrm{~mm}(10 \mathrm{in}$.$) ), this condition is also predicted, but not as$ accurately.

\begin{tabular}{||l|l|l|l|l|l||}
\hline \multicolumn{6}{||l}{$\begin{array}{l}\text { Table } 9 \\
\text { Comparison of Finite Element and Shear Ring results }\end{array}$} \\
\hline \hline \multirow{2}{*}{ Case } & FES & FEM & SRM & FEM & SRM \\
\hline \hline LL & 106.7 & 65.3 & 85.8 & 4.0 & 4.7 \\
\hline DD & 76.1 & 35.7 & 58.3 & 3.9 & 2.9 \\
\hline DL & 96.0 & 60.3 & 79.2 & 5.0 & 4.8 \\
\hline LD & 86.7 & 50.0 & 72.3 & 9.9 & 2.7 \\
\hline SS & 100.0 & 218.6 & 234.9 & 29.3 & 13.8 \\
\hline$\pi$ & 101.9 & 150.1 & 132.3 & 34.6 & 12.7 \\
\hline NN & 77.6 & 77.1 & 92.0 & 13.5 & 9.6 \\
\hline \hline Note: 1 kip-ft/ft $=4.45 \mathrm{kN}-\mathrm{m} / \mathrm{m} ; 1$ in. $=25.4 \mathrm{~mm}$. & & \\
\hline
\end{tabular}

The agreement of the two methods on bending moments is closer. The SRM calculates somewhat larger maximum moments, by 5 to 30 percent in "good" cases, and 40 to 50 percent in the worst (DD and LD) cases. In all cases, 
however, the agreement between FEM and SRM is closer than the FES values. It is interesting to note that the maximum moments given by FES can be smaller than FEM and SRM results (soft clay cases). These two cases, however, seem to be unconservative designs judged from the excessive deformations, and should probably be revised. 


\section{Shear Ring Method Mechanics}

\section{Basics of the Method}

The SRM is based on the assumption that the entire wall-soil system will rotate around a pivot point above the profile (Figure 8). Shear and normal deformations will occur inside the soil, and the wall will undergo lateral and bending deflections; but the system, as a whole, will experience this overall rotation. This basic assumption originated in a comprehensive, two-dimensional, nonlinear FEM study of a large number of retaining wall problems.

The stress-strain relationship for the wall is taken as linear, but the soil nonlinearity is taken into account. The model employed in RingWall is called the $f$-Model.

The center of rotation, or the pivot point, usually lies in the range between 3 and $30 \mathrm{~m} \mathrm{(10} \mathrm{and} 100 \mathrm{ft}$ ) above the top of the wall. Ideally, the program should find it automatically using a trial-and-error search process. The exact location is found by minimizing the potential energy. Since this can be a long process, and the analysis results are not very sensitive to the location of the pivot point, it is advisable to use an estimated value in early trials.

The basis of the method used for determination of the pivot elevation is a generalization of the principle of minimum potential energy. This is the principle used in variational FEM formulations (e.g., Desai and Abel 1972), which may be stated as "of all statically admissible states of stress and kinematically admissible states of deformation, the one that minimizes the total potential energy functional is the correct solution." Of course this would determine the correct SRM solutions, but not necessarily the "exact" solution of a given problem. The total potential energy functional can be evaluated in an SRM, after the solution, as

$$
T P E=S E-P E
$$

where $S E$ is the total strain energy stored in the system that can be obtained from the shear stresses $\sigma$ and strains $\varepsilon$ that are already computed, 


$$
S E=1 / 2 \int\{\varepsilon\}^{T}\{\sigma\} d V o l
$$

and $P E$ is the potential energy loss of external loads as the system deforms, which can be found by lumping the normal component of the resultant force on the upper half of a ring segment $P_{n u}$ and the normal component of the resultant force on the lower half of a ring segment $P_{n l}$ forces at the nodes, $P_{i}$, and pairing these with the corresponding displacements, $u_{i}$,

$$
P E=\Sigma P_{i} u_{i}
$$

The results of this calculation, for the cases used in the floodwall studies, indeed showed a clear minimum in the potential energy functional where the pivot point has to be, judging from the FEM results. These results indicate that the method is capable of selecting the "right" pivot elevation on its own, but a numerical minimization procedure is required, just as in a slope stability analysis.

\section{Soil Modulus Variation}

Shear modulus $G$ is evaluated for each ring element (separately for right and left halves) at three points: one at each end of the median arc and one at the center (Figure 30a). This three-point scheme allows a quadratic interpolation of $G$ along a ring:

$$
G(t)=N_{1} G_{L}+N_{2} G_{M}+N_{3} G_{R}
$$

where the subscripts $L, M$, and $R$ refer to the left end, middle, and right end, and the $N_{i}$ are quadratic interpolation functions in terms of a dimensionless distance parameter $t$ that varies from 0 to 1 along the median arc of a ring (Figure 30b):

$$
\begin{aligned}
& N_{1}=(2 t-1)(t-1) \\
& N_{2}=4 t(1-t)(15) \\
& N_{3}=t(2 t-1)
\end{aligned}
$$

In the initial step, the soil-only solution, the ring spring constant is calculated using the integral average,

$$
G=\left(G_{L}+4 G_{M}+G_{R}\right) / 6
$$

but in the total solution the modulus variation is combined with the displacement interpolation functions as shown in the following section.

\section{Displacement Functions}

In earlier phases of the development of SRM, a linear variation was used for approximating the variation of displacements across a ring element. This meant a constant strain approximation since strains are derivatives of displacements. This level of approximation was not found adequate in testing the method. 


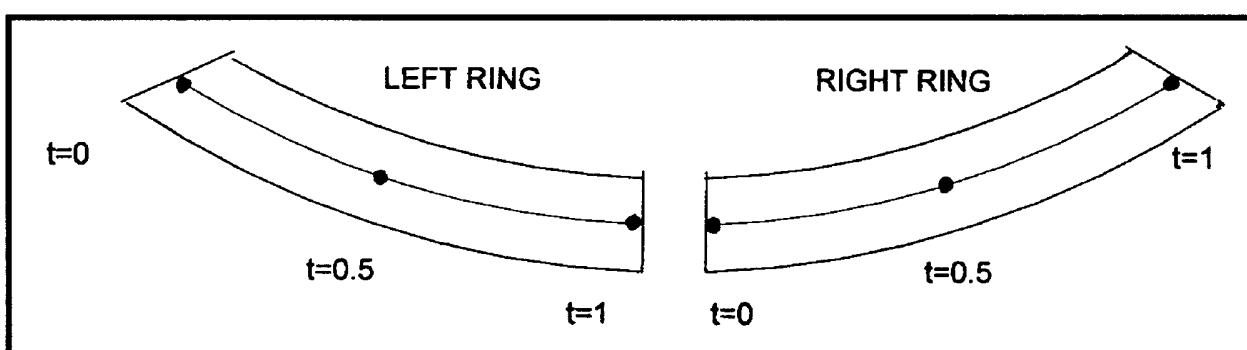

a. Points where shear modulus is evaluated
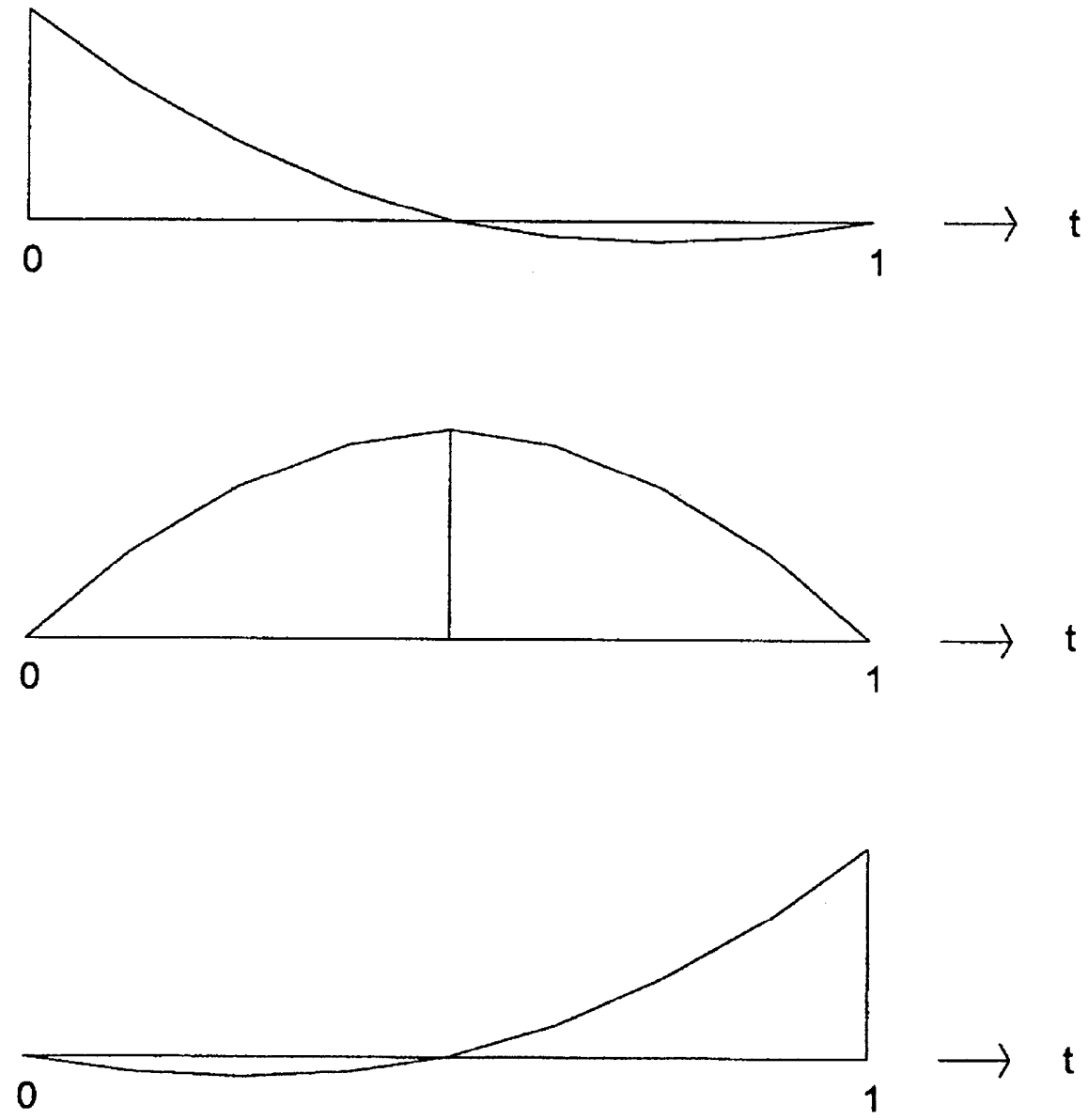

b. Quadratic interpolation functions

Figure 30. Elements of three-point (quadratic) interpolation 
Considering another midpoint displacement in each ring, the displacement interpolation functions were raised to quadratic functions and much improved results were obtained.

\section{Linear ring element}

At an earlier step during the development of the SRM, a four-node shear element was considered. This type of element is the simplest possible idealization when the free surfaces and the soil-pile interface plane are to be represented. It will be described first for clarity of discussion. A four-node geometry allows a linear interpolation of displacement in both radial and hoop directions, resulting in strain variations as follows:

a. Hoop strain:

$$
\varepsilon_{r}=\frac{u_{1}-u_{2}}{l_{1}}(1-r)+\frac{u_{3}-u_{4}}{l_{2}} r
$$

where $l_{1}$ and $l_{2}$ are the top and bottom lengths of the ring.

\section{b. Shear strain:}

$$
\gamma_{r t}=\frac{u_{1}-\rho u_{3}}{d}(1-t)+\frac{u_{2}-\rho u_{4}}{d} r
$$

in which $u_{i}$ are the nodal displacements in the tangential direction, $r$ and $t$ are dimensionless distances in $R$ direction and $\theta$ direction, and $d$ is the ring thickness,

$r=\left(R-R_{1}\right) /\left(R_{2}-R_{1}\right)$

$t=\left(\theta-\theta_{1}\right) /\left(\theta_{2}-\theta_{1}\right)$

and $\rho$ is the radius ratio,

$\rho=R_{1} / R_{2}$

where $R_{1}$ and $R_{2}$ are the radii of the top and bottom boundaries, respectively, of the ring, and $\theta_{1}$ and $\theta_{2}$ are the right and left end angles, respectively, for a ring. The $\rho$ factor has a very significant role here; it represents the rotational character of deformation in the mathematical model (through Equations 10 and 11).

Notice that the hoop strain is constant in the hoop $(t)$ direction, but varies linearly in the radial $(R)$ direction. Shear strain is constant in the radial $(R)$ direction, and varies linearly in the hoop $(t)$ direction. This is the highest degree of interpolation possible with a four-node element. To determine whether this 
degree of approximation is adequate, it was implemented and tested, using the plane strain FEM analysis results (Oner et al.) ${ }^{1}$ as a yardstick. The main steps of the derivation will be described now as these are shared by the more refined ring elements presented subsequently.

To derive the element stiffness matrix, the strain-displacement relationships are first expressed in matrix form as

$$
\{\varepsilon\}=[B]\{u\}
$$

where

$$
\begin{aligned}
& \{\varepsilon\}=\left\{\begin{array}{ll}
\varepsilon_{t} & \gamma_{r}
\end{array}\right\}^{T} \\
& \{u\}=\left\{u_{1}, u_{2}, u_{3}, u_{4}\right\}^{T} \\
& {[B]=\left[\begin{array}{cccc}
\frac{1-r}{l_{1}} & \frac{r-1}{l_{1}} & \frac{r}{l_{2}} & -\frac{r}{l_{2}} \\
\frac{1-t}{d} & \frac{t}{d} & \frac{(t-1) \rho}{d} & -\frac{t \rho}{d}
\end{array}\right]}
\end{aligned}
$$

which is then combined with the stress-strain relationship to give stresses,

$$
\begin{aligned}
& \{\sigma\}=[C]\{\varepsilon\} \\
& {[C]=\left[\begin{array}{ll}
H & 0 \\
0 & G
\end{array}\right]}
\end{aligned}
$$

where $H$ is called hoop modulus, explained in Appendix A. Finally, the element stiffness matrix $\left[k_{R}\right]$ is obtained as

$$
\left[k_{R}\right]=\int[B]^{T}[C][B] d V o l
$$

The bandwidth of the global linear equation system to be solved is 8 . It is indeed an economical system. However, the main limitation is that the local (active/passive-like) effects cannot be accounted for accurately, since a linear interpolation between the two ends of a long arc is a crude approximation. Notice again that the hoop stress is constant in that direction in a four-node element. Comparisons with results of plane strain FEM analysis also showed that the bending moments could not be predicted sufficiently accurately. Therefore, it was necessary to go to the next level of approximation, a quadratic model. Some of the details of the resulting quadratic element are given in the following section.

1 Oner et al. (1988), op. cit. 


\section{Quadratic ring element}

It is clear that allowing higher order interpolation functions for displacements would more closely represent the local (active/passive) effects. The price of this improvement is increased computational effort due to the addition of a central node along the arcs. This addition increases the number of unknowns by two per ring level used, and the bandwidth of the equation system increases from 8 to 10 .

The derivation of the element stiffness matrix follows the same basic steps as in the linear element. Since the shear strain in an element can now be calculated at three points in the hoop direction (at the two ends and the middle), a quadratic interpolation is achieved (Figure 30b):

$$
\begin{aligned}
& \gamma_{L}=\left(u_{1}-\rho u_{4}\right) / d \\
& \gamma_{M}=\left(u_{2}-\rho u_{5}\right) / d \\
& \gamma_{R}=\left(u_{3}-\rho u_{6}\right) / d \\
& \gamma(t)=\gamma_{L} N_{1}+\gamma_{M} N_{2}+\gamma_{R} N_{3}
\end{aligned}
$$

where $N$ s are the same quadratic interpolation polynomials (shape functions) used for shear modulus (Equation 8).

The normal strain in the hoop direction, being the first derivative of the quadratic displacement function in that direction, varies linearly with $t$. It also varies linearly in the radial direction as it can be interpolated between the top and the bottom of the element, thus,

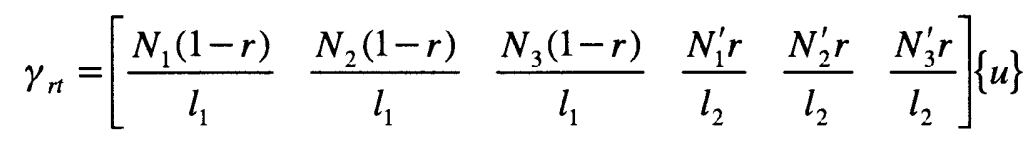

where $N$-primes are the derivatives of shape functions with respect to $t$ :

$$
\begin{aligned}
& N_{1}^{\prime}=4 t-3 \\
& N_{2}^{\prime}=4-8 t \\
& N_{3}^{\prime}=4 t-1
\end{aligned}
$$

The strain-displacement relationships formulated in this manner are then put in matrix form, giving the $[B]$ matrix, and this leads to the element stiffness matrix by the same integration as before. The element stiffness matrix obtained in this manner is given in Appendix B in an abbreviated form, in which $I_{i j}$ and $J_{i j}$ are the integrals (of up to sixth-order polynomials): 


$$
\begin{aligned}
& I_{i j}={ }_{0} \int^{1} N_{i} N_{j}^{\prime} H(t) d t \\
& J_{i j}={ }_{0} \int^{1} N_{i} N_{j} G(t) d t
\end{aligned}
$$

For a fast evaluation in the computer program these integrals were taken in closed form as shown in Appendix B.

\section{Quasi-cubic extension}

Although the accuracy obtained with the quadratic model was reasonable, another improvement step was undertaken. With the anticipation of a larger effect of localized stresses near the sheet pile in a drained case, it was felt that a higher order interpolation function would be desirable. The obvious way of achieving this is by adding more degrees of freedom to the ring element. However, this course was not taken as it would increase the complexity (and cost) of computations. Instead, it was assumed that the localization effects can be represented by a function that has a higher rate of decay in the vicinity of the pile. The following modified functions were derived to provide the desired effect:

$$
\begin{aligned}
& M_{1}=(2 t-1)(t-1)(1-t) \\
& M_{2}=4 t(1-t) \\
& M_{3}=(2 t-1) \mathrm{t} 2
\end{aligned}
$$

With the $N$ functions replaced by these $M$ functions, the derivations described in the preceding section were repeated. The modified stiffness matrix has the same closed form representation as in the quadratic case, with the $I$ and $J$ integrals changed to alternate forms as presented in Appendix B.

\section{Interface between the soil and the wall}

The stress conditions in the soil in proximity with the wall are evaluated in every ring (i.e., at various elevations and on both sides of the wall). No special elements, such as the interface elements in FEM, are employed to represent this region; therefore the soil displaces by the same amount as the wall in this area, and no relative displacement is explicitly allowed. The contact is broken mechanically only when the soil reaches failure in the contact area. The beam element used to represent the wall is given in Appendix C.

\section{Simulation of excavation}

The SRM uses a nonlinear soil stress-strain model, employing the stepwise nonlinear analysis technique (e.g., Desai and Abel 1972). This characteristic of the method allows the simulation of the sequence of operations of construction. The mechanics of this simulation is explained in Figures 31 and 32. Figure 31a shows the layers of soil removed in each calculation step, and $31 \mathrm{~b}$ shows 


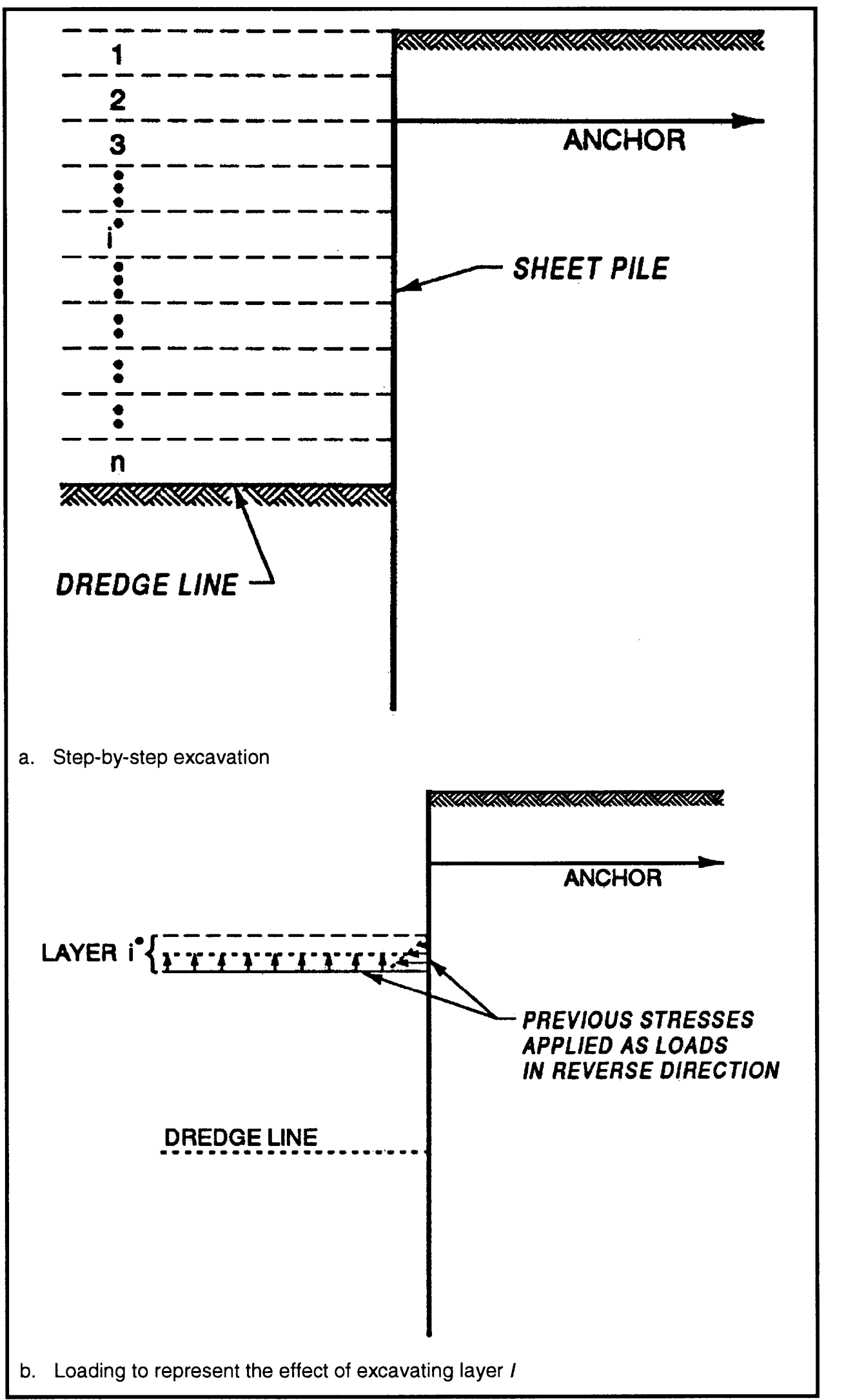

Figure 31. Simulation of excavation 


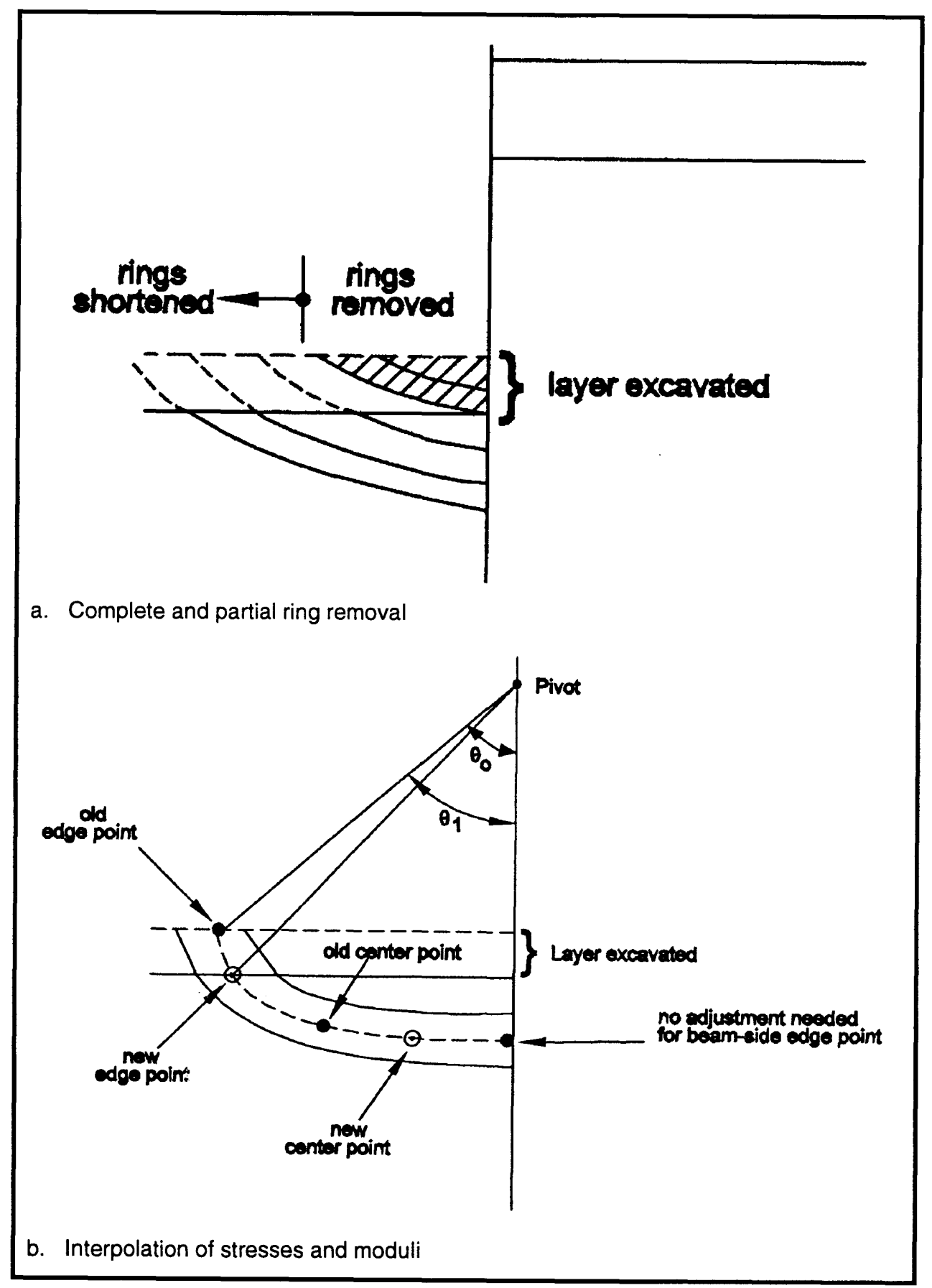

Figure 32. Some details of excavation simulation 
the inversion of stresses to represent the loading caused by the removal of one such layer. In order to represent the layer removal, the computer program RingWall performs further actions. These are described in Figure 32.

\section{Loading}

\section{Loading for floodwalls}

Undrained case. The loading considered on the system is the hydrostatic pressure acting on the exposed surfaces on the flood side. The external loads are calculated for each ring edge and accumulated, proceeding from the top ring toward the bottom ring to find the shear load carried by each ring. The incremental force for a given ring is found as follows. First, the water pressure is evaluated at the points of intersection of the ring boundaries with the surface line. To develop the working equations, consider one segment of the surface line, the edge of one ring. Calling the pressures at the two ends of the segment $p_{u}$ and $p_{l}$, the resultants for the two halves of the segment, $P_{u}$ and $P_{l}$, are found as

$$
\begin{aligned}
& P_{u}=l\left(3 p_{u}+p_{l}\right) / 8 \\
& P_{1}=l\left(p_{u}+3 p_{l}\right) / 8
\end{aligned}
$$

The rotational components of these forces (i.e., in the direction normal to the local radius) are added to the accumulated forces. The two halves need to be evaluated separately because the shear force acting on the central arc is required in the deformation calculation.

Drained case. In this case the hydrostatic pressures act on the wall only. For the exposed (not embedded) upper part of the wall a triangular hydrostatic pressure is used. For the embedded part of the wall the well-known constant water pressure is used as the resultant of the right and left hydrostatic pressures.

\section{Loading for excavation}

In problems where layers of soil are removed from the "front" side by excavation, the calculation of an equivalent loading is part of the simulation. It involves calculating the weight of the layer of soil placed and resolving this weight into a set of statically equivalent forces on the nodes. In addition to the nodal loads applied on the nodes that happen to be at the outer ends of the left side soil rings, some forces are also added in the loading vector that represent the removal of the lateral stresses acting on the left face of the wall adjacent to the layer being removed.

\section{Loading for backfilling}

In this case loads are applied on the nodes at the extreme right ends of the soil rings. These loads are calculated in a manner similar to those of the excavation forces, as statically equivalent forces representing the weight of the soil layer 
being placed each step. In addition, loads are applied on the segment of the sheet-pile wall adjacent to the soil layer being placed.

\section{The Soil Stress-Strain Model - The f-Model}

\section{The basis of the $f$-Model}

The $f$-Model is a variant of the simple, piecewise-elastic nonlinear soil constitutive models such as the Hyperbolic (Duncan and Chang 1970) and Parabolic models. Oner developed it in the 1970's as a result of discussions with Nilmar Janbu and Lars Grande. A great number of nonlinear models have been developed since then with increasing complexity. The reader is referred to a recent compilation by Desai and Siriwardane (1984).

\section{The general principles}

The $f$-Model is based on the following principles:

a. The model should capture the essential characteristics of the soil behavior.

$b$. The model should be as simple as possible.

c. There should be a minimum of soil "parameters" describing the model.

d. The soil (model) parameters should have simple and clear physical meaning.

The first principle is necessary to ensure that the FEM analyses using the model should be realistic and reliable. The second principle is a general idea behind any "law of nature." The third and fourth principles facilitate the implementation and usage of the model; the users should be able to guess the missing parameter values, if necessary, and be able to tell whether a measured value makes sense.

\section{The essential soil characteristics}

The following aspects of soil behavior are considered as the essential characteristics of soil behavior:

a. The soil gets stiffer as (effective) confining stresses on the soil increase.

$b$. The soil gets softer as failure is approached.

c. The soil reverts to an apparent stiff state upon unloading. 
These essential characteristics are represented in all soil models. For example, the hyperbolic model uses Janbu's (1963) equation for the first characteristic. The second characteristic is modeled by Kondner's (1963) hyperbola fit to the triaxial stress-strain curves (the hyperbolic model uses the Young's modulus $E$ and the bulk modulus $B$ ).

The third characteristic is a result of plasticity of the soil. In simple nonlinear soil models this behavior is modeled by assigning a higher stiffness to the soil (element) upon unloading. The hyperbolic model uses a linear unloading-reloading behavior. The $f$-Model uses nonlinear curves for both unloading and reloading, based on scaling of the skeleton curve. This is done by "Masing's rule" (Masing 1926).

\section{The working equations of the $f$-Model}

The $f$-Model uses the shear modulus $G$ and the bulk modulus $B$. The shear modulus varies with $f$, the degree of mobilization (of shear strength),

$$
G=G_{i}(1-f)
$$

where $G_{i}$ is the initial value of the shear modulus (initial, with respect to the triaxial test, or the isotropic stress condition).

The degree of mobilization is defined as the inverse of shear strength factor of safety,

$$
f=\frac{\tan \rho}{\tan \phi}, \phi>0
$$

where $\rho$ denotes the angle of a line tangent to the Mohr circle of stresses, from the origin (note that $\phi$ is the same angle for the failure condition). By inspection of a Mohr circle it can easily be verified that $f$ can be calculated as

$$
f=\frac{1-K}{2 \sqrt{K} \tan \phi}
$$

where $K$ is the minor to major principal stress ratio.

As a special case, the degree of mobilization becomes simply

$$
f=\tau_{\max } / c_{u} \text { for } \phi=0
$$

where $\tau_{\max }$ is the maximum shear stress.

Both moduli vary with the confining pressure. This is modeled by Janbu's (1963) equation: 


$$
M=m p_{a}\left(\frac{\sigma_{1}}{p_{a}}\right)^{n}
$$

where $p_{a}$ is one atmosphere (approximately $1 \mathrm{ton} / \mathrm{ft}^{2}, 1 \mathrm{~kg} / \mathrm{cm}^{2}$, or $100 \mathrm{kPa}$ ) and $\sigma_{1}$ is the major principal stress. The soil parameters $m$ and $n$ are dimensionless.

It is noted that the constrained modulus $M$ and the bulk modulus $B$ are related to Young's modulus and Poisson's ratio $v$ as

$$
\begin{aligned}
& M=\frac{E(1-v)}{(1+v)(1-2 v)} \\
& B=\frac{E}{3(1-2 v)}
\end{aligned}
$$

Similarly, the shear modulus $G$ is related as

$$
G=\frac{E}{2(1+v)}
$$

In the current implementations of the $f$-Model the bulk modulus is obtained from the $M$ modulus using the relationship between the two (Equations 40 and $41)$,

$$
M=\frac{3(1-v)}{1+v} B
$$

and taking the value of the Poisson's ratio $v$ at $K_{0}$ condition,

$$
v_{0}=\frac{K_{0}}{1+K_{0}}
$$

This gives $B$ at $K_{0}$ condition as

$$
B_{0}=\frac{1+2 K_{0}}{3} M_{0}
$$

Although the subscript 0 is used for the sake of generality, the bulk modulus can be assumed constant for practical purposes; therefore Equation 45 gives the value of B for any stress path. Note that this implies a variable Poisson's ratio. Alternatively, the Poisson's ratio can be varied with $f$ as

$$
v=v_{i}+\left(v_{f}-v_{i}\right) f^{4}
$$

where the subscripts $i$ and $f$ denote initial (or isotropic) and final (or failure) conditions. 
For the undrained condition of clayey soils ( $\phi=0$ condition) $n=0$ and $m$ takes on the meaning,

$$
m=\frac{E_{u}}{c_{u}}
$$

where $E_{u}$ is the undrained secant Young's modulus at a stress level of about 50 percent of the failure value. Since a modulus has the stress units, $m$ is again dimensionless.

\section{Sign of $f$}

The degree of mobilization $f$ does not normally have a sign. However, it is given a sign in the current implementations of the model. This was found convenint in modeling the unloading and reloading behavior (see next section).

The sign of $f$ is considered positive in "active-like" stress conditions and negative in "passive-like" stress conditions. An active-like stress condition is defined as one where the major principal stress is nearly vertical. The passivelike stress condition is the opposite of this; the horizontal stresses are larger in magnitude.

The sign convention employed is almost exactly the same as the one used in plotting the conventional stress paths ( $p-q$ diagrams). The advantage of assigning a sign in that case is the continuity of a stress path, for example, when a point in the ground starts at the $K_{0}$ condition (such that a "half" Mohr circle is plotted above the horizontal axis), and goes to the negative side of the vertical axis as the horizontal stress is increased to move toward the passive failure condition.

\section{Unloading-reloading behavior}

Equation 35 describes the basic initial loading curve of the stress-strain relationship. Upon unloading from a certain point the skeleton curve is scaled by employing what is generally known as the Masing's rule. According to this rule the material returns to its initial stiffness upon unloading. The unloading, when extended, can also cause failure. Therefore the unloading behavior is not linear. The skeleton curve is expanded in the stress direction (normally plotted on the $y$ axis), such that when failure is approached, the slope of the curve tends to zero. The reloading is also nonlinear, again based on a rescaling of the skeleton curve (Figure 33). This complicated behavior is modeled in the current version of the $f$-Model as follows.

The $f$ in the basic equation of the model (Equation 35) is replaced by a modified $f$ value, called $f^{\prime}$ which is defined as

$$
f^{\prime}=\frac{f-f_{c}}{f_{f}-f_{c}}
$$




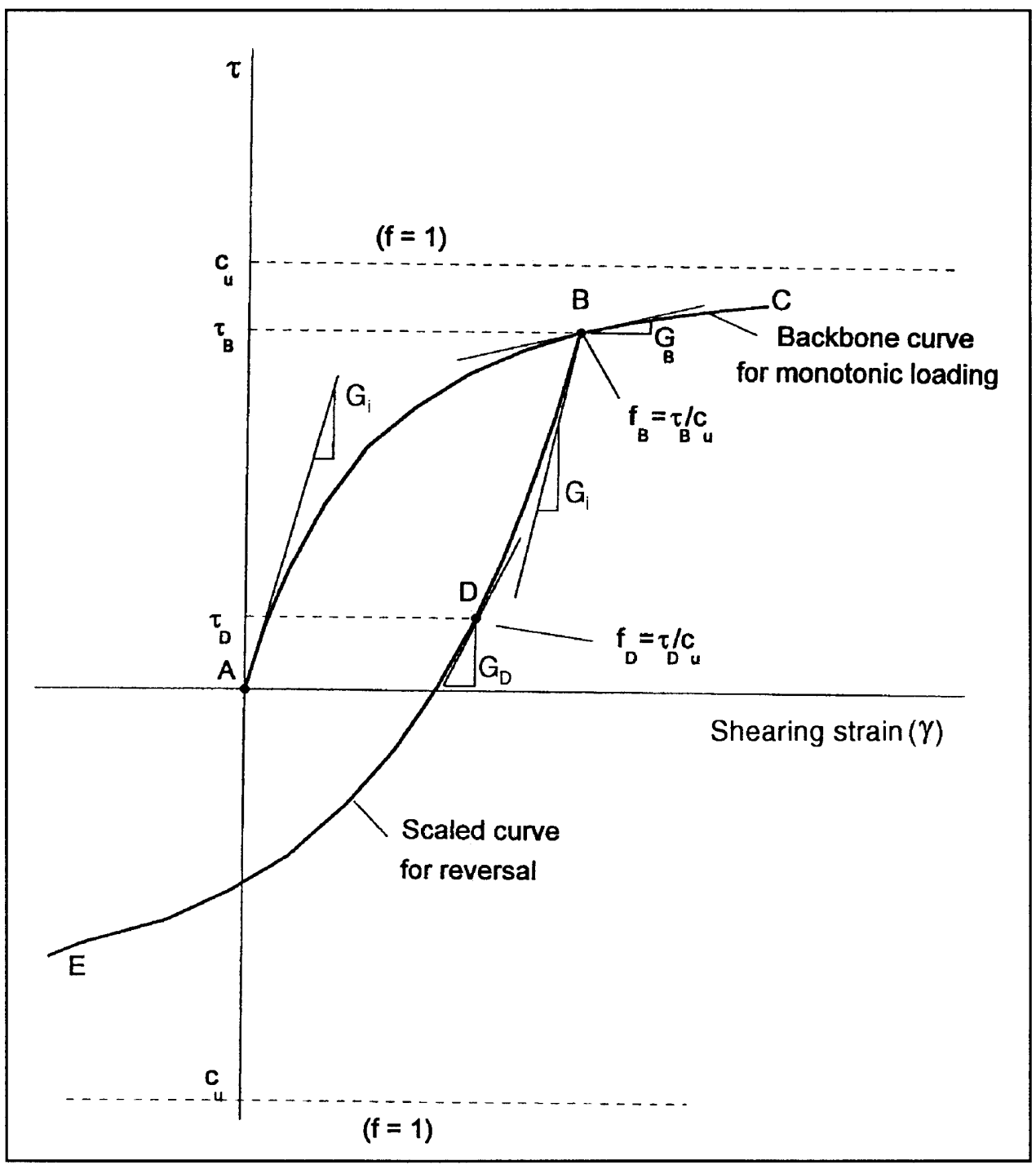

Figure 33. Shear stress-strain model using Masing's criterion

where $f_{c}$ denotes the "center" $f$ value; this is the value of $f$ at which the most recent unloading (or reloading) started. Initially it is zero, and its value changes as one or more cycles of unloading and reloading occur for the soil (element). The second parameter in Equation 48, $f_{f}$, is the value of $f$ at failure. That value is normally (and initially) equal to 1.0 ; but here it is given a sign. Therefore the $f$ value at failure becomes -1.0 when the soil fails in a passive condition.

\section{Determination of parameters}

There is no fixed procedure or restrictions on how the user sets the model parameters. Most of the parameters required are ordinary soil properties such as $K_{0}$, cohesion, and $\phi$ angle. The $m$ and $n$ are the only parameters to be selected. The method of selecting the parameters depends largely on the problem being analyzed and the purpose of the analysis. 
Determination of model parameters from laboratory data. The procedure of curve-fitting to triaxial test data to Equation 35 is straightforward:

a. $\quad c$ and $\phi$ are found by standard geotechnical practice.

b. For each data point, take the previous point and find the local slope $E_{\mathrm{t}}$.

c. For each interval, calculate the average $\sigma_{1}$ and the corresponding $f$.

d. Plot $E_{t}$ versus $f$; pass a straight line through data points to get $E_{i \text {. }}$

In the last step the straight line should be passed at the $f$ axis $(E=0)$ where $f=1$.

Determination of the model parameters using correlations. Correlations and typical parameter values are given in later sections of this report. These may be used to set the soil parameter values for use in an analysis. This is especially useful in two circumstances:

a. The user has already performed the curve fits for the hyperbolic model.

$b$. The user is setting the parameters by experience for a preliminary analysis.

\section{Typical parameter values}

Typical values of the stress-strain model parameters are:

a. Clay, undrained (short-term) condition:

Low-plasticity clays, $m=200$ to 1500

High-plasticity clays, $m=50$ to 300 , and $n=0$

b. Clay, drained (long-term) condition:

$m=10$ (very soft) to 50 (stiff), $n=0.7$ to 1

c. Sand and gravel (drained)

$m=100$ (loose), 200 (medium), to 500 (dense), and $n=0.5$

The initial Poisson's ratio is a somewhat less dominating parameter. Its value is typically in the range 0.2 to 0.4 for granular soils as well as for clayey soils in drained condition. Clayey soils in undrained condition are essentially "incompressible"; i.e., the Poisson's ratio is 0.5 . However, this value cannot be used exactly as it creates numerical problems. Therefore it is customary to approximate it as 0.49 . 


\section{Correlations with other models}

Relating Janbu's m-model with g-model. Janbu's original m-model was for the confined compression ( $K_{0}$ condition) where the constrained modulus $M$ was given as:

$$
M_{0}=m p_{a}\left(\sigma_{1} / p_{a}\right)^{n}
$$

Since shear deformation usually governs the deformation of soil masses, it may be more desirable to consider the shear modulus $G$ instead;

$$
G=g p_{a}\left(\sigma_{3} / p_{a}\right)^{n}
$$

where $g$ is considered to be the soil parameter.

The two models can be matched at $K_{0}$ stress conditions, yielding the relationship between $g$ and $m$.

a. For $c=0$ case:

$$
g=\frac{\left(1-K_{0}\right)}{2 K_{0}\left(1-f_{0}\right)} m
$$

b. For $\phi=0$ case:

$$
g=(2 / 3) m_{c}
$$

where $m_{c}$ indicates the $\left(E_{50} / c_{u}\right)$ ratio for this case. These are the forms used in the FEMSSI program internally.

Relating $f$-Model with the hyperbolic model. The hyperbolic model has been employed extensively in the last few decades. This has produced a considerable quantity of material property data. The user may wish to take advantage of this, either to estimate, verify, or "convert" the parameters from one model into another. The equations that match the two models are given in the following paragraph.

Matching the $G$ modulus values of the two models at an isotropic stress condition $(f=0)$ gives:

$$
\frac{K}{m}=\frac{1}{K_{0}{ }^{n}} \frac{\left(1-K_{0}\right)\left(1+v_{i}\right)}{1-f_{0}}
$$

Matching the $G$ modulus values of the two models at a $K_{0}$ stress condition $\left(f=f_{0}\right)$ gives:

$$
\frac{K}{m}=\frac{1-K_{0}}{\left(1+K_{0}\right) K_{0}^{n}} \frac{1+2 K_{0}}{\left(1-R_{f} / 2\right)^{2}}
$$

Note that it is entirely possible to select the failure ratio $R_{f}$ and $v_{i}$ independently. 


\section{The RingWall Program User's Guide}

\section{RingWall Screen}

The RingWall Main window contains the following elements: menus, problem title box, data entry/editing windows, text and graphics output windows, and icons.

a. Menus are used for issuing "commands" to the program such as loading and saving data and output files, printing, clipboard operations, and initiating design and analysis operations.

b. Problem title box is a text editing window to show the title of the problem the user is currently working on.

c. The windows are for entering and editing (modifying) data for a problem, as well as showing the results of the calculations. Some results are in text form while others are graphical. Note: the RingWall program uses non-SI units of measure.

d. Icons, which normally appear at the bottom of the screen, represent the windows that are minimized. Double clicking on an icon brings the corresponding window to its normal size.

\section{Windows of RingWall}

The RingWall screen contains a number of windows:

a. Data entry windows:

(1) Geometry Data window

(2) Wall Properties window 


\section{(3) Soil Properties window}

b. Text Output windows

c. Profile Plot window

d. Plots window

\section{e. Status Bar}

These windows may not be needed all the time. The ones that are not needed may be put out of the way by minimizing them (clicking on the button located at the upper right corner of each window). A minimized window is shown as an icon at the bottom of the screen (unless moved by the user). Any minimized window can be brought back to its original form by double clicking on its icon.

\section{General Procedure}

Because of the nature of Windows programs there is no single way of using this program as in a DOS program. The user can change any data, any time, and repeat the calculations. This is a general tool that can be used in different ways.

However, once the soil profile and the anchor elevation are fixed, it makes sense to run the design procedure in order to obtain a penetration depth. Next, the soil stress-strain parameters can also be added and the deformations analyzed. If these are reasonably small, then a good design is accomplished.

Although this general procedure will work most of the time, there will always be situations where deformations are very large even if the factors of safety used in conventional design method are considered adequate. It is also likely that lower factors of safety may be considered sufficient if the deformations are extremely small.

\section{Data Entry Windows}

\section{General rules for data entry}

There are general rules that apply to all data entry windows (Geometry, Wall Properties, and Soil Properties). In all cases there is a table, called a grid, that looks like a spreadsheet, and an associated text box for data entry, placed just above the grid.

Entering data in grids. Data entered in the text box above a grid are placed in the currently selected (highlighted) cell of the grid when the entry is completed 
and the ENTER key is pressed. Clicking somewhere else with the mouse will also cause the data to be accepted.

To enter a column of numbers, start with the top cell, enter the number, and press the DOWN ARROW key (instead of the ENTER key). This will enter the number as well as move the selecting (move the highlight) to the cell below.

To modify a value entered in a cell earlier, move the focus there (clicking on that cell or moving the highlight pressing the arrow keys), and either type the number again or press $\mathbf{F 2}$ to copy the number to the edit box where it can be modified.

Command buttons for data grids. There are two command buttons, labeled Accept and Reset, on each data entry window. The values entered (or edited) will be shown in the grid cells, but the program will actually change the internal data only when the Accept button is pressed. The Reset button will recall the values that were entered by the most recent Accept button click.

Changing column widths. The column widths in the grids are not fixed. They can be changed using the mouse as follows:

a. Move the mouse pointer in the first (labels) row, on the line between any two columns. The mouse pointer will change to a vertical line with two arrows pointing to the two sides.

$b$. Drag the boundary line (click with the right mouse button and move the pointer sideways) to the desired location.

Changing row heights. The row height in a grid can also be changed, by dragging the row boundary lines up or down similar to changing the column width, although this should not normally be needed.

Inserting and deleting grid rows. Pressing the INSERT key on the keyboard while the focus is on one of the data entry grids will insert a blank line into the grid at the currently selected row of the grid.

Pressing the DELETE key on the keyboard while the focus is on one of the data entry grids and one or more of the rows are selected by clicking on the row number $(s)$ will delete the selected row(s) of the grid. 


\section{Geometry Data window}

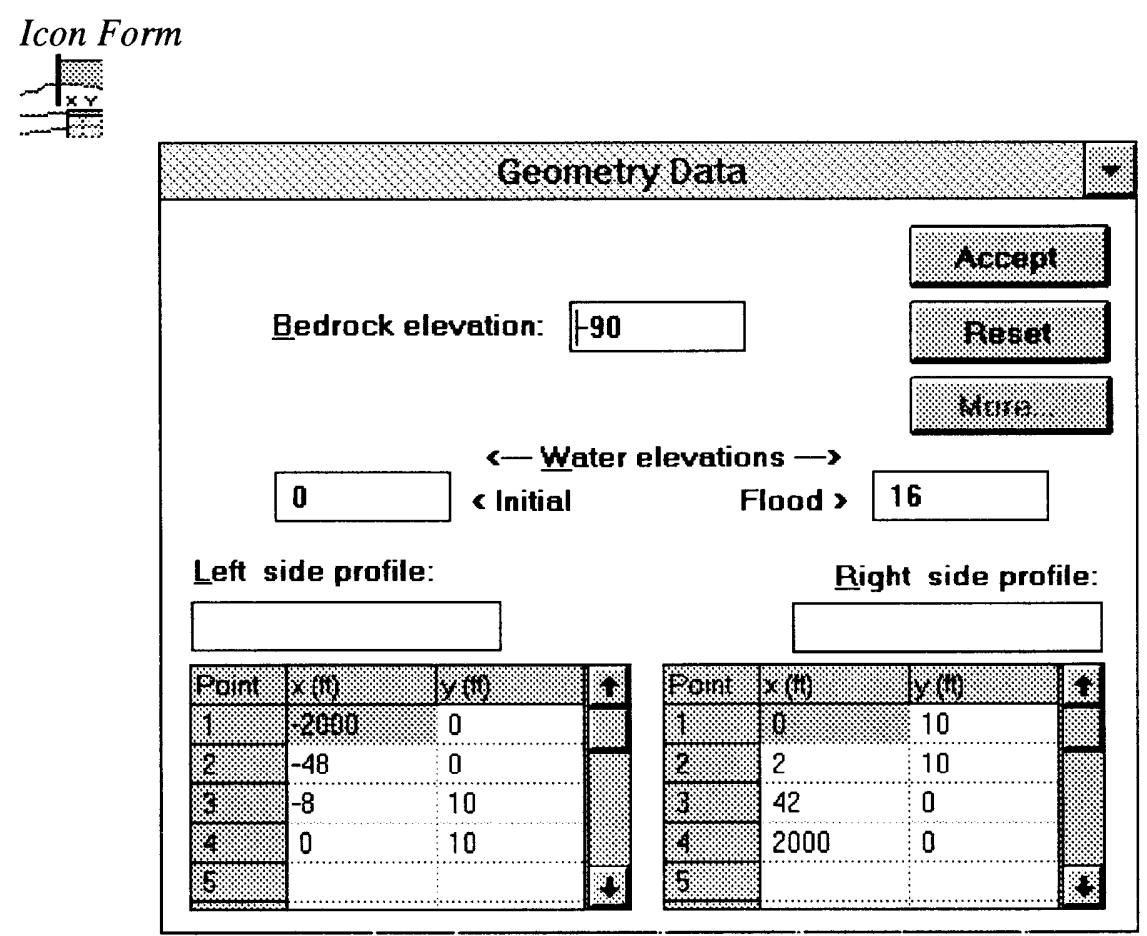

Geometric information defining the cross section to be analyzed is entered in this window. The $\mathrm{x}$ (horizontal) axis origin is always at the wall. $\mathrm{x}$-coordinates increase to the right. The y-axis is elevation (increasing upward) and the origin is arbitrary.

a. Anchor Elevation is the elevation of the anchor-wall connection. This box does not appear for a floodwall.

b. Bedrock elevation is the y-coordinate of the lowest level that should be considered in the analysis. The medium below this level is assumed to be undeformable due to excavation.

c. Excavate to elev(ation) is the box where the bottom of the planned excavation is entered. In a floodwall problem, this is replaced by the Flood Elevation.

d. Left and Right side profiles are entered in the two grids (see "Entering data in grids"). The numeric values are entered in the edit boxes just above the tables. The points should be entered in increasing $\mathrm{x}$-direction (from left to right). The last point of the left side and the first point of the right side profiles have to be on the wall $(\mathrm{x}=0)$.

e. The Accept button should be pressed for registering the data after editing in the tables. The Reset button will erase all the changes made and bring back the data as it was at the time the Accept button was last pressed. 


\section{Wall Properties window}
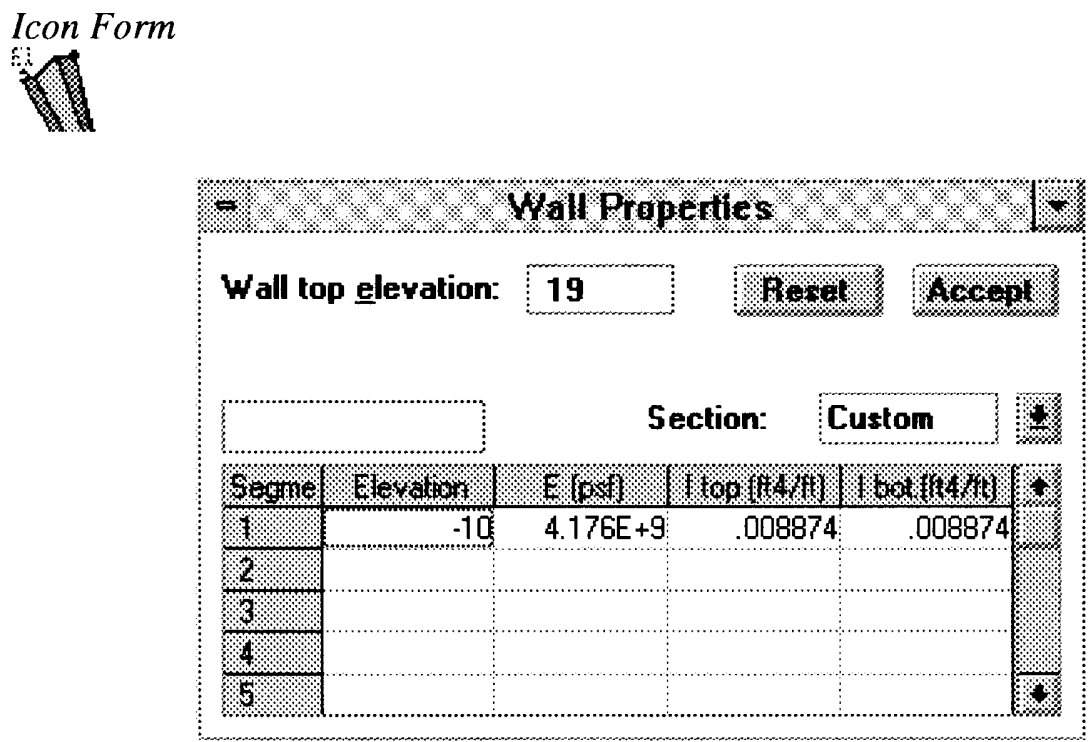

The wall properties window contains a text entry box for the top elevation of the wall. The elevation entered here should use the same elevation (i.e., the $y$ ) axis used for entering the geometric data for the profile. The wall can have a variable cross section. Each segment can have a linearly variable section. If the wall section is uniform (as in a steel sheet pile), only one line (row) of data needs to be entered in the grid (see "Entering data in grids").

For each segment of the wall the data to be entered are the Young's modulus $E$ and the value of the section's moment of inertia (i.e., the second moment of the area) at the top and the bottom of the wall segment. Entering a different number for these two will be taken as a linear variation.

The Drop-Down listbox labeled Section can be used to enter the section properties automatically for standard sheet-pile sections. Press the down arrow to the right of the text box to drop the list, and click on the section desired (e.g., PZ27). RingWall will enter the correct $E$ and $I$ values into the grid.

\section{Soil Properties window}

Icon Form

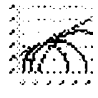

The Soil Properties window contains a grid (see "Entering data in grids") where the properties of each soil layer in the profile are listed, a text box to enter/edit the values, and the two standard command buttons. The column titles denote the following parameters: 


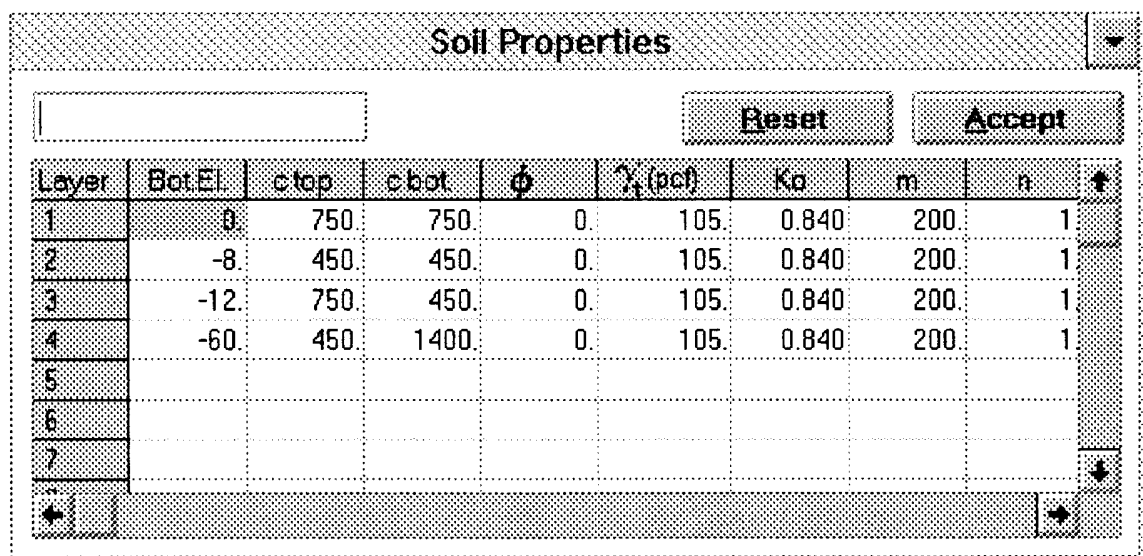

$\begin{array}{ll}\text { Layer } & \text { Soil layer number } \\ \text { Bot.El } & \text { Bottom elevation of the layer } \\ \text { c top } & \text { Cohesion value at the top of the layer } \\ \text { c bot. } & \text { Cohesion value at the bottom of the layer } \\ \phi & \text { Phi (friction) angle } \\ \gamma_{t}(\text { pcf }) & \text { Total unit weight } \\ \text { Ko } & \text { Coefficient of earth pressure at rest } \\ \mathbf{m ~ \& ~ n ~} & \text { Nonlinear soil model parameters }\end{array}$

\title{
Output Windows
}

\section{Text output windows}

\author{
Icon Form \\ \&:
}

The output windows are text-only windows containing design or analysis results. The conventional design results are put in the Design Output window, and the deformation analysis results are put in the Analysis Output window. This separation assures that valuable information is not lost accidentally.

The two windows can be identified easily in iconized (minimized) form: there is a letter " $A$ " in the analysis, and " $D$ " in the design window.

The same windows are used if the analysis or design is repeated (normally with modified data or parameters). The program gives a warning before that, so the user can save the current results to a file or print them before they are destroyed.

The design results come directly from the output of CWALSHT program, the format of which is documented separately.

The format of the analysis results is explained in Appendix E. 
The output windows can be resized and scrolled.

The results are also plotted in graphics windows, titled Profile Plot and Plots.

\section{Profile plot window}

Icon Form:

+1.

Once the geometry data entry has been completed (or modified), the profile is plotted.

A sample profile plot is shown below. The wall, the excavation level, the ground surface profile, the base rock, and soil layers are shown in the plot.

Clicking on the profile with the right mouse button will show the $\mathrm{x}$ - and $\mathrm{y}$ coordinates of the point clicked.

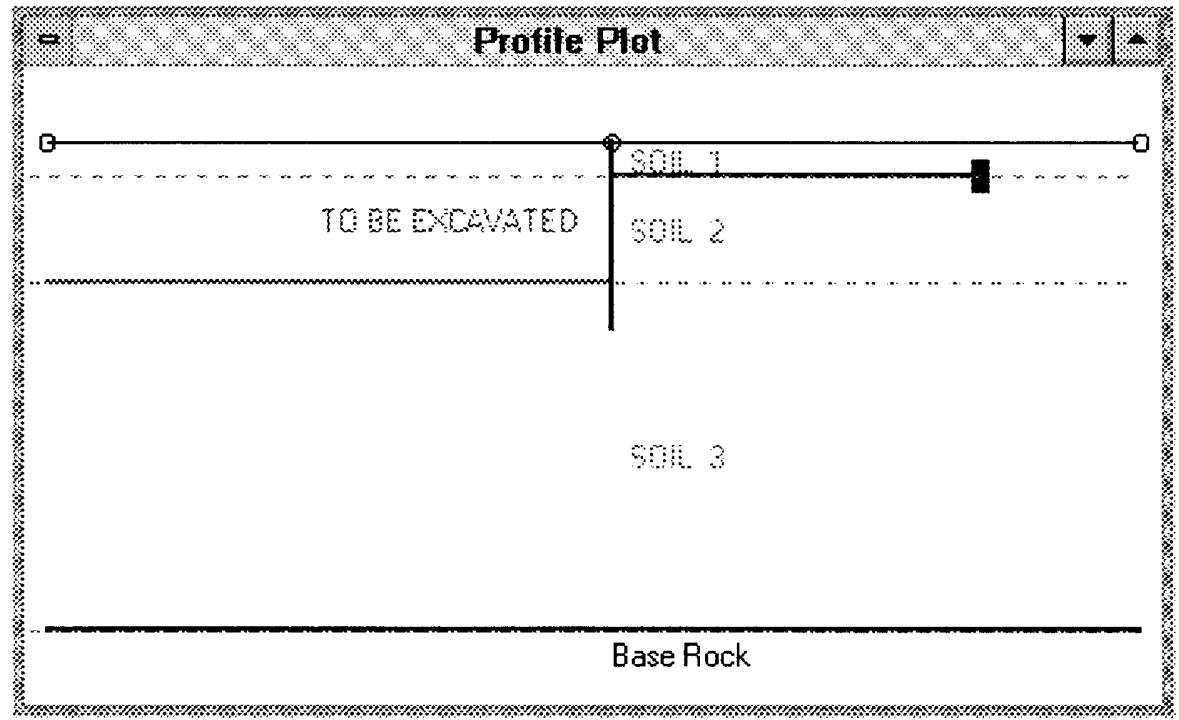

This example is for an anchored wall; for a floodwall problem the section will, of course, look different.

\section{Plots window}

\section{Icon Form}

S:

This window appears after an analysis by the SRM. The vertical axis is the elevation. The graphs are shown on the screen in this window for a quick visual 
inspection of the results. The actual numerical results are put in the Output window in text format in tables.

There are certain mouse operations that can be used in Plots Window:

a. Clicking on the left mouse button over a graph selects the graph (the selected status of a graph is shown with a colored frame drawn around it). After selection, the graph can be copied to Windows Clipboard for transferring to other programs (see "Edit menu"), or it can be written to a disk file in Windows Metafile format.

b. Clicking on a graph with the right mouse button will show the $\mathrm{x}-$ and $\mathrm{y}-$ coordinates of the point clicked in the units of the particular graph.

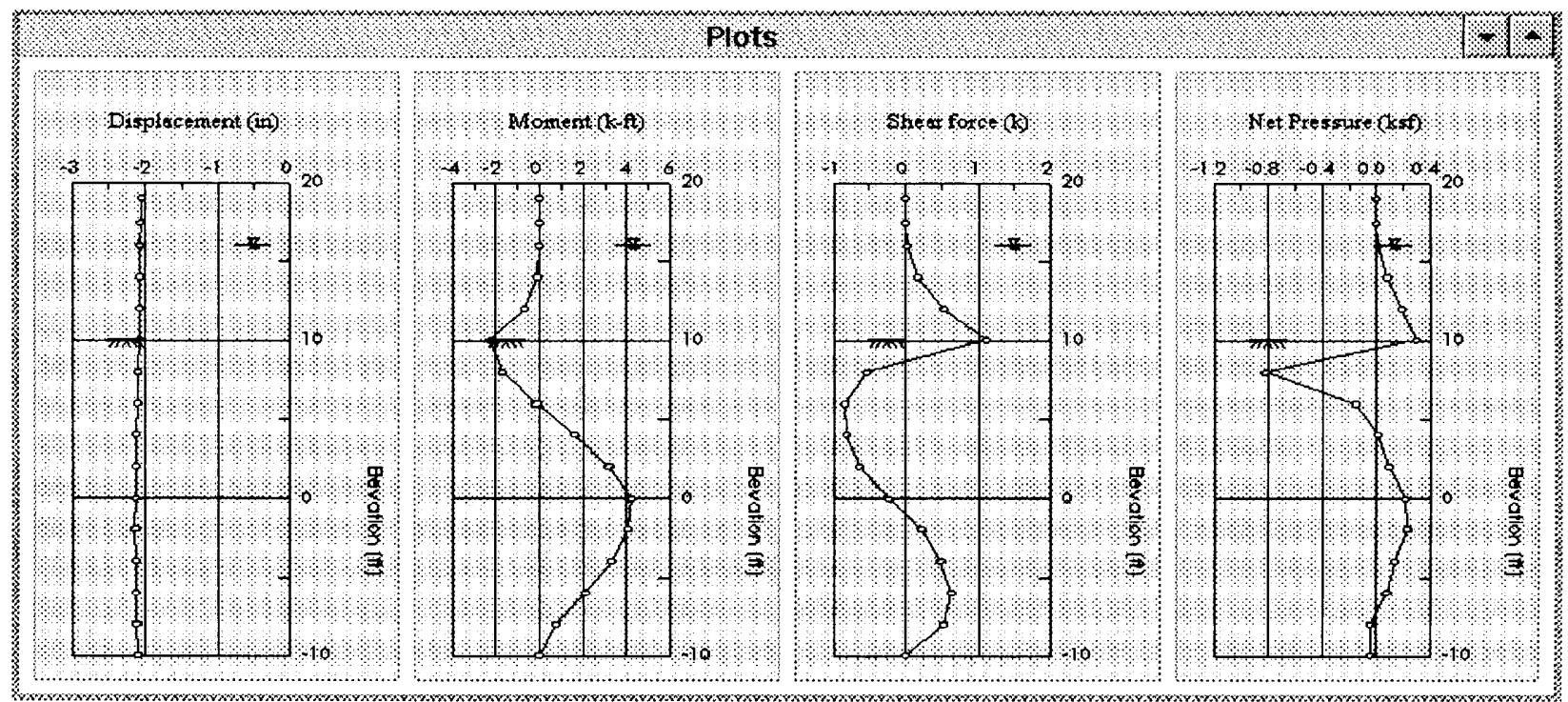

\section{Menus}

\section{Menus, buttons, and problem title}

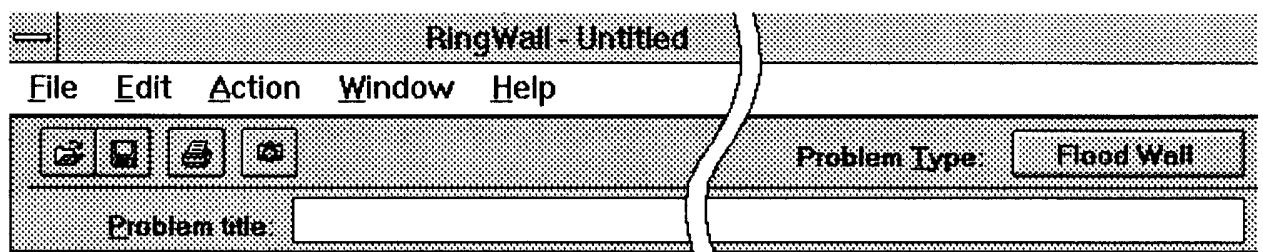

There are five command buttons below the menu row, and the problem title is entered in a text box. The text in this box can be edited after clicking on it. The problem title is shown at the top of the main window for quick identification of the problem being worked on. 
Command buttons. The command buttons are functionally equivalent to selecting a (sub-) menu item from the standard Windows drop-down menus:

a. File Open button

Pressing this button is the same as selecting Open under File menu; it brings up the file selection box. See also File+Open Command.

b. File Save button

Pressing this button is the same as selecting Save under File menu; it brings up the file selection box. See also File+Save Command.

c. Print button

Pressing this button is the same as selecting Print under File menu; it brings up the print options selection dialog box. See also File+Print Command.

\section{d. Copy button}

Pressing this button is the same as selecting Copy under Edit menu; it copies the currently selected graph or text to Windows Clipboard. See also Clipboard and Edit Menu: Cut, Copy, Paste Commands.

e. Problem title

This is a text entry box where the identification information for the current problem can be entered. The box is automatically filled when a file is loaded. The text inside this box gets written in the Title Box.

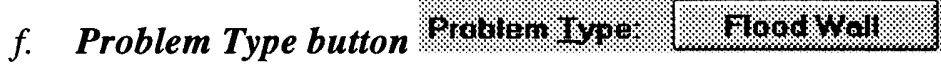

This button shows either Flood Wall or Anchored Wall depending on the problem type being considered. Clicking this button will change the problem type. Changing the problem type while some data for the other problem type is loaded will erase that data.

\section{File menu}

File menu: New Project command. This command clears any data in memory and starts over. This is useful for preparing to enter a new problem. This command is not necessary, however, if a new data file is to be read from the disk, since the memory clearing is done automatically in this case.

Before clearing the data in memory, in either case, the program will ask if you would like to save the output window contents, if any.

File menu: Open command. This command is used to read the problem data saved by the program earlier, so that one can continue to work on the same problem. One can also save a number of typical problems to reuse some of the data and save time. This command brings up the standard Windows file selection dialog box. This dialog box contains the directory and file list boxes. The file 
selection is done in the usual manner as in any Windows program (e.g., by double-clicking on the name of the file in the list box, or typing in the file name).

File menu: Save and Save As commands. This command saves all the data entered in various data entry windows to a disk file. A disk file saved this way can later be read back for further work on the same problem. The shear ring data files are given the extension.SRD

The File+Save As selection is to be used if the user loads a previously saved file, makes some changes, and wants to save the data under a new name. File+Save command does not give the renaming option.

File menu: Save Output command. This command saves the contents of the Output Window (text) to a disk file for use later. The filename extension .SRO is given automatically. If the design calculation results were saved earlier, the analysis results can be appended to the file. One can also append several design/analysis results to the same file. See also Save Graph command.

File menu: Save Graph command. This command is available only when a graph has been selected (by clicking on it). The graphs are saved in Windows Metafile format. Such files can be imported to almost all Windows programs. This capability is useful for saving graphs for such purposes as later use or for preparing reports. For immediate transfer of a graph to another concurrently running program, the Clipboard method may be more practical.

File menu: Print command. This command brings up the Print Options dialog box. There are two areas in this box, one for graphics and one for text type output. This dialog box is explained and illustrated later in this chapter.

File menu: Print Setup command. This command will bring up the system (Windows) printer setup dialog box. One can bring up the same dialog box from Print Manager and other system utilities. The setup done through this command, however, will affect only RingWall output and no other Windows application.

The Print Setup dialog allows the user to change the printer and any other printer-dependent options. The page orientation, however, is under program control. If your printer can print both in landscape and portrait orientations, RingWall will turn the page in the right orientation dynamically for each page it prints. For customizing page makeups see the INI file settings (see Appendix D).

File menu: Exit command. This command will end the execution of the program. It is also possible to end the program by double-clicking the control box (top left corner), or by pressing Alt+F4 key. 


\section{Edit menu: Cut, Copy, Paste commands}

If a graph is currently selected, the Copy selection will put a copy of the graph on Windows Clipboard in Metafile format. Graphs cannot be cut (copied to Clipboard and then erased), nor pasted from the Clipboard.

If no graph is selected, then these commands are available for text cut and paste operations. For example, using these commands, the output text in the Output window can be copied to Windows Clipboard and then pasted to a document in a word processor.

\section{Action menu}

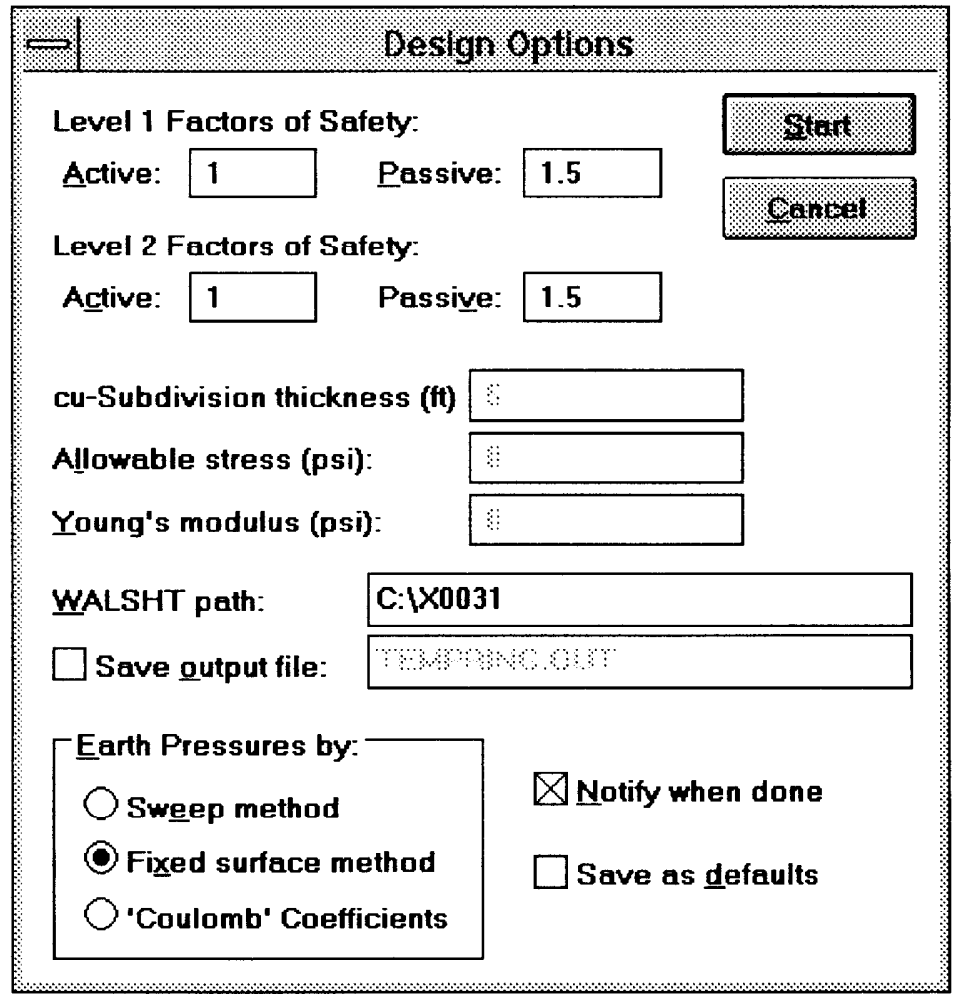

Action menu: Design command. The Action+Design command will activate the design function of the program. The necessary data should have been entered into the appropriate windows before this command can be issued. The current version of RingWall program calls the DOS program CWALSHT for doing the actual calculations once the user makes his/her selections in the Design Options dialog box (see accompanying sample screen) and presses the Start button.

RingWall prepares a data file for CWALSHT using the information it already has on your problem, runs CWALSHT in the background, and brings the output of that program into the Output window. RingWall does not automatically enter 
or change the wall height based on these results; the user has to make the design decision and enter this in the Wall Properties window.

For a complete discussion of the optional data to be entered in this dialog box, see the documentation of CWALSHT program (Dawkins 1990).

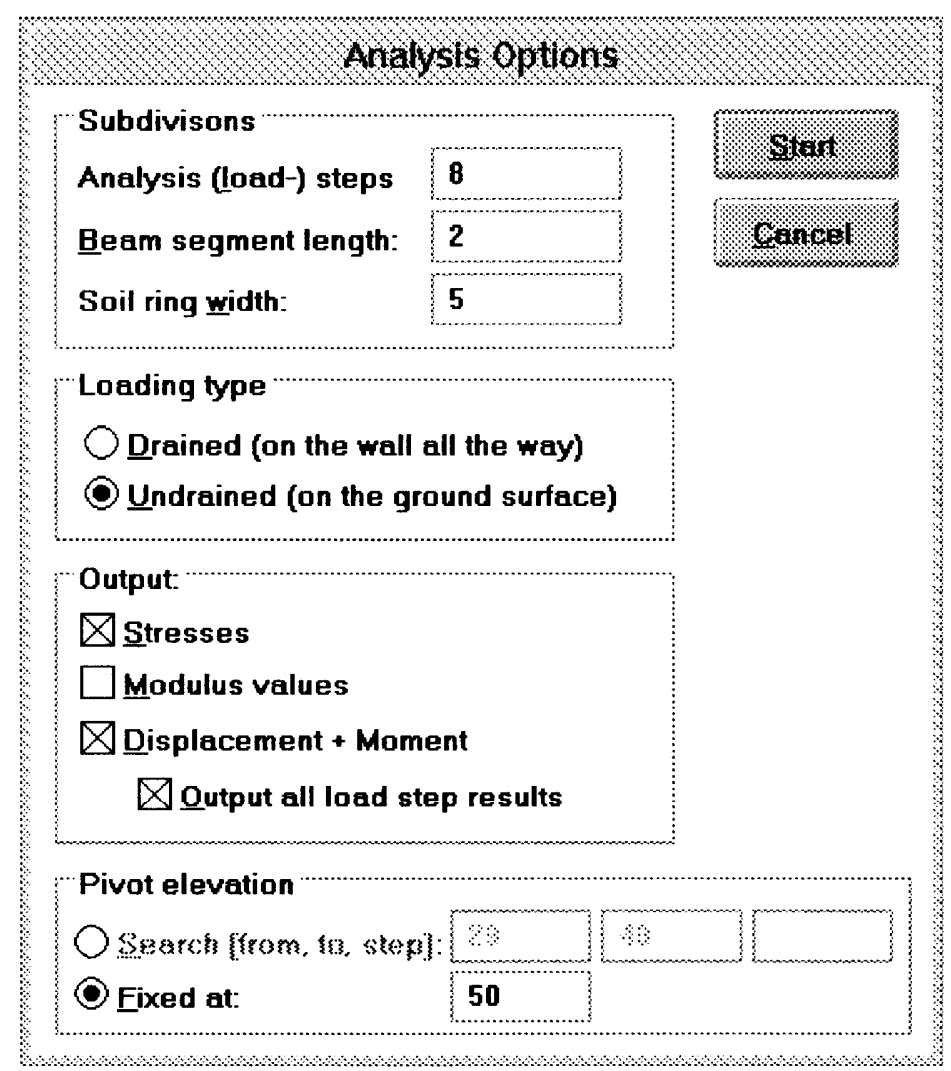

Action menu: Analyze command. This command initiates the advanced stress/deformation analysis of a trial design by the SRM (Chapters 2 and 3).

The ring method calculations are complex; therefore, an analysis usually takes a long time. Exactly how long it will take depends on many factors, but the typical range is from a few seconds to a few minutes on a 386/486 class computer. To be able to obtain a fast but approximate answer, one may

a. Choose a few load steps, say one or two instead of five to fifteen steps.

$b$. Force a coarser subdivision using a longer beam segment, say 3 to $5 \mathrm{ft}$ instead of 1 or $2 \mathrm{ft}$.

c. Use a coarser subdivision, similarly, for the soil below the pile tip.

d. Do not check the box labeled "Output all load step results." 
$e$. Fix the pivot elevation at the suggested value and do not choose the elevation scanning.

If the "Notify when done" box is checked, one can switch to some other application (by pressing Alt+Tab) while RingWall is busy calculating.

Action+Customize command. This command brings up the customization utility. The available options are selected by the buttons:

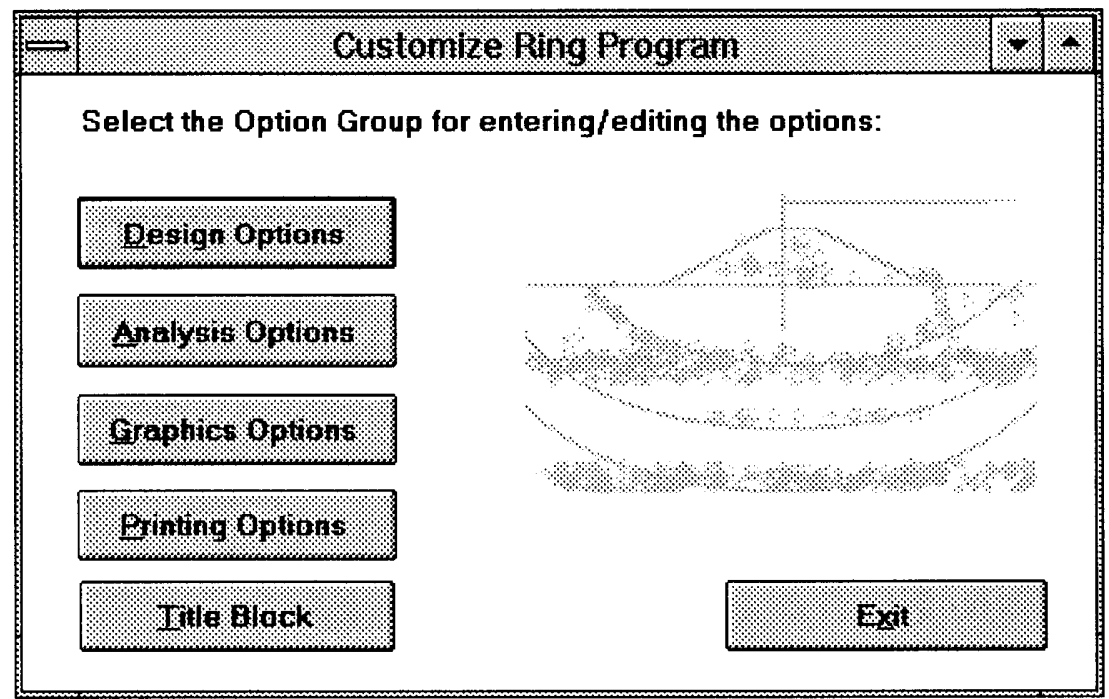

a. Design Options. This button is to set the default options you would like to see whenever an Action+Design command is issued.

b. Analysis Options. This button is to set the default options you would like to see whenever an Action+Analyze command is issued.

c. Graphics Options. This button is to set the detailed characteristics of plots.

d. Printing Options. This button is to set the default printing options.

e. Title Block. This button is to set up or modify the title block.

\section{Window menu: Tile, Cascade, Arrange Icons commands}

The selections in this Window menu are for rearrangement of the "child" windows and icons on the main RingWall window. Also there is a list of currently available windows that allows selection of windows by a sequence number. Using these commands, the work space can be ordered, and the windows that are lost in a crowded screen can be found easily. 


\section{Help menu}

The uses of the selections in the Help menu are as follows:

a. On Help: Windows Help utility is started and instructions are provided on how to use the Windows Help utility.

b. Theory-Design: A brief explanation of the theoretical background of the design method used is given.

c. Theory-Analysis: A brief explanation of the theoretical background of the analysis (ring) method used is given.

d. Program: Help on how to use the program is provided with this selection.

e. INI File: The settings in RINGWALL.INI file are explained. These are useful for customizing the program.

f. About: The "About Box" is displayed to show the current version information.

\section{RingWall INI file}

The uses of the INI file. The RINGWALL.INI file is an auxiliary file that holds the various options and selections made by the user during previous runs of RingWall. Using this file the program knows your preferences and saves you the trouble of repeating your selections every time you use the program. The expert user can modify this file directly using an ASCII file editor (such as Notepad).

The default INI file is shown in Appendix D. The format is the standard Windows INI file format; the various sections of the file are labeled with keywords in brackets [ ], and each line contains a keyword and its value. A line that starts with a semicolon is a comment. The entries in the [graph] sections are the margins in inches and the location and size of the legend block. The legend block can be any graphic, as long as it is saved in a disk file in Windows Metafile (.WMF) vector format. Any WMF will do, whether or not there is a "placeable header" (a.k.a. Aldus header) in the file.

The default INI file. The default INI file contains settings that are thought to reflect the choices most users would make. It is listed in Appendix D.

How to change the INI file. The INI file is a simple ASCII format file. Therefore, it can be edited by any pure-ASCII editor, such as Windows Notepad. Start Notepad by double-clicking on its icon in Program Manager, open RINGWALL.INI file, make the changes desired, and save. There is no need to restart Windows or RingWall for the changes to take effect. 


\section{Interacting with Windows}

RingWall is a Windows-based program that interacts with the system (Microsoft Windows) not only for standard menus and dialog boxes but also for its text and graphics output. Two such aspects of interaction deserve special explanation:

a. Printing, especially graphics: No special attention is required for printing because RingWall uses the default Windows printer that the user installs through the standard Windows procedures. RingWall allows the user to change the printer setting from within the program. The changes made using RingWall menus and dialogs do not affect any other Windows program.

$b$. Clipboard operations: One of the main features of Windows is its ability to easily transfer information from one program to another through this software mechanism. RingWall takes full advantage of this Windows feature by allowing the user to copy and paste text and graphics.

\section{Printing}

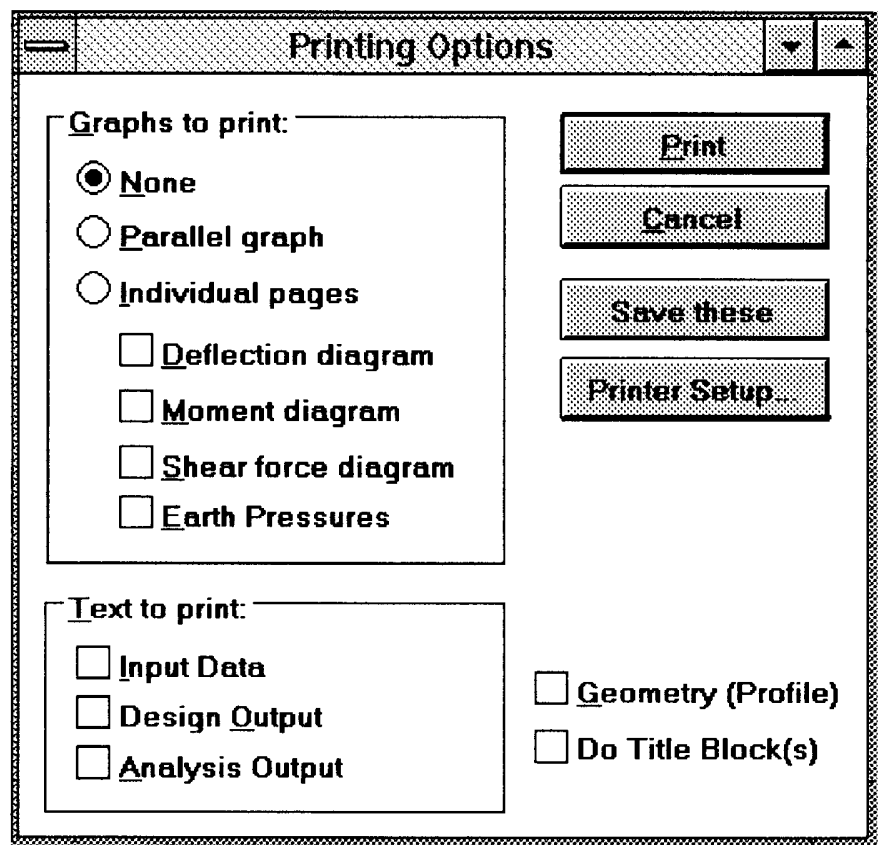

Printing is initiated by selecting Print from File Menu. This brings up the Print Options dialog box shown above. There are two areas in this box, one for graphics and one for text type output.

Text output has three choices, Input data, Design Output, and Analysis Output, which are self-explanatory. 
The graphics output is customizable. The user can compose the way graphs should be printed. They may be printed on a separate page (sheet) each (Individual page alternative), or they may be combined several on a page (Parallel graph alternative). Furthermore, the user can select which plots should be printed. The user can fine-tune the details of graph printing in the "INI File" (Appendix D).

\section{Clipboard}

Windows Clipboard is a temporary memory area used to transfer data (text, pictures, etc.) between Windows applications running simultaneously under Windows. In RingWall, the Clipboard is used mainly (a) to transfer the contents of the text output window, typically to a word processor, and (b) to copy the figures drawn by RingWall to other programs. The graphs are transferred to the Clipboard in Windows Metafile format (vector, as opposed to bitmap format) such that they can easily be scaled and printed with the host document without loss of resolution.

Text transfers through clipboard. To transfer some text from the output window to another application (say, a word processor), first select the text using the mouse or keyboard and then select Copy from Edit menu. To paste the text in the other application, switch to it (Alt+Tab) and insert at the desired place by either Edit+Paste menu command or by the keyboard shortcuts (Shift+Insert or Ctrl+v).

Graphics transfers through clipboard. To transfer a plot from the output window to another application (say, a word processor), first select the text, clicking on the figure using the left mouse button. A colored rectangle will be drawn around the figure to indicate that the figure has been selected. Then select Copy from Edit menu. To paste the figure in the other application, switch to it (Alt+Tab) and insert at the desired place by either Edit+Paste menu command or by the keyboard shortcuts (Shift+Insert or Ctrl+v). 


\section{Application of RingWall}

\section{Typical Sequence of Steps for Analysis and Design}

The method presented in this report, SRM, with the associated computer program, RingWall, is an advanced tool unlike other procedures and tools currently in use. Classical procedures, such as the FES method, consist of these steps: the engineer provides the data for the problem and the method produces an answer as the solution to the problem. Usually a factor of safety is selected at the outset and the method gives you a simple answer, such as "the wall has to penetrate the ground 25 feet if those are the geometric and soil parameters, and if that's the factor of safety desired." If the engineer chooses a higher factor of safety, he/she expects a larger depth of penetration, although there seems to be a set of factors that are generally considered adequate. In the case of RingWall, there is an addition to this process: a realistic analysis of deformations to expect in and around the wall, as well as the stress conditions in the soil. The procedure for designing a sheet-pile wall using the SRM depends on how the engineer wants to use this new tool, as explained in the chapter. Since the analysis procedure is a part of the design procedure it is discussed first.

\section{Procedure for analyzing a given system}

Procedure for the analysis of an existing (or selected) system starts with supplying the geometric, soil, and other data to the RingWall program. The data can be supplied by either reading an existing data file or by typing in the numbers and making selections in dialog boxes. Once the data set is complete, the program can analyze the response of the system to the design flood or wall construction.

The procedure is as follows:

a. Enter the problem data into the corresponding data entry boxes (please see the section of this report describing each of these boxes):

(1) Enter a problem title at the top of the RingWall window. 
(2) Enter geometry data. Note that it is a good idea to check the profile plot once the geometry data have been entered. Also recall that a right click with the mouse displays the coordinates of the point clicked.

(3) Enter soil properties.

(4) Enter the wall properties.

Note that in each data entry box the Accept button must be pressed for the data entered (or modified) to be registered by the program. The Reset button returns the data in the boxes to the values that existed in each box at the last time the Accept button was pressed.

$b$. Once the data boxes are all filled with values, it is a good idea to save the data in a file so that the data can be recovered for later use. To do this, use Save under File menu. Enter the folder where the file should go and a file name in the standard dialog box that will pop up.

c. Analyze the problem using Analyze under Action menu (or use the keyboard shortcut $\mathrm{Ctrl}+\mathrm{A})$. Depending on the speed and central processing unit (CPU) of the computer system as well as the options used, the analysis can take from a few seconds to a few minutes.

d. Print the results in text as well as graphical format, for documentation and presentation.

\section{Procedure for design}

The design of a sheet-pile wall using RingWall involves the use of both the conventional calculations and the SRM. RingWall is not only a program to perform SRM analyses, but it also provides the tools that can be used for interfacing with the conventional design computer program CWALSHT. With the exception of factors of safety, no additional data are required from the user to do this. RingWall takes the data already entered in the dialog boxes and forms a data file in the format expected by CWALSHT program. Next it executes that program in the background. Then it captures the output of CWALSHT and shows the results in a text box inside RingWall window. All this is done automatically without the intervention of the user.

The design process is made up of the following steps:

a. Enter the ground surface geometry and soil profile and properties. Set the problem type (floodwall or anchored wall) using the button at the top right corner. Enter the parameters needed to describe these in the corresponding data entry boxes.

$b$. Select Design under the Action menu. RingWall will call up the conventional design program (CWALSHT) and show you the results in a box once the other program has finished its calculations. 
c. Study the results and look at the Profile Plot box to get a feel of the penetration depth as calculated by the conventional procedure. Select the wall properties in the corresponding data entry box.

d. Now analyze the problem. Print the results. Study the results, especially the deformations as well as the bending moments and the anchor force, if it is an anchored wall. Check if the wall section and the anchor diameter that have been selected are adequate. If not, change these and reanalyze.

e. Make a design decision. If the deformation of the wall is acceptable, the conventional design result may be considered adequate, and the design process ends there. But it is also likely that the conventional design calculation may not produce a good design in terms of economy or performance; it may produce either an excessive depth of penetration (i.e., it is uneconomical) or excessive deformations. To make a good judgment, a few iterations may be necessary.

\section{Considerations in Modeling}

This section provides some suggestions for using the RingWall program. These are based on the experience gained in test runs as well as basic knowledge of mechanics of deformation calculations by similar methods.

\section{Subdivision into layers}

Subdivision of the wall and the soil profile into conceptual layers for analysis involves the selection of a few parameters. One of these is the width, in the radial direction, of a shear ring. If this width is too large, the results will not be very accurate. On the other hand, if the width is too small, then the computer can take a very long time to execute the analysis.

Although the currently available top-of-the-line computers, with $300+\mathrm{MHz}$ clock speed, take only a few seconds for the most demanding case, such systems are not yet widely available. The dominant operating system is still the 16-bit Windows. This last factor limits the array dimensions that can be used in the program, and very fine subdivisions are not at all possible (in such cases RingWall suggests that the user reduce the requirements). Until all engineers have access to more powerful computers, reasonable values should be used for the subdivision widths. In the tests that have been performed in the development studies the following values have been found adequate: a subdivision width of $0.6 \mathrm{~m}$ ( $2 \mathrm{ft}$ ) on the wall as well as right under the tip of the pile, and $1.5 \mathrm{~m}(5 \mathrm{ft})$ in the remainder of the system are adequate for the typical wall heights of 9 to $12 \mathrm{~m}$ ( 30 to $40 \mathrm{ft}$ ). Half of these values may be used for smaller walls and values twice as large may be adequate for larger walls. 


\section{Location of the pivot point}

The current version of the program selects the pivot point automatically unless there is a reason this value should be left alone. Tests have shown that the location of the pivot point does not influence the results appreciably. This is good because an automatic determination of the pivot location is a very timeconsuming process. In critical cases, however, it may be desirable to vary the pivot location somewhat and see if the results change. Then, a conservative selection can be made.

\section{Selecting soil parameters}

Perhaps the most critical set of parameters that governs the design of a sheetpile wall is the soil characteristics. The selection of the unit weight and shear strength parameters follows the normal procedures established over the years. The new parameters required for SRM analyses are those defining the stressstrain relationships of the soil layers in the profile. The engineers with a background of FEM analysis in geotechnical engineering are best suited to selecting the stress-strain parameters for soils. Considering that engineers with this particular specialization are not particularly abundant, it is strongly advised that the user study the section in Chapter 3 entitled "The Soil Stress-Strain Model - The $f$-Model." This section not only describes the soil constitutive model used, but it also gives the typical range of values for each parameter for different types of soils. Correlations are also presented in the same section as an aid to those with experience with other soil models. 


\section{Example Problems Using RingWall}

This chapter describes how to operate the program RingWall for design and analyses with the use of example problems.

\section{Operation of the Program}

\section{Starting the program}

RingWall is started just like any other Windows program, e.g., by doubleclicking its icon:

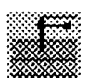

\section{Parts of the main screen}

The main screen consists of various parts, from top to bottom:
a. Title bar
b. Menu bar
c. Command buttons
d. Title line
e. Data entry windows
f. Icons
g. Status line 


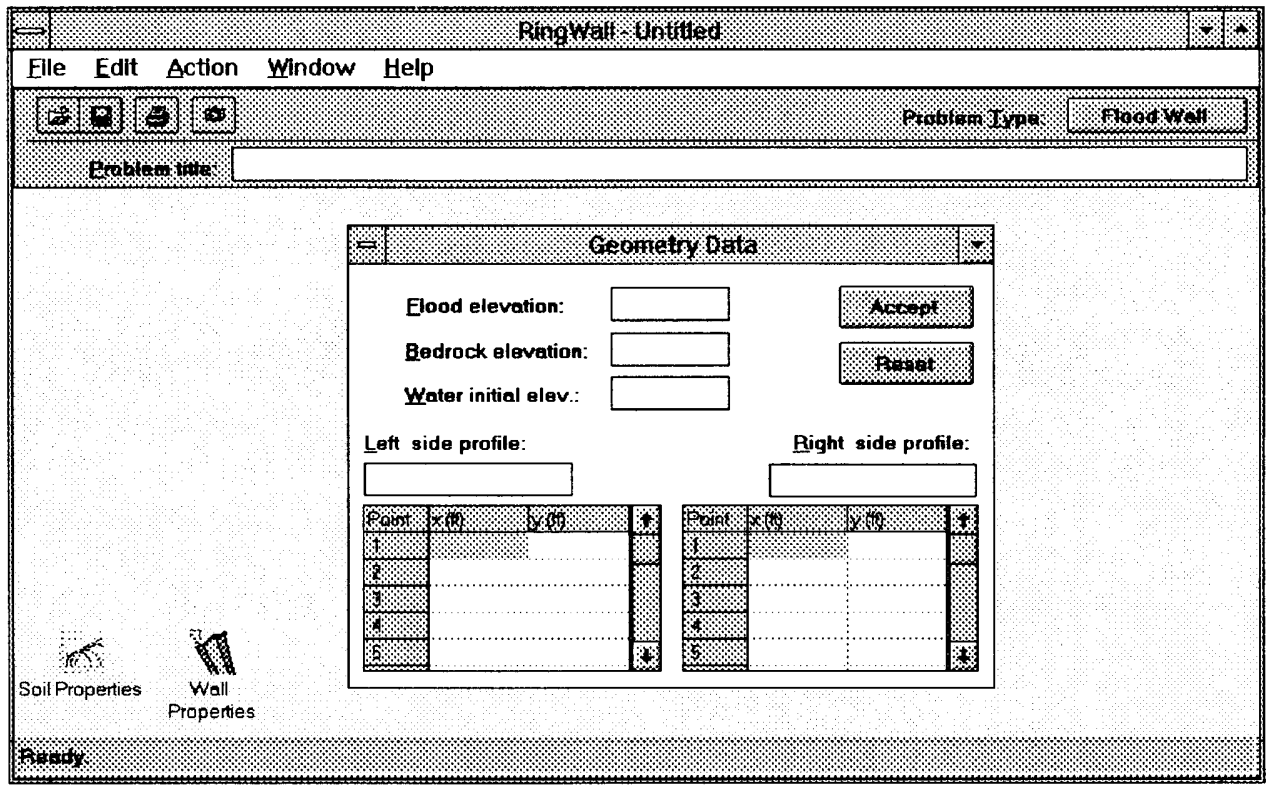

Title bar. The Title Bar contains, from left to right, the close box, the program and current file name, and minimize/maximize boxes. The functions of these are the same as in any other Windows program.

Menu Bar. The Menu Bar contains the following items:

a. File: Open and save files, save graphs, and exit the program.

b. Edit: Cut, Copy, and Paste operations.

c. Action: Design, Analyze, Customize, and Regenerate Graphs operations.

d. Window: Organize the main screen, and bring a selected window to the foreground.

e. Help: Get on-line help on using the program.

Command buttons. The Command Buttons on the left side are simply shortcuts for some common menu selections. From left to right, their equivalent menu selections (or commands) are

\section{a. File + Open \\ b. File + Save \\ c. File + Print \\ d. Edit + Copy}

The larger command button on the right side reads "Flood Wall" at the beginning. If clicked once it changes to "Anchored Wall" (and clicking again 
will change it back). If a data file is loaded (File + Open), it shows whatever type of problem it is.

Title line. The Title line is for entering/showing a short description of the problem being solved. In an original data entry, this box should be filled (with some short identifying text). It is (optionally) placed in the title blocks in the printed output.

Data entry windows. There are three data entry windows (or dialog boxes). Of these three boxes, the Geometry Data window is shown in normal size. The other two data entry windows are shown in minimized (icon) form.

Pressing the down arrow (minimize) box on any of these child windows will iconize that window; double-clicking on an icon will show it in normal size.

The program shows other child windows for presenting the results in text and graphics form. These appear only after calculations.

\section{Using the Data Entry Windows}

Data, numeric and textual information that describes a problem, are entered by typing in the text boxes. In addition to the occasional text boxes (such as the problem title box) the bulk of the data is entered in three data entry windows. The same rules apply in each of the three data entry windows. Therefore it is useful to review these rules at the outset.

\section{Data entry grids}

The three data entry windows (or dialog boxes) are:

a. Geometry Data.

b. Wall Properties Data.

c. Soil Properties Data.

In all three, there are tabular data entry areas (grids), separate fields such as the one for entering the top elevation of the wall, and two command buttons: Accept and Reset. The typing of data into the boxes is regarded as temporary. The command buttons register and reset (undo) the entries.

\section{Command buttons}

The numbers entered into a grid are not "registered" until the Accept button is pressed. Changes can be made anywhere, any time, but when the Reset button is pressed, the "old" data are brought back. "Old data" are the ones that were 
shown when the Accept button was last pressed. This mechanism provides a general "undo" capability.

\section{Navigation}

The aspect of the grids that concerns the users most is navigation (how to go from cell to cell easily). While entering numeric data into one cell of a grid, if you press the "up" or "down" cursor keys the program assumes that you are done with the current cell and now want to move on the cell above or below. The ENTER key enters the data into the current cell, but does not make any assumption about which way you want to go; so it simply stays on the same cell.

\section{Resizing}

Another aspect of the grids is the resizing method. The entire data entry window size cannot be changed, but the grid rows and columns can. To resize a column, put the mouse pointer in the title row (the gray top row). When the pointer is over a sensitive area between columns, its shape will change to a double arrow. Clicking the right mouse button and moving the pointer sideways (dragging) will resize the columns. A similar action is possible for resizing the rows.

\section{Example 1: Entering a New Problem}

\section{The problem}

The problem is to analyze and design a floodwall at a site where the soil is a saturated clay with a total unit weight of $2,002.5 \mathrm{~kg} / \mathrm{m}^{3}(125 \mathrm{pcf})$, and an undrained shear strength of $24 \mathrm{kPa}\left(500 \mathrm{lbf} / \mathrm{ft}^{2}\right)$. The soil extends to a depth of $18 \mathrm{~m}(60 \mathrm{ft})$ where there is a hard medium that can be called the bedrock. The

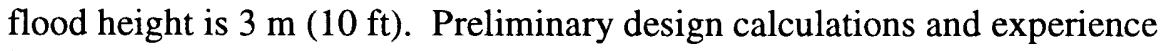
indicated a penetration depth of $4.6 \mathrm{~m}(15 \mathrm{ft})$.

\section{Entering data}

Entering the wall data. Start with the problem title, say, "Example Problem \#1." Click on the problem title text box and type this. You do not have to press ENTER at the end of the line. Then click on any of the three data entry windows, say the Wall Properties. 


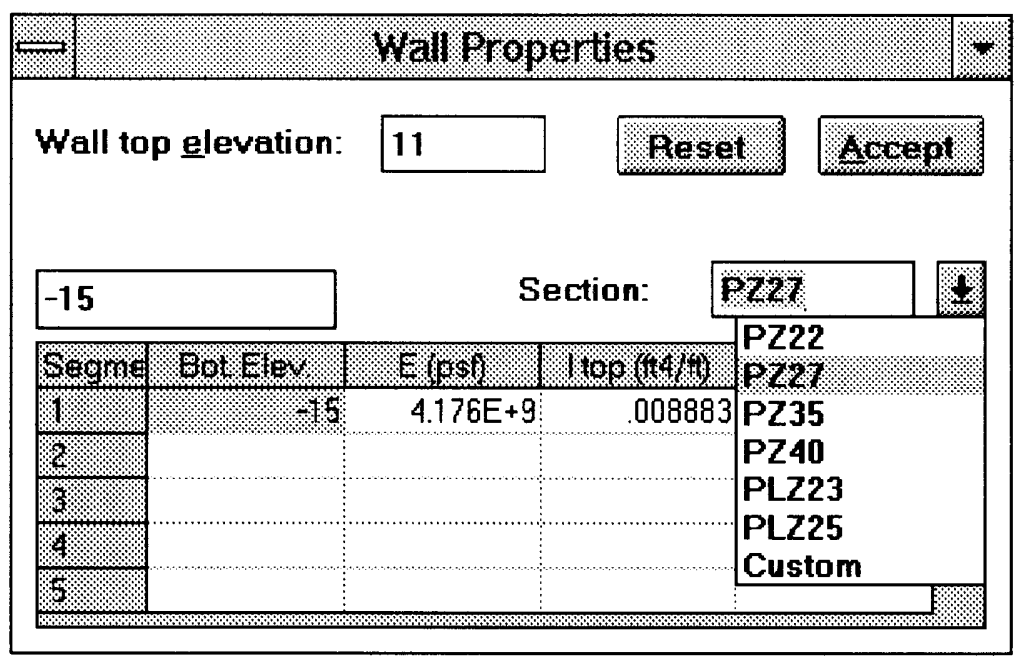

The cursor should be in the text box titled "Wall top elevation." Type $\mathbf{1 1}$ and then press Tab. This is $0.3 \mathrm{~m}(1 \mathrm{ft})$ above the design flood height for this problem. Also, it implies an origin for the axis system: the $y$-axis origin can be put anywhere. Here, entering $11 \mathrm{ft}(3.3 \mathrm{~m})$ for the top of the wall assumes that the origin is at the ground surface. The $x$-axis starts at the wall; distances are negative to the left and positive to the right.

The Tab key will take you to the next logical field to enter: the bottom elevation of the wall (segment). Since we have only one segment in the wall, this is also the tip of the wall. Enter -15 (i.e., type $\mathbf{- 1 5}$ and press ENTER). Then you can press any cursor key to move around in the grid, and stop somewhere and start entering data there.

In this first example we will use one of the standard steel sections. In this case there is no need to enter anything else. Click on the drop-down box (the one on the right side of the space between the grid and the command buttons). When the list of available sections drops down, click on one section, say PZ27. The Young's modulus value $E$ and the moment of inertia of the section $I$ will be entered in the table automatically.

Entering the soil data. Next, you might enter the Soil Properties. A row is available in the soil data grid for each soil layer in the profile. In this first example, we have only one soil layer, so we will fill in the first row only. 


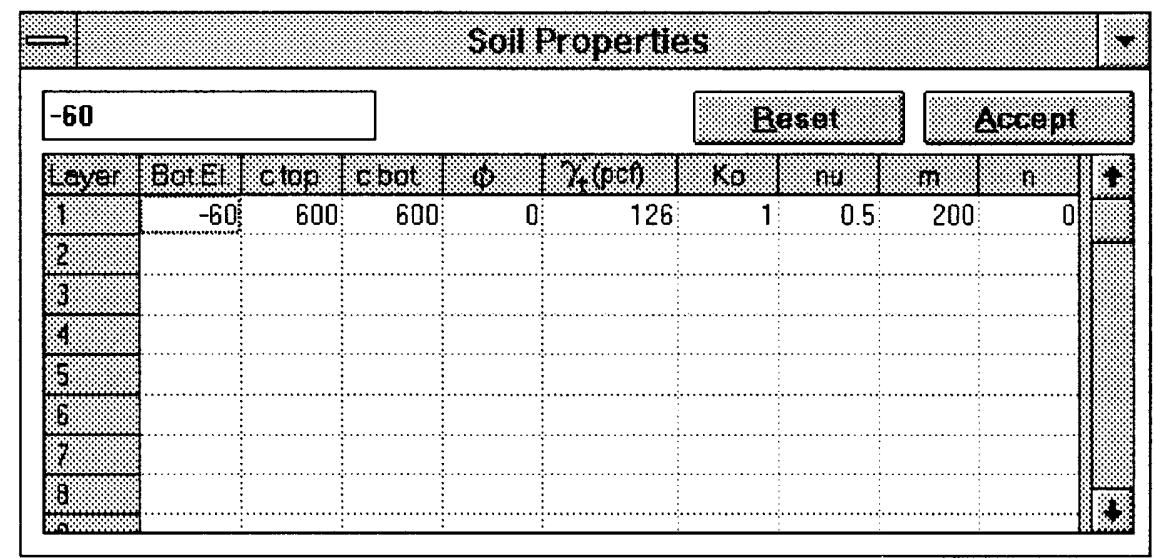

Type -60 for the bottom elevation of the soil layer, then ENTER. Cursor right to the next cell ( $c$ top) and enter 600 (ENTER, cursor right); repeat this for the next cell. The reason for this double value for the undrained shear strength is that there is usually a natural variation in $c_{u}$ in the vertical direction. Entering two values, one for the top of the layer and one for the bottom, can represent any variation easily.

When the data entry has been completed, the Geometry Data Window should look like the sample. Register this also by pressing Accept.

Entering the geometry data. Finally, we will enter the Geometry Data. Bring forward this window and see that the cursor is in the first field (text entry box), for "Flood elevation."

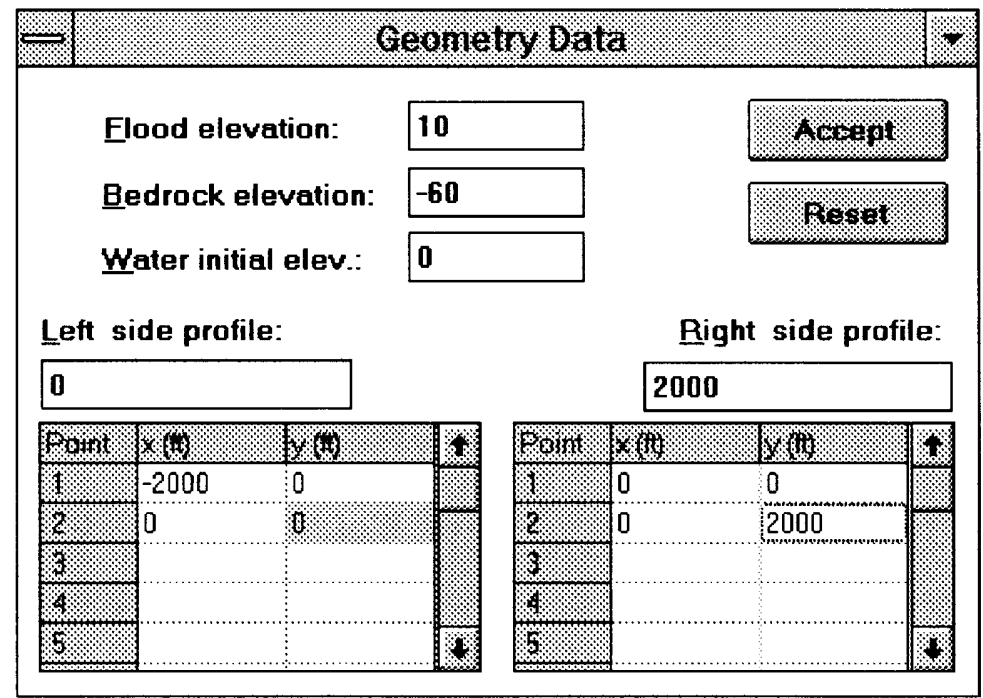

Type 10 and Tab. We are at the "Bedrock elevation." Type -60 and Tab. Then at the "Water initial elevation," type 0 and Tab. The zero initial water elevation signifies that the water was at the ground surface before the flood started. The last Tab bought us to the grid for left surface profile. Type $\mathbf{- 2 0 0 0}$ 
and ENTER, cursor right to move to the $y$-coordinate column, type $\mathbf{0}$, and ENTER. Move to the next row by any cursor key (or clicking by the mouse). The left ground surface profile consists of a horizontal line, starting from a faraway point $(609.6 \mathrm{~m}(2000 \mathrm{ft}))$ to the origin at the wall $(0,0)$. Enter the coordinates $\mathbf{0}$, and $\mathbf{0}$.

The Geometry Data window should now look like the sample.

To register the data just entered, press Accept. Now it is official.

Now a new window pops up: the Profile Plot Window:

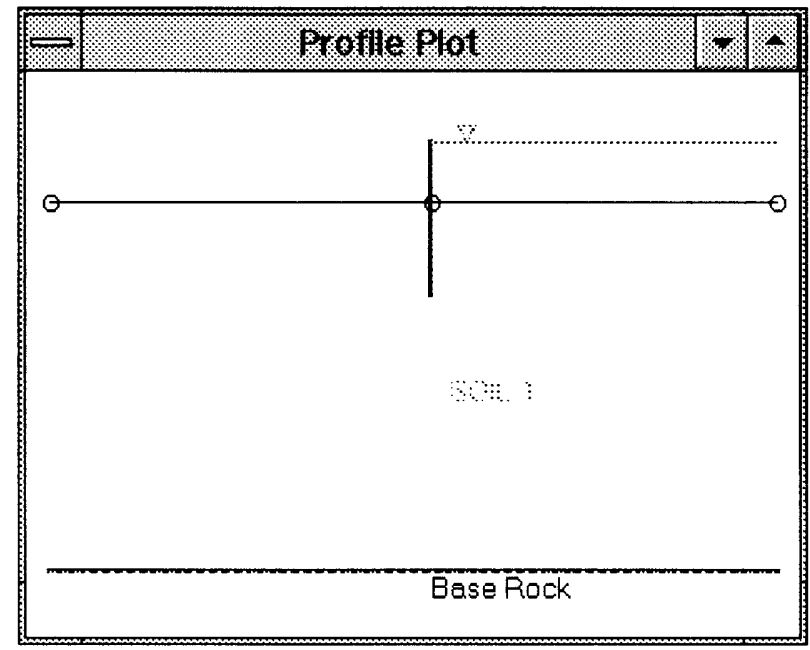

At this point it might be a good time to save the data to a disk file after spending so much time entering it. It is a good idea to save it even if something might be wrong in the data (especially if there is something wrong).

\section{Clicking on the Profile}

Clicking on the Profile with the right mouse button shows the coordinates of the point clicked in a pop-up window. This may be useful to check at the elevation of various points quickly.

Clicking on the Profile with the left mouse button will draw a red rectangle around the profile plot. This feature makes the mouse buttons consistent with the mouse behavior over the other graphs in the program. Currently no copying function is provided for the profile.

\section{Data entry for anchored wall case}

The data entry for an anchored retaining wall is only slightly different from that of a floodwall problem. The Wall Data and Soil Data windows are exactly the same, and they work the same way. The only data entry window that is 
different is the Geometry Data window. The grids are also the same as the floodwall case, but the text entry boxes in the upper part are different.

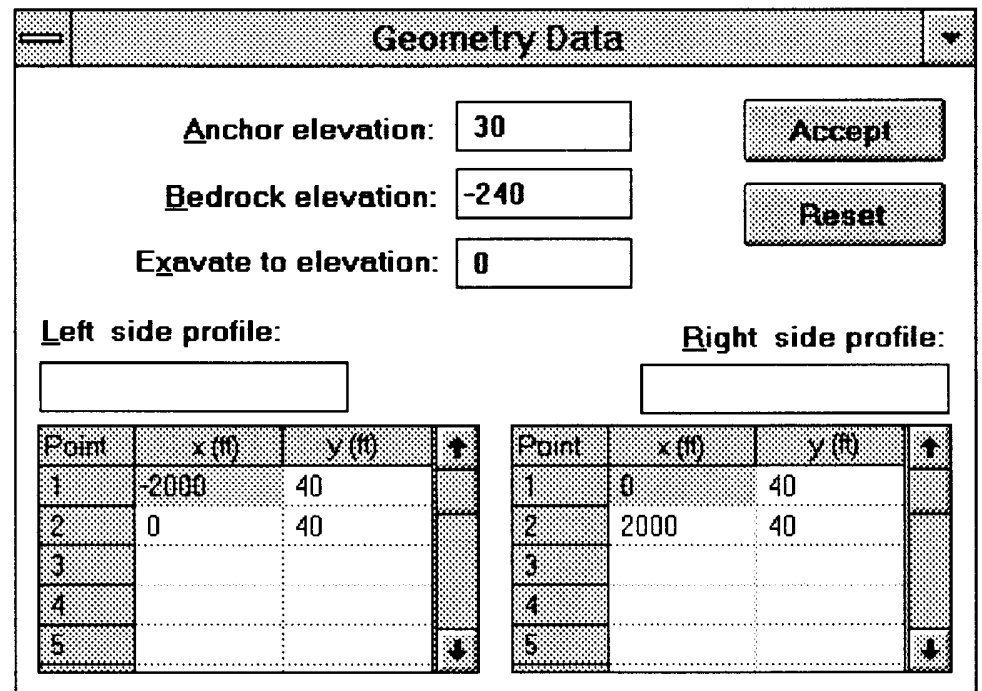

Note that in this case two text boxes are labeled Anchor Elevation and Excavate to Elevation (in the floodwall case, one is labeled "Initial Water Level" and the other is not there). In entering data in these boxes, the most important thing to keep in mind is that the same $y$-axis is used for these quantities as the one used for entering the soil profile, etc. A common pitfall is to enter the depth of excavation instead of the elevation of the bottom of excavation.

\section{Example 2: Loading and Saving Data Files}

\section{Saving the data entered}

Steps for saving data. To save, the steps are as follows:

a. Click File on the top menu bar.

$b$. Select Save from the drop-down menu.

c. When the dialog box appears, type a filename, say WORK1.SRD

d. Press OK.

(The keyboard shortcut for File + Save is Ctrl + S.)

SRD is short for Shear Ring Data. Although you do not have to use this extension, it is recommended that you do, since opening that file later will be easier. 
Data file sample. The file is saved in simple ASCII format as shown in the following example (which is the data file for Example Problem \#1). The data file can contain any number of comments anywhere (except in the middle of a table of numbers). A comment line is identified by a single quote sign.

The file format is quite "free" in the sense that it is labeled and this allows any sequence, generally, to be acceptable. The only required line is the first line, which is an identification of what it is and the version number. The version number is included for compatibility of old data files in future releases of the program (it is the version of the data file format and not of RingWall).

Although the format of the data file is quite simple, editing this file "manually," i.e., using a text editor, is not recommended.

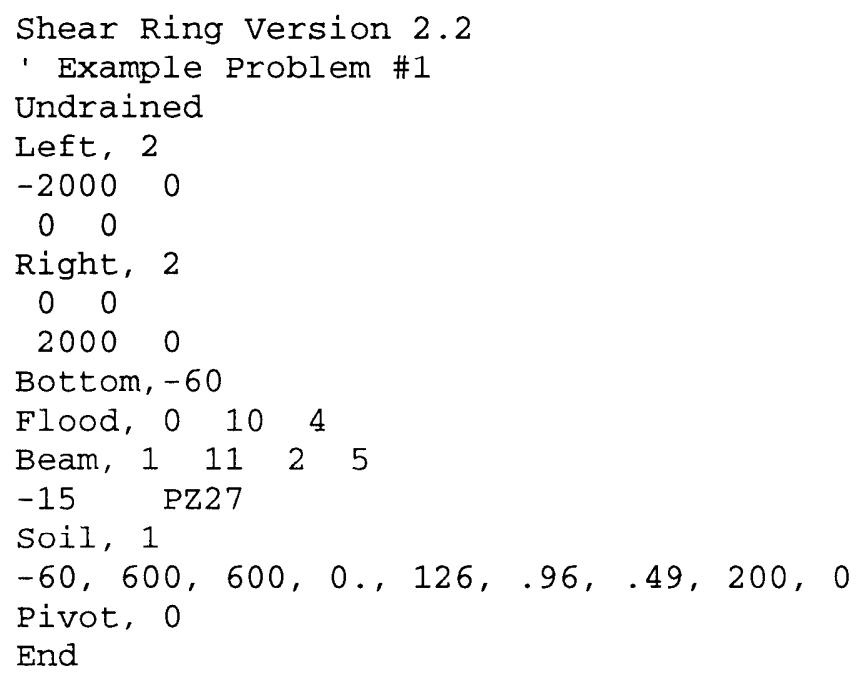

\section{Loading previously saved data (open)}

To bring back the data for a previously saved problem, the steps are as follows:

a. Click File on the top menu bar.

b. Select Open from the drop-down menu.

c. When the dialog box appears, select the filename

d. Press OK.

(The keyboard shortcut for File + Open is Ctrl + O.)

The files with SRD extensions will be shown in the dialog box to make the selection of the file easier. 
When the data are read from the file the profile is plotted if the profile window is shown.

\section{Example 3: Printing the Data and the Profile}

\section{Opening the data file}

Open the data file saved in Example 2. The data file will be loaded and the profile plotted.

\section{Setting the print options}

Select "Print..." from File menu. This will bring up the Printing Options dialog box (the keyboard shortcut for File + Print is Ctrl $+\mathbf{P}$ ).

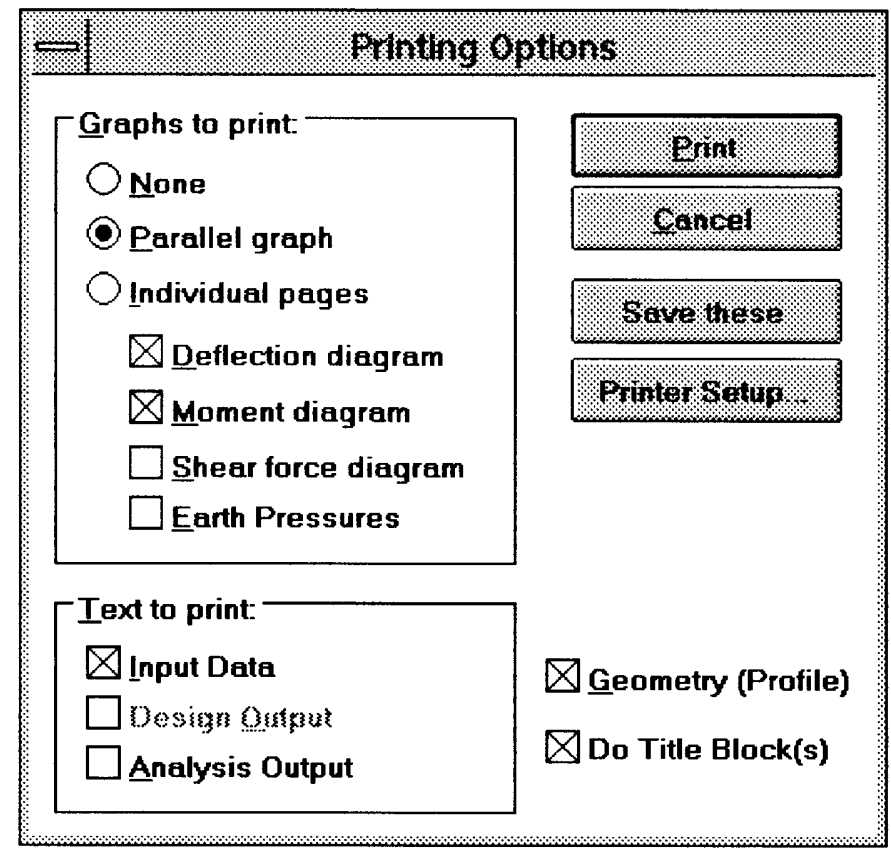

The options may seem overwhelming at first, but they are, basically, three types:

a. The plot of the geometry (or the profile).

b. The plots of displacement, etc.

c. Input and output texts.

The second group is available only if an analysis has been performed. These options are not available at this point (in the current exercise) because analysis has not been performed yet; so there is nothing to plot. 


\section{Printing the data file}

First print the input data. Uncheck all the boxes except the "Input data" checkbox. Then press the "Print" button. The mouse pointer will turn to an hourglass shape to show that the computer is busy. Then the printer will start printing. The data listing is quite similar to the actual data file saved, but this one is annotated with more labels (data file is labeled, too, but it is slightly more strictly formatted):

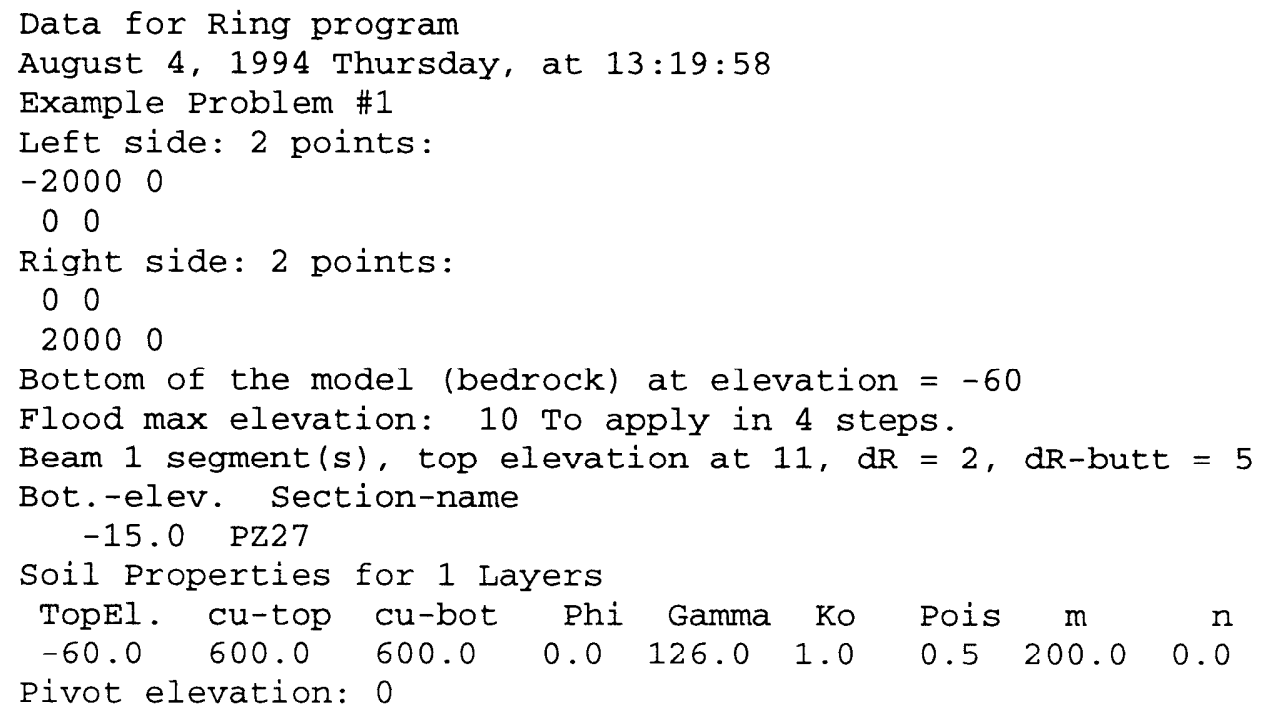

The pivot elevation is shown as zero in the example. This is because an analysis of the problem has not been performed yet, and the pivot elevation is set at that time.

\section{Printing the profile plot}

During printing the mouse pointer is turned to an hourglass shape. When the mouse pointer returns to normal, select File + Print again (or press $\mathbf{C t r l}+\mathbf{P}$ ). Then check the box labeled "Geometry," and uncheck the "Input Data" checkbox. Then press the "Print" button. The printing of the profile plot may take from a few seconds to a few minutes depending on the computer and the printer you are using.

\section{Rules and recommendations}

On options. It is recommended that you start with simpler printer outputs and try more complex ones progressively. In general, graphs are harder on the computer and the printer as well as the software. This is made even harder by a title block. You might want to start with just the data file listing, and then try the profile plot without a title block, and so on. 
Multiple selections. It is possible to plot one thing at a time or make all the selections and print all at once. But, at least for the first time, the simpler, one-ata-time procedure is recommended. The profile plot is always printed on a separate page.

The title block. Whether or not the title blocks are put on the printed plots is controlled by the status of the "Do Title Block(s)" check box. But how the title block looks and exactly how it is filled depends on the customization of RingWall. The easiest way to customize the program is to use the Customize utility. This program can be run separately. It can also be accessed from within RingWall main program (Action + Customize command).

\section{Example 4: Analyzing the Problem}

\section{Starting the analysis}

On the top menu bar of the main screen, click on Action. From the dropdown menu, select Analyze. The Analysis Options dialog box will be shown.

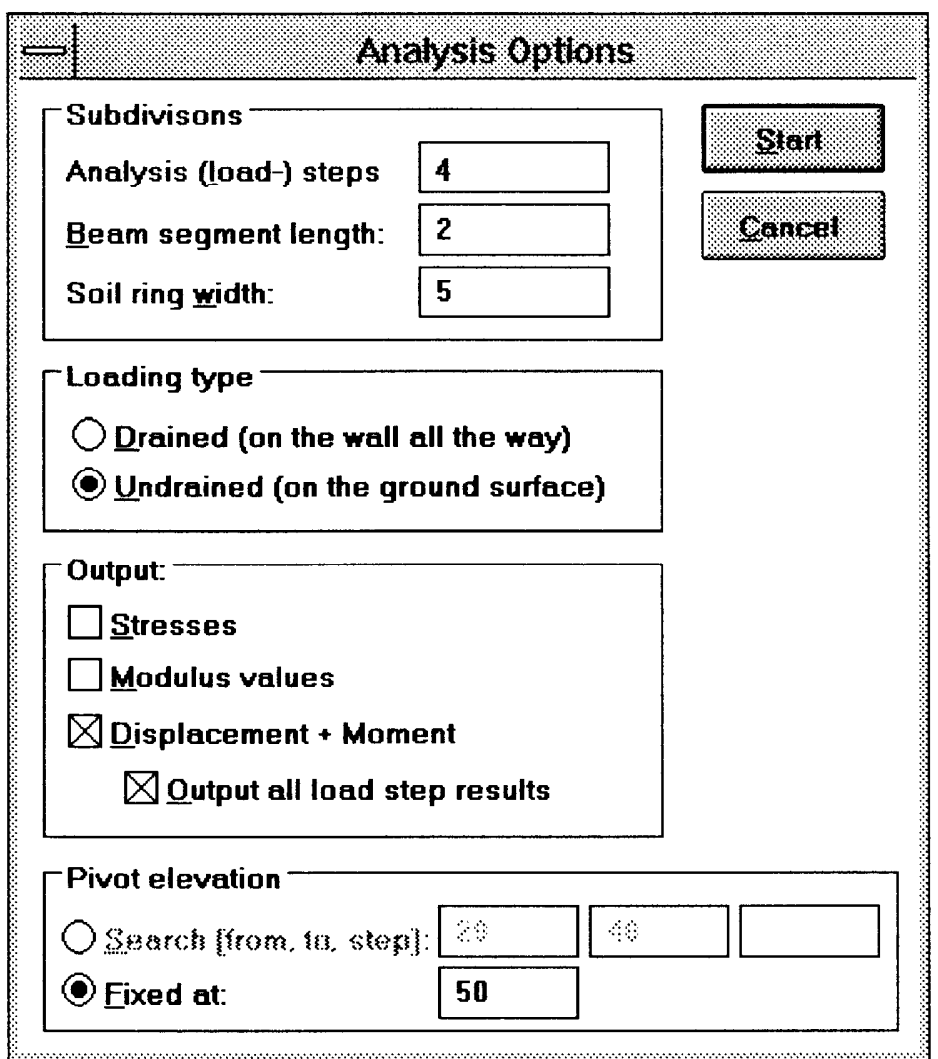




\section{Meaning of the analysis options}

Subdivisions group. The following options for subdividing and refining the analysis are available:

a. Analysis (or load) steps: This is required for simulation of the rise in the floodwater level (for the floodwall case) or the removal of layers of soil during an excavation (for the anchored wall case). Nonlinearity of the soil stress-strain relationship is simulated by an incremental procedure. The number of analysis steps depends on the problem; therefore, it may be determined by trial and error. Theoretically, the larger the number of steps, the better is the nonlinear simulation. As a general guide it should be noted that five to ten steps would work fine in most cases.

b. Beam segment length: The shorter (larger number of) beam segments, the better. The typical range is 0.3 to $1.5 \mathrm{~m}$ ( 1 to $5 \mathrm{ft}) ; 0.6$ or $0.9 \mathrm{~m}$ ( 2 or $3 \mathrm{ft}$ ) should be satisfactory in most cases.

c. Soil ring width: This is for the soil subdivision below the tip of the pile. Larger widths can be taken in this region (compared with the beam segment length) to economize the solution.

d. Output all load step results: This box can be checked if you wish to study the development of the wall behavior (say, deflection) as water level increases or as an excavation progresses.

Loading type options group. The following options are available:

a. (Drained/undrained) options: For soil profiles that consist of predominantly clayey soils, the undrained condition will prevail for the short duration of a flood or an excavation. However, the drained case should also be checked for long-term conditions in a permanent structure, even if the soils are clayey. For profiles that are predominantly cohesionless (sand and gravel), only drained conditions should be used.

b. Defaults: In RingWall the defaults are chosen with respect to the properties of the top soil layer. If the top layer is cohesive it is taken as undrained, and if cohesionless, it is taken as drained. However, this option should be selected by the engineer. The default is selected only because the program cannot work without making this selection.

Output options group. The following output options are available.

a. (Stresses, Modulus values, Displacements and Moments): These options control the amount of detail presented at the end of the analysis. An item checked will produce a table for the corresponding quantity.

b. Pivot elevation options: A reasonable pivot location is estimated by the program and shown in the "Fixed at" option text box. It is best to use this value, but it can be changed within the reasonable range of 3 to 
$30.5 \mathrm{~m} \mathrm{(10} \mathrm{to} 100 \mathrm{ft})$ above the top of the wall to study the effect of this assumption.

The meaning and the use of all the analysis options are explained in greater detail in Chapter 2.

\section{Analysis action}

The wall can now be analyzed for the design-basis flood. Assuming that you like all the options shown, press Start. RingWall will rearrange the scene for the action, and then ask for a file name for saving the results of the analysis. Give a file name, say WORK1.SRO (SRO is for "Shear Ring Output").

The analysis will take a few seconds. During this time the progress will be reported in a status box.

As a result of this action there will be two new windows: one is the text output, the Analysis Results window, and the other is the Plots window. The Plots window should look something like the following sample. You may have to bring the graphs window forward (normally, it is minimized; double-click on its icon).

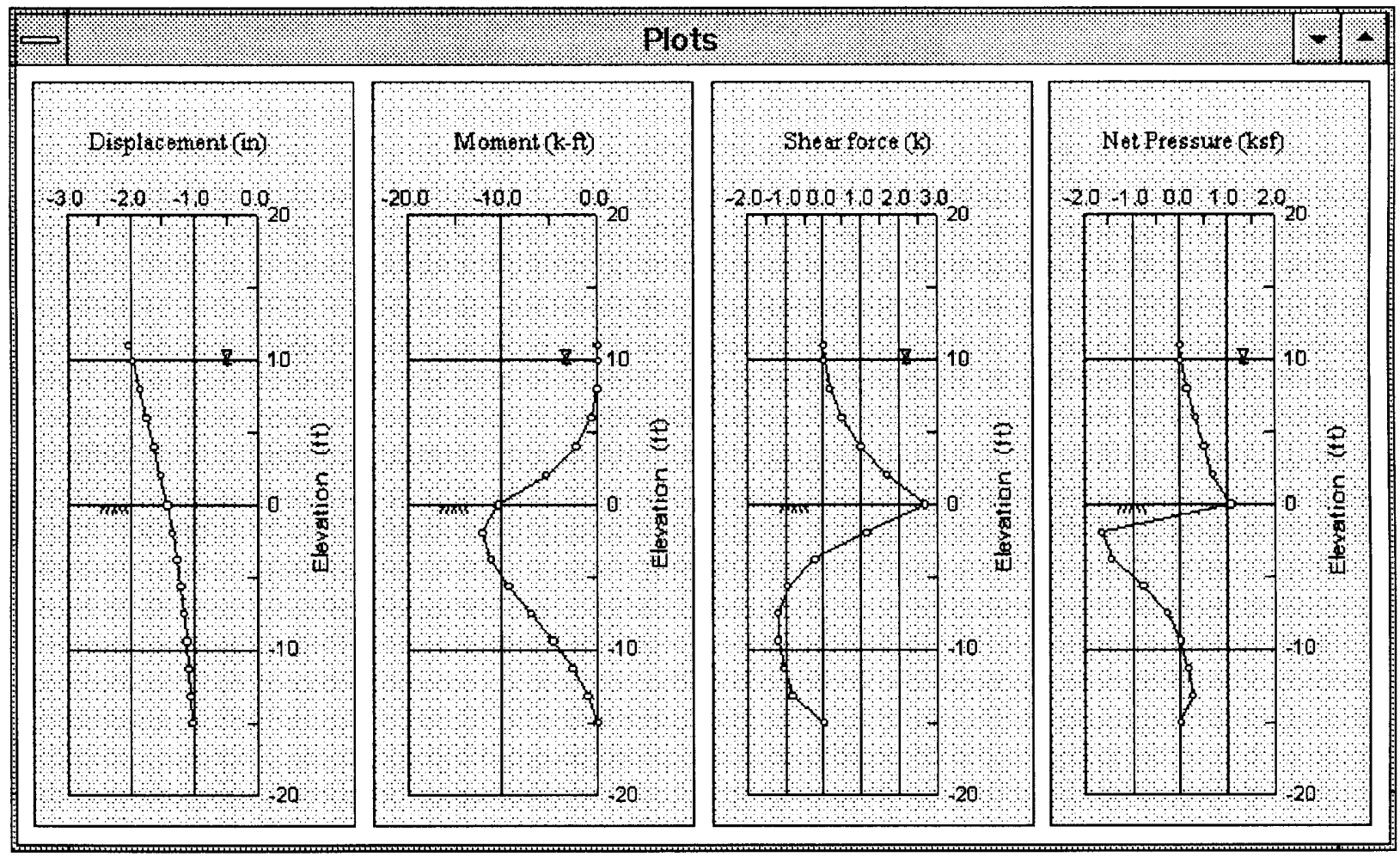

Notice how the wall deflects, and what the moment diagram looks like. The wall deflects approximately $50.8 \mathrm{~mm}(2 \mathrm{in}$.) at the top and $25.4 \mathrm{~mm}(1 \mathrm{in}$.) at the bottom. The entire system moves by about $25.4 \mathrm{~mm}$ ( 1 in.), and the wall deflects another $25.4 \mathrm{~mm}$ ( $1 \mathrm{in}$.) due to the deformation of the backfill and the front soil. 
Therefore, it may be said that half of the wall deflection is due to the local phenomena while the other half is due to the overall deformation. The bending moment has the same sign throughout. The wall is bent the same way all the way in this example, but it is not always so.

\section{Example 5: Printing the Results and Graphs}

\section{Setting the print options}

Now we have a great deal of items to print in our example problem. Select "Print..." from File menu to get the Printing Options dialog box. First, set the options to indicate what types of print outputs are required. The options available now include plots (graphs) in addition to geometry and input and output texts. The graphs are plots of displacement, moment, shear force, and net earth pressures.

The graphs are shown side by side in the Plots window. However, they are not necessarily printed the same way. You select the plot options to indicate how you want the printout to look.

The plot options include which ones to print and whether to print them side by side "parallel" or on individual pages. It is also possible to plot two of the graphs on one page and the other two on another, but this can be done only "manually" (that is printing twice and setting different options each time).

\section{Printing exercises}

For this exercise, select a Parallel plot of all graphs, and the Output text. Press OK. The printing of graphs may take a few minutes, depending on the printer and the number of requests made.

A printout sample. The printout of the analysis results for Example Problem \#1 is given in the following sample:

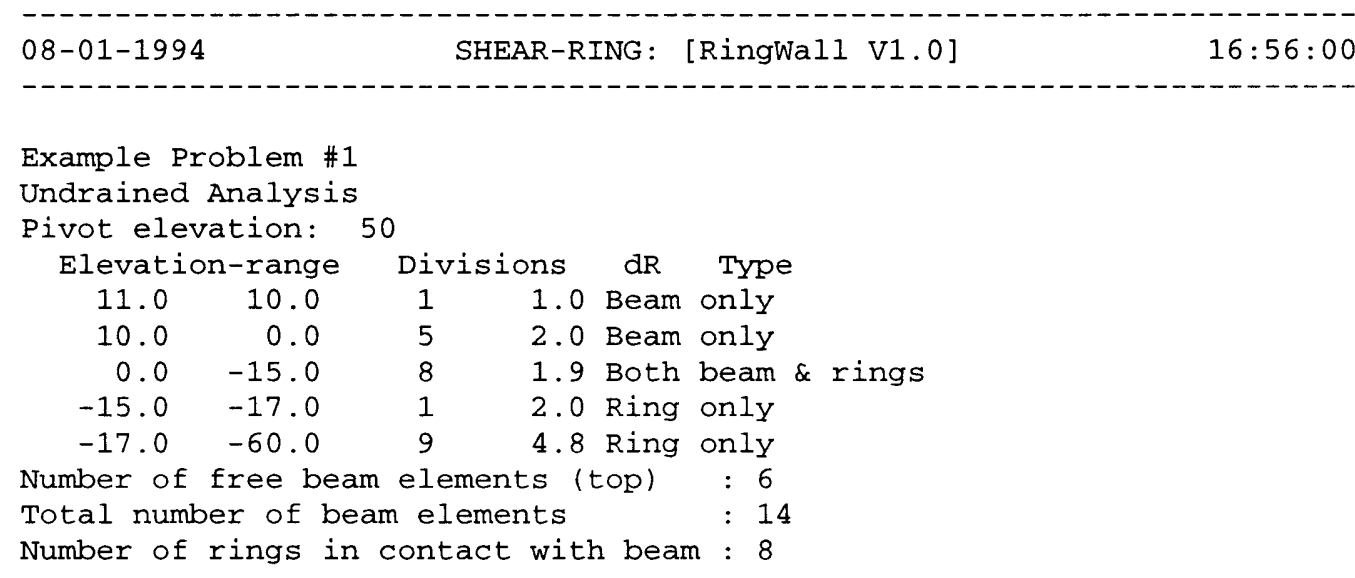




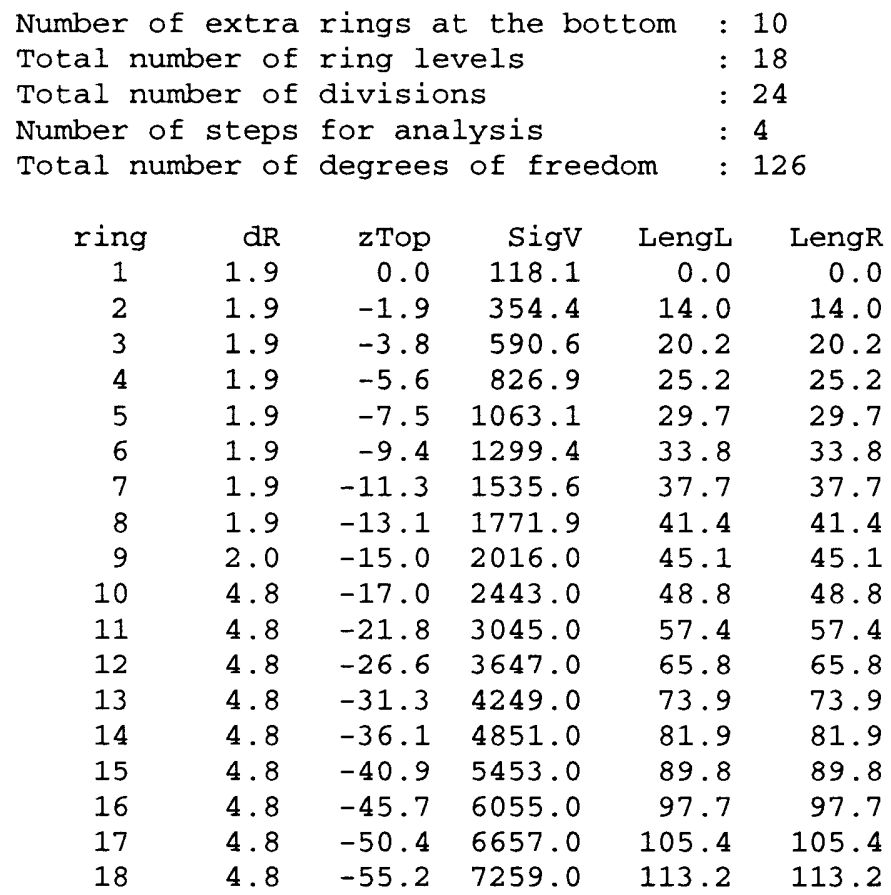

Initial conditions:

\begin{tabular}{|c|c|c|c|c|c|c|}
\hline \multicolumn{7}{|c|}{ begree of mobilization } \\
\hline$z$-top & $f-L$ & $f-C$ & $f-R$ & $E-L$ & $f-C$ & $f-R$ \\
\hline 0.0 & 0.00 & 0.00 & 0.00 & 0.00 & 0.00 & 0.00 \\
\hline-1.9 & 0.00 & 0.01 & 0.01 & 0.01 & 0.01 & 0.00 \\
\hline-3.8 & 0.00 & 0.01 & 0.02 & 0.02 & 0.01 & 0.00 \\
\hline-5.6 & 0.00 & 0.02 & 0.03 & 0.03 & 0.02 & 0.00 \\
\hline-7.5 & 0.00 & 0.03 & 0.04 & 0.04 & 0.03 & 0.00 \\
\hline-9.4 & 0.00 & 0.03 & 0.04 & 0.04 & 0.03 & 0.00 \\
\hline-11.3 & 0.00 & 0.04 & 0.05 & 0.05 & 0.04 & 0.00 \\
\hline-13.1 & 0.00 & 0.04 & 0.06 & 0.06 & 0.04 & 0.00 \\
\hline-15.0 & 0.00 & 0.05 & 0.07 & 0.07 & 0.05 & 0.00 \\
\hline-17.0 & 0.00 & 0.06 & 0.08 & 0.08 & 0.06 & 0.00 \\
\hline-21.8 & 0.00 & 0.07 & 0.10 & 0.10 & 0.07 & 0.00 \\
\hline-26.6 & 0.00 & 0.09 & 0.12 & 0.12 & 0.09 & 0.00 \\
\hline-31.3 & 0.00 & 0.10 & 0.14 & 0.14 & 0.10 & 0.00 \\
\hline-36.1 & 0.00 & 0.12 & 0.16 & 0.16 & 0.12 & 0.0 \\
\hline-40.9 & 0.00 & 0.13 & 0.18 & 0.18 & 0.13 & 0.00 \\
\hline-45.7 & 0.00 & 0.15 & 0.20 & 0.20 & 0.15 & 0.00 \\
\hline 50.4 & 0.00 & 0.16 & 0.22 & 0.22 & 0.16 & 0.00 \\
\hline-55.2 & 0.00 & 0.18 & 0.24 & 0.24 & 0.18 & 0.0 \\
\hline
\end{tabular}

Initial moduli in the rings $G$ moduli left

H moduli right

\begin{tabular}{|c|c|c|c|c|c|c|}
\hline ring & free & center & pile & pile & center & free \\
\hline 1.0 & 55.4 & 55.3 & 55.2 & 256.2 & 246.5 & 217.3 \\
\hline 2.0 & 55.4 & 54.9 & 54.8 & 333.1 & 304.2 & 217.3 \\
\hline 3.0 & 55.4 & 54.6 & 54.3 & 408.7 & 361.1 & 217.3 \\
\hline 4.0 & 55.4 & 54.3 & 53.9 & 483.1 & 417.1 & 217.3 \\
\hline 5.0 & 55.4 & 54.0 & 53.5 & 556.1 & 472.3 & 217.3 \\
\hline 6.0 & 55.4 & 53.7 & 53.0 & 628.0 & 526.6 & 217.3 \\
\hline 7.0 & 55.4 & 53.3 & 52.6 & 698.6 & 580.2 & 217.3 \\
\hline 8.0 & 55.4 & 53.0 & 52.2 & 767.9 & 633.0 & 217.3 \\
\hline 9.0 & 55.4 & 52.7 & 51.7 & 838.2 & 686.7 & 217.3 \\
\hline
\end{tabular}




$\begin{array}{rrrrrrr}10.0 & 55.4 & 52.1 & 50.9 & 957.9 & 778.7 & 217.3 \\ 11.0 & 55.4 & 51.3 & 49.8 & 1119.8 & 904.3 & 217.3 \\ 12.0 & 55.4 & 50.5 & 48.7 & 1273.5 & 1025.1 & 217.3 \\ 13.0 & 55.4 & 49.7 & 47.6 & 1419.0 & 1141.2 & 217.3 \\ 14.0 & 55.4 & 48.9 & 46.5 & 1556.4 & 1252.8 & 217.3 \\ 15.0 & 55.4 & 48.0 & 45.4 & 1685.6 & 1359.8 & 217.3 \\ 16.0 & 55.4 & 47.2 & 44.3 & 1806.6 & 1462.3 & 217.3 \\ 17.0 & 55.4 & 46.4 & 43.1 & 1919.5 & 1560.4 & 217.3 \\ 18.0 & 55.4 & 45.6 & 42.0 & 2024.2 & 1654.2 & 217.3\end{array}$

$===$ Operation step $===1$

\begin{tabular}{rccccrr}
$\begin{array}{c}\text { Elevation } \\
\text { (ft) }\end{array}$ & $\begin{array}{c}\text { d-left } \\
\text { (inch) }\end{array}$ & $\begin{array}{c}\text { d-beam } \\
\text { (inch) }\end{array}$ & $\begin{array}{c}\text { d-right } \\
\text { (inch) }\end{array}$ & $\begin{array}{c}\text { Moment } \\
\text { (k-ft) }\end{array}$ & $\begin{array}{c}\text { Shear } \\
\text { (kip) }\end{array}$ & \multicolumn{1}{c}{$\begin{array}{c}\text { Net Pres. } \\
\text { (ksf) }\end{array}$} \\
11.0 & $0.000 \mathrm{E}+00$ & $2.728 \mathrm{E}-01$ & $0.000 \mathrm{E}+00$ & $-7.047 \mathrm{E}-13$ & $0.000 \mathrm{E}+00$ & $0.000 \mathrm{E}+00$ \\
10.0 & $0.000 \mathrm{E}+00$ & $2.710 \mathrm{E}-01$ & $0.000 \mathrm{E}+00$ & $-3.570 \mathrm{E}-16$ & $-1.175 \mathrm{E}-12$ & $-1.175 \mathrm{E}-12$ \\
8.0 & $0.000 \mathrm{E}+00$ & $2.673 \mathrm{E}-01$ & $0.000 \mathrm{E}+00$ & $2.147 \mathrm{E}-14$ & $-6.875 \mathrm{E}-14$ & $1.106 \mathrm{E}-12$ \\
6.0 & $0.000 \mathrm{E}+00$ & $2.637 \mathrm{E}-01$ & $0.000 \mathrm{E}+00$ & $4.421 \mathrm{E}-14$ & $-4.601 \mathrm{E}-14$ & $2.274 \mathrm{E}-14$ \\
4.0 & $0.000 \mathrm{E}+00$ & $2.601 \mathrm{E}-01$ & $0.000 \mathrm{E}+00$ & $1.514 \mathrm{E}-13$ & $5.200 \mathrm{E}-03$ & $5.200 \mathrm{E}-03$ \\
2.0 & $0.000 \mathrm{E}+00$ & $2.564 \mathrm{E}-01$ & $0.000 \mathrm{E}+00$ & $-2.080 \mathrm{E}-02$ & $5.720 \mathrm{E}-02$ & $5.200 \mathrm{E}-02$ \\
0.0 & $2.263 \mathrm{E}-01$ & $2.529 \mathrm{E}-01$ & $2.818 \mathrm{E}-01$ & $-2.288 \mathrm{E}-01$ & $1.789 \mathrm{E}-01$ & $1.298 \mathrm{E}-01$ \\
-1.9 & $2.263 \mathrm{E}-01$ & $2.498 \mathrm{E}-01$ & $3.073 \mathrm{E}-01$ & $-3.136 \mathrm{E}-01$ & $3.099 \mathrm{E}-03$ & $-1.875 \mathrm{E}-01$ \\
-3.8 & $2.249 \mathrm{E}-01$ & $2.470 \mathrm{E}-01$ & $3.206 \mathrm{E}-01$ & $-2.404 \mathrm{E}-01$ & $-5.139 \mathrm{E}-02$ & $-5.812 \mathrm{E}-02$ \\
-5.6 & $2.230 \mathrm{E}-01$ & $2.445 \mathrm{E}-01$ & $3.288 \mathrm{E}-01$ & $-1.209 \mathrm{E}-01$ & $-6.107 \mathrm{E}-02$ & $-1.032 \mathrm{E}-02$ \\
-7.5 & $2.207 \mathrm{E}-01$ & $2.422 \mathrm{E}-01$ & $3.339 \mathrm{E}-01$ & $-1.140 \mathrm{E}-02$ & $-4.824 \mathrm{E}-02$ & $1.368 \mathrm{E}-02$ \\
-9.4 & $2.179 \mathrm{E}-01$ & $2.398 \mathrm{E}-01$ & $3.367 \mathrm{E}-01$ & $6.001 \mathrm{E}-02$ & $-2.505 \mathrm{E}-02$ & $2.474 \mathrm{E}-02$ \\
-11.3 & $2.147 \mathrm{E}-01$ & $2.374 \mathrm{E}-01$ & $3.378 \mathrm{E}-01$ & $8.253 \mathrm{E}-02$ & $5.486 \mathrm{E}-04$ & $2.730 \mathrm{E}-02$ \\
-13.1 & $2.110 \mathrm{E}-01$ & $2.349 \mathrm{E}-01$ & $3.373 \mathrm{E}-01$ & $5.796 \mathrm{E}-02$ & $2.201 \mathrm{E}-02$ & $2.289 \mathrm{E}-02$ \\
-15.0 & $2.070 \mathrm{E}-01$ & $2.324 \mathrm{E}-01$ & $3.356 \mathrm{E}-01$ & $0.000 \mathrm{E}+00$ & $0.000 \mathrm{E}+00$ & $0.000 \mathrm{E}+00$
\end{tabular}

$===$ Operation step $===2$

\begin{tabular}{rccccrr}
$\begin{array}{c}\text { Elevation } \\
\text { (ft) }\end{array}$ & $\begin{array}{c}\text { d-left } \\
\text { (inch) }\end{array}$ & $\begin{array}{c}\text { d-beam } \\
\text { (inch) }\end{array}$ & $\begin{array}{c}\text { d-right } \\
\text { (inch) }\end{array}$ & $\begin{array}{c}\text { Moment } \\
(\mathrm{k}-\mathrm{ft})\end{array}$ & $\begin{array}{r}\text { Shear } \\
\text { (kip) }\end{array}$ & \multicolumn{1}{c}{$\begin{array}{r}\text { Net Pres. } \\
\text { (ksf) }\end{array}$} \\
11.0 & $0.000 \mathrm{E}+00$ & $6.547 \mathrm{E}-01$ & $0.000 \mathrm{E}+00$ & $1.495 \mathrm{E}-13$ & $0.000 \mathrm{E}+00$ & $0.000 \mathrm{E}+00$ \\
10.0 & $0.000 \mathrm{E}+00$ & $6.455 \mathrm{E}-01$ & $0.000 \mathrm{E}+00$ & $1.721 \mathrm{E}-13$ & $1.727 \mathrm{E}-13$ & $1.727 \mathrm{E}-13$ \\
8.0 & $0.000 \mathrm{E}+00$ & $6.269 \mathrm{E}-01$ & $0.000 \mathrm{E}+00$ & $1.539 \mathrm{E}-13$ & $-4.779 \mathrm{E}-13$ & $-6.506 \mathrm{E}-13$ \\
6.0 & $0.000 \mathrm{E}+00$ & $6.084 \mathrm{E}-01$ & $0.000 \mathrm{E}+00$ & $-7.477 \mathrm{E}-14$ & $1.040 \mathrm{E}-02$ & $1.040 \mathrm{E}-02$ \\
4.0 & $0.000 \mathrm{E}+00$ & $5.898 \mathrm{E}-01$ & $0.000 \mathrm{E}+00$ & $-4.160 \mathrm{E}-02$ & $9.100 \mathrm{E}-02$ & $8.060 \mathrm{E}-02$ \\
2.0 & $0.000 \mathrm{E}+00$ & $5.714 \mathrm{E}-01$ & $0.000 \mathrm{E}+00$ & $-3.744 \mathrm{E}-01$ & $3.276 \mathrm{E}-01$ & $2.366 \mathrm{E}-01$ \\
0.0 & $4.823 \mathrm{E}-01$ & $5.536 \mathrm{E}-01$ & $6.002 \mathrm{E}-01$ & $-1.456 \mathrm{E}+00$ & $7.602 \mathrm{E}-01$ & $4.615 \mathrm{E}-01$ \\
-1.9 & $4.795 \mathrm{E}-01$ & $5.385 \mathrm{E}-01$ & $6.507 \mathrm{E}-01$ & $-1.888 \mathrm{E}+00$ & $1.565 \mathrm{E}-01$ & $-6.440 \mathrm{E}-01$ \\
-3.8 & $4.733 \mathrm{E}-01$ & $5.254 \mathrm{E}-01$ & $6.750 \mathrm{E}-01$ & $-1.713 \mathrm{E}+00$ & $-1.277 \mathrm{E}-01$ & $-3.032 \mathrm{E}-01$ \\
-5.6 & $4.665 \mathrm{E}-01$ & $5.143 \mathrm{E}-01$ & $6.888 \mathrm{E}-01$ & $-1.307 \mathrm{E}+00$ & $-2.230 \mathrm{E}-01$ & $-1.016 \mathrm{E}-01$ \\
-7.5 & $4.593 \mathrm{E}-01$ & $5.046 \mathrm{E}-01$ & $6.964 \mathrm{E}-01$ & $-8.590 \mathrm{E}-01$ & $-2.287 \mathrm{E}-01$ & $-6.139 \mathrm{E}-03$ \\
-9.4 & $4.515 \mathrm{E}-01$ & $4.959 \mathrm{E}-01$ & $6.997 \mathrm{E}-01$ & $-4.729 \mathrm{E}-01$ & $-1.882 \mathrm{E}-01$ & $4.322 \mathrm{E}-02$ \\
-11.3 & $4.432 \mathrm{E}-01$ & $4.878 \mathrm{E}-01$ & $6.996 \mathrm{E}-01$ & $-1.968 \mathrm{E}-01$ & $-1.261 \mathrm{E}-01$ & $6.625 \mathrm{E}-02$ \\
-13.1 & $4.342 \mathrm{E}-01$ & $4.799 \mathrm{E}-01$ & $6.967 \mathrm{E}-01$ & $-4.812 \mathrm{E}-02$ & $-6.321 \mathrm{E}-02$ & $6.706 \mathrm{E}-02$ \\
-15.0 & $4.245 \mathrm{E}-01$ & $4.721 \mathrm{E}-01$ & $6.912 \mathrm{E}-01$ & $0.000 \mathrm{E}+00$ & $0.000 \mathrm{E}+00$ & $0.000 \mathrm{E}+00$
\end{tabular}

$===$ Operation step $===3$

\begin{tabular}{rccccrr}
$\begin{array}{c}\text { Elevation } \\
\text { (ft) }\end{array}$ & $\begin{array}{c}\text { d-left } \\
\text { (inch) }\end{array}$ & $\begin{array}{c}\text { d-beam } \\
\text { (inch) }\end{array}$ & $\begin{array}{c}\text { d-right } \\
\text { (inch) }\end{array}$ & $\begin{array}{c}\text { Moment } \\
\text { (k-ft) }\end{array}$ & $\begin{array}{c}\text { Shear } \\
\text { (kip) }\end{array}$ & \multicolumn{1}{c}{$\begin{array}{c}\text { Net Pres. } \\
\text { (ksf) }\end{array}$} \\
11.0 & $0.000 \mathrm{E}+00$ & $1.215 \mathrm{E}+00$ & $0.000 \mathrm{E}+00$ & $-7.893 \mathrm{E}-13$ & $0.000 \mathrm{E}+00$ & $0.000 \mathrm{E}+00$ \\
10.0 & $0.000 \mathrm{E}+00$ & $1.189 \mathrm{E}+00$ & $0.000 \mathrm{E}+00$ & $2.993 \mathrm{E}-13$ & $-8.955 \mathrm{E}-13$ & $-8.955 \mathrm{E}-13$ \\
8.0 & $0.000 \mathrm{E}+00$ & $1.137 \mathrm{E}+00$ & $0.000 \mathrm{E}+00$ & $1.499 \mathrm{E}-13$ & $1.560 \mathrm{E}-02$ & $1.560 \mathrm{E}-02$ \\
6.0 & $0.000 \mathrm{E}+00$ & $1.085 \mathrm{E}+00$ & $0.000 \mathrm{E}+00$ & $-6.240 \mathrm{E}-02$ & $1.248 \mathrm{E}-01$ & $1.092 \mathrm{E}-01$ \\
4.0 & $0.000 \mathrm{E}+00$ & $1.034 \mathrm{E}+00$ & $0.000 \mathrm{E}+00$ & $-5.200 \mathrm{E}-01$ & $4.043 \mathrm{E}-01$ & $2.795 \mathrm{E}-01$ \\
2.0 & $0.000 \mathrm{E}+00$ & $9.831 \mathrm{E}-01$ & $0.000 \mathrm{E}+00$ & $-1.851 \mathrm{E}+00$ & $8.645 \mathrm{E}-01$ & $4.602 \mathrm{E}-01$ \\
0.0 & $7.908 \mathrm{E}-01$ & $9.351 \mathrm{E}-01$ & $9.823 \mathrm{E}-01$ & $-4.555 \mathrm{E}+00$ & $1.578 \mathrm{E}+00$ & $7.607 \mathrm{E}-01$ \\
-1.9 & $7.816 \mathrm{E}-01$ & $8.951 \mathrm{E}-01$ & $1.058 \mathrm{E}+00$ & $-5.530 \mathrm{E}+00$ & $5.387 \mathrm{E}-01$ & $-1.108 \mathrm{E}+00$
\end{tabular}




\begin{tabular}{|c|c|c|c|c|c|c|}
\hline-3.8 & $7.667 \mathrm{E}-01$ & $8.611 \mathrm{E}-01$ & $1.091 \mathrm{E}+00$ & $-5.114 E+00$ & $-2.050 \mathrm{E}-01$ & $-7.933 E-01$ \\
\hline-5.6 & $7.515 \mathrm{E}-01$ & $8.328 \mathrm{E}-01$ & $1.107 \mathrm{E}+00$ & $-4.126 \mathrm{E}+00$ & $-5.165 E-01$ & $-3.322 \mathrm{E}-01$ \\
\hline-7.5 & $7.357 E-01$ & $8.092 \mathrm{E}-01$ & $1.114 \mathrm{E}+00$ & $-2.980 E+00$ & $-5.953 E-01$ & $-8.402 E-02$ \\
\hline-9.4 & $7.198 E-01$ & $7.890 \mathrm{E}-01$ & $1.115 \mathrm{E}+00$ & $-1.907 E+00$ & $-5.538 E-01$ & $4.423 E-02$ \\
\hline-11.3 & $7.036 E-01$ & $7.710 \mathrm{E}-01$ & $1.111 \mathrm{E}+00$ & $-1.023 E+00$ & $-4.493 \mathrm{E}-01$ & 1. $115 \mathrm{E}-01$ \\
\hline-13.1 & $6.868 E-01$ & $7.542 \mathrm{E}-01$ & $1.103 E+00$ & $-3.864 E-01$ & $-3.150 E-01$ & 1. $433 \mathrm{E}-01$ \\
\hline-15.0 & $6.695 \mathrm{E}-01$ & $7.379 \mathrm{E}-01$ & $1.092 \mathrm{E}+00$ & $0.000 \mathrm{E}+00$ & $0.000 \mathrm{E}+00$ & $0.000 \mathrm{E}+00$ \\
\hline \multicolumn{2}{|c|}{$===$ Operation step } & 4 & & & & \\
\hline \multicolumn{2}{|l|}{ Elevation } & $\begin{array}{l}\text { d-beam } \\
\text { (inch) }\end{array}$ & $\begin{array}{r}\text { d-right } \\
\text { (inch) }\end{array}$ & $\begin{array}{c}\text { Moment } \\
(k-f t)\end{array}$ & $\begin{array}{l}\text { Shear } \\
\text { (kip) }\end{array}$ & $\begin{array}{c}\text { Net Pres. } \\
(\text { ksf })\end{array}$ \\
\hline 11.0 & $0.000 \mathrm{E}+00$ & $2.035 E+00$ & $0.000 \mathrm{E}+00$ & $5.474 \mathrm{E}-13$ & $0.000 E+00$ & $0.000 \mathrm{E}+00$ \\
\hline 10.0 & $0.000 \mathrm{E}+00$ & $1.978 \mathrm{E}+00$ & $0.000 \mathrm{E}+00$ & $1.810 \mathrm{E}-13$ & $1.387 \mathrm{E}-02$ & $1.387 \mathrm{E}-02$ \\
\hline 8.0 & $0.000 E+00$ & $1.864 \mathrm{E}+00$ & $0.000 \mathrm{E}+00$ & $-8.320 E-02$ & 1. $586 \mathrm{E}-01$ & 1. $447 \mathrm{E}-01$ \\
\hline 6.0 & $0.000 E+00$ & $1.750 \mathrm{E}+00$ & $0.000 \mathrm{E}+00$ & $-6.656 E-01$ & $4.810 E-01$ & 3. $224 \mathrm{E}-01$ \\
\hline 4.0 & $0.000 \mathrm{E}+00$ & $1.638 \mathrm{E}+00$ & $0.000 \mathrm{E}+00$ & $-2.246 E+00$ & $9.821 \mathrm{E}-01$ & $5.011 \mathrm{E}-01$ \\
\hline 2.0 & $0.000 \mathrm{E}+00$ & 1. $529 \mathrm{E}+00$ & $0.000 \mathrm{E}+00$ & $-5.325 E+00$ & $1.664 \mathrm{E}+00$ & $6.819 \mathrm{E}-01$ \\
\hline 0.0 & $1.163 \mathrm{E}+00$ & 1. $427 \mathrm{E}+00$ & 1. $449 \mathrm{E}+00$ & $-1.040 E+01$ & $2.668 \mathrm{E}+00$ & $1.071 \mathrm{E}+00$ \\
\hline-1.9 & $1.143 \mathrm{E}+00$ & 1. $342 \mathrm{E}+00$ & $1.549 \mathrm{E}+00$ & $-1.210 E+01$ & 1. $133 \mathrm{E}+00$ & $-1.638 E+00$ \\
\hline-3.8 & $1.114 \mathrm{E}+00$ & $1.272 E+00$ & $1.586 \mathrm{E}+00$ & $-1.124 E+01$ & $-2.152 \mathrm{E}-01$ & $-1.438 \mathrm{E}+00$ \\
\hline-5.6 & $1.086 \mathrm{E}+00$ & $1.213 E+00$ & $1.599 E+00$ & $-9.263 E+00$ & $-9.406 E-01$ & $-7.737 E-01$ \\
\hline-7.5 & $1.057 \mathrm{E}+00$ & $1.166 E+00$ & $1.601 \mathrm{E}+00$ & $-6.929 E+00$ & $-1.195 E+00$ & $-2.713 E-01$ \\
\hline-9.4 & $1.029 E+00$ & $1.126 \mathrm{E}+00$ & $1.594 \mathrm{E}+00$ & $-4.647 E+00$ & $-1.194 E+00$ & $1.041 \mathrm{E}-03$ \\
\hline-11.3 & $1.002 \mathrm{E}+00$ & $1.091 \mathrm{E}+00$ & $1.582 \mathrm{E}+00$ & $-2.649 E+00$ & $-1.049 E+00$ & $1.549 \mathrm{E}-01$ \\
\hline-13.1 & $9.733 \mathrm{E}-01$ & $1.060 \mathrm{E}+00$ & $1.566 \mathrm{E}+00$ & $-1.075 E+00$ & $-8.158 E-01$ & $2.483 \mathrm{E}-01$ \\
\hline-15.0 & $9.458 E-01$ & $1.029 \mathrm{E}+00$ & $1.546 \mathrm{E}+00$ & $0.000 E+00$ & $0.000 E+00$ & $0.000 \mathrm{E}+00$ \\
\hline- & & & & VI & & 5 \\
\hline
\end{tabular}

The text output can be shorter or longer than this, depending on the selections made in the Analysis Options dialog box.

Changing the font of printouts. The actual font and character sizes used in these outputs depend on the selections made in Customize utility. Customize can be brought up from within RingWall by selecting Action + Customize command.

Once in Customize utility, select the Print Options in the main screen. Then select the Text Output fonts. You should have installed fonts in Windows to be able to utilize these options. To be able to use different character sizes of any typeface you should have scalable typefaces installed on your system.

One important point should be mentioned here. You should select an equally spaced typeface for text output. Otherwise the columns of numbers will not align. The typeface used in the examples here is Courier New (the scalable, TrueType version of Courier). 


\section{Example 6: Clipboard Operations}

\section{The problem}

Example Problem \#2 will be used for this exercise. Example Problem \#1 could also be used, but this new problem is preferred because it has several interesting aspects. The data file (WORK2.SRD) contains the following.

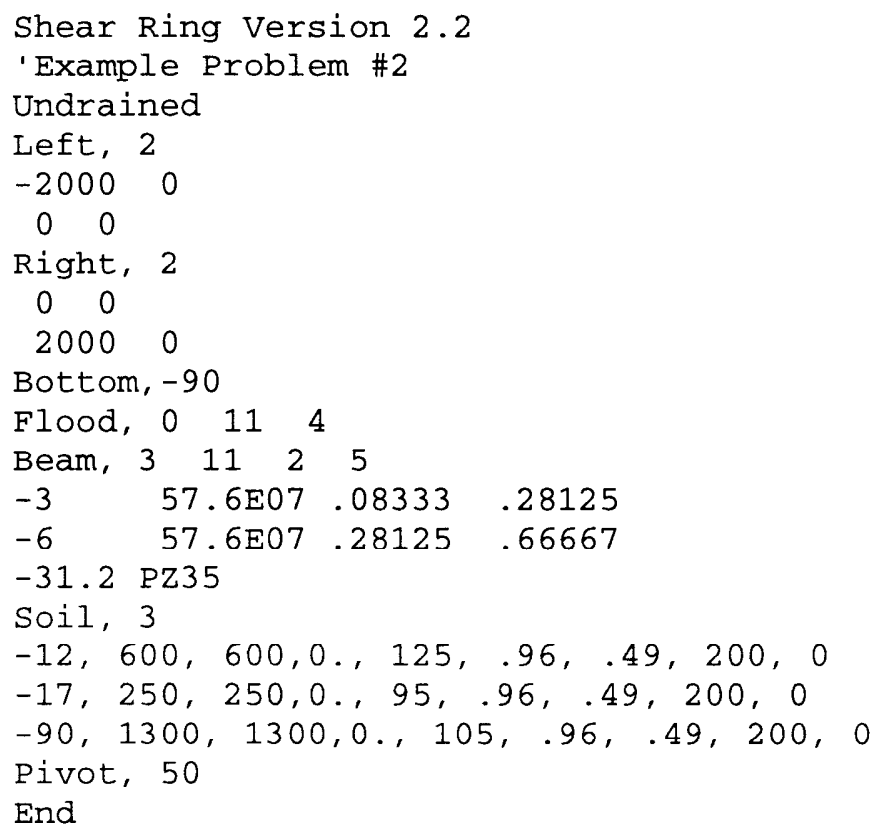

First open the data file named WORK2.SRD in EXAMPLE directory. This problem involves a variable cross-section wall and three soil layers.

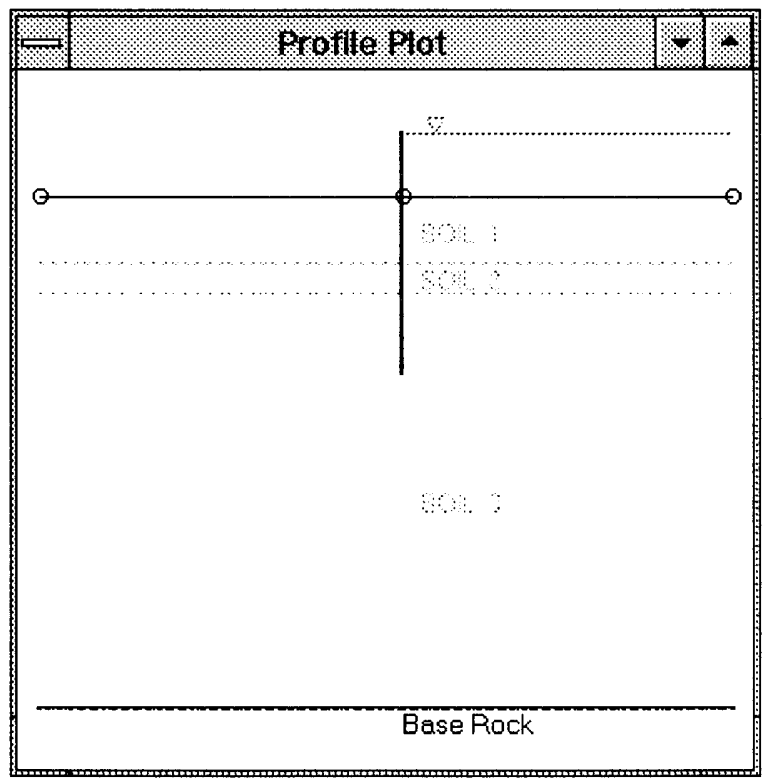




\section{Analyzing the problem}

Select Action + Analyze and accept the defaults. Press OK to start the analysis. When the analysis is done, bring the graphs window forward. It should look like the following sample.

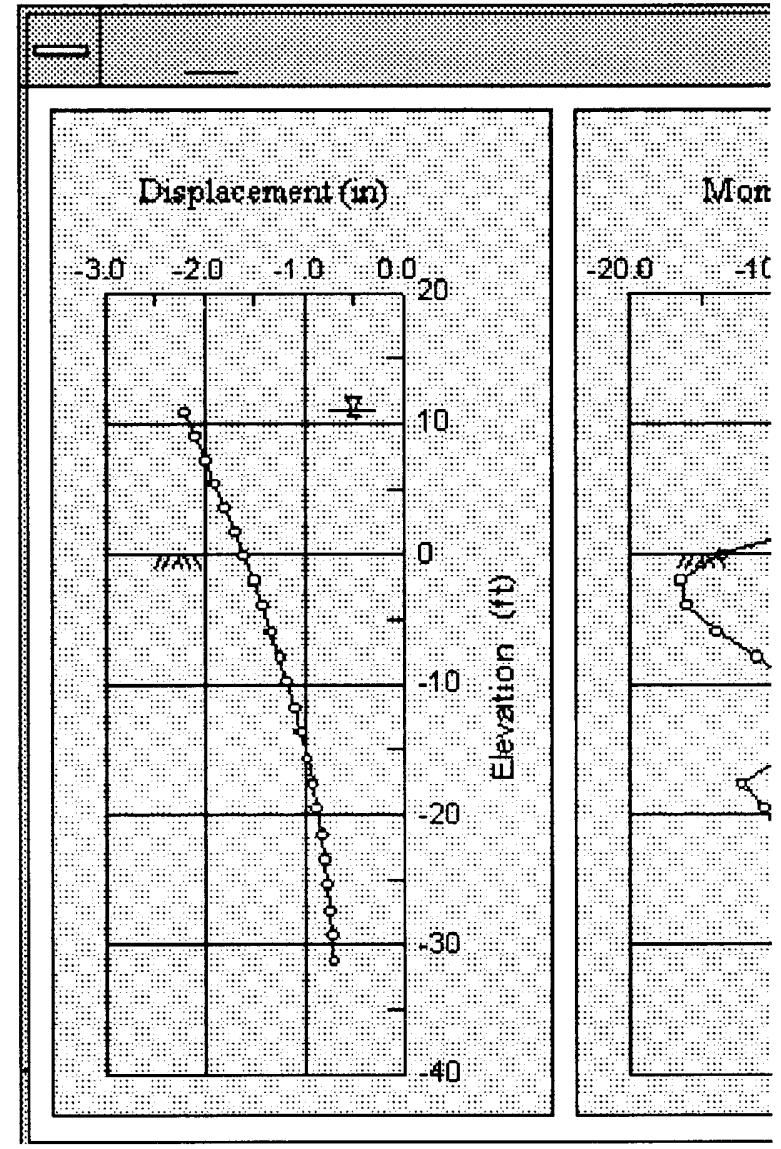

\section{Mouse buttons}

Experiment with clicking on the graphs. The two mouse buttons do different things when clicked on the graphs:

Left mouse button. Clicking on a graph with the left mouse button will draw a red rectangle around that graph. This is a mark that indicates that that graph has been "selected." The use of selection is explained in the next section. For now, note that clicking on the same graph again "deselects" it (notice the red rectangle disappear). Clicking on another graph also deselects the old selection.

Right mouse button. Clicking a graph with the right mouse button shows the coordinates of the point clicked in a pop-up window. The units used in this display are whatever units are used in the graph clicked. 


\section{Copying to clipboard and pasting}

Click on one of the graphs, say displacement. See that the red rectangle is drawn around the graph. From the main menu, select Edit + Copy. The selected graph is now on the clipboard, ready to be pasted into some other application.

To practice pasting, switch to some other Windows application, for example, Windows' Write. Press Alt + Tab (repeatedly if necessary) to see the Program Manager and start Write by double-clicking its icon. On Write's main menu, select Edit + Paste. Write has a peculiarity of not recognizing the size of a pasted Metafile (it may look as little as $6.4 \mathrm{~mm}(0.25 \mathrm{in}$.) square). To bring it to the desired size, select Edit + Size Picture. The mouse pointer will change. Move the mouse pointer around until the right size is reached. The result should look similar to the following sample (the text was typed separately).

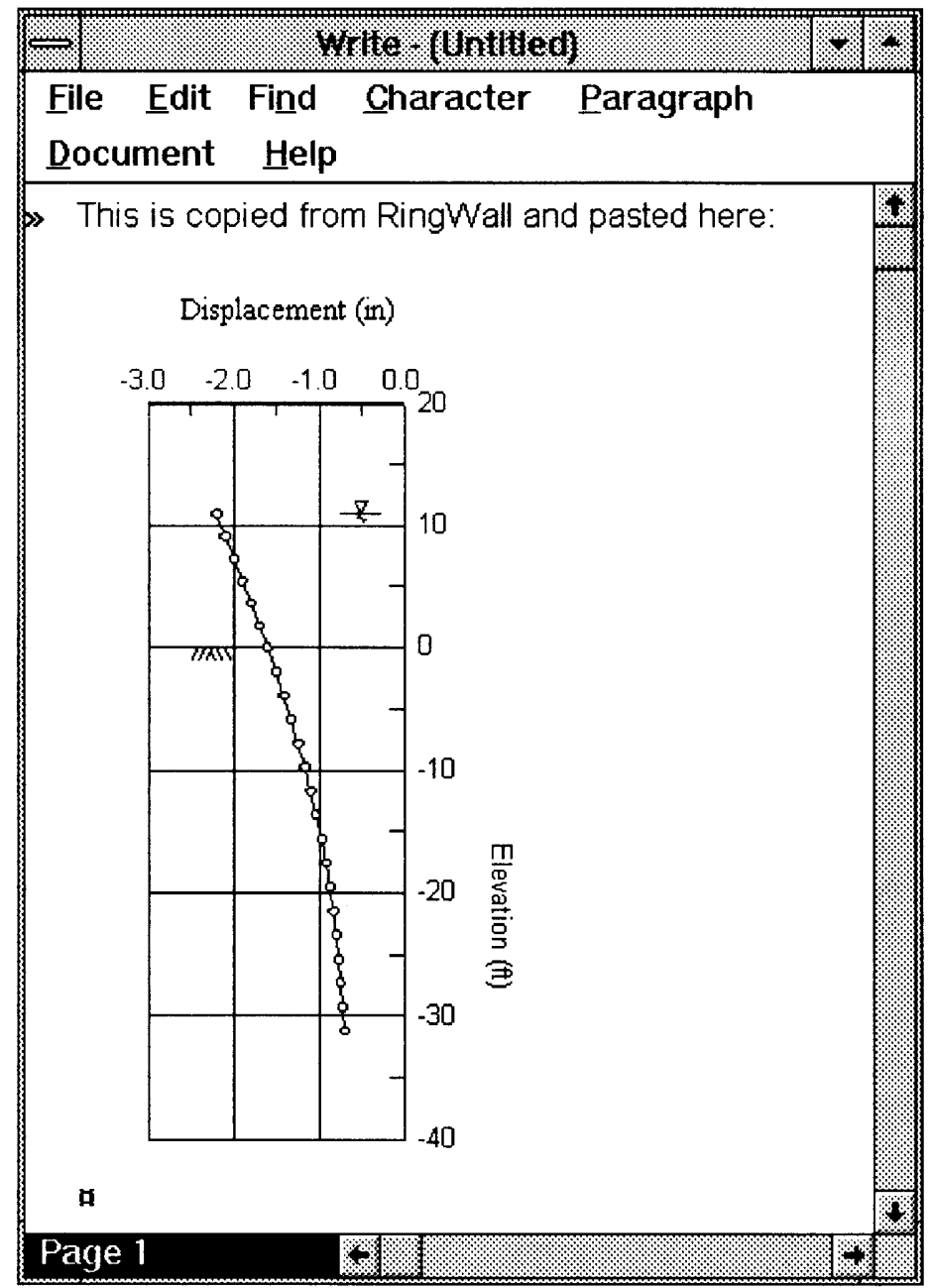




\section{Example 7: Design Example}

\section{The problem}

The data of Example Problem \#2 will be used for this example. It has been entered and saved in the directory EXAMPLE in the file WORK2.SRD. Open this file (File + Open). The profile will be plotted when the file is loaded. It should look like the following sample. As this plot shows, this profile has three different soil layers.

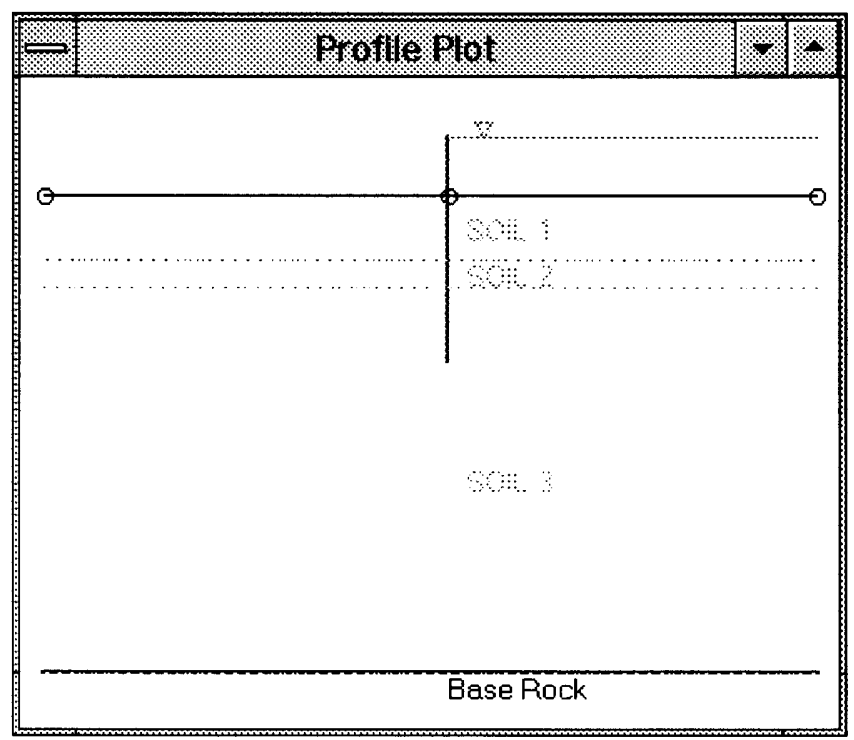

\section{Designing the wall}

Bring forward the Soil Data entry window to see how three-layer soil data looks. The undrained shear strengths of the clay layers are $c_{u}=28.8,12$, and $62.4 \mathrm{kPa}\left(600,250\right.$, and $\left.1,300 \mathrm{lbf} / \mathrm{ft}^{2}\right)$. The elevation of the ground surface is taken as zero. The base rock is at a depth of $15.2 \mathrm{~m}(50 \mathrm{ft})$.

The first step is to have the conventional design calculation done. To do so, select Design from the Action menu. RingWall will pop up a dialog box where design details can be specified, such as the factors of safety to use and where the CWALSHT program is located. Nothing has to be changed in this dialog box for this exercise. Click OK to start the conventional design calculation.

Windows opens a black DOS window to execute CWALSHT. In some versions of Windows and under some user setup conditions, the DOS window opened does not automatically close. If this happens, just close the DOS window by any of the standard Windows methods. Once the CWALSHT program has been completed, RingWall pulls the results into one of its child windows to present the results. 
This operation (conventional design) will give the following results:

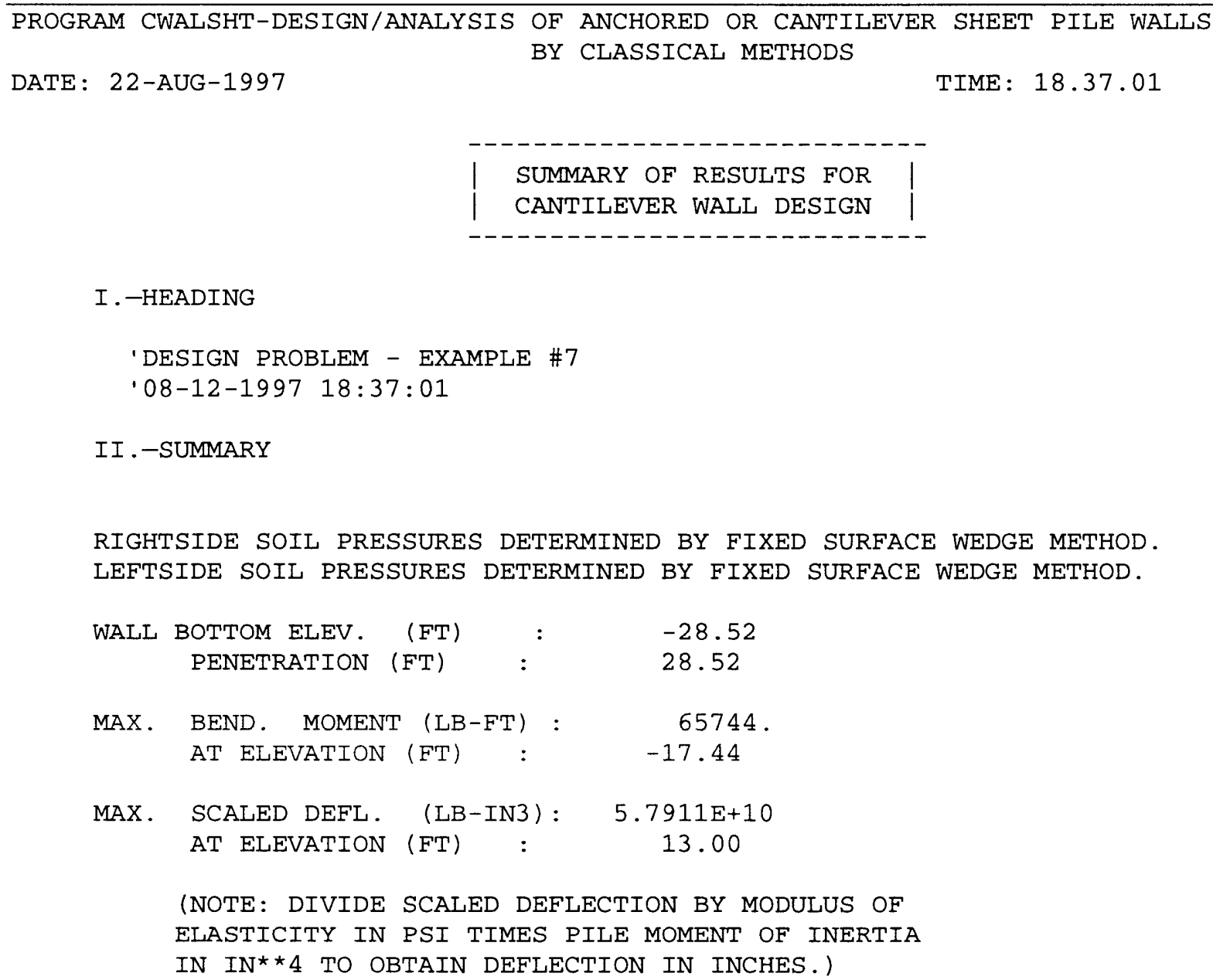

The conventional usage of these results is to (a) take the penetration depth as the minimum safe depth required to achieve the specified factors of safety, and (b) select a sheet-pile section based on the maximum bending moment. The allowable bending moment for a given pile section can be calculated as $M_{\text {all }}=$ $24 S$ where $S$ is the section modulus per unit length ( $\mathrm{ft}$ ). Using an allowable tensile strength of $165.5 \mathrm{Mpa}$ ( $24 \mathrm{ksi}$ ) for steel, the values shown in the following tabulation are obtained. 


\begin{tabular}{|l|l|l|l||}
\hline Section & $\begin{array}{l}\text { Section Modulus } \\
\mathbf{S}, \text { in. }\end{array}$ & Driving Distance, in. & $\begin{array}{l}\text { Mall } \\
\text { kip-ft/ft }\end{array}$ \\
\hline PZ40 & 60.7 & 19.69 & 74.0 \\
\hline PZ38 & 46.8 & 18.00 & 62.4 \\
\hline PZ35 & 48.5 & 22.64 & 51.4 \\
\hline PZ27 & 30.2 & 18.00 & 40.3 \\
\hline PZ22 & 18.1 & 22.00 & 19.8 \\
\hline Note: 1 in. $^{3}=0.000016 \mathrm{~m}^{3} ; 1$ in. $=25.4 \mathrm{~mm} ; 1 \mathrm{kip}-\mathrm{ft} / \mathrm{ft}=4.4 \mathrm{kN}-\mathrm{m} / \mathrm{m}$. \\
\hline
\end{tabular}

A comparison of these values with the maximum bending moment the conventional design calculation supplies, $292 \mathrm{kN}-\mathrm{m} / \mathrm{m}(65.7 \mathrm{lb}-\mathrm{ft} / \mathrm{ft})$ shows only the heaviest section, PZ40, to be strong enough. This is the end of the conventional design procedure, and the result is: "Use PZ40 and drive down to a depth of $28.5 \mathrm{ft} . "$

\section{Analyzing wall using SRM}

When more reliable values are obtained by the SRM analysis, we find out that the bending moments can be substantially smaller than those indicated by the conventional method. We select PZ35 and the penetration depth found, $8.7 \mathrm{~m}$ $(28.5 \mathrm{ft})$, tentatively.

The next step is to analyze the problem using SRM. To perform the analysis, select Analyze from the Action menu. The only question RingWall is going to ask is a file name for saving the results. Once the OK button is clicked the analysis starts. This can take from a few minutes to a few seconds. Summary results will be shown in a simple box first. Then detailed results are automatically listed in one child window and plotted in another. Enlarge and relocate these windows to study the results.

The results of the SRM analysis show a maximum bending moment of $92.9 \mathrm{kN}-\mathrm{m} / \mathrm{m}(20.9 \mathrm{kip}-\mathrm{ft} / \mathrm{ft})$ - about one-third of what the conventional method predicts! Also, the maximum displacement, at the top of the wall, is found as $64.3 \mathrm{~mm}$ ( $2.53 \mathrm{in}$.). It is clear that the conventional method is very conservative. With this small bending moment even the lightest available sheet-pile section will be able to handle this flood. This is savings number one.

The graphs show that toward the tip of the pile there are irregularities. Such zigzags in bending moment, shear force, and soil contact pressures are indicative of redundant pile material extending into the ground. This is known from classical soil-structure interaction analyses that produce sine-curve-like zigzags in these quantities when the structure is too long. The following sample shows the plots. 

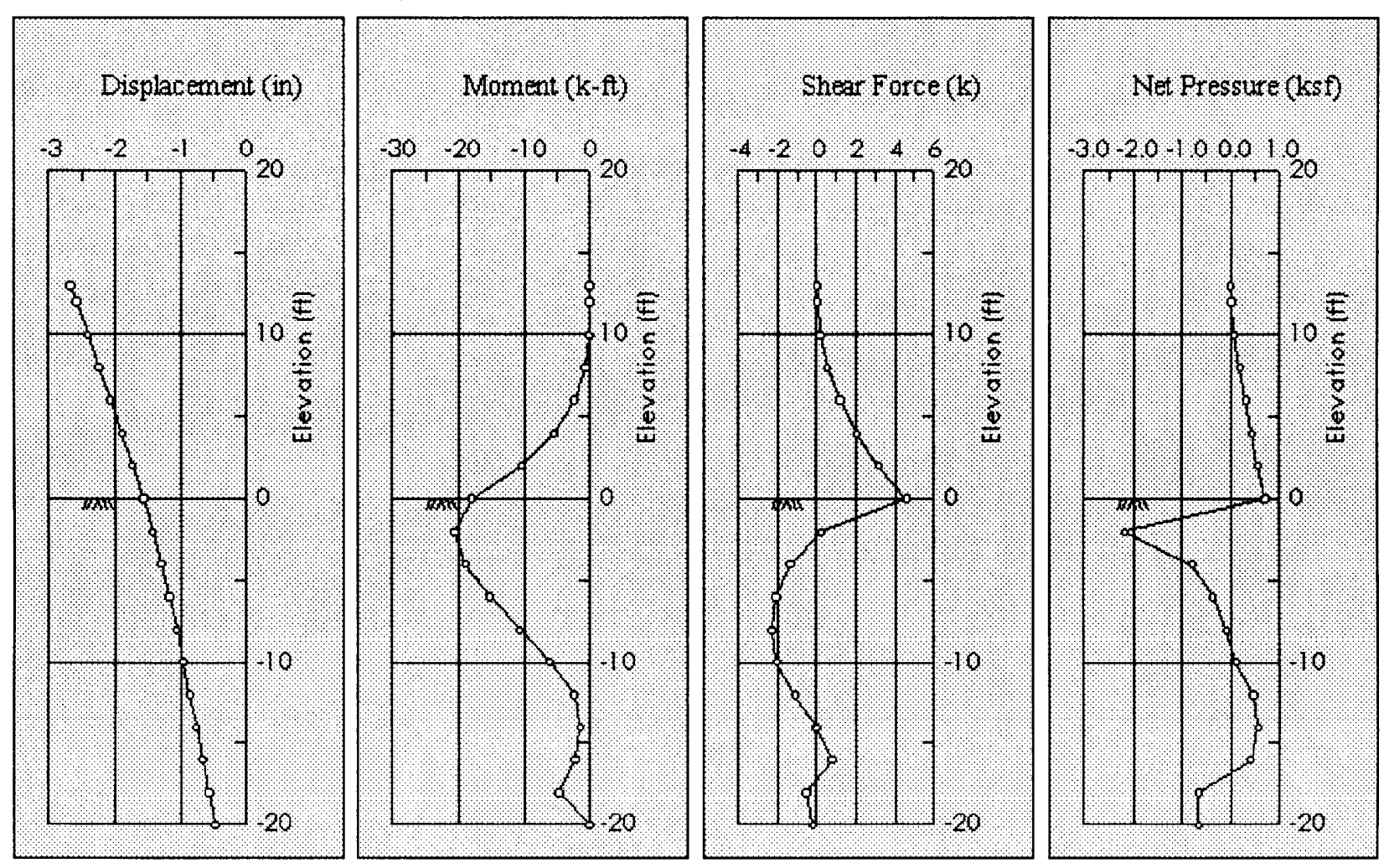

Next the soil stress conditions (the degree of mobilization, $f$ tables in the Analysis Results box) are considered. Recall that a value of $f=1$ indicates soil failure condition, and $f=0$ is the isotropic, or perfectly safe, condition. In this case the $f$ values are all less than 0.5 (or a factor of safety of 2). Therefore the soil is in a safe stress condition. So we may decide to decrease the depth of penetration and see how the results would change because it may be possible to achieve a more economical solution.

Modifying the "Bottom Elevation" value in the "Wall Properties" data entry window effects the change in the depth of penetration. Change the value there,

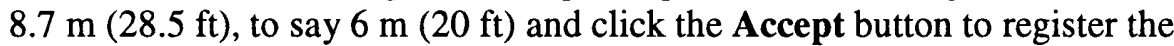
change. Then re-analyze the problem using the menu command Action + Analyze. The maximum bending moment does not change appreciably; now it is $91.6 \mathrm{kN}-\mathrm{m}$ (20.6 kip-ft) (versus $92.9 \mathrm{kN}-\mathrm{m} / \mathrm{m}$ (20.9 kip-ft/ft) of the initial case). The top deflection increases to $67.8 \mathrm{~mm}$ (2.67 in.) from $64.3 \mathrm{~mm}$ (2.53 in.). If this can be tolerated, then we save $2.6 \mathrm{~m}(8.5 \mathrm{ft})$ of penetration depth. Checking the soil $f$ values we see that the soil is not overstressed. Plots also show dampened zigzags.

Seeing these results, one is tempted to try an even shorter penetration depth. To see what would happen to the wall for a penetration depth of $4.6 \mathrm{~m}(15 \mathrm{ft})$, we reanalyze. For this case the maximum moment is $91.6 \mathrm{kN}-\mathrm{m} / \mathrm{m}(20.6 \mathrm{kip}-\mathrm{ft} / \mathrm{ft})$, and the top deflection is $66.3 \mathrm{~mm}$ (2.61 in.). The plots are shown in the following sample. 

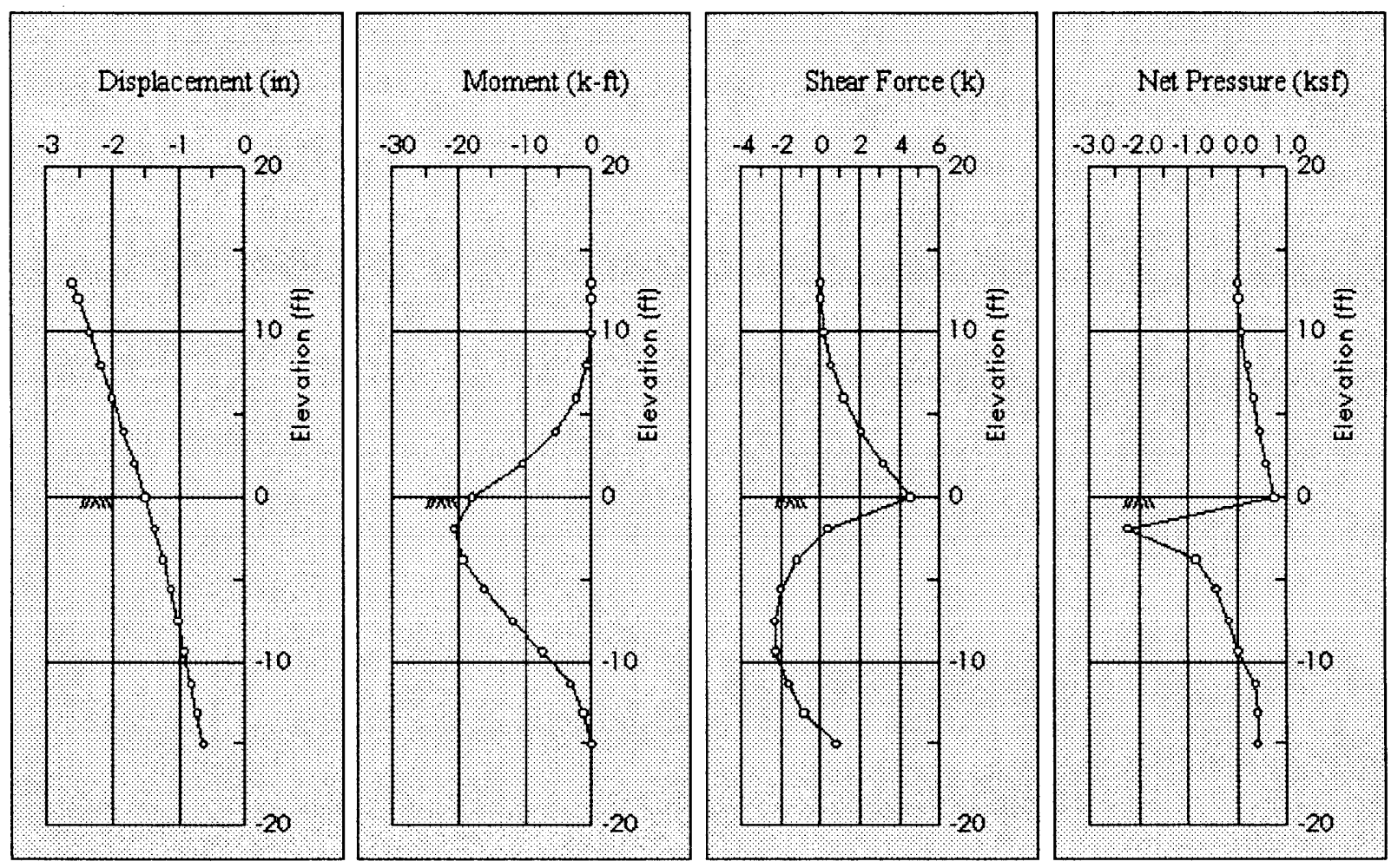

These results appear to be in the form expected for short/stiff walls: passive pressure in the upper front area and reversal at a depth close to the tip of the sheet-pile wall.

The design by this procedure clearly is more complicated, in the sense that the engineer has to play a more significant role and use his/her judgment. In the conventional design, the engineer's role is a mere data provider to a mechanical method. With these tools the engineer is freed from doing all the long calculations of the conventional design method by hand or feeding the same information to a computer program, and faithfully accepting whatever comes out of it. The SRM and the RingWall program give the responsibility of a design back to the engineer. 


\section{References}

Bjerrum, L., Clausen, C. J. F., and Duncan, J. M. (1972). "Earth pressures on flexible structures (A state of the art report)." Structures subjected to lateral forces, $5^{\text {th }}$ European conference on soil mechanics and foundation engineering, Madrid, 10-13 April 1972. Vol 2, 169-196. Reprint, 1972, Publication No. 91, Norwegian Geotechnical Institute, Oslo, Norway, 1-28.

Clough, G. W., and Duncan, J. M. (1971). "Finite element analyses of retaining wall behavior," Journal of Soil Mechanics and Foundations Division, ASCE, 97(12), 1657-1673.

Dawkins, W. P. (1990). "User's guide: Computer program for design and analysis of sheet pile walls by classical methods (CWALSHT)," Instruction Report ITL-90-1, U.S. Army Engineer Waterways Experiment Station, Vicksburg, MS.

Dawkins, W. P. (1994a). "User's guide: Computer program for analysis of beam-column structures with nonlinear supports (CBEAMC)," Instruction Report ITL-94-6, U.S. Army Engineer Waterways Experiment Station, Vicksburg, MS.

Dawkins, W. P. (1994b). "User's guide: Computer program for Winkler soilstructure interaction analysis of sheet-pile walls (CWALSSI)," Instruction Report ITL-94-5, U.S. Army Engineer Waterways Experiment Station, Vicksburg, MS.

Desai, C. S., and Abel, J. F. (1972). Introduction to the finite element method. Van Nostrand Reinhold, New York.

Desai, C. S., and Siriwardane, H. J. (1984). Constitutive laws for engineering materials with emphasis on geologic materials. Prentice-Hall, Englewood Cliffs, NJ.

Duncan, J. M., and Chang, C. Y. (1970). "Nonlinear analysis of stress and strain in soils," Journal of the Soil Mechanics and Foundations Division, ASCE, 96(SM5), 1629-1652. 
Foott, R., and Ladd, C. C. (1981). "Undrained settlement of plastic and organic clays," Journal of the Geotechnical Engineering Division, ASCE, 107(GT8), 1079-1094.

Holtz, R. D., and Kovacs, W. D. (1981). Geotechnical engineering. PrenticeHall, Englewood Cliffs, NJ.

Jackson, R. B. (1988). "E99 sheet pile wall field load test report," Technical Report No. 1, U.S. Army Engineer Division, Lower Mississippi Valley, Vicksburg, MS.

Janbu, N. (1963). "Soil compressibility as determined by oedometer and triaxial tests." Proceedings: Problems of settlements and compressibility of soils, Wiesbaden, West Germany. European Conference on Soil Mechanics and Foundation Engineering, 1, 19-25.

Kondner, R. L. (1963). "Hyperbolic stress-strain response: Cohesive soils," Journal of the Soil Mechanics and Foundations Division, ASCE, 89(SM1), 115.

Kulhawy, F. H., Duncan, J. M., and Seed, H. B. (1969). "Finite element analyses of stresses and movements in embankments during construction," Contract Report S-69-8, U.S. Army Engineer Waterways Experiment Station, Vicksburg, MS.

Leavall, D. A., Peters, J. F., Edris, E.V., and Holmes, T. L. (1989). "Development of finite-element-based design procedure for sheet-pile walls," Technical Report GL-89-14, U.S. Army Engineer Waterways Experiment Station, Vicksburg, MS.

Ladd, C. C., Foott, R., Ishihara, K., Schlosser, F., and Poulos, H. G. (1977). "Stress-deformation and strength characteristics." Proceedings, $9^{\text {th }}$ international conference on soil mechanics and foundation engineering, Tokyo, Japan, 1977. 2, 421-494.

Masing, G. (1926). "Eigenspannungen und Verfestigung beim Messing." Proceedings of the 2nd International Congress on Applied Mechanics (conference proceedings in German), Zurich.

Oner, M., and Janbu, N. (1976). "Nonlinear analysis of foundation vibrations." Proceedings, 2nd International Conference on Numerical Methods in Geomechanics, Blacksburg, VA, June 1976. C. S. Desai, ed., ASCE, New York, 1025-1037.

Rowe, P. W. (1952). "Anchored sheet pile walls." Proceedings, Institution of Civil Engineers, London, Part 1, 1(5788), 27-70.

Rowe, P. W. (1955). "A theoretical and experimental analysis of sheet pile walls." Proceedings, Institution of Civil Engineers, London, 4(I), 32-69. 
Smith, I. M., and Boorman, R. (1974). "The analysis of flexible bulkheads in sands." Proceedings, Institution of Civil Engineers, 57(2), 413-436.

Youd, T. L. (1973). "Factors controlling maximum and minimum densities of sands." Evaluation of relative density and its role in geotechnical projects involving cohesionless soils, A symposium presented at the 75th annual meeting, American Society for Testing and Materials, Los Angeles, June 2530, 1972. ASTM Special Technical Publication 523, E. T. Selig and R. S. Ladd, eds., American Society for Testing and Materials, Philadelphia, 98-112. 


\section{Appendix A Derivation of Hoop Modulus}

Recalling the generalized Hooke's law, in $r, \mathrm{~s}, t$ coordinates,

$$
\begin{aligned}
& \varepsilon_{r}=\left[\sigma_{r}-v\left(\sigma_{s}+\sigma_{r}\right)\right] \\
& \varepsilon_{s}=\left[\sigma_{s}-v\left(\sigma_{t}+\sigma_{r}\right)\right] \\
& \varepsilon_{t}=\left[\sigma_{t}-v\left(\sigma_{r}+\sigma_{s}\right)\right]
\end{aligned}
$$

where $\varepsilon$ is strain, $\sigma$ is stress, and $v$ is Poisson's ratio. Under plane strain conditions, working in the $r$ - $t$ plane, where $t$ direction is along the arc, $r$ denotes the radial direction, and $s$ is the third direction perpendicular to the analysis plane, Hooke's law can be specialized by setting $\varepsilon_{\mathrm{s}}=0$, as

$$
\begin{aligned}
& \sigma_{s}=v\left(\sigma_{r}+\sigma_{t}\right) \\
& \varepsilon_{t}=\left[\sigma_{r}\left(1-v^{2}\right)-\sigma_{r}\left(v+v^{2}\right)\right] / E \\
& \varepsilon_{r}=\left[-\sigma_{r}\left(v+v^{2}\right)+\sigma_{r}\left(1-v^{2}\right)\right] / E
\end{aligned}
$$

In the formulation of shear ring stiffness matrices, a "hoop modulus," $H$, is required that relates the hoop stress to hoop strain,

$$
H=\sigma_{t} / \varepsilon_{t}
$$

It can easily be derived from these expressions that (a) if $\sigma_{r}=0$, i.e., the ring offers no resistance to radial spreading under compression, or is "free" laterally, then

$$
H_{\text {free }}=\frac{E}{1-v^{2}}=\frac{2 G}{1-v}
$$

where $E$ is Young's modulus and $G$, the shear modulus, and (b) if, in the other extreme, $\varepsilon^{r}=0$, i.e., the ring has no freedom to expand laterally under compression, or is "fixed," then 


$$
H_{\text {fixed }}=\frac{E(1-v)}{(1+v)(1-2 v)}=\frac{2 G(1-v)}{1-2 v}
$$

A judgement has to be made as to which $H$ better represents the conditions of the problem being analyzed. In a floodwall problem it may be argued that the "free" condition is more appropriate for the regions close to the ground surface while it seems more appropriate to adopt the "fixed" condition at larger depths. In the current version of the shear ring computer program, $\mathrm{H}$ is linearly varied between $H_{\text {free }}$ and $H_{\text {fixed }}$ between the top and the bottom of the cross section being analyzed. 


\section{Appendix B}

\section{Stiffness Matrix of the Quadratic Shear Ring Element}

The quadratic ring element stiffness matrix is obtained by evaluating the integrals in Equation 21 using Equations 18 and 20, as follows.

$\left[k_{R}\right]=d\left(l_{1}+l_{2}\right) / 2$ times the following matrix

$$
\begin{aligned}
& {\left[\frac{I_{11}}{3 l_{1}^{2}}+\frac{J_{11}}{d^{2}} \frac{I_{12}}{3 l_{1}^{2}}+\frac{J_{12}}{d^{2}} \frac{I_{13}}{3 l_{1}^{2}}+\frac{J_{13}}{d^{2}} \frac{I_{11}}{6 l_{1} l_{2}}-\frac{\rho J_{12}}{d^{2}} \frac{I_{12}}{6 l_{1} l_{2}}-\frac{\rho J_{12}}{d^{2}} \frac{I_{13}}{6 l_{1} l_{2}}-\frac{\rho J_{13}}{d^{2}}\right.} \\
& \frac{I_{2}}{3 l_{1}^{2}}+\frac{J_{22}}{d^{2}} \frac{I_{23}}{3 l_{1}^{2}}+\frac{J_{23}}{d^{2}} \frac{I_{12}}{6 l_{1} I_{2}}-\frac{\rho J_{12}}{d^{2}} \frac{I_{22}}{6 l_{1} l_{2}}-\frac{\rho J_{22}}{d^{2}} \frac{I_{23}}{6 l_{1} l_{2}}-\frac{\rho J_{23}}{d^{2}} \\
& \frac{I_{33}}{3 l_{1}^{2}}+\frac{J_{33}}{d^{2}} \frac{I_{13}}{6 l_{1} l_{2}}-\frac{\rho J_{13}}{d^{2}} \frac{I_{23}}{6 l_{1} l_{2}}-\frac{\rho J_{23}}{d^{2}} \frac{I_{33}}{6 l_{1} l_{2}}-\frac{\rho J_{33}}{d^{2}} \\
& \frac{I_{11}}{3 l_{2}^{2}}+\frac{J_{11} \rho^{2}}{d^{2}} \frac{I_{12}}{3 l_{2}^{2}}+\frac{J_{12} \rho^{2}}{d^{2}} \frac{I_{13}}{3 l_{2}^{2}}+\frac{J_{13} \rho^{2}}{d^{2}} \\
& \text { symmetric } \\
& \frac{I_{2}}{3 l_{2}^{2}}-\frac{J_{2} \rho^{2}}{d^{2}} \frac{I_{23}}{3 l_{2}^{2}}+\frac{J_{23} \rho^{2}}{d^{2}} \\
& \frac{I_{33}}{3 l_{2}^{2}}+\frac{J_{33} \rho^{2}}{d^{2}}
\end{aligned}
$$

where $l_{1}$ and $l_{2}$ are the top and bottom arc lengths, $d$ is the ring thickness, $\rho$ is the radius ratio, and the abbreviations $I i j$ and $J i j$ stand for: 


$$
\begin{aligned}
& I_{11}=\left(37 H_{L}+36 H_{M}-3 H_{R}\right) / 30 \\
& I_{12}=-\left(22 H_{L}+16 H_{M}+2 H_{R}\right) / 15 \\
& I_{13}=\left(7 H_{L}-4 H_{M}+7 H_{R}\right) / 30 \\
& I_{22}=\left(24 H_{L}+32 H_{M}+24 H_{R}\right) / 15 \\
& I_{23}=-\left(2 H_{L}+16 H_{M}+22 H_{R}\right) / 15 \\
& I_{33}=\left(-3 H_{L}+36 H_{M}+37 H_{R}\right) / 30 \\
& J_{11}=\left(39 G_{L}+20 G_{M}-3 G_{R}\right) / 420 \\
& J_{12}=\left(5 G_{L}+4 G_{M}-2 G_{R}\right) / 105 \\
& J_{13}=-\left(3 G_{L}+8 G_{M}+3 G_{R}\right) / 420 \\
& J_{22}=\left(4 G_{L}+48 G_{M}+4 G_{R}\right) / 105 \\
& J_{23}=\left(-2 G_{L}+4 G_{M}+5 G_{R}\right) / 105 \\
& J_{33}=\left(-3 G_{L}+20 G_{M}+39 G_{R}\right) / 420
\end{aligned}
$$

where $H$ is the hoop strain and $G$ is the shear modulus.

The subscripts $L, M$, and $R$ denote the left end, middle, and right end values of the parameter. 


\section{Appendix C Beam Element Stiffness Matrix}

The elements used to model the sheet pile are the commonplace flexural members. For the sake of completeness the beam element stiffness matrix used in this work is given in Equation C1.

$$
\left[k_{B}\right]=\left[\begin{array}{cccc}
12 & 6 L & -12 & 6 L \\
6 L & 4 L^{2} & -6 L & 2 L^{2} \\
-12 & 2 L^{2} & 12 & -6 L \\
6 L & 2 L^{2} & -6 L & 4 L^{2}
\end{array}\right] \frac{E I}{L^{3}}
$$

where $L$ is the length of the beam element, $E$ is the Young's modulus, and $I$ is the moment of inertia per unit width. The generalized coordinates are ordered as top displacement, top rotation, bottom displacement, and bottom rotation. 


\section{Appendix D Default INI File}

\section{Introduction}

The default INI file of RingWall listed in this appendix can be used by advanced users in customizing the program to suit their needs.

The format of the INI file is the standard Windows format: There are sections labeled with brackets [], and there are key=value pairs under each section label. This file can be changed by any plain text editor (such as Windows Notepad). Any change made in this file will take effect immediately because RingWall reads the information whenever it needs that information. For example, if the user changes the name in the "User=" entry in the [Customize] section, and then prints a title block, the new name will be printed.

Although a technically minded user will prefer this method because it gives complete control to the user, it also gives him/her the right to make mistakes. So, you may want to stick to the Action + Customize command and let the program change the INI file for you.

\section{INI File Listing}

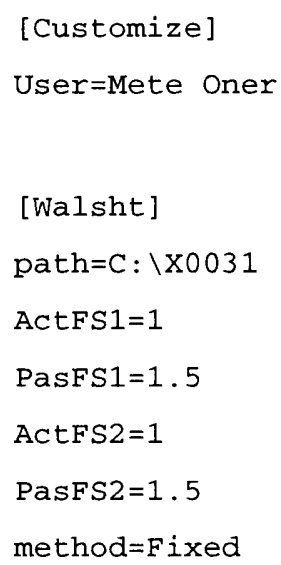




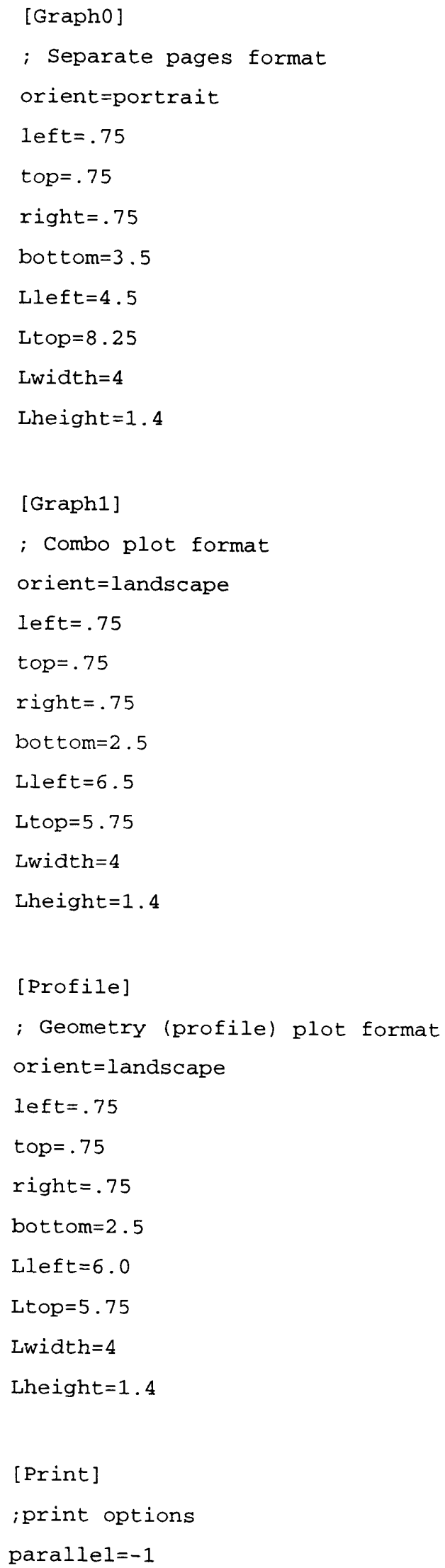




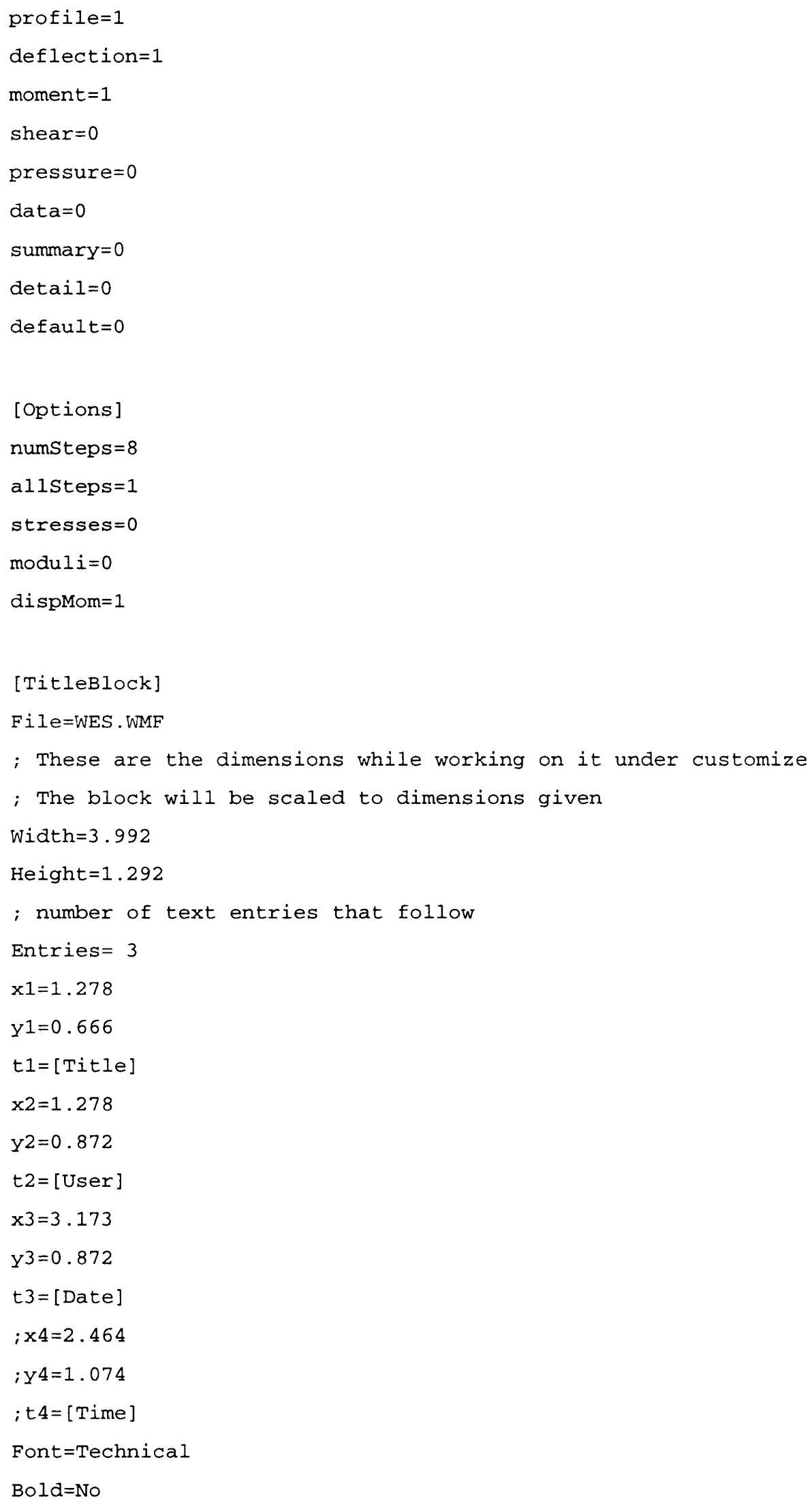


Italic $=$ No

Size $=10$

; The font size will be scaled inside a title block

[Textoutput]

; These are for printing the data and output texts Font=Courier New

Bold=No

Italic $=$ No

Size=8 


\section{Appendix E I/O File Formats}

It is not necessary to know the format of the data file RingWall uses to store problem data. Although an average user may never need it, advanced users may find it useful to know the format. The file is in ASCII (text only) form. With the exception of the first and last lines, any data block can be placed anywhere in the file. This is best shown by an example.

\section{Data File Format}

The following is an annotated listing of the data file for the sample problem. The information given in the column on the right-hand side is for explanation only and is not part of the data file.

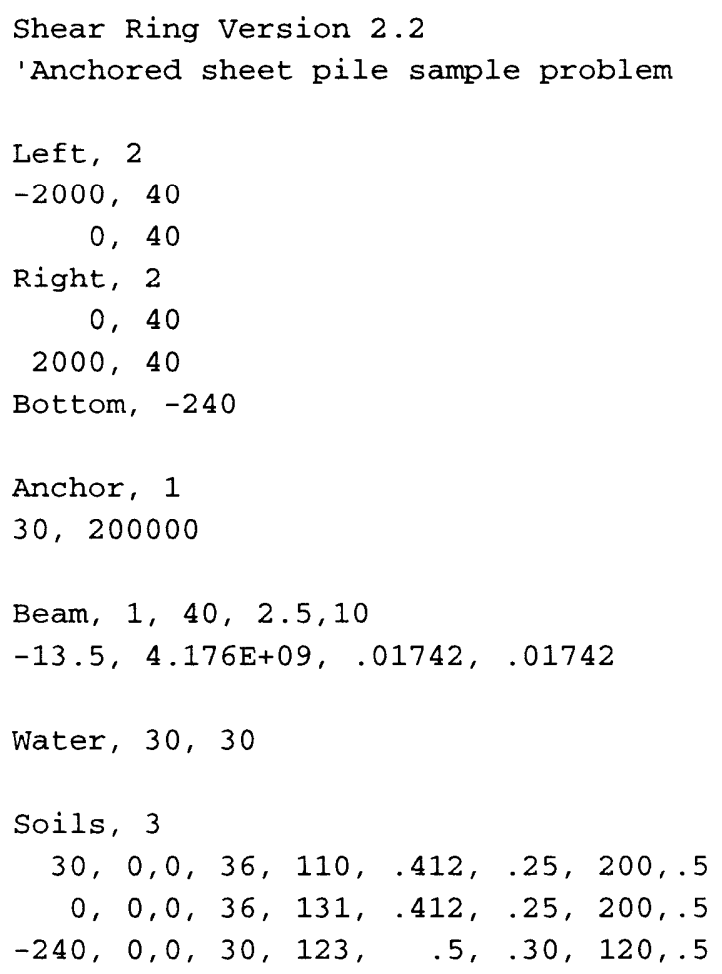

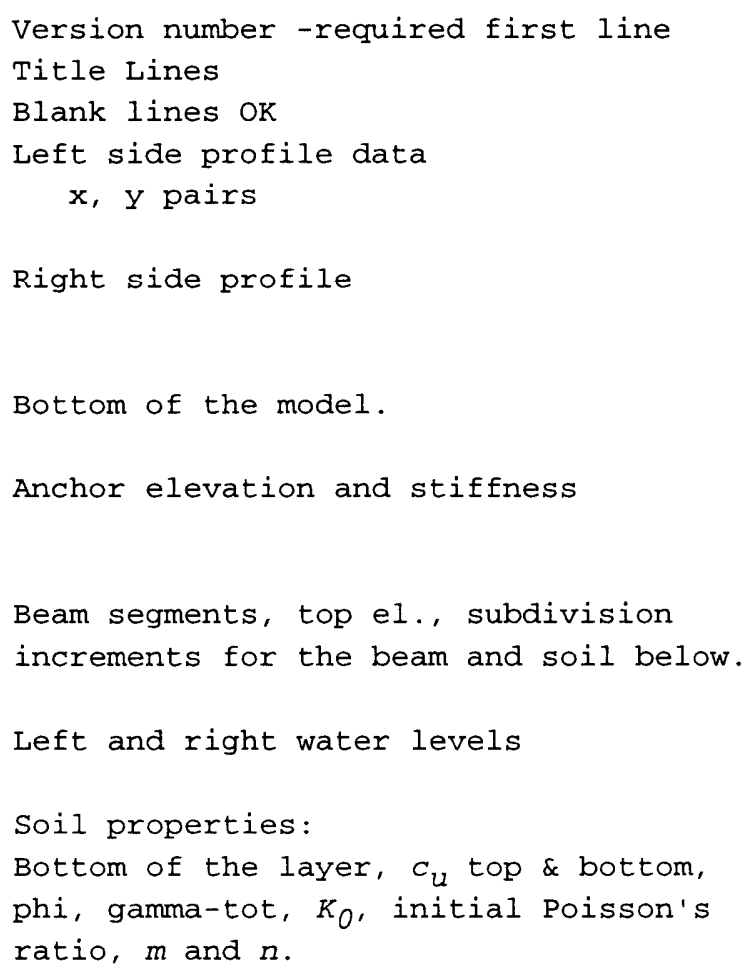




\section{Output File Format}

The Action + Analysis command in RingWall runs a shear ring analysis of the current problem. The results of the analysis are presented in a window. An explanation of parts of this output is given in this section.

If the results for the intermediate loading steps are not requested in the Analysis Options dialog box, only the last step results are given. If all steps are requested in the dialog box, the output will be many times longer.

After some detail information on how the wall-soil system was subdivided for analysis purposes, the output lists two main tables of information (repeated for each step, if requested).

The first table gives the stresses and the $f$ values. $f$ denotes the degree of mobilization of shear strength as a fraction; 1 means 100 percent of the shear strength is mobilized (or failure). Column labels and the contents of each column are, from left to right:

elev Elevation of the row of data

vSig Vertical normal stress near the beam on the left side

hSig Horizontal normal stress near the beam on the left side

tau Shear stress near the beam on the left side

f3 $f$ value near the ground surface on the left side

f2 $f$ value in the middle of the left ring

f1 $f$ value near the beam on the left side

vSig Vertical normal stress near the beam on the right side

hSig Horizontal normal stress near the beam on the right side

tau Shear stress near the beam on the right side

f2 $f$ value in the middle of the right ring

f3 $f$ value near the ground surface on the right side

f1 f value near the beam on the right side 
The second table contains the displacements and the internal forces (shear and moment) for the wall. These represent the situation at the end of the current load step. 


\section{WATERWAYS EXPERIMENT STATION REPORTS PUBLISHED UNDER THE COMPUTER-AIDED STRUCTURAL ENGINEERING (CASE) PROJECT}

Title

Date

Technical Report K-78-1

Instruction Report 0-79-2

Technical Report K-80-1

Technical Report K-80-2

Instruction Report K-80-1

Instruction Report K-80-3

Instruction Report K-80-4

Instruction Report K-80-6

Instruction Report K-80-7

Technical Report K-80-4

Technical Report K-80-5

Instruction Report K-81-2

Instruction Report K-81-3

Instruction Report K-81-4

Instruction Report K-81-6

Instruction Report K-81-7

Instruction Report K-81-9

Technical Report K-81-2

Instruction Report K-82-6
List of Computer Programs for Computer-Aided Structural Engineering

User's Guide: Computer Program with Interactive Graphics for Analysis of Plane Frame Structures (CFRAME)

Survey of Bridge-Oriented Design Software

Evaluation of Computer Programs for the Design/Analysis of Highway and Railway Bridges

User's Guide: Computer Program for Design/Review of Curvilinear Conduits/Culverts (CURCON)

A Three-Dimensional Finite Element Data Edit Program

A Three-Dimensional Stability Analysis/Design Program (3DSAD)

Report 1: General Geometry Module

Report 3: General Analysis Module (CGAM)

Report 4: Special-Purpose Modules for Dams (CDAMS)

Basic User's Guide: Computer Program for Design and Analysis of Inverted-T Retaining Walls and Floodwalls (TWDA)

User's Reference Manual: Computer Program for Design and Analysis of Inverted-T Retaining Walls and Floodwalls (TWDA)

Documentation of Finite Element Analyses

Report 1: Longview Outlet Works Conduit

Report 2: Anchored Wall Monolith, Bay Springs Lock

Basic Pile Group Behavior

User's Guide: Computer Program for Design and Analysis of Sheet Pile Walls by Classical Methods (CSHTWAL)

Report 1: Computational Processes

Report 2: Interactive Graphics Options

Validation Report: Computer Program for Design and Analysis of Inverted-T Retaining Walls and Floodwalls (TWDA)

User's Guide: Computer Program for Design and Analysis of Cast-in-Place Tunnel Linings (NEWTUN)

User's Guide: Computer Program for Optimum Nonlinear Dynamic Design of Reinforced Concrete Slabs Under Blast Loading (CBARCS)

User's Guide: Computer Program for Design or Investigation of Orthogonal Culverts (CORTCUL)

User's Guide: Computer Program for Three-Dimensional Analysis of Building Systems (CTABS80)

Theoretical Basis for CTABS80: A Computer Program for Three-Dimensional Analysis of Building Systems

User's Guide: Computer Program for Analysis of Beam-Column Structures with Nonlinear Supports (CBEAMC)
Feb 1978

Mar 1979

Jan 1980

$\operatorname{Jan} 1980$

Feb 1980

Mar 1980

Jun 1980

Jun 1982

Aug 1983

Dec 1980

Dec 1980

Dec 1980

Dec 1980

Dec 1980

Feb 1981

Mar 1981

Feb 1981

Mar 1981

Mar 1981

Mar 1981

Aug 1981

Sep 1981

Jun 1982

(Continued) 


\title{
WATERWAYS EXPERIMENT STATION REPORTS PUBLISHED UNDER THE COMPUTER-AIDED STRUCTURAL ENGINEERING (CASE) PROJECT
}

\author{
(Continued)
}

Title

Date

Jun 1982

Instruction Report K-82-7

User's Guide: Computer Program for Bearing Capacity Analysis of Shallow Foundations (CBEAR)

Instruction Report K-83-1

Instruction Report K-83-2

User's Guide: Computer Program with Interactive Graphics for Analysis of Plane Frame Structures (CFRAME)

User's Guide: Computer Program for Generation of Engineering Geometry (SKETCH)

Instruction Report K-83-5

Technical Report K-83-1

Technical Report K-83-3

Technical Report K-83-4

Instruction Report K-84-2

Instruction Report K-84-7

Instruction Report K-84-8

Instruction Report K-84-11

Technical Report K-84-3

Technical Report ATC-86-5

Technical Report ITL-87-2

Instruction Report ITL-87-1

Instruction Report ITL-87-2

Technical Report ITL-87-6

Instruction Report ITL-87-3
User's Guide: Computer Program to Calculate Shear, Moment, and Thrust (CSMT) from Stress Results of a Two-Dimensional Finite Element Analysis

Basic Pile Group Behavior

Sep 1983

Reference Manual: Computer Graphics Program for Generation of Engineering Geometry (SKETCH)

Case Study of Six Major General-Purpose Finite Element Programs of Nonlinear Metal Plates Under Blast Loading (CSDOOR)

User's Guide: Computer Program for Determining Induced Stresses and Consolidation Settlements (CSETT)

Seepage Analysis of Confined Flow Problems by the Method of Fragments (CFRAG)

User's Guide for Computer Program CGFAG, Concrete General

Computer-Aided Drafting and Design for Corps Structural Engineers

Decision Logic Table Formulation of $\mathrm{ACI}$ 318-77, Building Code Requirements for Reinforced Concrete for Automated Constraint Processing, Volumes I and II

A Case Committee Study of Finite Element Analysis of Concrete Flat Slabs

User's Guide: Computer Program for Two-Dimensional Analysis of U-Frame Structures (CUFRAM)

User's Guide: For Concrete Strength Investigation and Design (CASTR) in Accordance with ACI 318-83

Finite-Element Method Package for Solving Steady-State Seepage Problems

User's Guide: A Three-Dimensional Stability Analysis/Design

Program (3DSAD) Module

Report 1: Revision 1: General Geometry

Report 2: General Loads Module

Report 6: Free-Body Module
User's Guide: Computer Program for Optimum Dynamic Design Flexure Analysis with Graphics
Jan 1983

Jun 1983

Jul 1983

Sep 1983

Oct 1983

Jan 1984

Aug 1984

Sep 1984

Sep 1984

Oct 1984

Jun 1986

Jan 1987

Apr 1987

May 1987

May 1987

Jun 1987

Jun 1987

Sep 1989

Sep 1989

(Continued) 


\title{
WATERWAYS EXPERIMENT STATION REPORTS PUBLISHED UNDER THE COMPUTER-AIDED STRUCTURAL ENGINEERING (CASE) PROJECT
}

\author{
(Continued) \\ Title \\ Date \\ Instruction Report ITL-87-4 \\ User's Guide: 2-D Frame Analysis Link Program (LINK2D) \\ Jun 1987 \\ Technical Report ITL-87-4 \\ Finite Element Studies of a Horizontally Framed Miter Gate \\ Aug 1987 \\ Report 1: Initial and Refined Finite Element Models (Phases \\ $A, B$, and C), Volumes I and II \\ Report 2: Simplified Frame Model (Phase D) \\ Report 3: Alternate Configuration Miter Gate Finite Element \\ Studies-Open Section \\ Report 4: Alternate Configuration Miter Gate Finite Element \\ Studies-Closed Sections \\ Report 5: Alternate Configuration Miter Gate Finite Element \\ Studies-Additional Closed Sections \\ Report 6: Elastic Buckling of Girders in Horizontally Framed \\ Miter Gates \\ Report 7: Application and Summary \\ Instruction Report GL-87-1 \\ Instruction Report ITL-87-5 \\ Instruction Report ITL-87-6 \\ Technical Report ITL-87-8 \\ Instruction Report ITL-88-1 \\ Technical Report ITL-88-1 \\ Technical Report ITL-88-2 \\ Instruction Report ITL-88-2 \\ Instruction Report ITL-88-4 \\ Instruction Report GL-87-1 \\ Technical Report ITL-89-3 \\ Technical Report ITL-89-4 \\ User's Guide: UTEXAS2 Slope-Stability Package; Volume I, \\ User's Manual \\ Sliding Stability of Concrete Structures (CSLIDE) \\ Aug 1987 \\ Oct 1987 \\ Criteria Specifications for and Validation of a Computer Program \\ for the Design or Investigation of Horizontally Framed Miter \\ Gates (CMITER) \\ Procedure for Static Analysis of Gravity Dams Using the Finite \\ Element Method - Phase 1a \\ User's Guide: Computer Program for Analysis of Planar Grid \\ Structures (CGRID) \\ Development of Design Formulas for Ribbed Mat Foundations \\ on Expansive Soils \\ User's Guide: Pile Group Graphics Display (CPGG) Post- \\ processor to CPGA Program \\ Dec 1987 \\ Jan 1988 \\ Feb 1988 \\ Apr 1988 \\ Apr 1988 \\ User's Guide for Design and Investigation of Horizontally Framed \\ Miter Gates (CMITER) \\ User's Guide for Revised Computer Program to Calculate Shear, \\ Moment, and Thrust (CSMT) \\ User's Guide: UTEXAS2 Slope-Stability Package; Volume II, \\ Theory \\ Jun 1988 \\ Sep 1988 \\ Feb 1989 \\ User's Guide: Pile Group Analysis (CPGA) Computer Group \\ Jul 1989 \\ CBASIN-Structural Design of Saint Anthony Falls Stilling Basins \\ According to Corps of Engineers Criteria for Hydraulic \\ Structures; Computer Program X0098 \\ Aug 1989
}




\title{
WATERWAYS EXPERIMENT STATION REPORTS PUBLISHED UNDER THE COMPUTER-AIDED STRUCTURAL ENGINEERING (CASE) PROJECT
}

\author{
(Continued) \\ Title \\ Technical Report ITL-89-5 \\ CCHAN-Structural Design of Rectangular Channels According \\ to Corps of Engineers Criteria for Hydraulic \\ Structures; Computer Program X0097 \\ Technical Report ITL-89-6 \\ The Response-Spectrum Dynamic Analysis of Gravity Dams Using \\ the Finite Element Method; Phase II \\ Contract Report ITL-89-1 \\ State of the Art on Expert Systems Applications in Design, \\ Construction, and Maintenance of Structures \\ Instruction Report ITL-90-1 \\ User's Guide: Computer Program for Design and Analysis \\ of Sheet Pile Walls by Classical Methods (CWALSHT) \\ Technical Report ITL-90-3 \\ Investigation and Design of U-Frame Structures Using \\ Program CUFRBC \\ Volume A: Program Criteria and Documentation \\ Volume B: User's Guide for Basins \\ Volume C: User's Guide for Channels \\ Instruction Report ITL-90-6 \\ User's Guide: Computer Program for Two-Dimensional Analysis \\ of U-Frame or W-Frame Structures (CWFRAM) \\ Instruction Report ITL-90-2 \\ User's Guide: Pile Group-Concrete Pile Analysis Program \\ (CPGC) Preprocessor to CPGA Program \\ Technical Report ITL-91-3 \\ Application of Finite Element, Grid Generation, and Scientific \\ Visualization Techniques to 2-D and 3-D Seepage and \\ Groundwater Modeling \\ Instruction Report ITL-91-1 \\ User's Guide: Computer Program for Design and Analysis \\ of Sheet-Pile Walls by Classical Methods (CWALSHT) \\ Including Rowe's Moment Reduction \\ Instruction Report ITL-87-2 \\ User's Guide for Concrete Strength Investigation and Design \\ (CASTR) in Accordance with ACI 318-89 \\ (Revised) \\ Technical Report ITL-92-2 \\ Finite Element Modeling of Welded Thick Plates for Bonneville \\ Navigation Lock \\ Technical Report ITL-92-4 \\ Introduction to the Computation of Response Spectrum for \\ Earthquake Loading \\ Concept Design Example, Computer-Aided Structural \\ Modeling (CASM) \\ Report 1: Scheme A \\ Report 2: Scheme B \\ Report 3: Scheme C \\ Instruction Report ITL-92-4 \\ User's Guide: Computer-Aided Structural Modeling \\ (CASM) -Version 3.00 \\ Instruction Report ITL-92-5 Tutorial Guide: Computer-Aided Structural Modeling \\ (CASM) -Version 3.00
}

Date

Aug 1989

Aug 1989

Sep 1989

Feb 1990

May 1990

Oct 1991

Mar 1992

Sep 1990

Jun 1990

Sep 1990

Jun 1992

Jun 1992

Jun 1992

Apr 1992

Apr 1992

May 1992

Jun 1992 


\section{WATERWAYS EXPERIMENT STATION REPORTS PUBLISHED UNDER THE COMPUTER-AIDED STRUCTURAL ENGINEERING (CASE) PROJECT}

(Continued)

Title

Date

Contract Report ITL-92-1

Technical Report ITL-92-7

Contract Report ITL-92-2

Contract Report ITL-92-3

Instruction Report GL-87-1

Technical Report ITL-92-11

Technical Report ITL-92-12

Instruction Report GL-87-1

Technical Report ITL-93-1

Technical Report ITL-93-2

Technical Report ITL-93-3

Instruction Report ITL-93-3

Instruction Report ITL-93-4

Technical Report ITL-94-2

Instruction Report ITL-94-1

Instruction Report ITL-94-2

Technical Report ITL-94-4

Technical Report ITL-94-5
Optimization of Steel Pile Foundations Using Optimality Criteria

Refined Stress Analysis of Melvin Price Locks and Dam

Knowledge-Based Expert System for Selection and Design of Retaining Structures

Evaluation of Thermal and Incremental Construction Effects for Monoliths AL-3 and AL-5 of the Melvin Price Locks and Dam

User's Guide: UTEXAS3 Slope-Stability Package; Volume IV, User's Manual

The Seismic Design of Waterfront Retaining Structures

Computer-Aided, Field-Verified Structural Evaluation

Report 1: Development of Computer Modeling Techniques for Miter Lock Gates

Report 2: Field Test and Analysis Correlation at John Hollis Bankhead Lock and Dam

Report 3: Field Test and Analysis Correlation of a Vertically Framed Miter Gate at Emsworth Lock and Dam

User's Guide: UTEXAS3 Slope-Stability Package; Volume III, Example Problems

Theoretical Manual for Analysis of Arch Dams

Steel Structures for Civil Works, General Considerations for Design and Rehabilitation

Soil-Structure Interaction Study of Red River Lock and Dam No. 1 Subjected to Sediment Loading

User's Manual-ADAP, Graphics-Based Dam Analysis Program

Load and Resistance Factor Design for Steel Miter Gates

User's Guide for the Incremental Construction, Soil-Structure Interaction Program SOILSTRUCT with Far-Field Boundary Elements

Tutorial Guide: Computer-Aided Structural Modeling (CASM);

Version 5.00

User's Guide: Computer-Aided Structural Modeling (CASM); Version 5.00

Dynamics of Intake Towers and Other MDOF Structures Under Earthquake Loads: A Computer-Aided Approach

Procedure for Static Analysis of Gravity Dams Including Foundation Effects Using the Finite Element Method - Phase 1B
Jun 1992

Sep 1992

Sep 1992

Sep 1992

Nov 1992

Nov 1992

Nov 1992

Dec 1992

Dec 1993

Dec 1992

Jul 1993

Aug 1993

Sep 1993

Aug 1993

Oct 1993

Mar 1994

Apr 1994

Apr 1994

Jul 1994

Jul 1994

(Continued) 


\title{
WATERWAYS EXPERIMENT STATION REPORTS PUBLISHED UNDER THE COMPUTER-AIDED STRUCTURAL ENGINEERING (CASE) PROJECT
}

\author{
(Concluded) \\ Title \\ Instruction Report ITL-94-5 \\ Instruction Report ITL-94-6 \\ Instruction Report ITL-94-7 \\ Contract Report ITL-95-1 \\ Technical Report ITL-95-5 \\ Instruction Report ITL-95-1 \\ Technical Report ITL-95-8 \\ Instruction Report ITL-96-1 \\ Instruction Report ITL-96-2 \\ Technical Report ITL-96-8 \\ Instruction Report ITL-96-3 \\ Instruction Report ITL-97-1 \\ Instruction Report ITL-97-2 \\ Instruction Report ITL-98-1 \\ Technical Report ITL-98-4 \\ Technical Report ITL-98-5 \\ User's Guide: Computer Program for Winkler Soil-Structure \\ Interaction Analysis of Sheet-Pile Walls (CWALSSI) \\ User's Guide: Computer Program for Analysis of Beam-Column \\ Structures with Nonlinear Supports (CBEAMC) \\ User's Guide to CTWALL - A Microcomputer Program for the \\ Analysis of Retaining and Flood Walls \\ Comparison of Barge Impact Experimental and Finite Element \\ Results for the Lower Miter Gate of Lock and Dam 26 \\ Soil-Structure Interaction Parameters for Structured/Cemented \\ Silts \\ User's Guide: Computer Program for the Design and Investigation \\ of Horizontally Framed Miter Gates Using the Load and Resistance \\ Factor Criteria (CMITER-LRFD) \\ Constitutive Modeling of Concrete for Massive Concrete Structures, \\ A Simplified Overview \\ User's Guide: Computer Program for Two-Dimensional Dynamic \\ Analysis of U-Frame or W-Frame Structures (CDWFRM) \\ Computer-Aided Structural Modeling (CASM), Version 6.00 \\ Report 1: Tutorial Guide \\ Report 2: User's Guide \\ Report 3: Scheme A \\ Report 4: Scheme B \\ Report 5: Scheme C \\ Hyperbolic Stress-Strain Parameters for Structured/Cemented Silts \\ User's Guide: Computer Program for the Design and Investigation \\ of Horizontally Framed Miter Gates Using the Load and Resistance \\ Factor Criteria (CMITERW-LRFD) Windows Version \\ User's Guide: Computer Aided Inspection Forms for Hydraulic Steel \\ Structures (CAIF-HSS), Windows Version \\ User's Guide: Arch Dam Stress Analysis System (ADSAS) \\ User's Guide for the Three-Dimensional Stability Analysis/Design \\ (3DSAD) Program \\ Investigation of At-Rest Soil Pressures due to Irregular Sloping Soil \\ Surfaces and CSOILP User's Guide \\ The Shear Ring Method and the Program Ring Wall
}

Date

Aug 1996

Sep 1996

Aug 1997

Sep 1998

Sep 1998

Nov 1994

Nov 1994

Dec 1994

Jun 1995

Aug 1995

Aug 1995

Sep 1995

Jun 1996

Jun 1996

Sep 1997

Sep 1998 


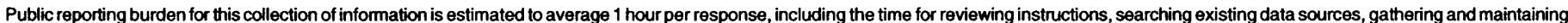

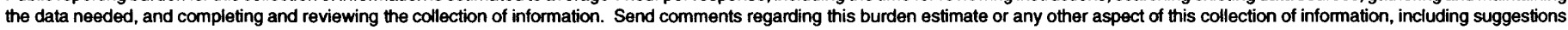

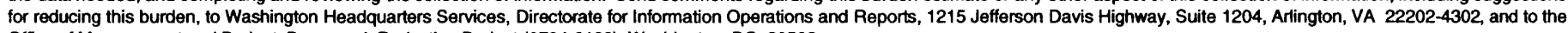
Office of Management and Budget, Paperwork Reduction Project (0704-0188), Washington, DC 20503.
1. AGENCY USE ONLY (Leave blank)
2. REPORT DATE
3. REPORT TYPE AND DATES COVERED
September 1998
Final report

4. TITLE AND SUBTITLE

The Shear Ring Method and the Program RingWall

5. FUNDING NUMBERS

Work Unit 31589

\section{AUTHOR(S)}

Mete Oner, Reed L. Mosher

\section{PERFORMING ORGANIZATION NAME(S) AND ADDRESS(ES)}

1809 South Mansfield Street, Stillwater, OK 74078;

U.S. Army Engineer Waterways Experiment Station, 3909 Halls Ferry Road,

Vicksburg, MS 39180-6199

9. SPONSORINGMONITORING AGENCY NAME(S) AND ADDRESS(ES)

U.S. Army Corps of Engineers, Washington, DC 20314-1000

8. PERFORMING ORGANIZATION REPORT NUMBER

Technical Report ITL-98-5

10. SPONSORINGMONITORING AGENCY REPORT NUMBER

11. SUPPLEMENTARY NOTES

Available from National Technical Information Service, 5285 Port Royal Road, Springfield, VA 22161.

12a. DISTRIBUTIONAVAILABILITY STATEMENT

12b. DISTRIBUTION CODE

Approved for public release; distribution is unlimited.

\section{ABSTRACT (Maximum 200 words)}

This report describes the Shear Ring Method and the computer program RingWall. The Shear Ring Method was developed based on observations that the conventional soil-structure interaction analysis (beam on elastic foundation) did not accurately duplicate the results of full-scale test results or plane strain finite element results on floodwalls. From tests and analyses, the principal mode of motion was found to be horizontal with a rotational component and the soil, as opposed to the pile, was the major component of the system that determines the overall deformations.

The Shear Ring Method models the two-dimensional geometry of the pile-soil system using plane strain finite elements, but the analysis is reduced to a one-dimensional model as in the conventional SSI. The reduction is obtained by assuming that the soil deformation due to an unbalanced geometry or loading will result essentially in a rotational failure. This method was found to produce reasonably accurate results compared with those of nonlinear, plane strain finite element analyses of typical floodwall sections and is considerably easier to perform. The method was subsequently extended to single-anchored sheet-pile walls.

\begin{tabular}{|c|c|c|}
\hline \multicolumn{3}{|l|}{ 14. SUBJECT TERMS } \\
\hline \multicolumn{3}{|c|}{ Shear Ring } \\
\hline \multicolumn{3}{|c|}{ Sheet-pile wall } \\
\hline \multirow{2}{*}{\multicolumn{3}{|c|}{ Soil-structure interaction }} \\
\hline & & \\
\hline $\begin{array}{l}\text { 17. SECURITY CLASSIFICATION } \\
\text { OF REPORT }\end{array}$ & $\begin{array}{l}\text { 18. SECURITY CLASSIFICATION } \\
\text { OF THIS PAGE }\end{array}$ & $\begin{array}{l}\text { 19. SECURTYY CLASSIFICATION } \\
\text { OF ABSTRACT }\end{array}$ \\
\hline UNCLASSIFIED & UNCLASSIFIED & \\
\hline
\end{tabular}

NSN 7540-01-280-5500

15. NUMBER OF PAGES 127

16. PRICE CODE

20. LIMITATION OF ABSTRACT

Standard Form 298 (Rev. 2-89) Prescribed by ANSI Std. Z39-18 298-102 